KLEIBER LIMA DE BESSA

REDUÇÃO DE ARRASTO POR ADIÇÃO DE POLÍMEROS EM ESCOAMENTO PULSÁTIL LAMINAR E TURBULENTO EM LEITOS ARTERIAIS CAUDAIS DE RATOS NORMOTENSOS E HIPERTENSOS E TUBOS RÍGIDOS

Tese apresentada à Escola Politécnica da Universidade de São Paulo para obtenção do Título de Doutor em Engenharia. 
Kleiber Lima de Bessa

\section{REDUÇÃO DE ARRASTO POR ADIÇÃO DE POLÍMEROS EM ESCOAMENTO PULSÁTIL LAMINAR E TURBULENTO EM LEITOS ARTERIAIS CAUDAIS DE RATOS NORMOTENSOS E HIPERTENSOS E TUBOS RÍGIDOS}

Tese apresentada à Escola Politécnica da Universidade de São Paulo para obtenção do Título de Doutor em Engenharia.

Área de Concentração:

Energia e Fluido

Orientador:

Prof. Dr. Jayme Pinto Ortiz

São Paulo

2008 
Este exemplar foi revisado e alterado em relação à versão original, sob responsabilidade única do autor e com anuência de seu orientador.

São Paulo, 26 de maio de 2008.

Assinatura do autor:

Assinatura do orientador:

Bessa, Kleiber Lima de

Redução de arrasto por adição de polímeros em escoamento pulsátil laminar e turbulento em leitos arteriais caudais de ratos normotensos e hipertensos e tubos rígidos / K.L. de Bessa. -São Paulo, 2008.

$138 \mathrm{p}$.

Tese (Doutorado) - Escola Politécnica da Universidade de São Paulo. Departamento de Engenharia Mecânica.

1. Endotélio 2. Polímeros (Materiais) 3. Modelagem computacional 4. Polietileno glicol 5. Reatividade vascular 6 . Redução de arrasto 7. Tensão de cisalhamento I. Universidade de São Paulo. Escola Politécnica. Departamento de Engenharia Mecânica II. t. 


\section{DEDICATÓRIA}

Dedico esse trabalho a minha esposa

Kero pela compreensão e perseverança demonstradas em todos esses anos e ao nosso filho(a) que está a caminho. 


\section{AGRADECIMENTOS}

Ao Prof. Dr. Jayme Pinto Ortiz, pela orientação, compreensão, paciência, amizade ao longo desse trabalho e, pela oportunidade em aprender e compartilhar seus conhecimentos.

A Professora Dra. Luciana Venturini Rossoni pela sua enorme contribuição para o desenvolvimento desse trabalho que se mostrou sempre receptiva e bastante favorável a discussões a respeito do tema e por ter disponibilizado a infraestrutura laboratorial, sem a qual esse trabalho não teria sido realizado.

A Juliana Fernandes Beletatti, por ter aceitado o desafio de trabalhar nessa interdisciplinaridade. trabalho.

Ao Professor Raul Gonzalez Lima pelas sugestões para o enriquecimento desse

Aos amigos do Laboratório de Mecânica dos Fluidos, Daniel, Ricardo e Henrique pela sua amizade e ajuda. E, particularmente, a Daniel que acompanhou e compartilhou algumas etapas desse trabalho.

Aos amigos e associados do Laboratório de Fisiologia Vascular, pelas inúmeras experiências compartilhadas, profissionais e pessoais. Obrigado pela convivência tão agradável, pelo respeito mútuo, pela ajuda e pela disponibilidade.

Ao Professor Carlos Frederico Martins Menck, pelos seus conselhos e por disponibilizar o microscópio óptico para medição dos diâmetros arteriais.

A Eduardo Marcic pela sua contribuição e experiência para adaptações na bancada experimental.

Aos técnicos do Laboratório de MecFlu, Douglas e Laércio, pela sua contribuição experimental.

Aos amigos, Faggioni, Moacir, Ana Maria e Andréia, pela amizade sempre presente.

A todos aqueles que de forma direta ou indireta contribuíram para a realização desse trabalho.

Ao CNPq, pelo apoio financeiro. 
"O único homem que está isento de erros,

é aquele que não arrisca acertar."

Albert Einstein 


\section{RESUMO}

Nesse trabalho, foi analisada a redução de arrasto, a partir da utilização de duas bancadas experimentais, onde uma delas está situada no laboratório de Mecânica dos Fluidos (EPUSP) e a outra, no laboratório de Fisiologia Vascular (ICB-USP). A redução de arrasto foi investigada a partir do uso dos seguintes polímeros: poliacrilamida 1822S e 1340S, polietileno glicol (PEG4000) e óxido de polietileno (Polyox WSR-301). O comportamento reológico das soluções poliméricas do PEG4000 e das poliacrilamidas foi adquirido experimentalmente, enquanto do Polyox WSR-301 foi obtido da literatura. Esses polímeros foram utilizados na bancada experimental da EPUSP, simulador hidrodinâmico, mas somente o PEG4000 foi utilizado na bancada experimental do ICBI em leitos arteriais caudais de ratos normotensos (Wistar) e espontaneamente hipertensos (SHR). No simulador hidrodinâmico, foi estudada a redução de arrasto em escoamentos pulsáteis laminares e turbulentos, cuja faixa de Reynolds varia entre 2300 a 13700, com concentrações poliméricas que variaram entre 5 e $100 \mathrm{ppm}$, porém para o PEG4000 essa concentração atingiu valor de 5000 ppm. Em leitos arteriais caudais de ratos, a redução de arrasto foi analisada para escoamento laminar, cuja faixa de Reynolds varia entre 100 e 700, com concentração polimérica de 5000 ppm. Além disso, a redução de arrasto foi estudada na presença e ausência das células endoteliais. Simulações computacionais utilizando o método dos volumes finitos (Fluent) foram realizadas a partir dos dados obtidos da bancada experimental do ICB-I, para avaliar a distribuição da tensão de cisalhamento sobre a parede do vaso na presença e ausência das células endoteliais e do PEG4000, considerando a parede da artéria rígida. A partir dos dados obtidos da análise da viscosidade, ficou constatado que o PEG4000 com concentração de 5000 ppm e as poliacrilamidas $1822 \mathrm{~S}$ e $1340 \mathrm{~S}$ com concentrações de 5 e 10 ppm apresentaram comportamento de fluido Newtoniano. Para as poliacrilamidas, concentrações poliméricas acima de $10 \mathrm{ppm}$ apresentaram comportamento de fluido não-Newtoniano. De acordo com a literatura, o Polyox WSR-301 apresentou comportamento de fluido Newtoniano para todas as concentrações poliméricas utilizadas nesse trabalho. O PEG4000 não apresentou o fenômeno da redução de arrasto em nenhuma concentração polimérica analisada, quando aplicado na bancada experimental da EPUSP. As poliacrilamidas e o Polyox WSR-301 apresentaram reduções de arrasto que foram dependentes do número de Reynolds e da concentração utilizada, muito embora o Polyox WSR-301 tenha se mostrado mais eficiente em promover esse fenômeno. Nos leitos arteriais caudais, o PEG4000 apresentou redução de arrasto para a concentração de 5000 ppm, que foi acentuada pela presença das células endoteliais. Os valores da tensão de cisalhamento foram maiores para o animal SHR quando comparados com o animal Wistar. Além disso, no animal Wistar, o endotélio controlou o aumento dessa tensão via produção de substâncias vasodilatadoras, mas apresentou disfunção no animal SHR. A partir dos resultados apresentados acima, podese concluir que o Polyox WSR-301 é mais eficiente para promover a redução de arrasto em tubos rígidos. Por outro lado, muito embora o PEG4000 não tenha apresentado efeito na bancada experimental da EPUSP, esse se mostrou um bom redutor de arrasto em leitos arteriais caudais, tendo sua ação intensificada pela presença das células endoteliais.

Palavras-chave: redução de arrasto, endotélio, polímeros, tensão de cisalhamento, modelagem física e computacional. 


\begin{abstract}
In this work, the drag reduction was analyzed in two benches located at Laboratory of Fluid Mechanics at Polytechnic School (EPUSP) and at Laboratory of Vascular Physiology at Institute of Biomedical Science (ICB-USP). The drag reduction was investigated for the following polymers: polyacrilamide $1822 \mathrm{~S}$ and $1340 \mathrm{~S}$, polyethylene glycol (PEG4000) and polyethylene oxide (Polyox WSR-301). The rheological behavior of polymeric solutions of polyacrilamide and PEG4000 was acquired experimentally; while it was obtained from the literature for Polyox WSR-301. All of these polymers were used in the hydrodynamic simulator, but only PEG4000 was employed in the tails arterial bed from normotensive (Wistar) and spontaneously hypertensive rats (SHR) at ICB-1. In the hydrodynamic simulator, the drag reduction was analyzed in laminar and turbulent pulsatile flow, in the range varying between 2300 and 13700, with polymeric concentrations between 5 and $100 \mathrm{ppm}$, but for PEG4000, concentration has reached $5000 \mathrm{ppm}$. On the other hand, in the tail arterial beds, the drag reduction was analyzed for laminar flow, in the range between 100 and 700, with polymeric concentration of $5000 \mathrm{ppm}$. In addition, it was studied in the presence and absence of endothelial cells. Computational simulation using the finite volume method (Fluent) was performed using data obtained from ICB-1 in order to analyze the wall shear stress distribution along of wall vessel both in the presence and absence of endothelial cells and PEG4000, considering the rigid walls. Polyacrilamide 1822S and $1340 \mathrm{~S}$ as well as PEG4000 showed behavior of Newtonian fluid in the following concentrations: 5 and $10 \mathrm{ppm}$ and $5000 \mathrm{ppm}$, respectively. On the other hand, for polyacrilamides, concentrations higher than $10 \mathrm{ppm}$ showed behaviour of nonNewtonian fluids. According to the literature, the Polyox WSR-301 behaved as a Newtonian fluid in all concentrations used in this work. At EPUSP's bench, while PEG4000 did not show drag reduction for any polymeric concentration analyzed, this phenomenon could be seen for polyacrilamides and Polyox WSR-301, being dependent on Reynolds number as well as polymeric concentration. More important, Polyox WSR301 showed to be the most efficient drag reducer of them. Interestingly, in the assays employing the tail arterial beds, PEG4000 showed drag reduction in the concentration of $5000 \mathrm{ppm}$ and it was increased by the presence of the endothelial cells. Thus, Polyox WSR-301 seems to be more efficient to promote drag reduction in the rigid tubes. On the other hand, while PEG4000 did not show drag reduction at EPUSP's bench, it was a good drag reducer in the tail arterial beds, being intensified by the action of endothelial cells.
\end{abstract}

Keywords: drag reduction, endothelium, polymers, shear stress, computational and physical modeling. 


\section{LISTA DE FIGURAS}

Figura 3.1 - Representação esquemática do fator de atrito versus número de Reynolds: (1) escoamento laminar; (2) escoamento turbulento em tubos lisos; (3) assíntota de máxima redução de arrasto de Virk; (4), (5) e (6) três típicos comportamentos para soluções de polímeros, surfactantes e

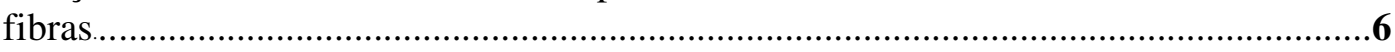

Figura 5.1 - Estrutura química da acrilamida .................................................17

Figura 6.1 - Registro do aumento da velocidade com o tempo de um escoamento turbulento num tubo através de um anemômetro de filme quente

Figura 6.2 - Registro do fluxo sangüíneo na aorta descendente de um cão apresentando a turbulência durante a fase de desaceleração da sístole

Figura 6.3 - Estabilidade do escoamento sangüíneo na aorta descendente de cães anestesiados influenciados pelo pico do número de Reynolds e número de Womersley. Os pontos ligados referem-se ao mesmo animal. Círculos abertos, escoamento laminar; círculos preenchidos, escoamento turbulento; círculos parcialmente preenchidos, escoamento na fase de transição.

Figura 6.4 - Perfil de velocidade completamente desenvolvido num tubo adimensionalizado com a velocidade máxima

Figura 6.5 - Perfil de velocidade $\left(\mathrm{u}_{\mathrm{s}}\right)$ completamente desenvolvido, velocidade máxima $\left(\hat{\mathrm{u}}_{\mathrm{s}}\right)$ e velocidada média $\left(\overline{\mathrm{u}}_{\mathrm{s}}\right)$ como sendo metade da velocidade máxima.. 30

Figura 6.6 - Gradiente de pressão pulsátil $k(t)$ consiste de um parte constante, $\mathrm{k}_{\mathrm{s}}$, e uma parte puramente oscilatória, $\mathrm{k}_{\phi}(\mathrm{t})$.

Figura 6.7 - Perfis de velocidade oscilatórios num tubo rígido com número de Womersley $\Omega=1$. 39

Figura 6.8 - Perfis de velocidade oscilatórios num tubo rígido com número de Womersley $\Omega=3$..... 40

Figura 6.9 - Perfis de velocidade oscilatórios num tubo rígido com número de Womersley $\Omega=10$.

Figura 6.10 - Variação da taxa de vazão volumétrica oscilatória $q_{\phi}$ no ciclo oscilatório comparada com a variação correspondente do gradiente de pressão com o número de Womersley $\Omega=1$.

Figura 6.11 - Variação da taxa de vazão volumétrica oscilatória $q_{\phi}$ no ciclo oscilatório comparada com a variação correspondente do gradiente de pressão com o número de Womersley $\Omega=3$. 
Figura 6.12 - Variação da taxa de vazão volumétrica oscilatória $q_{\phi}$ no ciclo oscilatório comparada com a variação correspondente do gradiente de pressão com o número de Womersley $\Omega=10$.

Figura 6.13 - Curva do pulso de pressão e gradiente de pressão arterial medidos entre dois pontos distantes $5 \mathrm{~cm}$ na artéria femoral de cão .47

Figura 6.14 - Gráfico discretizado do gradiente de pressão oscilatório em 50 partes iguais:

$7,2^{\circ}$

Figura 6.15 - Representação do pulso oscilatório de vazão e do gradiente de pressão na artéria femoral de um cão.. 50

Figura 7.1 - Representação dos cilindros e perfil de velocidade entre cilindros concêntricos: (a) cilindro interno girando; (b) distribuição de velocidades; (c) cilindro interno .52

Figura 7.2 - Viscosímetro capilar de força gravitacional: Ubbelohde. .53

Figura 7.3 - Simulador hidrodinâmico para estudos in vitro do sistema cardiovascular. A - unidade central de bombeamento; B - seção de teste .56

Figura 7.4 - Descrição da unidade central de bombeamento e da seção de teste do simulador hidrodinâmico para estudos in vitro do sistema cardiovascular. $\mathrm{R}$ reservatório; 1 - motor de corrente contínua; 2 - câmara do pistão; 3 e 4 - válvulas unidirecionais; 5

manômetros. .57

Figura 7.5 - Moldes utilizados para o desenvolvimento dos tubos de silicone: (A) molde sem estenose; (B) moldes com $30 \%$ e $50 \%$ de redução de

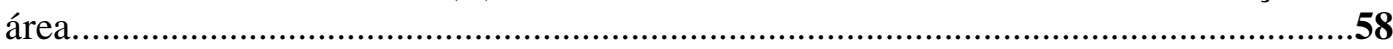

Figura 7.6 - Representação dos tubos estenosados de silicone (Sylgard 184, Dow Corning)

Figura 7.7 - Descrição da bancada experimental utilizada no ensaio de redução de arrasto em leitos arteriais caudais

Figura 7.8 - Artérias caudais de rator normotensos (Wistar) e espontaneamente hipertensos

(SHR)

Figura 7.9 - Malha computacional que representa a artéria caudal mostrando a camada limite

Figura 8.1 - Tensão de cisalhamento versus taxa de deformação para a solução polimérica (PEG4000 - 5000 ppm) sem e com Krebs 
Figura 8.2 - Viscosidade versus taxa de deformação para a solução polimérica (PEG4000 - 5000 ppm) sem e com Krebs.

Figura 8.3 - Tensão de cisalhamento versus taxa de deformação para as soluções da poliacrilamida $1340 \mathrm{~S}$ e $1822 \mathrm{~S}$ : A - $5 \mathrm{ppm}$ e B $-10 \mathrm{ppm}$, comparando-se com o comportamento da água destilada.

Figura 8.4 - Tensão de cisalhamento com a taxa de deformação para as soluções da poliacrilamida $1340 \mathrm{~S}$ e $1822 \mathrm{~S}$ : A - $30 \mathrm{ppm}, \mathrm{B}-60 \mathrm{ppm}, \mathrm{C}-75 \mathrm{ppm}$ e D - 100

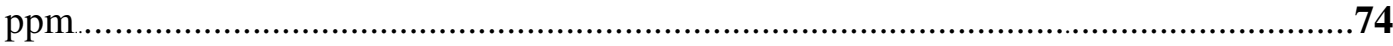

Figura 8.5 - Viscosidade versus taxa de deformação para a solução da poliacrilamida $1822 \mathrm{~S}$ e para água destilada. .75

Figura 8.6 - Viscosidade versus taxa de deformação para a solução da poliacrilamida 1340 S e para água destilada. .75

Figura 8.7 - Simulador hidrodinâmico para estudos in vitro do sistema cardiovascular. 1 - conversor CA/CC; 2 - dispositivo guia; 3 - tubo de silicone. 77

Figura 8.8 - Representação das cavidades do coração, das artérias e veias (em vermelho) juntamente com o caminho percorrido pelo sangue durante o ciclo sistólicodiastólico (em amarelo) 78

Figura 8.9 - Unidade central de bombeamento do simulador hidrodinâmico para estudos in vitro do sistema cardiovascular. $\mathrm{R}$ - reservatório; 1 e 2 - válvulas unidirecionais; 3 - câmara do pistão 79

Figura 8.10 - Curva do gradiente de pressão x número de Reynolds no tubo capilar de silicone para diferentes concentrações poliméricas da poliacrilamida $1822 \mathrm{~S}$. .80

Figura 8.11 - Curva do gradiente de pressão x número de Reynolds no tubo capilar de silicone para diferentes concentrações poliméricas da poliacrilamida $1340 \mathrm{~S}$ 81

Figura 8.12 - Curva do gradiente de pressão x número de Reynolds no tubo capilar de silicone para diferentes concentrações poliméricas do Polyox WSR-301 .82

Figura 8.13 - Curva do gradiente de pressão x número de Reynolds no tubo capilar de silicone para concentração polimérica de $5 \mathrm{ppm}$ para os polímeros: poliacrilamidas 1822 S e 1340 S e Polyox WSR-301. 82

Figura 8.14 - Curva do gradiente de pressão x número de Reynolds no tubo capilar de silicone para concentração polimérica de 100 ppm para os polímeros: poliacrilamidas 1822 S e 1340 S e Polyox WSR-301 .83

Figura 8.15 - Redução de arrasto versus número de Reynolds para concentração polimérica de 5 ppm para os polímeros: poliacrilamidas 1340S e 1822S e Polyox WSR301 
Figura 8.16 - Redução de arrasto versus número de Reynolds para concentração polimérica de $30 \mathrm{ppm}$ para os polímeros: poliacrilamidas 1340S e $1822 \mathrm{~S}$ e Polyox WSR-

301

Figura 8.17 - Redução de arrasto versus número de Reynolds para concentração polimérica de 100 ppm para os polímeros: poliacrilamidas $1340 \mathrm{~S}$ e $1822 \mathrm{~S}$ e Polyox WSR-

301 .86

Figura 8.18 - Ilustração da medição do comprimento da artéria caudal .87

Figura 8.19 - Diâmetros arteriais caudais proximais e distais de ratos normotensos (Wistar) e espontaneamente hipertensos (SHR). Teste $\mathrm{t}$; $\mathrm{P}<0,05 *$ vs Wistar. .88

Figura 8.20 - Variação do diâmetro interno e da espessura da parede do vaso nas porções proximais e distais de uma artéria de rato normotenso (aumento de 10x). 88

Figura 8.21 - Alguns componentes da parede do vaso arterial caudal de um rato normotenso: célula endotelial e muscular (aumento de 40x)

Figura 8.22 - Curva de PPM x fluxo em leitos arteriais caudais de ratos normotensos (Wistar) e espontaneamente hipertensos (SHR). ANOVA; P<0,05* vs fluxo; \# vs Wistar.

Figura 8.23 - Curva de PPM x fluxo em leitos arteriais caudais de ratos normotensos (Wistar) e espontaneamente hipertensos (SHR) na presença e ausência de PEG. E+ indica presença das células endoteliais. ANOVA; P<0,05* vs fluxo; \# vs Wistar; + vs ausência

Figura 8.24 - Curva de PPM x fluxo em leitos arteriais caudais de ratos normotensos (Wistar): com (E+) e sem (E-) endotélio, e após a infusão durante trinta minutos com LNAME (LN), indometacina (INDO) ou tetraetilamônio (TEA). ANOVA; P<0,05*vs fluxo; \# $\quad$ vs E+. 91

Figura 8.25 - Curva de PPM x fluxo em leitos arteriais caudais de ratos hipertensos (SHR): com (E+) e sem (E-) endotélio, e após a infusão durante trinta minutos com LNAME (LN), indometacina (INDO) ou tetraetilamônio (TEA). ANOVA; P<0,05* vs fluxo; \#

$\mathrm{E}+$ .92

Figura 8.26 - Curva de PPM x fluxo em leitos arteriais caudais de ratos normotensos (Wistar): com (E+) e sem (E-) endotélio, e após a infusão durante trinta minutos com LNAME (LN), indometacina (INDO) ou tetraetilamônio (TEA) na presença e ausência do PEG4000. ANOVA; $\mathrm{P}<0,05 \quad * \quad$ vs fluxo; \# vs

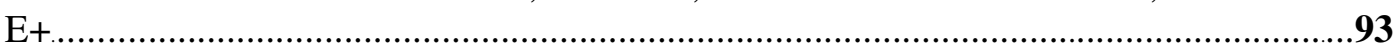


Figura 8.27 - Curva de PPM x fluxo em leitos arteriais caudais de ratos hipertensos (SHR): com (E+) e sem (E-) endotélio, e após a infusão durante trinta minutos com LNAME (LN), indometacina (INDO) ou tetraetilamônio (TEA) na presença e ausência do PEG4000. ANOVA; $\mathrm{P}<0,05 \quad * \quad$ vs fluxo; \# vs

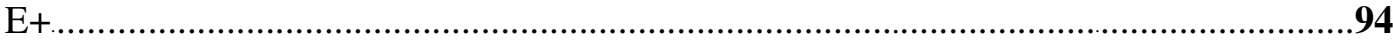

Figura 8.28 - Variação do fator de atrito versus número de Reynolds na presença (E+) e ausência (E-) das células endoteliais e comparando-se com o fator de atrito laminar .95

Figura 8.29 - Variação do fator de atrito versus número de Reynolds em leitos arteriais caudais de ratos normotensos (Wistar) e espontaneamente hipertensos (SHR) na presença do PEG4000 e na presença (E+) das células endoteliais .96

Figura 8.30 - Variação do fator de atrito versus número de Reynolds em leitos arteriais caudais de ratos normotensos (Wistar) e espontaneamente hipertensos (SHR) na presença do PEG4000 e na ausência (E-) das células endoteliais. .97

Figura 8.31 - Porcentagem de redução de arrasto versus fluxo em leitos arteriais caudais de ratos normotensos (Wistar) e espontaneamente hipertensos (SHR) na presença das células endoteliais $(\mathrm{E}+)$ e na ausência das células endoteliais (E) ........

Figura 8.32 - Pulsos de pressão de perfusão média versus tempo em leitos arteriais caudais de ratos normotensos (Wistar): (A) na presença do endotélio (E+) e ausência do PEG4000; (B) na presença do endotélio (E+) e do PEG4000; (C) na ausência das células endoteliais (E-) e do PEG4000; (D) na ausência das células endoteliais (E-) e na presença

Figura 8.33 - Pulsos de pressão de perfusão média versus tempo em leitos arteriais caudais de ratos espontaneamente hipertensos (SHR): (A) na presença do endotélio (E+) e ausência do PEG4000; (B) na presença (E+) do endotélio e do PEG4000; (C) na ausência (E-) do endotélio e do PEG4000; (D) na ausência (E-) do endotélio e do PEG4000.

Figura 8.34 - Pulsos de pressão de perfusão média versus tempo em leitos arteriais caudais de ratos normotensos (Wistar) e espontaneamente hipertensos (SHR) na presença e ausência do PEG4000: (A) na presença do endotélio (E+) (Wistar); (B) na ausência do endotélio (E-) (Wistar); (C) na presença do endotélio (E+) (SHR); (D) na ausência do endotélio (E-) (SHR)

Figura 8.35 - Distribuição espacial e temporal da tensão de cisalhamento em leitos arteriais caudais de ratos normotensos (Wistar) e espontaneamente hipertensos (SHR) na presença $(E+)$ e ausência (E-) do endotélio e na ausência do PEG4000 nos instantes especificados acima 
Figura 8.36 - Distribuição espacial e temporal da tensão de cisalhamento em leitos arteriais caudais de ratos normotensos (Wistar) e espontaneamente hipertensos (SHR) na presença $(\mathrm{E}+)$ do endotélio $\mathrm{e}$ na presença do PEG4000 103

Figura 8.37 - Distribuição espacial e temporal da tensão de cisalhamento em leitos arteriais caudais de ratos normotensos (Wistar) e espontaneamente hipertensos (SHR) na ausência (E-) do endotélio e na presença do PEG4000.............................................104

Figura 9.1 - Diagrama reológico: tensão de cisalhamento e viscosidade versus taxa de cisalhamento de fluido newtoniano e não-Newtoniano. 105

Figura 9.2 - Formas de algumas substâncias dispersas no líquido em repouso e fluindo através de um tubo. 107

Figura 9.3 - Viscosidade versus taxa de cisalhamento para a solução de PEO para concentrações de 10, 20, 40, 60, 100, 150, 200 e 500 ppm e água destilada .113

Figura 9.4 - Mecanismo de liberação de óxido nítrico em resposta ao fluxo sangüíneo

Figura 9.5 - Porcentagem de redução de arrasto das células endoteliais e do PEG4000 ao longo da parede do vaso para fluxo de $2,5 \mathrm{~mL} / \mathrm{min}$ (Wistar)

Figura 9.6 - Porcentagem de redução de arrasto das células endoteliais e do PEG4000 ao longo da parede do vaso para fluxo de $2,5 \mathrm{~mL} / \mathrm{min}$ (SHR) 


\section{LISTA DE TABELAS}

Tabela 6.1 - Aplicação da série de Fourier para obtenção dos coeficientes de

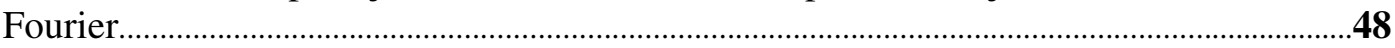

Tabela 6.2 - Cálculo dos parâmetros de Womersley …..............................................49

Tabela 8.1 - Dados gerais sobre o viscosímetro e a solução analisada..........................71

Tabela 8.2 - Análise do valor absoluto da viscosidade cinemática da solução polimérica (PEG4000 - 5000 ppm) com a adição da solução de Krebs ..........................................72 


\section{LISTA DE SÍMBOLOS}

A

a

$C_{i}$

$C_{f} \quad$ Concentração final

d

$\Delta p$

$\Delta p_{S}$

$\Delta p_{P}$

\section{$\Delta p_{\phi}$}

$f$

$f_{F} \quad$ Fator de atrito de Fanning

$f_{F S} \quad$ Fator de atrito de Fanning na presença do solvente

$f_{F P} \quad$ Fator de atrito de Fanning na presença do polímero

$g$

$\mathrm{h}_{\mathrm{lt}} \quad$ Perda de carga total

$\mathrm{h}_{1} \quad$ Perda de carga distribuída

$\mathrm{h}_{\mathrm{lm}} \quad$ Perda de carga localizada

$J_{0} \quad$ Função de Bessel de ordem zero de primeiro tipo

K Constante para o cálculo do Reynolds crítico

$k_{s} \quad$ Gradiente de pressão em regime permanente

$k_{\phi} \quad$ Gradiente de pressão em regime oscilatório

$l \quad$ Comprimento do conduto

M Módulo da harmônica 


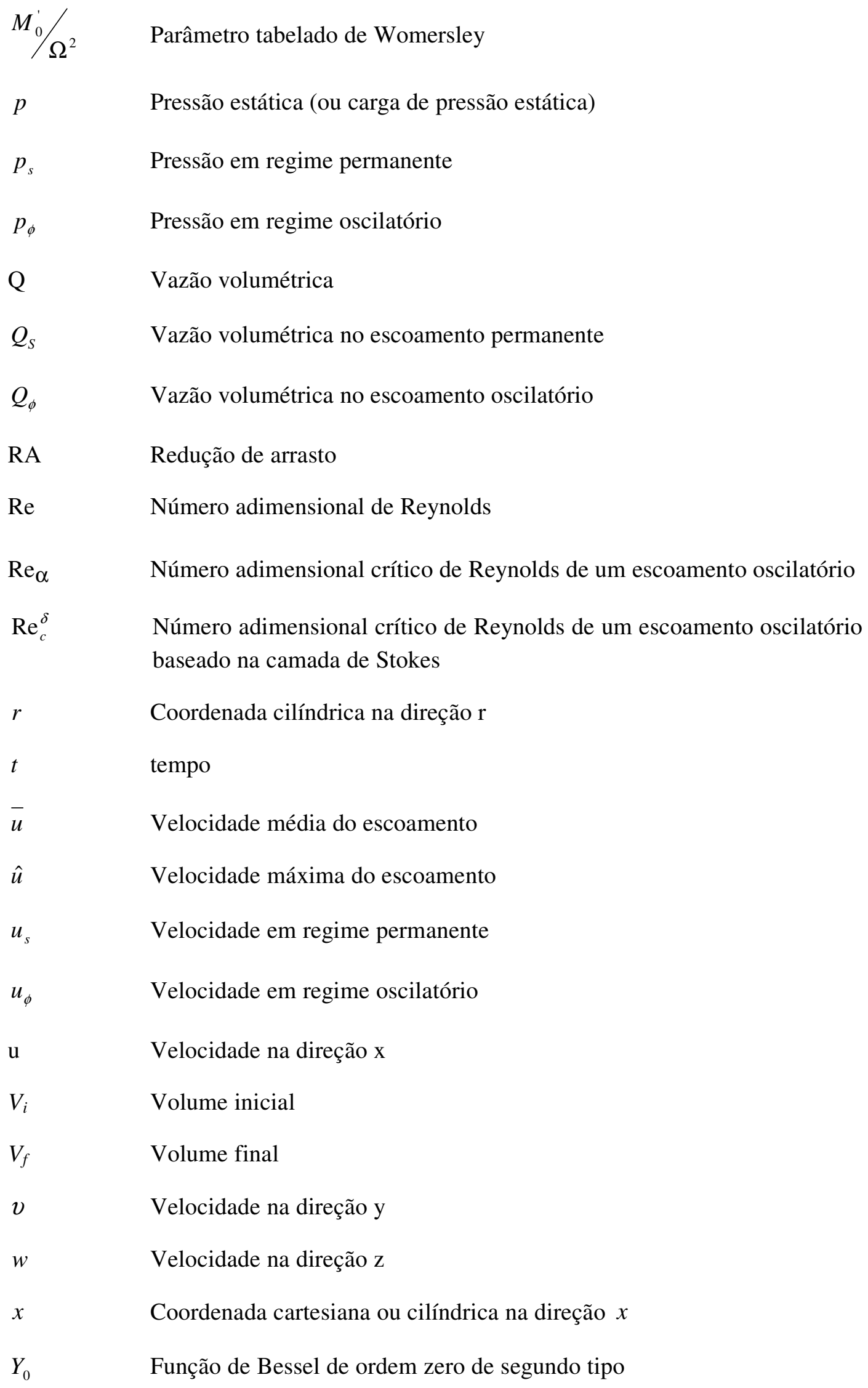




\section{Letras Gregas}

$\varepsilon_{0} \quad$ Parâmetro tabelado de Womersley

$\varphi \quad$ Fase da harmônica

$\Lambda \quad$ Parâmetro de freqüência complexo relacionado com o número de Womersley

$\mu \quad$ Viscosidade dinâmica

$v \quad$ Viscosidade cinemática

$\theta \quad$ Coordenada cilíndrica na direção $\theta$

$\rho \quad$ Densidade

$\tau \quad$ Tensão de Cisalhamento

$\tau_{w} \quad$ Tensão de Cisalhamento na parede

$\tau_{w P} \quad$ Tensão de Cisalhamento na parede na presença do polímero

$\tau_{w s} \quad$ Tensão de Cisalhamento na parede na presença do solvente

$\quad$ Freqüência de oscilação

$\Omega \quad$ Número adimensional de Womersley

$\zeta \quad$ Variável complexa relacionada a coordenada radial $r$ 


\section{SUMÁRIO}

\section{RESUMO}

\section{ABSTRACT}

LISTA DE FIGURAS

LISTA DE TABELAS

LISTA DE SÍMBOLOS

1. INTRODUÇÃO......................................................................................... 1

2. OBJETIVOS ........................................................................................... 3

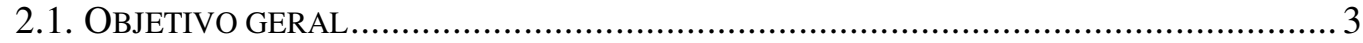

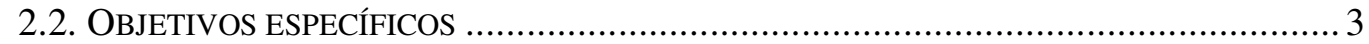

3. O FENÔMENO DA REDUÇÃO DE ARRASTO.................................. 4

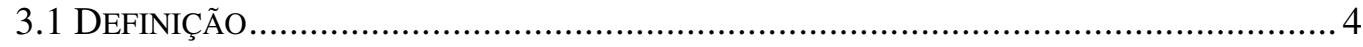

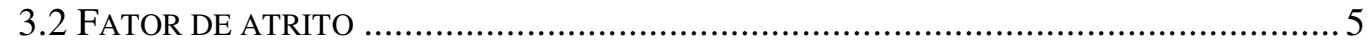

4. REVISÃO BIBLIOGRÁFICA............................................................... 8

4.1 REDUÇÃO DE ARRASTO POR ADIÇÃO DE POLÍMEROS - TUBULAÇÃO RÍGIDA ............. 8

4.2 REDUÇÃO DE ARRASTO POR ADIÇÃO DE POLÍMEROS - SISTEMA VASCULAR ........... 10

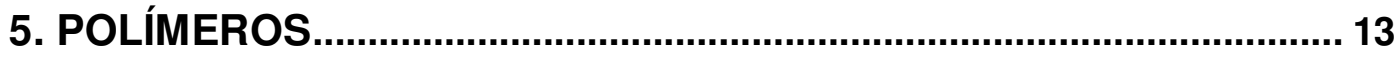

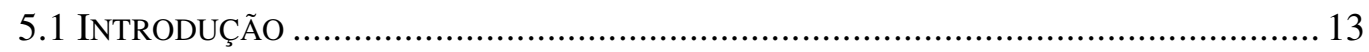

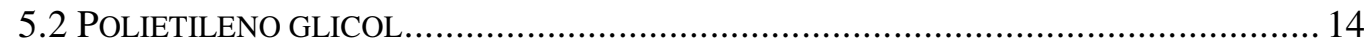

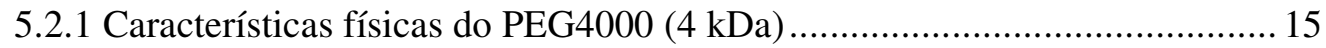

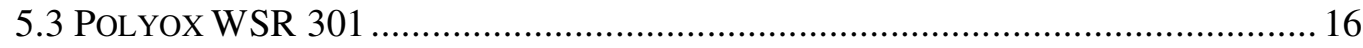

5.3.1 Características físicas do Polyox WSR301 .............................................. 16

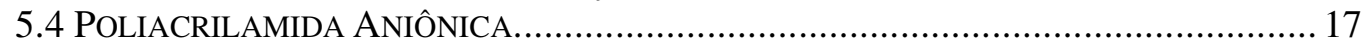

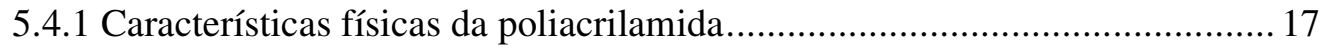

\section{MODELAGEM MATEMÁTICA DE ESCOAMENTOS EM TUBOS RÍGIDOS}

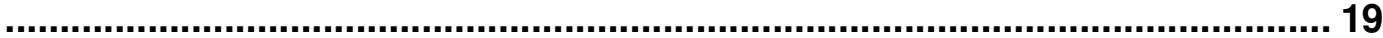

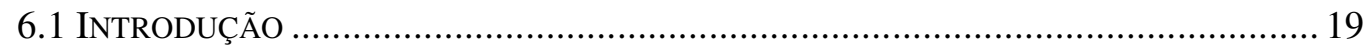

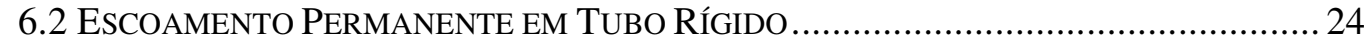

6.3 ESCOAMENTO NÃO-PERMANENTE EM TUBO RÍGIDO …................................... 31

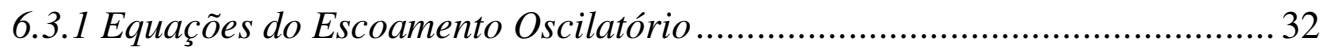

6.3.2 Gradiente de Pressão Complexo e Equação de Bessel ................................. 34

6.3.3 Solução da Equação de Bessel .................................................................. 36

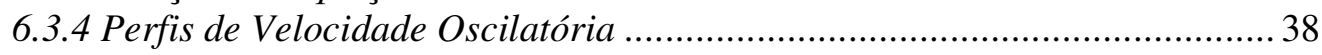

6.3.5 Vazão Volumétrica Oscilatória ............................................................... 42

6.4 OBTENÇÃO DO PERFIL OSCILATÓRIO DA VAZÃO A PARTIR DE UM GRADIENTE DE

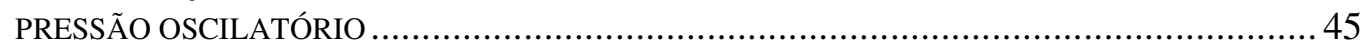

7. METODOLOGIA................................................................................ 51

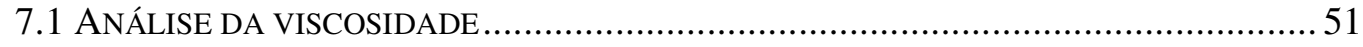

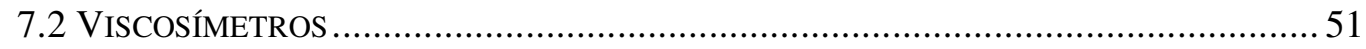

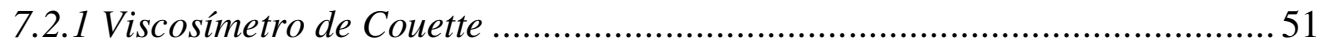


7.2.2 Viscosímetro Capilar de Força Gravitacional .........................................5 53

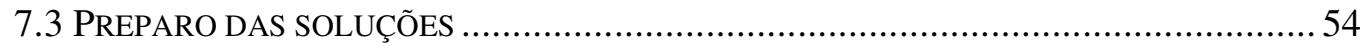

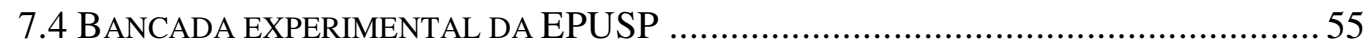

7.4.1 Descrição da bancada experimental da EPUSP ........................................56 56

7.4.2 Confecção dos tubos de silicone sem e com estenose ................................57

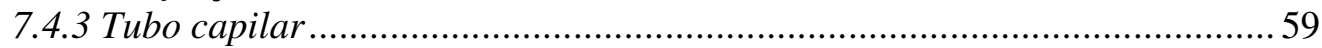

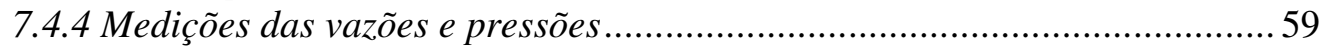

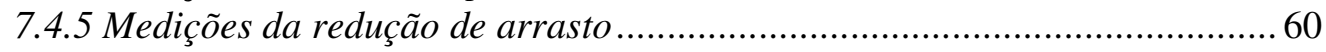

7.5 BANCADA EXPERIMENTAL DO ICB-USP - LEITOS ARTERIAIS CAUDAIS ................60 60

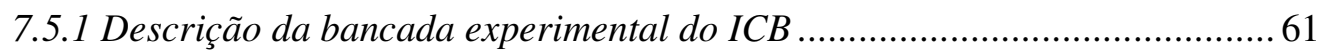

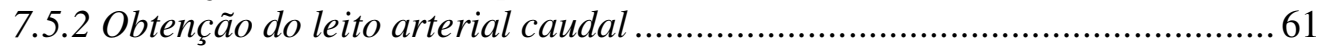

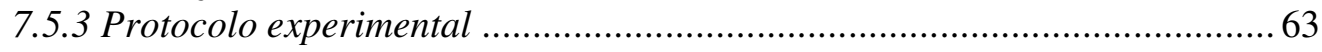

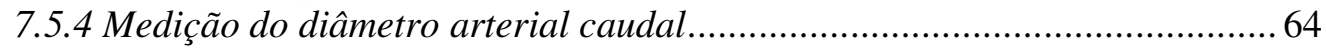

7.5.5 Cálculo da redução de arrasto a partir do fator de atrito ............................65

7.6 DISTRIBUIÇÃO ESPACIAL E TEMPORAL DA TENSÃO DE CISALHAMENTO AO LONGO DO LEITO ARTERIAL CAUDAL DE RATOS NORMOTENSOS (WISTAR) E ESPONTANEAMENTE

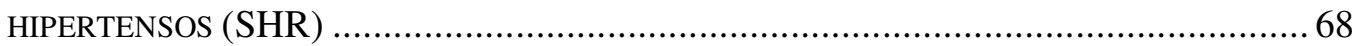

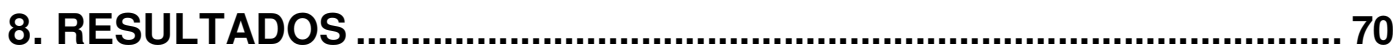

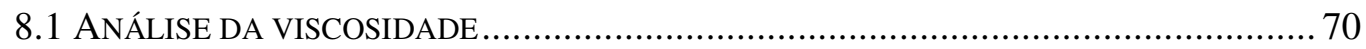

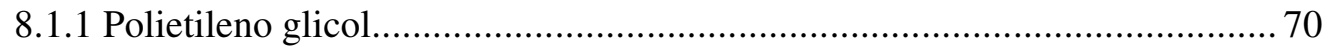

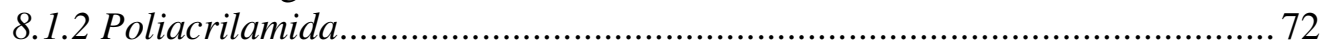

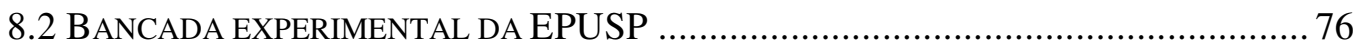

8.2.1 Comparação entre a função ventricular e o simulador hidrodinâmico........ 76

8.2.2 Redução de arrasto nos tubos de silicone com e sem estenose e em tubos

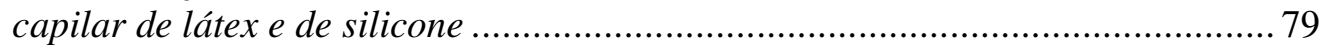

8.3 BANCADA EXPERIMENTAL DO ICB-USP - LEITOS ARTERIAIS CAUDAIS ................ 86

8.3.1 Comprimento e diâmetro arterial caudal ................................................. 87

8.3.2 Avaliação da reatividade vascular do leito arterial caudal em resposta a

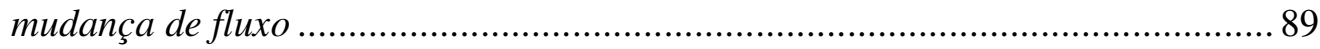

8.3.3 Avaliação do polietileno glicol (PEG4000) no leito arterial caudal em resposta as mudanças de fluxo. ..................................................................... 90

8.3.4 Avaliação da influência do endotélio, do óxido nítrico, do fator

hiperpolarizante derivado do endotélio e das prostaglandinas sobre a ação da perfusão do polietileno glicol nos leitos arteriais caudais. .................................. 91

8.3.5 Avaliação da redução de arrasto a partir do cálculo do fator de atrito nos leitos arteriais caudais de ratos normotensos (Wistar) e espontaneamente hipertensos $(\mathrm{SHR})$............................................................................... 95

8.3.6 Distribuição espacial e temporal da tensão de cisalhamento nos leitos arteriais caudais de ratos normotensos (Wistar) e espontaneamente hipertensos

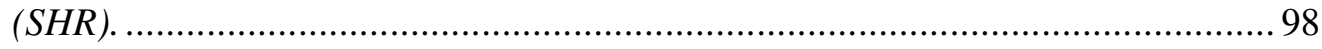

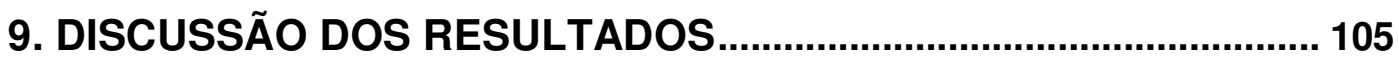

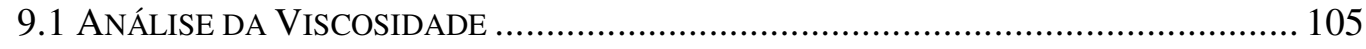

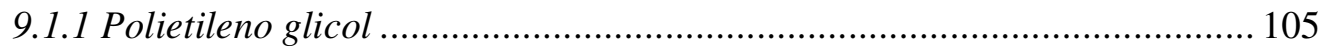

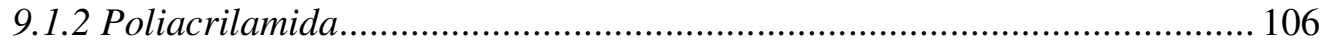

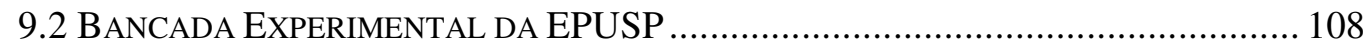

9.2.1 Comentários gerais sobre a redução de arrasto em tubos de silicone com e sem estenose e em tubos capilares de látex e de silicone .................................... 108

9.2.2 Redução de arrasto no tubo capilar de silicone ........................................ 110 
9.3 BANCADA EXPERIMENTAL DO ICB ................................................................. 113

9.3.1 Reatividade do leito arterial caudal em resposta ao fluxo ........................ 113

9.3.2 Influência do endotélio, do óxido nítrico, do fator hiperpolarizante derivado do endotélio e das prostaglandinas sobre a ação da perfusão do polietileno glicol nos leitos arteriais caudais .......................................................................... 114 9.3.3 Redução de arrasto a partir do cálculo do fator de atrito nos leitos arteriais caudais de ratos normotensos (Wistar) e espontaneamente hipertensos (SHR). . 116 9.3.4 Distribuição espacial e temporal da tensão de cisalhamento nos leitos arteriais caudais de ratos normotensos (Wistar) e espontaneamente hipertensos (SHR).

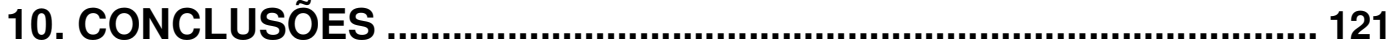

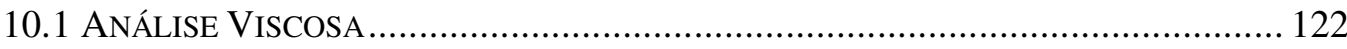

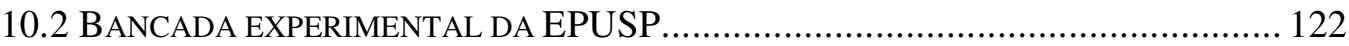

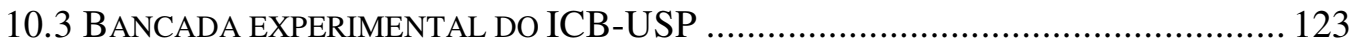

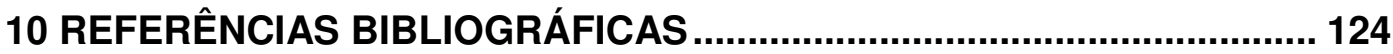

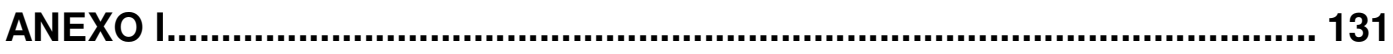

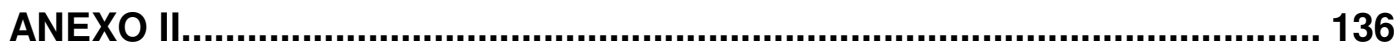




\section{INTRODUÇÃO}

O fenômeno da redução de arrasto (RA) foi primeiramente mencionado na literatura por Toms (1949) quando este apresentou que pequenas quantidades de polímeros de cadeias longas adicionadas ao escoamento poderiam reduzir a perda de carga. Porém, as fibras usadas no processo de fabricação de papel já eram usadas para se obter o fenômeno de RA (Radin et al., 1975). Mas, Toms foi quem apresentou pela primeira vez que pequena quantidade, 5-10 ppm (partes por milhões), de polímeros poderia ter um excelente efeito na RA.

Desde a descoberta de Toms, a aplicação do fenômeno da RA tem-se ampliado bastante e, inúmeros são os trabalhos apresentados para entender esse fenômeno. Porém, a metodologia de abordar o problema levou os pesquisadores a obter diferentes interpretações. Dessa forma, a necessidade da ampliação do campo de estudo para melhor entender o fenômeno de RA tornou-se necessário.

O fenômeno da RA não é aleatório quanto à sua ocorrência e alcance. Existem dependências bem definidas quanto ao tipo de substância, concentração, peso molecular e as próprias condições do escoamento: 1) o fenômeno da RA, de forma geral, aumenta com o incremento da concentração polimérica, até atingir o valor da Assíntota de Máxima Redução de Arrasto (A.M.R.A.), valor a partir do qual maiores concentrações não produzem mais efeito redutor. 2) o fenômeno da RA varia com o diâmetro da tubulação. Maiores reduções de arrasto são conseguidas para tubulações de pequenos diâmetros. Em tubulações de diâmetros maiores, para se obter a mesma porcentagem de RA é necessária maior concentração polimérica. 3) Embora os polímeros sejam as soluções mais utilizadas na RA, a utilização de suspensões de partículas finas ou fibras e soluções surfactantes, segundo alguns autores, também provoca o efeito da RA. 4) Para escoamento laminar (número de Reynols $(\mathrm{Re})<2300$ ), as soluções poliméricas obedecem à lei de Poiseuille em tubulações lisas e rugosas, quando aplicadas em tubulação rígida. Na transição de escoamento laminar para turbulento, ambos - solução polimérica e solvente - tem o mesmo comportamento. No escoamento turbulento existe redução do fator de atrito ( f ) até um valor de concentração, a partir do qual, não há mais nenhum efeito na redução de f. Esse limite, conforme comentado acima, é conhecido como Assíntota de Máxima Redução de Arrasto (A.M.R.A.). Porém, a redução de arrasto no escoamento laminar em leitos arteriais caudais de ratos 
normotensos e hipertensos foi verificada durante o desenvolvimento desse trabalho e, é acentuada pela presença das células endoteliais.

Independentemente das inúmeras pesquisas realizadas até hoje, o fenômeno da RA ainda permanece em estudo não sendo totalmente compreendido, muito menos quando a sua aplicação é voltada para o escoamento vascular. Acredita-se que polímeros redutores de arrasto, no âmbito do escoamento vascular, foram utilizados pela primeira vez na década de 70. Mostardi et. al. (1976) apresentaram que as perturbações no escoamento ocasionadas nas regiões pós-estenótica, na artéria aorta de cães, eram diminuídas quando intravenosamente era administrada injeção de Separan AP-30 (polímero redutor de arrasto). E, desde então, a pesquisa sobre polímeros redutores de arrasto tem se desenvolvido para utilizá-los em patologias do escoamento vascular.

Nesse trabalho, a influência da RA foi analisada na bancada experimental da EPUSP, simulador hidrodinâmico, e na bancada experimental do ICB, onde se utiliza a artéria caudal de ratos normotensos (Wistar) e espontanemanete hipertensos (SHR) para estudo de reatividade desse vaso. Na hipertensão, se tem elevada pressão, devido ao aumento da resistência ao escoamento que ocorre através da redução do diâmetro interno do vaso. O regime de escoamento nesse caso é laminar pulsátil e, enquanto, no simulador hidrodinâmico, obtêm-se fluxo laminar e turbulento pulsáteis. Os seguintes polímeros redutores de arrasto foram usados: poliacrilamida, polietileno glicol (PEG) e o polyox WSR-301. Esses polímeros foram utilizados com diferentes concentrações e pesos moleculares. 


\section{OBJETIVOS}

\subsection{Objetivo geral}

Analisar a influência da adição de polímeros na redução do arrasto em escoamentos laminares e turbulentos.

\subsection{Objetivos específicos}

$\checkmark$ Analisar o comportamento da viscosidade das soluções poliméricas com polietileno glicol (PEG4000) e Poliacrilamidas 1822S e 1340S para diferentes concentrações. Obter a máxima concentração desses polímeros no solvente, de modo a não alterar o comportamento do fluido de trabalho;

$\checkmark$ Analisar a redução de arrasto no simulador hidrodinâmico utilizando o PEG4000, as poliacrilamidas 1822S e 1340S e o Polyox WSR-301 em diferentes concentrações e pesos moleculares;

$\checkmark$ Analisar a redução de arrasto em leitos arteriais caudais de ratos normotensos (Wistar) e espontaneamente hipertensos (SHR) com e sem endotélio, bem como na presença e ausência do PEG4000;

$\checkmark$ Analisar numericamente a distribuição da tensão de cisalhamento em leitos arteriais caudais de ratos normotensos e espontaneamente hipertensos (SHR) na presença ou ausência do PEG4000 e das células endoteliais;

$\checkmark$ Analisar a redução de arrasto através das simulações numéricas para os leitos arteriais caudais. 


\section{O Fenômeno da Redução de Arrasto}

\subsection{Definição}

Como comentando na introdução o fenômeno da redução de arrasto surgiu quando Toms (1949) apresentou seus primeiros resultados e, desde então, inúmeros trabalhos foram desenvolvidos para entender esse fenômeno.

A redução de arrasto foi descoberta ao se observar uma redução no diferencial de pressão num tubo, quando submetido à mesma vazão volumétrica na presença de aditivos. As forças que estão envolvidas no escoamento num tubo praticamente são duas: as forças normais devido à pressão e as forças tangenciais. As forças normais são aquelas que dirigem o escoamento e as forças tangenciais retardam o escoamento, pois dissipam a energia do escoamento na forma de calor devido à viscosidade do fluido e, conseqüentemente, consumindo energia. Dessa forma, os polímeros minimizam essas forças tangenciais facilitando o escoamento. Assim, a definição de redução de arrasto utilizada por Lumley (1969) e que será considerada nesse trabalho é:

"Redução de arrasto é a redução da tensão de cisalhamento na parede $\left(\tau_{\mathrm{w}}\right) \mathrm{e}$, conseqüentemente, no fator de atrito da solução polimérica, a valores inferiores a tensão de cisalhamento do solvente".

A partir da definição apresentada acima, a redução de arrasto, RA, é obtida através da relação entre a tensão de cisalhamento na parede, da solução polimérica, sendo representada pelo sufixo "P" $\left(\tau_{w P}\right)$ e, do solvente, sendo representado pelo sufixo "S" $\left(\tau_{w S}\right)$ :

$$
R A=\frac{\tau_{w P}}{\tau_{w S}}
$$

A tensão de cisalhamento na parede e o fator de atrito de Fanning $\left(\mathrm{f}_{\mathrm{F}}\right)$ são relacionados por

$$
f_{F}=\frac{2 \tau_{w}}{\rho u^{-2}}
$$


onde $\bar{u}$ é a velocidade média dada por

$$
\bar{u}=\frac{Q}{A}
$$

sendo Q a vazão volumétrica $\left(\mathrm{m}^{3} / \mathrm{s}\right)$ e A é a área da seção transversal do tubo $\left(\mathrm{m}^{2}\right)$.

Dessa forma a equação (3.1) pode ser escrita em função do fator de atrito como apresentado abaixo

$$
R A=\frac{f_{F P}}{f_{F S}}
$$

Comumente a redução de arrasto é expressa em termos de porcentagem de redução de arrasto

$$
\begin{aligned}
& R A(\%)=1-\frac{\tau_{w P}}{\tau_{w S}} \\
& \text { ou } \\
& R A(\%)=1-\frac{f_{F P}}{f_{F S}} \\
& \text { ou } \\
& R A(\%)=1-\frac{\Delta p_{P}}{\Delta p_{S}}
\end{aligned}
$$

sendo $\Delta p$ a queda de pressão num trecho considerado.

\subsection{Fator de atrito}

O comportamento do fator de atrito num escoamento em um tubo está apresentado na figura 3.1. Essas curvas referem-se a escoamentos de fluido newtoniano em tubos de parede lisa. O fator de atrito para o escoamento laminar está apresentado pela curva 1 e é definido como 


$$
f_{F}=\frac{16}{\operatorname{Re}}
$$

onde Re é o número de Reynolds definido como

$$
\operatorname{Re}=\frac{\bar{u} d}{v}
$$

e $\bar{u}$ é a velocidade média do escoamento $(\mathrm{m} / \mathrm{s}), \mathrm{d}$ é o diâmetro do conduto $(\mathrm{m})$ e $v$ é a viscosidade cinemática do líquido $\left(\mathrm{m}^{2} / \mathrm{s}\right)$. A curva 2 representa o comportamento do fator de atrito para escoamento turbulento liso e matematicamente é representado pela lei de Prandtl-von Kármán

$$
f_{F}^{-1 / 2}=4 \log \left(\operatorname{Re} f_{F}^{1 / 2}\right)-0.4
$$

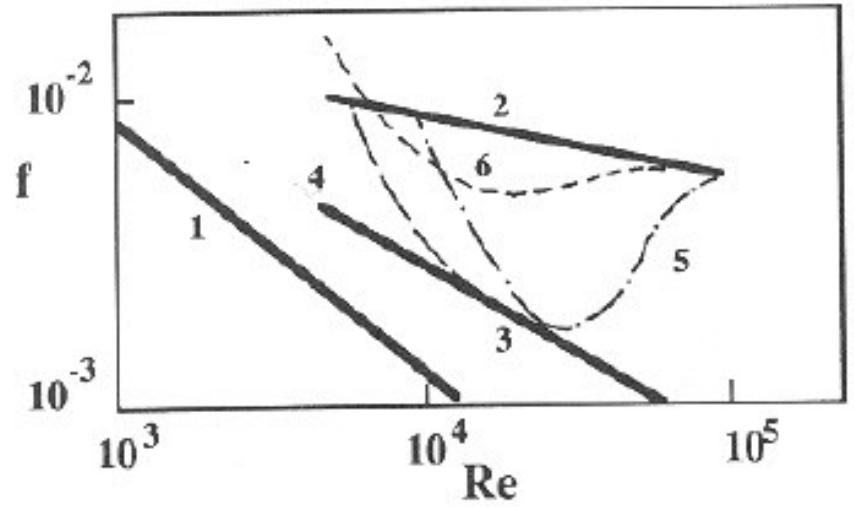

Figura 3.1. Representação esquemática do fator de atrito versus número de Reynolds: (1) escoamento laminar; (2) escoamento turbulento em tubos lisos; (3) assíntota de máxima redução de arrasto de Virk; (4), (5) e (6) três típicos comportamentos para soluções de polímeros, surfactantes e fibras. Extraído de Gyr \& Bewersdorff (1995).

As curvas do fator de atrito versus Reynolds para escoamento laminar e turbulento são separadas mostrando a transição do escoamento laminar para turbulento onde ocorrem as instabilidades, as quais não são reproduzíveis. A curva 3 representa a assíntota de máxima redução de arrasto proposta por Virk (apud Gyr \& Bewersdorff, 1995) cuja equação matemática está apresentada pela equação (3.9) 


$$
f_{F}^{-1 / 2}=19 \log \left(\operatorname{Re} f_{F}^{1 / 2}\right)-32,4
$$

As curvas obtidas através da adição de polímeros devem se situar entre as curvas 2 (escoamento turbulento) e 3 (assíntota de máxima redução de arrasto) apresentadas na figura 3.1. 


\section{Revisão Bibliográfica}

Nesse capítulo foi realizada uma pesquisa sobre a redução de arrasto em canais e tubulações rígidas e, em escoamentos vasculares. No escoamento vascular, os pesquisadores analisaram várias regiões da árvore arterial, desde os vasos de condutância até os vasos de resistência. Os estudos da redução de arrasto evoluíram concomitantemente nas aplicações aos sistemas vasculares, assim como nas aplicações industriais.

\subsection{Redução de arrasto por adição de polímeros - Tubulação rígida}

Vários foram os pesquisadores que analisaram a redução de arrasto utilizando diferentes polímeros e diferentes concentrações poliméricas com o intuito de obter a máxima redução de arrasto sem alterar de forma acentuada as propriedades físicas do fluido.

Driels \& Ayyash (1976) analisaram o efeito da R.A. utilizando o polímero Polyox WSR 301 dissolvido em água nas seguintes concentrações: 12,5; 25; 50 e 100 ppm. A frequiência de oscilação foi imposta por um motor obtendo um valor máximo de número de Reynolds igual a 2000, assim tem-se um escoamento laminar e pulsátil. Nessas condições, eles apresentaram que a redução de arrasto ocorreu e melhores resultados ocorreram para a menor concentração do polímero (12,5 ppm).

Scrivener \& Kopp (1977) realizaram um estudo sobre as alterações da estrutura da turbulência na presença do PEO 301 usando duas técnicas experimentais: método fotográfico e sistema de anemometria a laser (Laser Doppler Velocimeter - LDV). Eles apresentaram que o perfil de velocidade média do escoamento não é afetado para valores baixos de concentrações do polímero (5 ppm). Mostraram ainda que o polímero age na camada de transição (buffer layer) e confirmaram que ocorre transferência de energia das altas freqüências para as baixas freqüências na estrutura da turbulência.

Sellin et al. (1982) fizeram um levantamento sobre a R.A. apresentado nos últimos anos e mostraram que o mecanismo da R.A. ocorre na região de parede e mais precisamente na camada de transição (buffer layer). Apresentaram que os polímeros têm um efeito sobre o balanço de energia, entre a produção e a dissipação turbulenta, e atribuíram isso às propriedades elásticas das moléculas. Com isso relacionaram a capacidade redutora de arrasto de um polímero qualquer com a sua capacidade de armazenar energia por estiramento. 
Usui \& Komoda (1988) analisaram a R.A. através da injeção da solução polimérica. O polímero utilizado foi o óxido de polietileno (PEO) e as medições foram realizadas através da anemometria a laser $(L D V)$. No primeiro experimento a solução foi homogênea, ou seja, o polímero foi diluído no solvente e, em seguida iniciou-se o escoamento e foram realizadas as medições. No segundo experimento a solução polimérica foi injetada no centro da tubulação através de um pequeno tubo onde o solvente já estava em regime de escoamento. Eles mostraram que a forma de injeção do polímero é importante para a redução de arrasto. No caso dos polímeros injetados no escoamento, esses causaram um aumento na espessura da camada de transição (buffer layer), um aumento na viscosidade turbulenta e a supressão dos menores turbilhões, dessa forma, obtendo um maior efeito na redução de arrasto.

McAndrew et al. (1993) mostraram que a degradação mecânica da polivinilamina (PVAm - peso molecular $8 \times 10^{6} \mathrm{Da}$ ) é maior do que em outros polímeros redutores de arrasto como óxido de polietileno e poliacrilamida. Porém os níveis de redução de arrasto são inferiores quando comparados com o PEO ou poliacrilamida.

Vilalta \& Ortiz (1995) apresentaram o fenômeno da R.A. causada por soluções poliméricas de IQAPOL PA de peso molecular $1,7 \times 10^{6} \mathrm{Da}$ em um escoamento turbulento num tubo de P.V.C. de 102,95 mm de diâmetro interno. Eles verificaram uma R.A. de $30 \%$ para valores de $\operatorname{Re}=5 \times 10^{5}$ com concentração polimérica maior que 70 ppm.

Xueming \& Jianzhong (2001) apresentaram que a adição da poliacrilamida no escoamento não suprimiu as flutuações turbulentas, mas aumentou os picos das flutuações turbulentas quando comparados com a situação de ausência da solução polimérica. O que ocorre é uma reestruturação da turbulência. A intensidade axial da turbulência é aumentada e a intensidade radial é diminuída, de modo que ocorre muito mais uma reestruturação da turbulência do que uma supressão da turbulência.

Vilalta \& Ortiz (2000) apresentaram um estudo experimental da influência da adição de polímeros na estrutura de escoamentos turbulentos em canais. Para análise da R.A. foram utilizados três polímeros: Iqapol PA, Iqapac 731 e o Polivinilacetato com pesos moleculares de $1,7 \times 10^{6}, 4-6 \times 10^{3}$ e $9 \times 10^{3}$ Da, respectivamente, cuja faixa de Reynolds foi de $8 \times 10^{3}-10^{5}$. Eles apresentaram uma R.A. de 60 e $30 \%$ para polímeros de alto e baixo peso molecular, respectivamente. Eles concluíram que os polímeros atuam no sentido de amortecer parcialmente a turbulência. 
Kulik (2001) analisou a R.A. ao longo de um tubo de diâmetro interno $2 \mathrm{~mm}$ e comprimento de $4 \mathrm{~m}$ através do uso de óxido de polietileno (PEO) com concentrações de 1 a 100 ppm. O número de Reynolds foi de $8 \times 10^{4}$ e a pressão de operação foi de 16 MPa. O resultado obtido por esse autor mostrou que a R.A. não é um valor constante, mas depende do tempo e da interação entre o polímero e o escoamento turbulento.

Ptasinski et al. (2001) analisaram a redução de arrasto através da inserção de poliacrilamida nas seguintes concentrações: 20, 103, 175 e 435 ppm num tubo de comprimento de $34 \mathrm{~m}$ e diâmetro interno de 40,37 $\mathrm{mm}$. As medições foram realizadas utilizando a técnica de anemometria a laser $(L D V)$. Eles mostraram que os valores das flutuações turbulentas axiais aumentavam para baixas concentrações de polímeros e diminuíam chegando a valores próximos do solvente (água) para as maiores concentrações poliméricas, enquanto os valores de flutuações na direção normal caíam drasticamente contribuindo para a redução de arrasto.

\subsection{Redução de arrasto por adição de polímeros - Sistema vascular}

Mostardi et al. (1976) usaram poliacrilamida aniônica (Separan AP-30) intravenosamente em cães e mostraram que, a alteração no fluxo proveniente da estenose foi diminuída na presença do polímero, diminuindo a perda de carga. Através da continuação deste trabalho, Mostardi et al. (1978) analisaram o desenvolvimento de

placas de aterosclerose em coelhos através de uma dieta rica em colesterol. Um grupo foi utilizado como controle e ao outro foi administrado Separan AP-30. No grupo tratado com Separan AP-30 ocorreu uma diminuição na formação de placas ateroscleróticas quando comparado com aquele que não recebeu o polímero. Eles atribuíram esse resultado a capacidade do polímero de diminuir ou suprimir os vórtices gerados nas bifurcações ou após estenoses.

Faruqui et al. (1987) analisaram o efeito inibitório da poliacrilamida aniônica Separan AP-30 na formação de placas ateroscleróticas nas aortas de coelhos. Esses receberam uma dieta de colesterol (2\%) num período que se estendeu de 37 - 170 dias. As análises das placas ateroscleróticas foram realizadas através de cortes histológicos da seção transversal da aorta. Eles verificaram nesse trabalho que o Separan AP-30 exercia um forte efeito na inibição das placas em toda a aorta, inibindo o desenvolvimento da placa em menos da metade no arco aórtico e um quinto na aorta descendente.

Hutchison et al. (1989) analisaram a redução de arrasto através da administração do Separan AP-273 em seis cães numa concentração de $2 \mathrm{mg} / \mathrm{kg}$. Estenose foi criada na 
artéria carótida dos cães. As vazões e a turbulência no centro da artéria foram medidas usando um fluxômetro eletromagnético e um velocímetro Doppler ultra-sônico pulsado. Os autores apresentaram que o Separan AP-273 reduziu o pico máximo de velocidade na artéria carótida o qual foi correlacionada com a redução da vazão volumétrica nessa artéria, apresentada pelo fluxômetro eletromagnético, mas não foi estatisticamente diferente. Eles, também, mostraram que ocorreu uma redução no nível da turbulência na região da zona de recirculação e no centro da artéria carótida o que correlacionaram com o fenômeno da redução de arrasto.

Sawchuk et al. (1999) mostraram o efeito do Polyox WSR 301, com peso molecular de aproximadamente $14 * 10^{6} \mathrm{Da}$, na redução do desenvolvimento das placas ateroscleróticas. As placas ateroscleróticas se desenvolvem em regiões cujos valores de tensão de cisalhamento são baixos $(-0,4<\tau<0,4 \mathrm{~Pa})$. Nesse estudo foram utilizados seis cães, nos quais foram criadas estenoses na artéria aorta. Eles observaram que houve um aumento da taxa de deformação, nas áreas de recirculação, cujos valores foram:

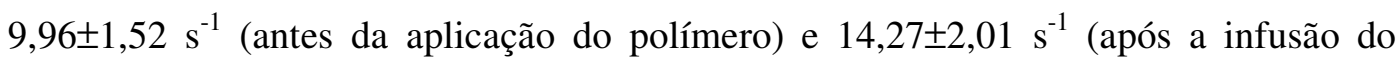
polímero). Através desses resultados, sugeriram que a redução das placas ateroscleróticas com o uso desses polímeros pode ser atribuída ao aumento no valor da tensão de cisalhamento em áreas normalmente expostas a baixas tensões de cisalhamento.

Kameneva et al. (2003) analisaram a eficiência do polietileno glicol (PEG20 $20 \mathrm{kDa}$ ) na redução de hemólise em circulação extracorpórea. Células vermelhas bovinas foram submetidas ao estresse da bomba de circulação extracorpórea na presença de soluções de PEG e de soluções salinas. Os autores demonstraram que, na presença do PEG, ocorreu $40 \%$ de redução no índice de hemólise quando comparada com a solução salina.

Kameneva et al. (2004) estudaram os efeitos do PEG 200 (200 kDa), do PEG 3500 (3500 kDa) e de um polímero extraído de Aloe Vera (AVP) no choque hemorrágico agudo. Um grupo de ratos anestesiados recebeu a infusão dos polímeros e outro grupo recebeu uma solução salina. Os autores demonstraram que às porcentagens de sobrevivência dos animais durante um período de duas horas foram 19\% no grupo controle, 14\% no grupo tratado com PEG 200 (200 kDa) e 100\% no grupo tratado com PEG3500 (3500 kDa) e com AVP (4000 kDa). Eles atribuíram isso ao fenômeno da redução de arrasto apresentado pelos polímeros PEG3500 e AVP, pois o PEG200 não apresenta o fenômeno da redução de arrasto devido ao seu peso molecular ser menor 
que $1000 \mathrm{kDa}$. Eles também demonstraram que a infusão destes polímeros melhorou a perfusão e a oxigenação tecidual.

Macias et al. (2004) analisaram o efeito de polímeros redutores de arrasto derivado de Aloe Vera em modelos de ratos hemorrágicos. Os ratos anestesiados foram submetidos à hemorragia sobre uma taxa constante durante 25 minutos. No protocolo $\mathrm{A}$, a perda total de sangue foi de $2,45 \mathrm{~mL} / 100 \mathrm{~g}$ e, no protocolo $\mathrm{B}$, a perda total sangüínea foi de 3,15 mL/100g. Cinco minutos após o início da hemorragia, os animais foram ressuscitados com $7 \mathrm{~mL} / \mathrm{kg}$ de solução salina ou solução salina com o polímero (50 $\mu \mathrm{g} / \mathrm{mL}$ ) extraído da Aloe Vera. Eles obtiveram como resultado a sobrevivência no protocolo A de $50 \%$, e no protocolo B de $80 \%$ dos ratos por 4 horas. As pressões arteriais foram maiores no grupo tratado com o polímero extraído da Aloe Vera (89 48 vs. $68 \pm 5 \mathrm{mmHg}$ ), respectivamente. Dessa forma, eles concluíram que a ressuscitação utilizando o polímero redutor de arrasto extraído da Aloe Vera prolonga a taxa de sobrevivência dos ratos ao choque hemorrágico.

Samsamshariat et al. (2005) analisaram o efeito do polietileno glicol (PEG 400 $400 \mathrm{kDa}$ ) no sistema cardiovascular. Eles usaram 20 ratos machos pesando 250-300 g. Dez ratos receberam solução salina e outros 10 receberam PEG 400, 2 mL/kg, duas vezes ao dia durante uma semana. Depois de quatro semanas os ratos foram anestesiados e os parâmetros hemodinâmicos foram medidos usando um cateter pressão-volume (Miller catheter). Os parâmetros hemodinâmicos foram iguais em ambos os grupos, exceto a elastância arterial, a qual foi diminuída no grupo tratado com PEG.

Marhefka et al. (2006) utilizaram o poli(N-vinilformamide) (PNVF) com peso molecular 4,5*10 $0^{6} \mathrm{Da}$,em escoamento turbulento, num tubo de vidro de $0,44 \mathrm{~cm}$ de diâmetro interno e comprimento de $91,5 \mathrm{~cm}$ em fluxos que variaram de 2-6 L/min, obtendo números de Reynolds entre 10.000-25.000. Paralelamente este polímero foi injetado intravenosamente numa concentração de $100 \mu \mathrm{g} / \mathrm{mL}$ durante um período de 5 min na veia jugular de ratos. Eles obtiveram como resultado uma redução de arrasto em torno de $20 \%$ quando a concentração foi de $0,1 \mathrm{mg} / \mathrm{mL}$ e $32 \%$ de redução quando a injeção foi de $0,5 \mathrm{mg} / \mathrm{mL}$ no tubo e $20 \%$ na redução da resistência vascular do animal quando a concentração foi de $0,5 \mathrm{mg} / \mathrm{mL}$. Eles obtiveram, ainda, resultados que mostraram uma menor degradação mecânica do PNVF quando comparado com o PEG. Assim, eles concluíram que esse polímero é um possível candidato para uso clínico. 


\section{Polímeros}

\subsection{Introdução}

A principal categoria de materiais na engenharia após os metais é a dos sólidos moleculares. Estes são compostos não-metálicos que comumente se originam de materiais orgânicos. A madeira é um material comum de construção, como também o são outras substâncias orgânicas como o couro para a vedação, feltro para forração, cortiça para isolamento, óleos para lubrificação e resinas para camadas de proteção intensamente recomendadas em aplicações de engenharia.

O desenvolvimento da pesquisa no que diz respeito aos materiais orgânicos se preocupa tanto com a melhoria desses materiais quanto com o desenvolvimento de muitas substâncias sintéticas. Os polímeros têm propiciado aos engenheiros uma variedade cada vez maior de materiais para suas aplicações.

Existe uma semelhança entre os conceitos de macromoléculas e polímeros. Literalmente, macromoléculas são moléculas grandes, de elevado peso molecular, o qual decorre de sua complexidade química, podendo ou não ter unidades repetidas. A palavra polímero ("poly" + "mer", muitas partes), vem do Grego e foi criada por Berzelius, em 1832, para designar compostos de pesos moleculares múltiplos, em contraposição ao termo isômero, empregado para compostos de mesmo peso molecular, porém de estruturas químicas diferentes, como acetileno e benzeno (Mano \& Mendes, 2004).

Polímeros são macromoléculas caracterizadas por seu tamanho, estrutura química e interações intra e intermoleculares. Possuem unidades químicas ligadas por covalências, repetidas regularmente ao longo da cadeia, denominados meros. O número de meros da cadeia polimérica é denominado grau de polimerização, sendo geralmente simbolizado por n ou DP (“degree of polymerization”).

Os polímeros de baixo peso molecular são denominados oligômeros (“oligomers", poucas partes), que também vem do grego; são geralmente produtos viscosos, de peso molecular da ordem de $10^{3} \mathrm{Da}$.

Quando o polímero tem apenas um tipo de mero, usa-se a expressão homopolímeros. Quando há mais de um tipo de mero, é designado como copolímero, e os monômeros que lhe dão origem são chamados de comonômeros. O termo copolímero 
é geral; quando há três ou mais monômeros na reação, pode-se particularizar este número, usando a expressão terpolímero, tetrapolímero, etc.

Os polímeros podem ter suas cadeias sem ramificações e, são denominados como polímeros lineares. Esses podem apresentar ramificações e são denominados polímeros ramificados. Podem ainda exibir cadeias mais complexas, com ligações cruzadas, formando polímeros reticulados. Conseqüentemente, surgem propriedades diferentes no polímero, decorrentes de cada tipo de cadeia, especialmente em relação à solubilidade. A formação de retículos, devido às ligações cruzadas entre moléculas, impede o seu deslizamento umas sobre as outras, aumentando muito a resistência mecânica e tornando o polímero insolúvel.

Os polímeros utilizados neste trabalho foram: o polietileno glicol, Polyox WSR 301 e as poliacrilamidas $1822 \mathrm{~S}$ e 1340S. Estes polímeros são descritos na literatura como polímeros redutores de arrasto e apresentam algumas características particulares, como por exemplo:

- Cadeia linear;

- Solúvel em água.

\subsection{Polietileno glicol}

O polietileno glicol (PEG) é uma classe de polímeros lineares solúveis em água formados a partir da reação do oligômero etileno glicol $\left(\mathrm{CH}_{2} \mathrm{OHCH}_{2} \mathrm{OH}\right)$. O termo glicol representa os dois grupos hidroxil $(\mathrm{OH})$ ligados a diferentes átomos de carbono. Esse polímero é líquido ou sólido dependendo do peso molecular a temperatura ambiente. Para valores de peso molecular abaixo de $1000 \mathrm{Da}(1 \mathrm{kDa})$, esse se apresenta na forma líquida e acima de $1000 \mathrm{Da}(1 \mathrm{kDa})$, encontra-se na forma sólida. O PEG apresentando diferentes pesos moleculares possui diferentes aplicações e apresenta diferentes propriedades físicas (viscosidade) devido ao comprimento das moléculas, porém as propriedades químicas são semelhantes. A fórmula molecular do polietileno glicol é $\mathrm{H}-\left(\mathrm{OCH}_{2} \mathrm{CH}_{2}\right)_{\mathrm{n}}-\mathrm{OH}$, onde o n é o número de repetições do óxido de etileno. Por exemplo, o PEG com $n=80$ representa aproximadamente o PEG 3500, pois tem-se o seguinte cálculo: 
- $2 \mathrm{H}+320 \mathrm{H}=322 \mathrm{H}=322 * 1=322$

- $1 \mathrm{O}+80 \mathrm{O}=81 \mathrm{O}=81 * 16=1296$

- $2 * 80 \mathrm{C}=160 \mathrm{C}=160 * 12=\underline{1920}$

- Total $=\quad=3538$

logo, o peso molecular médio desse PEG é 3500 Da.

A partir desse ponto, a nomenclatura para o PEG utilizada nesse trabalho deve ser lida da seguinte maneira: PEG4000 representa o polímero polietileno glicol cujo peso molecular é $4000 \mathrm{Da}$ ou $4 \mathrm{kDa}$. Polímeros com a mesma estrutura química do polietileno glicol, mas com peso molecular superior a $2 \times 10^{4} \mathrm{Da}$ ou $20 \mathrm{kDa}$, serão denominados como óxido de polietileno (Harris, 1992).

Como comentado anteriormente, o PEG é um polímero solúvel em água, não carregado eletricamente, não apresenta qualquer afinidade específica por um determinado órgão, não-tóxico e não imunogênico e difere entre si pelos diferentes pesos moleculares (Harris \& Chess, 2003). PEG é utilizado como laxante mais especificamente o PEG3350, apresentando nome comercial de Miralax® (Medline Plus). O PEG20 ou o cetomacrogol é utilizado como creme para pele e como lubrificante sexual freqüentemente combinado com glicerina.

\subsubsection{Características físicas do PEG4000 (4 kDa)}

Abaixo seguem as características físicas do PEG:

- Estado físico

- Cor

- $\mathrm{PH}$ sol. $5 \% / 25^{\circ} \mathrm{C}$

- Peso molecular

- Ponto de fusão

- Solubilidade em água $\left(20^{\circ} \mathrm{C}\right), \%$ por peso

- Viscosidade a $100^{\circ} \mathrm{C}$ sólido

Pó granulado branco ${ }^{\mathrm{b}}$;

$6,16^{\mathrm{a}}$

3.874,3 $\mathrm{Da}^{\mathrm{a}}$;

$57-59{ }^{\circ} \mathrm{C}^{\mathrm{b}}$

$66^{\mathrm{b}}$

$124 \mathrm{cSt}^{\mathrm{a}}$

- Número médio de repetição da cadeia de óxido de etileno $90,5^{\text {b; }}$; 
a - Dados retirados do Boletim Analítico fornecido pela LabSynth Labsynth Produtos para Laboratórios Ltda;

b - Manual do fabricante.

\subsection{Polyox WSR 301}

Polyox WSR (Water Soluble Resins) - resinas hidrossolúveis - são polímeros não iônicos de polietileno glicol, disponíveis na forma de pó e são classificados de acordo com a viscosidade de suas soluções. Os pesos moleculares dessa classe de produtos para os cuidados pessoais variam desde 100.000 a 4.000.000 Da. Os Polyoxs oferecem alternativas tanto na seleção do tipo, quanto na concentração necessária para obter-se o efeito de deslizamento e a harmonização perfeita para cada produto (Amerchol - The Elegance Engineers).

Esse tipo de polímero tem sido usado na indústria farmacêutica e ultimamente tem sido aplicado como veículos de drogas. O princípio por trás dessa forma de entrega da droga trata da forma da dose liberada até o polímero dissolver na camada da mucosa. Os benefícios dessa forma de entrega são maior tempo de entrega da droga, terapia gênica e freqüentemente um aumento na biodisponibilidade (Technical Data - Polyox

${ }^{\mathrm{TM}}$ Water-Soluble Resins, Bottenberg et al., 1991).

\subsubsection{Características físicas do Polyox WSR301}

Abaixo seguem as características físicas do Polyox WSR:

- Estado físico

- Cor

- Peso molecular

- Ponto de fusão

- Solubilidade sólido ${ }^{\mathrm{a}}$;

Pó granulado branco ${ }^{\mathrm{b}}$; $4000 \mathrm{kDa}^{\mathrm{a}}$; $62-67{ }^{\circ} \mathrm{C}^{\mathrm{b}}$ não determinada; 


\subsection{Poliacrilamida Aniônica}

A poliacrilamida é formada por subunidades de acrilamidas cujo composto químico é o seguinte: $\mathrm{C}_{3} \mathrm{H}_{5} \mathrm{NO}$ cuja estrutura química está apresentada na figura 5.1.

$$
-\left[\begin{array}{cl}
\mathrm{H} & \mathrm{H} \\
\mathrm{I} & \mathrm{I} \\
-\mathrm{C} & -\mathrm{C}- \\
\mathrm{I} & \mathrm{I} \\
\mathrm{II} & \mathrm{C}=\mathrm{O} \\
& \mathrm{I}=\mathrm{H} \\
& \mathrm{N}=\mathrm{H}
\end{array}\right] \mathbf{n}
$$

Figura 5.1. Estrutura química da acrilamida. Extraído de Gyr \& Bewersdorff (1995).

Muitas acrilamidas são usadas para sintetizar poliacrilamidas cuja aplicação será utilizada na clarificação da água, em processos de separação sólidos-líquidos via desidratação em esteiras filtrantes, filtros prensa e centrífugas. Podem ser comercializados em pó ou emulsão (Kemwater Brasil S.A.).

A agência Internacional de Pesquisa em Câncer (The International Agency for Research on Cancer - IARC) classificou a acrilamida em 1994 como sendo uma substância em potencial para o desenvolvimento de câncer em humanos com bases em experimentos em animais. Experimentos em ratos com a acrilamida mostraram um aumento na incidência de tumores no sistema nervoso central e na tiróide (Johnson et. al., 1986).

Mediante as informações acima, a poliacrilamida foi usada apenas na bancada experimental do laboratório de Mecânica dos Fluidos e não em leitos arteriais caudais dos ratos. Foram utilizadas poliacrilamidas com diferentes pesos moleculares. Essas poliacrilamidas são especificadas como: OPTIFLOC A-1340S e OPTIFLOC 1822S.

\subsubsection{Características físicas da poliacrilamida}

Abaixo seguem as características físicas das poliacrilamidas com diferentes pesos moleculares:

- OPTIFLOC $1822 \mathrm{~S}$

○ Estado físico

Sólido; 
- Cor

○ pH (solução a 0,5\%)

- Peso molecular

- Viscosidade à $25^{\circ} \mathrm{C}$

- Densidade $\left(\mathrm{kg} / \mathrm{m}^{3}\right)$

- OPTIFLOC A 1340S

- Estado físico

- Cor

○ pH (solução a $0,5 \%$ )

- Peso molecular

- Viscosidade à $25^{\circ} \mathrm{C}$

○ Densidade $\left(\mathrm{kg} / \mathrm{m}^{3}\right)$
Pó granulado branco;

$5-7$;

$1,3 \times 10^{6} \mathrm{Da}$;

100 mPa.s;

$800 \pm 50$.

Sólido;

Pó granulado branco;

$5-7$;

$2,0 \times 10^{6} \mathrm{Da}$

$150 \mathrm{mPa} . \mathrm{s}$;

$825 \pm 50$. 


\section{Modelagem Matemática de Escoamentos em Tubos Rígidos}

\subsection{Introdução}

Para o desenvolvimento da modelagem matemática dos escoamentos permanente e não-permanente em condutos forçados foram utilizadas as seguintes referências bibliográficas: Zamir (2000), Fung (1997) e McDonald (1974).

Para identificar se um escoamento é laminar ou turbulento é necessário utilizar um número adimensional de Reynolds,

$$
\operatorname{Re}=\frac{\rho \bar{u} d}{\mu}
$$

onde $\rho$ é a massa específica do fluido $\left(\mathrm{kg} / \mathrm{m}^{3}\right), \bar{u}$ é a velocidade média do escoamento (m/s), d é o diâmetro do tubo (m) e $\mu$ é a viscosidade dinâmica do fluido (Pa.s). A experiência de Reynolds, de modo qualitativo, representa a diferença entre escoamento laminar e turbulento. Basicamente, esta clássica experiência utiliza um grande reservatório de onde o fluido de trabalho escoa para um tubo transparente por onde ocorre o escoamento. Através da injeção de corante na entrada do tubo, a visualização do fluxo é permitida. Para baixas vazões (baixos números de Reynolds), o corante permanece num único filamento, ou seja, não há mistura macroscópica do corante caracterizando-se o escoamento laminar. Assim, o escoamento laminar é aquele no qual o fluido escoa em lâminas ou camadas não havendo mistura de camadas adjacentes do fluido. Com o aumento da vazão através do tubo, o filamento do corante que antes era contínuo, agora passa a sofrer alterações apresentando um comportamento instável; a linha de corante é esticada e torcida e, rapidamente se dispersa por todo o campo de escoamento. Esse comportamento caracteriza um escoamento turbulento e, esse tipo de comportamento, ocorre devido a flutuações de velocidades, as quais são de baixa e de alta frequiência, superpostas ao movimento principal. A mistura de partículas de camadas adjacentes de fluido resulta na rápida dispersão do corante.

O valor adimensional do número de Reynolds que caracteriza a transição do escoamento laminar para turbulento ocorre entre 2.000 e 13.000 dependendo da rugosidade do tubo e das condições de entrada do fluido na tubulação em estudo. Quando um extremo cuidado é utilizado na experiência pode-se elevar esse número para 
100.000 (Fox \& McDonald, 1998). Um consenso existe na literatura para aceitar um valor crítico de transição em torno de 2.300 .

Esse valor crítico (2.300) para a transição do escoamento ocorre para escoamento permanente num tubo rígido. No escoamento vascular, onde o escoamento é não-permanente e a parede do tubo é flexível, este valor crítico não é conhecido, embora alguns experimentos foram realizados in vitro e in vivo com o intuito de determiná-lo.

Considere-se o escoamento não-permanente num tubo (Nerem \& Seed, 1972) apresentando um aumento gradual da velocidade e, consequientemente, do número de Reynolds (Figura 6.1). Nessa figura tem-se no eixo da ordenada o valor da velocidade do escoamento em $\mathrm{cm} / \mathrm{s}$ e no eixo da abscissa o valor do tempo em $\mathrm{s}$. A linha tracejada representa o valor do número de Reynolds crítico (2.300) onde deveria ocorrer à transição do escoamento laminar para turbulento, porém, isto não ocorre. A turbulência surge quando o número de Reynolds atinge o valor de 9.500. Esse fato ocorre devido ao gradiente de pressão adverso. Durante a fase de aceleração do fluido, o escoamento ocorre a favor do gradiente de pressão no sentido do escoamento, e durante a fase de desaceleração do escoamento, esse ocorre contra um gradiente de pressão e, isto conduz a instabilidade no perfil de velocidade gerando a turbulência, mesmo em valores inferiores ao valor do número de Reynolds crítico (2.300). Seed \& Wood (1971), investigaram o aparecimento da turbulência na aorta de cães. Eles perceberam que a turbulência estava sempre associada à fase de desaceleração do escoamento, ou seja, no final da sístole e início da diástole e associaram esse fenômeno a um perfil de velocidade instável induzido pelo gradiente de pressão adverso (Figura 6.2). 


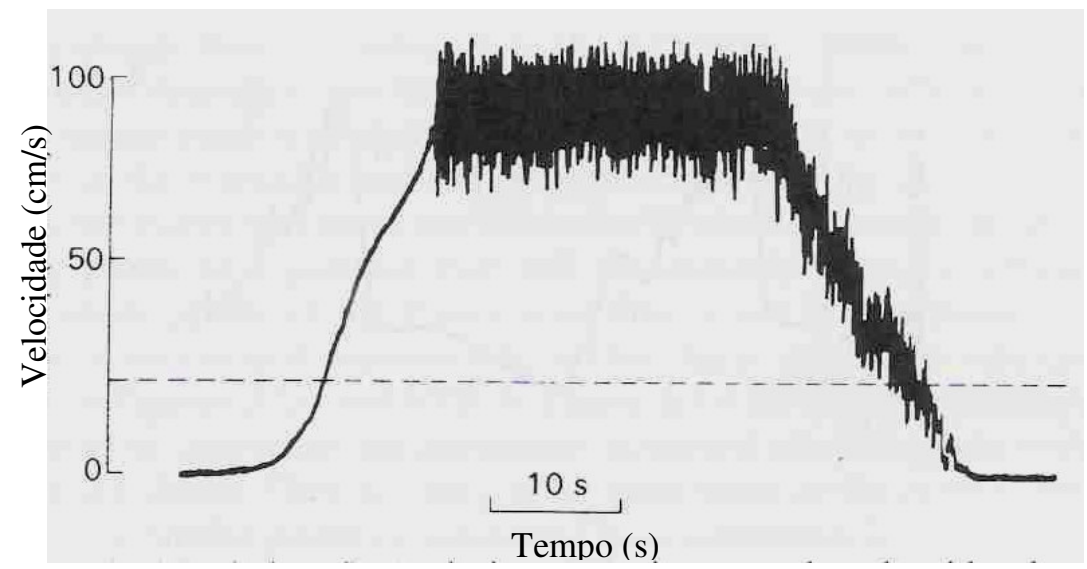

Figura 6.1. Registro do aumento da velocidade com o tempo de um escoamento turbulento num tubo através de um anemômetro de filme quente. Extraído de Nerem \& Seed (1972).

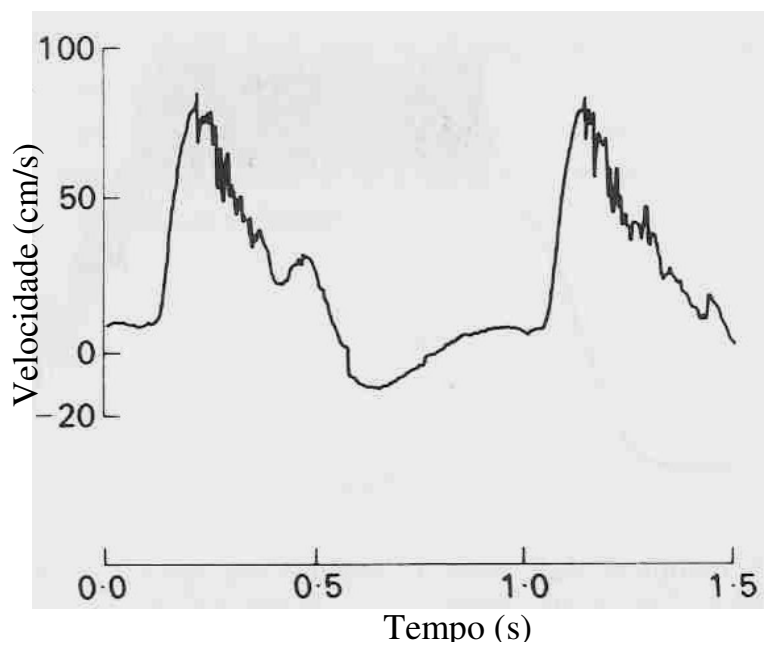

Figura 6.2. Registro do fluxo sangüíneo na aorta descendente de um cão apresentando a turbulência durante a fase de desaceleração da sístole. Extraído de Seed \& Wood (1971).

Nerem et al (1971) apresentaram que o limite entre um escoamento nãoperturbado (laminar) e um escoamento altamente perturbado (turbulento) seguia aproximadamente uma linha definida por

$$
\operatorname{Re}_{\alpha}=K \Omega
$$

onde o valor de $K$ era 150 para a aorta ascendente e 250 para aorta descendente de cães (figura 6.3) e $\Omega$ é um parâmetro adimensional denominado número de Womersley definido através da relação entre a força de inércia oscilatória e a força cisalhante: 


$$
\Omega=a \sqrt{\frac{\rho \varpi}{\mu}}
$$

onde a é o raio do tubo, $\rho$ é a densidade do fluido, $\mu$ é a viscosidade dinâmica e $\omega$ é a freqüência de oscilação. Quanto maior o valor de $\Omega$ maior será o valor crítico do número de Reynolds (esta equação é inválida para $\Omega$ tendendo a zero).

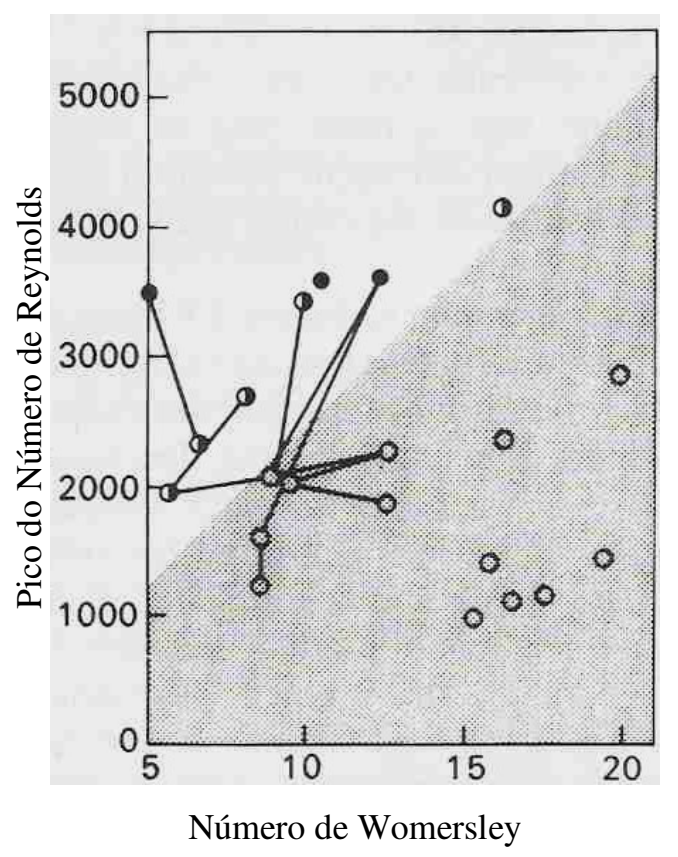

Figura 6.3. Estabilidade do escoamento sangüíneo na aorta descendente de cães anestesiados influenciados pelo pico do número de Reynolds e número de Womersley. Os pontos ligados referem-se ao mesmo animal. Círculos abertos, escoamento laminar; círculos preenchidos, escoamento turbulento; círculos parcialmente preenchidos, escoamento na fase de transição. Extraído de Nerem \& Seed (1972).

Tradicionalmente, em medicina assume-se que o escoamento turbulento na circulação vascular é geralmente encontrado nas estenoses valvulares e pode ser detectado como um "murmurs" via estetoscópio (Leon \& Shaver, 1974 apud Wood, 1999). Nerem (1992) sugeriu que o escoamento na aorta humana era laminar exceto durante exercício físico, mas não citou evidências. Wood (1999) analisou a turbulência através da utilização de ressonância magnética e, mostrou que geralmente não é observada a geração de turbulência na aorta. Porém, através de exercícios físicos a transição de laminar para turbulento ocorre na aorta e, denomina essa transição como transição natural ou turbulência natural. Essa turbulência natural poderia ser importante no entendimento dos benefícios trazidos pela prática de exercícios físicos. 
Métodos de simulações numéricas diretas empregadas por Orszag \& Patera (1983) para escoamento permanente foram posteriormente aplicados para escoamentos oscilatórios em canais por Akhavan et al. (1991b), e comparados com experimento em tubos por Akhavan et al. (1991a) com o intuito de definir um número de Reynolds crítico. Assim, baseados na espessura de camada de Stokes,

$$
\delta=\sqrt{\left(\frac{2 v}{\varpi}\right)}
$$

onde $v$ é a viscosidade cinemática do fluido e $\varpi$ é a frequiência de oscilação, eles propuseram um número de Reynolds crítico,

$$
\operatorname{Re}_{c}^{\delta}=\bar{u} \sqrt{\frac{2}{v \varpi}}
$$

o qual comenta-se que está de acordo com os resultados experimentais obtidos em laboratório. Os resultados de Akhavan et al. (1991a) podem ser comparados com os resultados empíricos de Nerem et al. (1971) para escoamentos na artéria aorta,

$$
\frac{\operatorname{Re}}{\Omega}=\frac{2 \bar{u}}{\sqrt{v \varpi}}=\sqrt{2} \operatorname{Re}_{c}^{\delta}=K
$$

Os menores valores de número de Reynolds críticos obtidos por Nerem et al. (1971) podem ser devido aos maiores níveis de perturbações encontrados nas artérias aortas em relação àqueles encontrados nos experimentos de laboratório. O escoamento na artéria aorta ascendente são afetados pelas perturbações geradas pelo ventrículo e pela válvula aórtica, enquanto na aorta descendente são criadas pelas curvas e ramos saindo dessa.

Mediante o comentado acima, percebe-se que o número de Reynolds crítico no escoamento vascular ainda permanece em estudo, mas tende a valores inferiores àqueles encontrados para escoamentos em tubos rígidos, pois de uma maneira geral as perturbações geradas no escoamento vascular são maiores conduzindo a menores valores para o número de Reynolds crítico. 


\subsection{Escoamento Permanente em Tubo Rígido}

Algumas hipóteses são assumidas para o desenvolvimento matemático das equações que representam o escoamento permanente num tubo rígido.

Considere um escoamento completamente desenvolvido num tubo de seção transversal circular, reto e longo. Utilizando essas hipóteses, a equação de NavierStokes e a equação da continuidade podem ser simplificadas e trabalhadas matematicamente para a obtenção das equações que representam o escoamento permanente num tubo rígido. Estas equações estão representadas abaixo em coordenadas cilíndricas,

$$
\begin{aligned}
& \rho\left(\frac{\partial u}{\partial t}+u \frac{\partial u}{\partial x}+v \frac{\partial u}{\partial r}+\frac{w}{r} \frac{\partial u}{\partial \theta}\right)+\frac{\partial p}{\partial x}=\mu\left(\frac{\partial^{2} u}{\partial x^{2}}+\frac{\partial^{2} u}{\partial r^{2}}+\frac{1}{r} \frac{\partial u}{\partial r}+\frac{1}{r^{2}} \frac{\partial^{2} u}{\partial \theta^{2}}\right) \\
& \rho\left(\frac{\partial v}{\partial t}+u \frac{\partial v}{\partial x}+v \frac{\partial v}{\partial r}+\frac{w}{r} \frac{\partial v}{\partial \theta}-\frac{w^{2}}{r}\right)+\frac{\partial p}{\partial r}=\mu\left(\frac{\partial^{2} v}{\partial x^{2}}+\frac{\partial^{2} v}{\partial r^{2}}+\frac{1}{r} \frac{\partial v}{\partial r}-\frac{v}{r^{2}}+\frac{1}{r^{2}} \frac{\partial^{2} v}{\partial \theta^{2}}-\frac{2}{r^{2}} \frac{\partial w}{\partial \theta}\right)(6.8 \\
& \rho\left(\frac{\partial w}{\partial t}+u \frac{\partial w}{\partial x}+v \frac{\partial w}{\partial r}+\frac{w}{r} \frac{\partial w}{\partial \theta}+\frac{v w}{r}\right)+\frac{1}{r} \frac{\partial p}{\partial \theta}=\mu\left(\frac{\partial^{2} w}{\partial x^{2}}+\frac{\partial^{2} w}{\partial r^{2}}+\frac{1}{r} \frac{\partial w}{\partial r}-\frac{w}{r^{2}}+\frac{1}{r^{2}} \frac{\partial^{2} w}{\partial \theta^{2}}+\frac{2}{r^{2}} \frac{\partial v}{\partial \theta}\right) \\
& \frac{\partial u}{\partial x}+\frac{\partial v}{\partial r}+\frac{v}{r}+\frac{1}{r} \frac{\partial w}{\partial \theta}=0
\end{aligned}
$$

Mediante duas condições comentadas acima, onde o tubo é reto e a seção transversal é circular, e na ausência de forças externas que causariam a rotação do fluido, o campo do escoamento será simétrico em relação ao eixo longitudinal do tubo e, com isso as componentes da velocidade e suas derivadas na direção angular são todas nulas,

$$
w \equiv \frac{\partial w}{\partial \theta} \equiv \frac{\partial v}{\partial \theta} \equiv \frac{\partial u}{\partial \theta} \equiv \frac{\partial p}{\partial \theta} \equiv 0
$$

Os termos em $w$ na equação de Navier-Stokes (6.9) e na equação da continuidade (6.10) são identicamente zero, e utilizando as condições apresentadas na equação (6.11), as equações $(6.7,6.8,6.9$, e 6.10$)$ passam a ser, 


$$
\begin{aligned}
& \rho\left(\frac{\partial u}{\partial t}+u \frac{\partial u}{\partial x}+v \frac{\partial u}{\partial r}\right)+\frac{\partial p}{\partial x}=\mu\left(\frac{\partial^{2} u}{\partial x^{2}}+\frac{\partial^{2} u}{\partial r^{2}}+\frac{1}{r} \frac{\partial u}{\partial r}\right) \\
& \rho\left(\frac{\partial v}{\partial t}+u \frac{\partial v}{\partial x}+v \frac{\partial v}{\partial r}\right)+\frac{\partial p}{\partial r}=\mu\left(\frac{\partial^{2} v}{\partial x^{2}}+\frac{\partial^{2} v}{\partial r^{2}}+\frac{1}{r} \frac{\partial v}{\partial r}-\frac{v}{r^{2}}\right) \\
& \frac{\partial u}{\partial x}+\frac{\partial v}{\partial r}+\frac{v}{r}=0
\end{aligned}
$$

Utilizando mais uma das considerações anteriores, escoamento completamente desenvolvido, onde por definição,

$$
\frac{\partial u}{\partial x} \equiv \frac{\partial v}{\partial x} \equiv 0
$$

tem-se que, a equação da continuidade pode ser reduzida para,

$$
\frac{\partial v}{\partial r}+\frac{v}{r}=\frac{1}{r} \frac{\partial(r v)}{\partial r}=0
$$

Como $v$ deve ser zero na parede do tubo $(r=a)$, isto implica que a componente radial da velocidade deve ser identicamente igual a zero,

$$
v=0
$$

Levando em consideração as condições de contorno acima (6.15) e (6.17), a equação da continuidade (6.14) é satisfeita. Pelas mesmas razões comentadas acima, os termos em $v$ da equação de Navier-Stokes (6.13) são zeros, assim esta equação torna-se,

$$
\frac{\partial p}{\partial r} \equiv 0
$$

e a equação (6.12), após simplificações será

$$
\rho \frac{\partial u}{\partial t}+\frac{\partial p}{\partial x}=\mu\left(\frac{\partial^{2} u}{\partial r^{2}}+\frac{1}{r} \frac{\partial u}{\partial r}\right)
$$


A equação (6.19) é a forma simplificada da equação da quantidade de movimento, onde as soluções clássicas dos escoamentos não-permanente e permanente são baseadas. A partir desta equação (6.19) fica claro que a velocidade é função somente de $r$ e $t$, enquanto a pressão é função de $x$ e $t$,

$$
u=u(r, t) \quad p=p(x, t)
$$

Considerando um escoamento num tubo onde o gradiente de pressão não é função do tempo, então o campo de velocidade, também, será independente do tempo prevalecendo o escoamento permanente. Sendo assim, a equação (6.20) torna-se,

$$
u=u_{s}(r) \quad p=p_{s}(x)
$$

onde o subscrito "s" se refere ao escoamento permanente. Assim, a equação (6.19) sofre algumas simplificações reduzindo-se para,

$$
\frac{\partial p_{s}}{\partial x}=\mu\left(\frac{\partial^{2} u_{s}}{\partial r^{2}}+\frac{1}{r} \frac{\partial u_{s}}{\partial r}\right)
$$

Uma importante característica desse escoamento é que as equações são independentes da densidade, $\rho$. Isto ocorre devido os termos de aceleração serem iguais à zero. Essa equação representa o balanço de força representada pelo gradiente de pressão e pela resistência viscosa do fluido.

Analisando a equação (6.22), percebe-se que o primeiro membro da equação é função somente de $x$ e o segundo membro é função somente de $r$. Para satisfazer esta equação é necessário igualar os dois lados da equação a uma constante, por exemplo $k_{s}$, assim

$$
\frac{\partial p_{s}}{\partial x}=k_{s}
$$




$$
\mu\left(\frac{\partial^{2} u_{s}}{\partial r^{2}}+\frac{1}{r} \frac{\partial u}{\partial r}\right)=k_{s}
$$

Solucionando a equação (6.23), tem-se

$$
p_{s}(x)=p_{s}(0)+k_{s} x
$$

onde $x$ é a distância axial no tubo. Se a saída do tubo apresenta um comprimento $x=l$, então a constante $k_{s}$ é dada por,

$$
k_{s}=\frac{p_{s}(l)-p_{s}(0)}{l}
$$

Solucionando a equação (6.23), tem-se

$$
u_{s}(r)=\frac{k_{s}}{4 \mu} r^{2}+A \ln r+B
$$

onde $A$ e $B$ são constantes de integração. As condições de contorno necessárias para encontrar os valores de $A$ e $B$ são: condição de não-escorregamento na parede do tubo e a velocidade finita no centro do tubo, isto é

$$
u_{s}(a)=0 \quad \text { e } \quad\left|u_{s}(0)\right|<\infty
$$

o qual fornece

$$
A=0 \quad \text { e } \quad B=-\frac{k_{s} a^{2}}{4 \mu}
$$

Assim, o valor da velocidade final torna-se 


$$
u_{s}=\frac{k_{s}}{4 \mu}\left(r^{2}-a^{2}\right)
$$

Essa é a solução clássica para escoamento permanente num tubo rígido, denominada como escoamento de Poiseuille.

O perfil de velocidade obtido acima se apresenta como um perfil de velocidade parabólico no tubo indicando que a máxima velocidade $(\hat{u})$ ocorre no eixo do tubo $(r=$ $0)$ e velocidade igual à zero na parede do tubo $(r=a)$ devido à condição de nãoescorregamento, assim,

$$
\hat{u}_{s}=u_{s}(0)=-\frac{k_{s} a^{2}}{4 \mu} \quad u_{s}(a)=0
$$

O sinal de menos na equação acima indica que a velocidade é positiva na direção negativa do gradiente de pressão. Adimensionalizando a equação (6.30) com a equação de velocidade máxima (6.31) no centro do tubo, tem-se

$$
\frac{u_{s}(r)}{\hat{u}_{s}}=1-\left(\frac{r}{a}\right)^{2}
$$

cujo perfil de velocidade é representado na figura 6.4, 


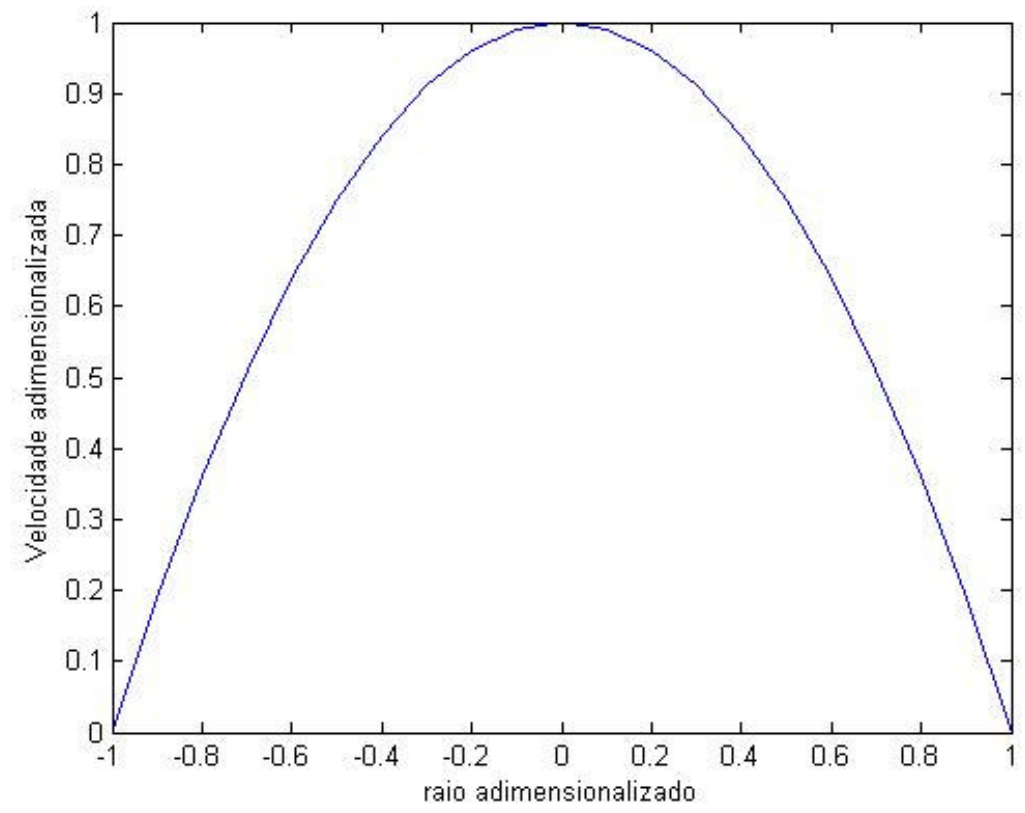

Figura 6.4. Perfil de velocidade completamente desenvolvido num tubo, adimensionalizado com a velocidade máxima.

A vazão volumétrica é obtida integrando a equação de perfil de velocidade (6.30) sobre a seção transversal do tubo,

$$
Q_{s}=\int_{0}^{a} u_{s} 2 \pi r d r=-\frac{k_{s} \pi a^{4}}{8 \mu}
$$

Novamente, o sinal de menos indica que o gradiente de pressão e o fluxo volumétrico possuem sinais opostos, isto é, o gradiente de pressão produz fluxo na direção positiva de $x$. A velocidade média $\bar{u}_{s}$ é obtida a partir da equação (6.33),

$$
\bar{u}_{s}=\frac{Q_{s}}{\pi a^{2}}=-\frac{k_{s} a^{2}}{8 \mu}
$$

Comparando as equações (6.31) e (6.34) percebe-se que a velocidade média é igual à metade da velocidade máxima no centro do tubo (Figura 6.5). 


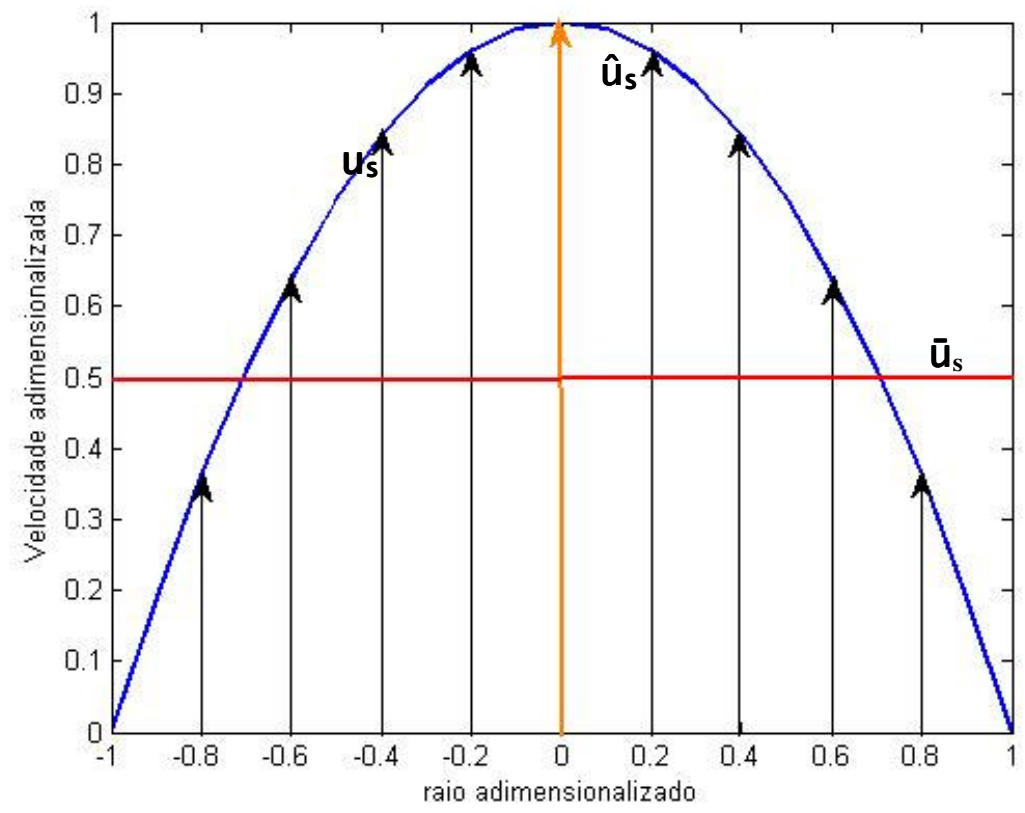

Figura 6.5. Perfil de velocidade $\left(u_{s}\right)$ completamente desenvolvido, velocidade máxima $\left(\hat{u}_{s}\right)$ e velocidada média $\left(\bar{u}_{s}\right)$ como sendo metade da velocidade máxima.

Como as componentes de velocidade radial e angular, $v$ e $w$ são iguais a zero no escoamento de Poiseuille e a componente de velocidade axial é função somente de $r$, então a tensão de cisalhamento é definida somente com uma componente da tensão,

$$
\tau_{S}=-\tau_{r x}(a)=-\mu\left(\frac{d u_{S}}{d r}\right)_{r=a}=-\frac{k_{S} a}{2}
$$

onde o primeiro índice " $\mathrm{r}$ " indica a direção normal a face na qual a tensão está atuando e o segundo índice " $x$ " indica a direção em que a tensão está atuando. Substituindo o valor de $k_{s}$ da equação (6.33), tem-se

$$
\tau_{s}=\frac{4 \mu q_{s}}{\pi a^{3}}
$$

Assim, conclui-se o equacionamento do escoamento permanente num tubo rígido. 


\subsection{Escoamento não-Permanente em Tubo Rígido}

O escoamento no sistema circulatório é obviamente não-permanente devido à natureza pulsátil do bombeamento do coração. Esse tipo de escoamento se encontra presente no coração e nas maiores artérias. A combinação entre o efeito da complacência e da dissipação viscosa nos pequenos vasos amortece a pulsação e no sistema venoso o fluxo é essencialmente permanente (Berger et al., 1996). Mediante o efeito pulsátil no escoamento vascular, aborda-se nesse item a formulação matemática do escoamento pulsátil em tubos rígidos.

O escoamento num tubo onde o gradiente de pressão varia com o tempo é dado pela equação (6.18),

$$
\rho \frac{\partial u}{\partial t}+\frac{\partial p}{\partial x}=\mu\left(\frac{\partial^{2} u}{\partial r^{2}}+\frac{1}{r} \frac{\partial u}{\partial r}\right)
$$

onde neste caso $p$ é função de $x$ e $t$ e a velocidade é função de $r$ e $t$. Para a análise deste tipo de escoamento será considerado que o gradiente de pressão será oscilatório no tempo, variando através de uma função trigonométrica seno ou cosseno. À medida que o gradiente de pressão varia no tempo, a vazão volumétrica o acompanha; se a variação de pressão é lenta, a variação da vazão volumétrica estará em fase com o gradiente de pressão, mas se a variação de pressão é rápida, a vazão volumétrica sofrerá um atraso em sua resposta devido à inércia do fluido. Devido a este atraso, o pico alcançado pela vazão volumétrica em cada ciclo será menor do que aquele alcançado no escoamento de Poiseuille submetido ao mesmo gradiente de pressão. Essa perda ocorrida no pico da vazão é tanto maior quanto maior for à freqüência de oscilação do gradiente de pressão. Por outro lado, para baixas freqüências de oscilações, o escoamento aumentará e diminuirá em fase com a pressão e o pico alcançado pela vazão volumétrica será praticamente igual aquele do escoamento de Poiseuille. Da mesma forma que a vazão volumétrica, o perfil de velocidade no escoamento oscilatório será tão próximo do perfil de velocidade no escoamento de Poiseuille quanto menor for à frequiência de oscilação. O contrário, também é verdadeiro, quanto maior a freqüência de oscilação mais distante o perfil de velocidade oscilatório estará do perfil de velocidade do escoamento de Poiseuille. Esses comentários servem para contextualizar o assunto a ser tratado nesse item. Mais adiante, os comentários acima serão apresentados em forma de gráficos e, com isso, tornar-se-ão mais claros. 
As hipóteses adotadas aqui para o desenvolvimento do escoamento oscilatório são essencialmente as mesmas adotadas para o escoamento permanente. A área de seção transversal deve ser circular e a simetria axial deve prevalecer para que as velocidades e derivadas na direção $\theta$ sejam iguais à zero. O tubo deve ser longo o suficiente para que o escoamento seja desenvolvido e independente de $x$.

\subsubsection{Equações do Escoamento Oscilatório}

A ação de bombeamento do coração produz uma diferença de pressão através da árvore arterial, a qual muda ritmicamente com aquela ação. O efeito produzido por esta ação pode ser dividido numa parte permanente que produz o escoamento numa única direção (escoamento de Poiseuille), e numa parte oscilatória que move o fluido de um lado para outro. Os termos permanente e oscilatório referem-se a essas duas componentes do escoamento, enquanto o termo pulsátil se refere à combinação dessas duas componentes.

A equação (6.19) é linear para a pressão, $p(x, t)$, e para a velocidade, $u(x, t)$, logo esta equação pode ser tratada matematicamente separando-se em parte permanente e parte oscilatória. Deve-se lembrar que a parte permanente desta equação já foi solucionada no item 6.2. Identificando a parte permanente e a parte oscilatória da pressão e velocidade pelos subscritos "s" e “ $\phi$ ”, respectivamente, tem-se:

$$
\begin{aligned}
& p(x . t)=p_{s}(x)+p_{\phi}(x, t) \\
& u(r, t)=u_{s}(r)+u_{\phi}(r, t)
\end{aligned}
$$

Substituindo esta equação (6.37) na equação (6.19), obtém-se

$$
\left[\frac{d p_{s}}{d x}-\mu\left(\frac{d^{2} u_{s}}{d r^{2}}+\frac{1}{r} \frac{d u_{s}}{d r}\right)\right]+\left[\rho \frac{\partial u_{\phi}}{\partial t}+\frac{\partial p_{\phi}}{\partial x}-\mu\left(\frac{\partial^{2} u_{\phi}}{\partial r^{2}}+\frac{1}{r} \frac{\partial u_{\phi}}{\partial r}\right)\right]=0
$$

onde os termos foram agrupados naqueles que não dependem do tempo (primeiro grupo) e naqueles que dependem do tempo (segundo grupo). O primeiro grupo foi solucionado no item 6.2, sendo assim o segundo grupo será igualado a zero, 


$$
\rho \frac{\partial u_{\phi}}{\partial t}+\frac{\partial p_{\phi}}{\partial x}-\mu\left(\frac{\partial^{2} u_{\phi}}{\partial r^{2}}+\frac{1}{r} \frac{\partial u_{\phi}}{\partial r}\right)=0
$$

Conforme foi realizada a separação das partes permanente e oscilatória do escoamento apresentado na equação (6.37), o gradiente de pressão também será separado,

$$
k(t)=k_{s}+k_{\phi} t
$$

onde

$$
\begin{aligned}
& k(t)=\frac{\partial p}{\partial x} \\
& k_{s}=\frac{\partial p_{s}}{\partial x} \\
& k_{\phi}(t)=\frac{\partial p_{\phi}}{\partial x}
\end{aligned}
$$

Assim, $k(t)$ é o gradiente de pressão total no escoamento pulsátil, $k_{s}$ é o termo permanente e $k_{\phi}$ é a parte puramente oscilatória do gradiente de pressão, como está ilustrado na figura 6.6.

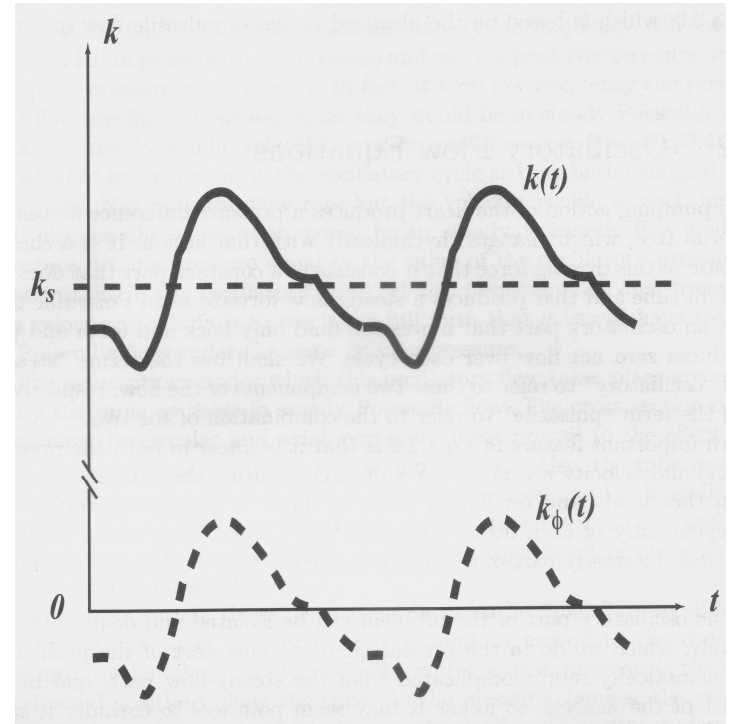

Figura 6.6. Gradiente de pressão pulsátil k(t) consiste de uma parte constante, $\mathrm{k}_{\mathrm{s}}$, e uma parte puramente oscilatória, $\mathrm{k}_{\phi}(\mathrm{t})$. 
Assim como o gradiente de pressão, $k_{s}$, no escoamento de Poiseuille, o gradiente de pressão oscilatório, $k_{\phi}$, é calculado através da diferença de pressão $\Delta p_{\phi}$ entre dois pontos do tubo e, neste caso, dependente do tempo,

$$
\Delta p_{\phi}=p_{\phi}(l, t)-p_{\phi}(0, t)=k_{\phi}(t) l
$$

onde $l$ é o comprimento do tubo e $p_{\phi}(x, t)$ é a pressão na posição axial $x$ ao longo do tubo no tempo $t$. Assim, a equação do escoamento oscilatório é,

$$
\mu\left(\frac{\partial^{2} u_{\phi}}{\partial r^{2}}+\frac{1}{r} \frac{\partial u_{\phi}}{\partial r}\right)-\rho \frac{\partial u_{\phi}}{\partial t}=k_{\phi}(t)
$$

\subsubsection{Gradiente de Pressão Complexo e Equação de Bessel}

A solução da equação (6.43), onde o gradiente de pressão oscilatório é uma função seno ou cosseno, é mais tratável matematicamente se utilizarmos à forma exponencial complexa, isto é,

$$
k_{\phi}(t)=k_{s} e^{i \varpi t}=k_{s}(\cos \omega t+i \sin \omega t)
$$

onde $i=\sqrt{-1}$. A equação exponencial complexa resulta em duas soluções: uma sendo $k_{\phi}(t)=k_{s} \cos \varpi t$ e a outra sendo $k_{\phi}(t)=k_{s} \sin \varpi t$. A primeira é obtida tomando a parte real da solução e a segunda tomando a parte imaginária da solução.

Para efeito de comparação com o escoamento de Poiseuille onde o gradiente de pressão é constante, $k_{s}$, a amplitude do gradiente de pressão oscilatório na equação (6.44) é o próprio $k_{s}$. Assim, o pico de vazão volumétrica e o perfil de velocidade oscilatória podem ser comparados à vazão volumétrica e ao perfil de velocidade do escoamento de Poiseuille através do gradiente de pressão constante, $k_{s}$.

Inserindo a equação (6.44) na equação que rege o escoamento oscilatório (6.43), tem-se: 


$$
\frac{\partial^{2} u_{\phi}}{\partial r^{2}}+\frac{1}{r} \frac{\partial u_{\phi}}{\partial r}-\frac{\rho}{\mu} \frac{\partial u_{\phi}}{\partial t}=\frac{k_{s}}{\mu} e^{i \omega t}
$$

A equação acima, pode ser simplificada matematicamente pela substituição de

$$
u_{\phi}(r, t)=U_{\phi}(r) e^{i \varpi t}
$$

e, cancelando-se o termo $e^{i \varpi t}$ através de manipulações algébricas obtém-se uma equação diferencial ordinária de $U_{\phi}(r)$,

$$
\frac{d^{2} U_{\phi}}{d r^{2}}+\frac{1}{r} \frac{d U_{\phi}}{d r}-\frac{i \Omega^{2}}{a^{2}} U_{\phi}=\frac{k_{s}}{\mu}
$$

onde $a$ é o raio do tubo e $\Omega$ conforme definido anteriormente é definido como sendo a razão entre a força de inércia oscilatória e a força cisalhante:

força de inércia oscilatória: $\rho \varpi u$;

$$
\text { força cisalhante : } \mu \frac{u}{l^{2}}
$$

$$
\Omega=a \sqrt{\frac{\rho \varpi}{\mu}}
$$

Se o número de Womersley é elevado, a força de inércia oscilatória domina o escoamento, caso contrário serão as forças viscosas.

Após as devidas manipulações algébricas obtêm-se a equação (6.47) que é uma equação diferencial ordinária e, dessa forma, mais simples de ser solucionada em relação à equação (6.45). De fato a equação (6.47) é a forma da equação de Bessel, a qual tem uma solução padrão que será analisada no próximo item.

Algumas considerações devem ser apresentadas a respeito das hipóteses adotadas para se chegar na equação (6.47). O gradiente de pressão na equação (6.44) e a velocidade na equação (6.46) apesar de apresentarem a mesma forma oscilatória na variável de tempo $t$, isto não significa que o gradiente de pressão e a velocidade estão em fase. Uma das possíveis razões para que eles não estejam em fase é devido o termo 
$U_{\phi}(r)$ que é um termo complexo como pode ser visto na equação (6.47). O produto deste termo complexo com $e^{i \varpi t}$ na equação (6.46) altera a fase das partes reais e imaginárias da velocidade $u_{\phi}(r, t)$ que, em geral, são diferentes daquelas partes reais e imaginárias do termo de gradiente de pressão $k_{\phi}(t)$.

\subsubsection{Solução da Equação de Bessel}

A equação (6.47) é uma forma da equação de Bessel que possui uma solução geral conhecida (McLachlan, 1955; Watson, 1958),

$$
U_{\phi}(r)=\frac{i k_{s} a^{2}}{\mu \Omega^{2}}+A J_{0}(\zeta)+B Y_{0}(\zeta)
$$

onde $A$ e $B$ são constantes arbitrárias e $J_{0}$ e $Y_{0}$ são funções de Bessel de ordem zero e de primeiro e segundo tipo, respectivamente, satisfazendo a equação de Bessel padrão

$$
\begin{aligned}
& \frac{d^{2} J_{0}}{d \zeta^{2}}+\frac{1}{\zeta} \frac{d J_{0}}{d \zeta}+J_{0}=0 \\
& \frac{d^{2} Y_{0}}{d \zeta^{2}}+\frac{1}{\zeta} \frac{d Y_{0}}{d \zeta}+Y_{0}=0
\end{aligned}
$$

A variável $\zeta$ é uma variável complexa relacionada com a coordenada radial $r$ definida como sendo,

$$
\zeta(r)=\Lambda \frac{r}{a}
$$

onde $\Lambda$ é um parâmetro de freqüência relacionada com o número de Womersley definido como sendo,

$$
\Lambda=\left(\frac{i-1}{\sqrt{2}}\right) \Omega
$$


Devido às relações apresentadas acima e devido aos parâmetros $\Lambda$ e $\Omega$ aparecerem implicitamente e explicitamente em todos os elementos da solução, o valor numérico do número de Womersley apresenta uma importante característica na definição do campo do escoamento.

As condições de contorno devem ser analisadas para encontrar os valores das constantes arbitrárias $A$ e $B$ e, com isso, obter a solução da equação (6.47). Estas condições que a solução deve satisfazer para o escoamento oscilatório num tubo são bastante semelhantes àquelas condições mencionadas no item anterior (6.2) para a solução do escoamento permanente num tubo rígido; assim, são elas: a condição de nãoescorregamento na parede do tubo e a velocidade finita ao longo do eixo do tubo,

$$
\begin{aligned}
& U_{\phi}(a)=0 \\
& \left|U_{\phi}(0)\right|<\infty
\end{aligned}
$$

É sabido das propriedades de $Y_{0}(\zeta)$ que ela torna-se infinita quando $\zeta \rightarrow 0$ (McLachlan, 1955; Watson, 1958), a qual ocorre no eixo do tubo quando $r=0$, assim a condição de contorno na equação (6.54) conduz a

$$
B=0
$$

e a primeira condição de contorno fornece

$$
A=-\frac{i k_{s} a^{2}}{\mu \Omega^{2} J_{0}(\Lambda)}
$$

e, lembrando da equação (6.51) que

$$
\zeta(a)=\Lambda
$$

tem-se todos os parâmetros necessário para a solução da $U_{\phi}$, 


$$
U_{\phi}=\frac{i k_{s} a^{2}}{\mu \Omega^{2}}\left(1-\frac{J_{0}(\zeta)}{J_{0}(\Lambda)}\right)
$$

A equação (6.58) representa a solução da equação de Bessel representada pela equação (6.47).

\subsubsection{Perfis de Velocidade Oscilatória}

Após a transformação da equação (6.45) numa equação diferencial ordinária através da substituição da equação (6.46) nesta equação, chega-se à solução desta equação diferencial ordinária conforme apresentado na equação (6.58). Substituindo este resultado na equação (6.46), obtém-se a solução completa da equação (6.45),

$$
\overbrace{u_{\phi}(r, t)=}^{(\mathbf{I})}(\overbrace{\frac{i k_{s} a^{2}}{\mu \Omega^{2}}\left(1-\frac{J_{0}(\zeta)}{J_{0}(\Lambda)}\right) e^{i \sigma t}}^{(\mathbf{I I})}\left(\mathrm{III}^{\prime}\right)
$$

A equação (6.59) é a forma clássica da solução do escoamento oscilatório num tubo rígido, apresentada algumas vezes com termos diferentes da equação acima por diferentes pesquisadores como Womersley (1955), Uchida (1956), McDonald (1974) e Milnor (1989).

O primeiro termo da equação (6.59) ( I ) é um coeficiente constante cujo valor depende da amplitude do gradiente de pressão $k_{s}$, do raio do tubo $a$, da viscosidade do fluido $\mu$, e do número de Womersley $\Omega$. O segundo termo ( II ) é função de $r$ que descreve o perfil de velocidade na seção transversal do tubo. E o terceiro e último termo ( III ) é função do tempo, o qual multiplica e logo modifica o perfil de velocidade com o tempo dentro do ciclo oscilatório, desta maneira produzindo uma seqüência de perfis de velocidades oscilatórias.

Para efeito de comparação dos perfis de velocidades oscilatórias com o perfil de velocidade parabólico constante produzido pelo escoamento de Poiseuille, considere um escoamento permanente e um oscilatório num mesmo tubo de raio $a$. Para facilitar a comparação, a velocidade do escoamento oscilatório $u_{\phi}(r, t)$ é dividida pela máxima velocidade obtida do escoamento de Poiseuille $\hat{u}_{s}$, usando as equações (6.31), (6.52) e (6.59), 


$$
\frac{u_{\phi}(r, t)}{\hat{u}_{s}}=-\frac{4}{\Lambda^{2}}\left(1-\frac{J_{0}(\zeta)}{J_{0}(\Lambda)}\right) e^{i \omega t}
$$

Essa forma adimensional da velocidade oscilatória apresenta uma escala conveniente, onde o valor 1,0 representa a velocidade igual à velocidade máxima correspondente no escoamento de Poiseuille.

Da análise da equação (6.59), a forma dos perfis de velocidades oscilatórios depende fortemente da frequiência de oscilação $\varpi$, pois essa determina os valores do número de Womersley, da freqüência complexa $\Lambda$, da variável complexa $\zeta$, da função de Bessel $J_{0}$ e da velocidade oscilatória $u_{\phi}$. Considerando um número de Womersley igual a 1, onde se tem um escoamento a baixa freqüência e a parte do gradiente de pressão sendo $k_{s} \cos \varpi t$, perfis de velocidade oscilatória são apresentados na figura 6.7.

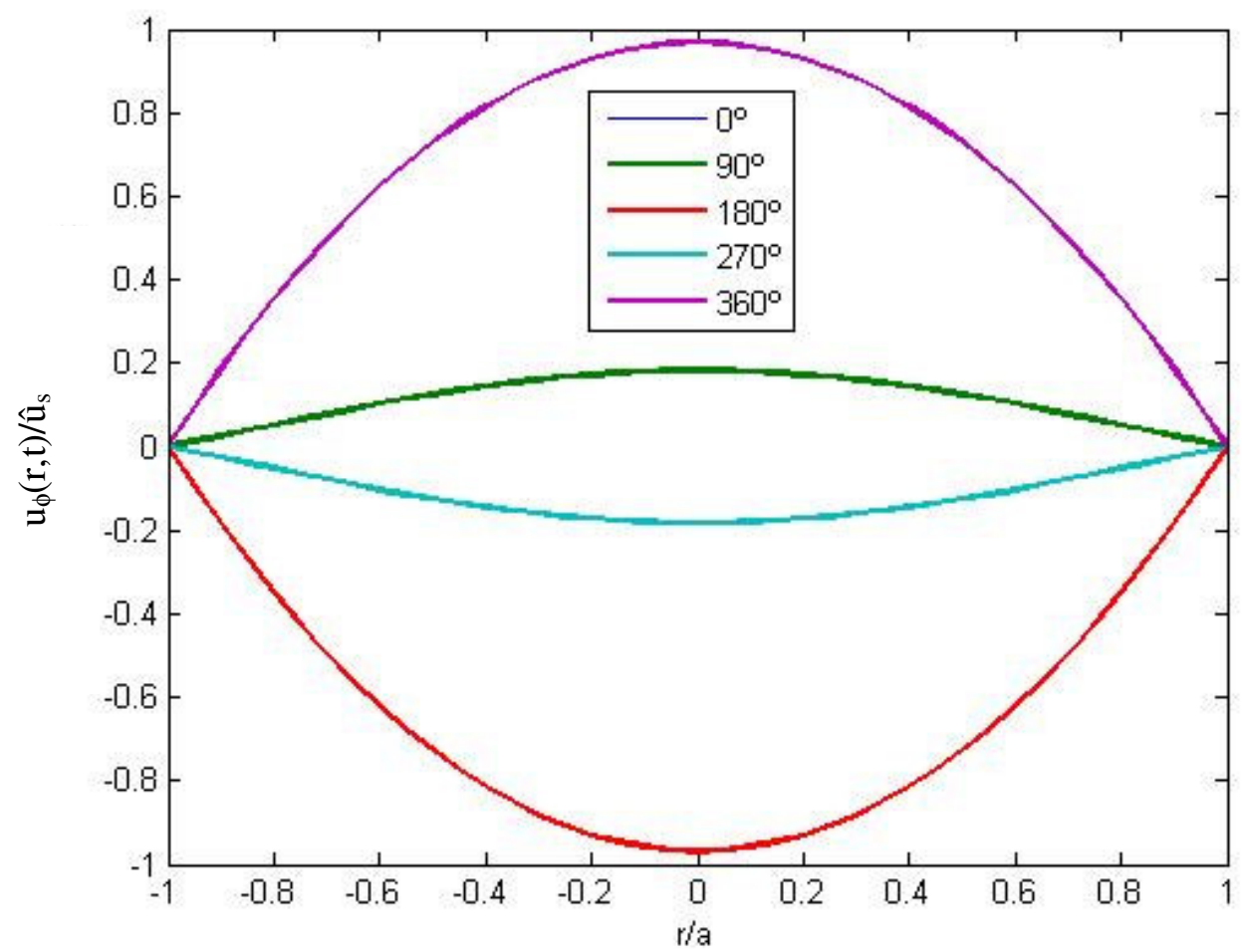

Figura 6.7. Perfis de velocidade oscilatórios num tubo rígido com número de Womersley $\Omega=1$.

Num escoamento a baixa freqüência, a vazão volumétrica é capaz de acompanhar a variação do gradiente de pressão. De fato, para freqüência de oscilação muito baixa ou 
no limite de freqüência zero, a discrepância de fase entre a vazão volumétrica e o gradiente de pressão desaparece tornando-se instantânea, ou seja, ocorrendo à variação do gradiente de pressão a vazão volumétrica varia em fase. Isso indica que cada ponto no tempo do perfil de velocidade dentro do ciclo oscilatório é o mesmo que seria no escoamento de Poiseuille submetido a um gradiente de pressão igual ao valor do gradiente de pressão oscilatório naquele instante. Essa situação é denominada de "escoamento oscilatório de Poiseuille" (Zamir, 2000).

A figura 6.7 apresentou os perfis de velocidade para um número de Womersley igual a 1, agora considere um escoamento com número de Womersley igual a 3, onde os perfis de velocidade estão apresentados na figura 6.8 .

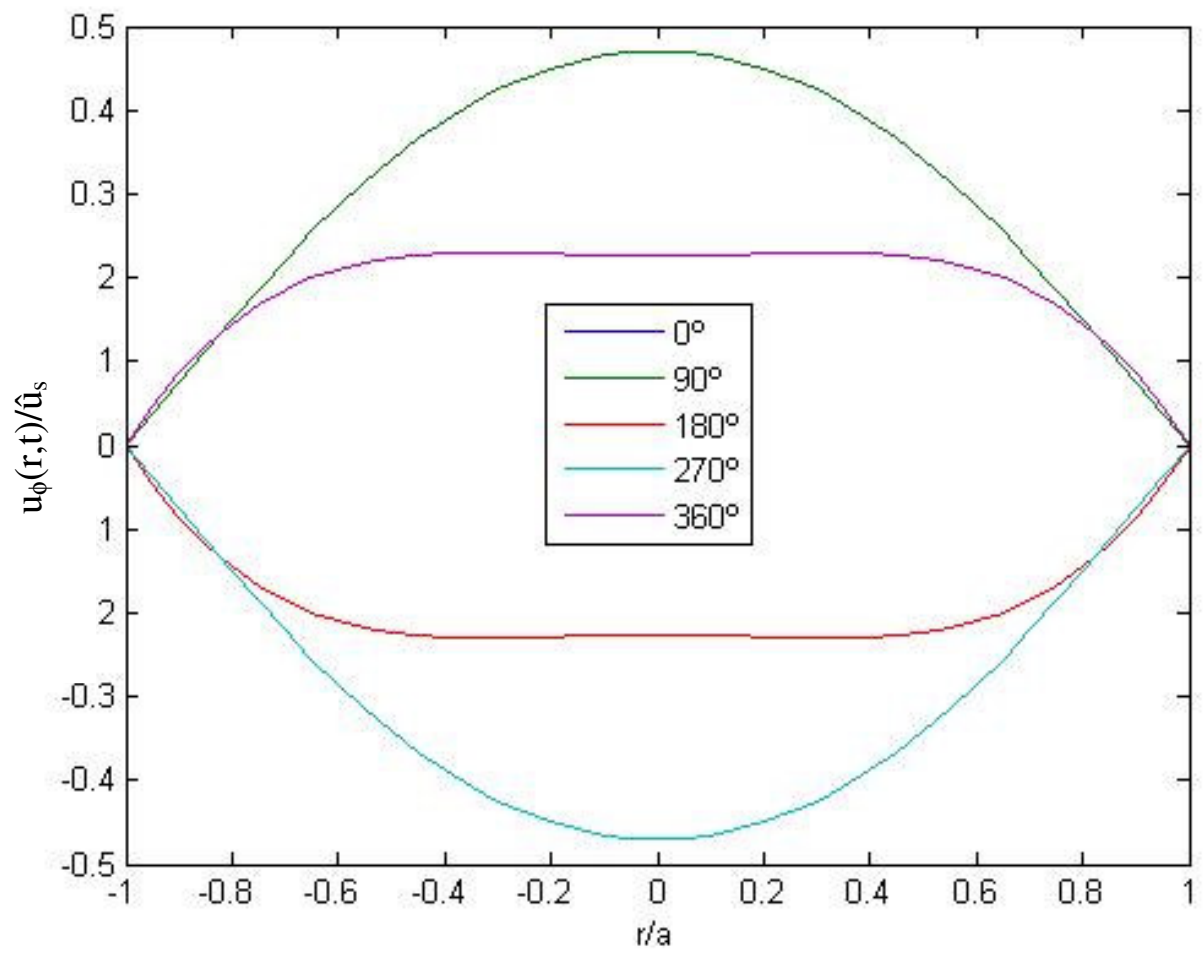

Figura 6.8. Perfis de velocidades oscilatórios num tubo rígido com número de Womersley $\Omega=3$.

É possível visualizar na figura 6.8 que os picos de velocidades oscilam entre um pico na direção positiva e um pico na direção negativa. A fase e a amplitude desses picos não correspondem aos picos do gradiente de pressão oscilatório. Primeiro porque os picos na direção positiva e negativa do gradiente de pressão, sendo $k_{s} \cos \varpi t$, ocorrem na fase $0^{\circ}$ e $180^{\circ}$, enquanto o correspondente pico do perfil de velocidade ocorre na fase $90^{\circ} \mathrm{e}$ $270^{\circ}$. Isto ocorre devido ao atraso da velocidade oscilatória em relação ao gradiente de 
pressão onde esse efeito é atribuído à inércia do fluido, como comentado anteriormente. E, segundo, devido ao valor da velocidade máxima alcançada ser menor que 1,0 , o que significa que é menor do que a velocidade alcançada no escoamento de Poiseuille.

Ao contrário do escoamento de baixa freqüência, no escoamento a elevada frequiência oscilatória, a vazão volumétrica é incapaz de acompanhar a variação brusca do gradiente de pressão e, portanto, o perfil de velocidade obtido no escoamento de Poiseuille completamente desenvolvido torna-se distante de ser alcançado em cada ciclo. À medida que a freqüência de oscilação aumenta, menores são os valores máximos de velocidade alcançada. No limite de freqüência infinita, a velocidade de pico alcançada em cada ciclo é zero, isto é o fluido move-se como um todo. A figura 6.9 apresenta os perfis de velocidade para um número de Womersley igual a 10 e, esse valor é considerado como moderado no escoamento vascular. Nessa figura (6.9) percebe-se que os perfis de velocidade são planos dividindo-se em duas partes: uma região irrotacional (com baixa taxa de deformação) e uma região de alta taxa de deformação confinada próxima à parede do vaso. Devido a menor inércia do fluido próximo à região de parede, o perfil de velocidade nessa região inverte mais rapidamente do que o centro do escoamento que apresenta uma inércia maior. 


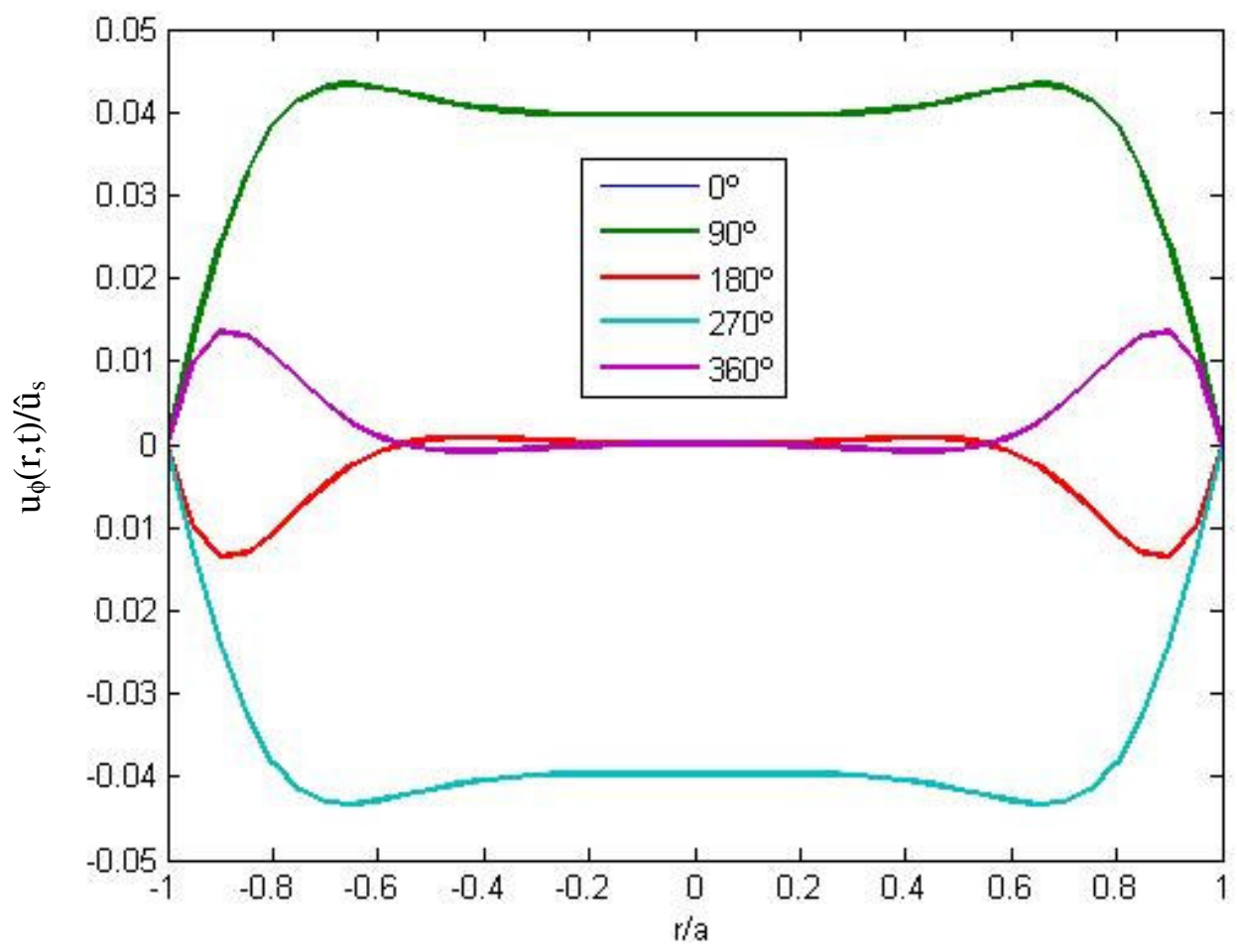

Figura 6.9. Perfis de velocidade oscilatórios num tubo rígido com número de Womersley $\Omega=10$.

\subsubsection{Vazão Volumétrica Oscilatória}

A taxa de vazão volumétrica $\mathrm{Q}_{\phi}$ no escoamento oscilatório através do tubo é obtida pela integração do perfil de velocidade sobre a seção transversal do tubo. Assim, integrando a equação (6.59) tem-se,

$$
Q_{\phi}(t)=\int_{0}^{a} 2 \pi r u_{\phi}(r, t) d r
$$

Substituindo o valor de $u_{\phi}(r, t)$ na equação acima tem-se,

$$
Q_{\phi}(t)=\frac{2 \pi k_{s} i a^{2}}{\mu \Omega^{2}} e^{i \varpi t} \int_{0}^{a} r\left(1-\frac{J_{0}(\zeta)}{J_{0}(\Lambda)}\right) d r
$$

Após a integração tem-se 


$$
Q_{\phi}(t)=\frac{i \pi k_{s} a^{4}}{\mu \Omega^{2}}\left(1-\frac{2 J_{1}(\Lambda)}{\Lambda J_{0}(\Lambda)}\right) e^{i \omega t}
$$

A equação acima representa a vazão volumétrica no escoamento oscilatório.

Para analisar a variação da vazão volumétrica no ciclo oscilatório é conveniente adimensionalizar a equação (6.63) como foi feito para a velocidade no item anterior. Adimensionalizando a equação (6.63) pela vazão volumétrica do escoamento de Poiseuille, equação (6.32), tem-se

$$
\overbrace{\frac{Q_{\phi}(t)}{Q_{s}}=-}^{(\mathbf{I})} \overbrace{\frac{8}{\Lambda^{2}}\left(1-\frac{2 J_{1}(\Lambda)}{\Lambda J_{0}(\Lambda)}\right) e^{i \omega t}}^{(\mathbf{I I})}
$$

Esta razão representa uma escala da vazão volumétrica oscilatória em relação à vazão volumétrica do escoamento de Poiseuille, assim o valor 1,0 representa a vazão volumétrica igual à vazão volumétrica no escoamento de Poiseuille no mesmo tubo e sob o gradiente de pressão igual a $k_{s}$. O segundo membro da equação (6.64) ( II ) mostra claramente que a vazão volumétrica oscilatória depende fortemente da freqüência de oscilação. Por exemplo, para um número de Womersley, $\Omega=1$, a figura 6.10 apresenta que a diferença de fase entre o gradiente de pressão oscilatório e a vazão volumétrica é bastante pequena, enquanto que para um número de Womersley, $\Omega=3$, a diferença de fase entre o gradiente de pressão oscilatório e a vazão volumétrica torna-se maior (fig. 6.11). O valor de pico obtido pela taxa de vazão volumétrica oscilatória é menor do que 1,0, o que significa que o valor máximo alcançado pela vazão volumétrica oscilatória é menor do que aquele alcançado pela vazão volumétrica do escoamento de Poiseuille sob um gradiente de pressão constante $k_{s}$. A razão disso é a inércia do fluido que deve ser acelerado em cada ciclo. 


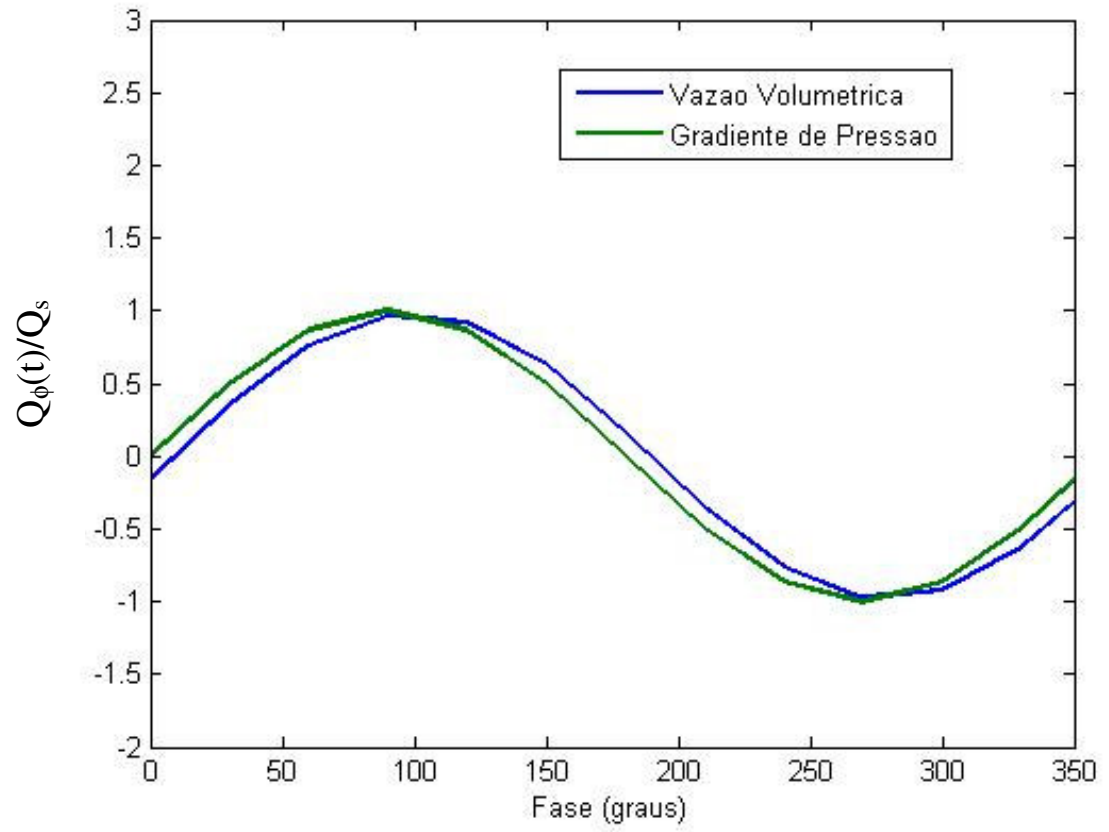

Figura 6.10. Variação da taxa de vazão volumétrica oscilatória $Q_{\phi}$ no ciclo oscilatório comparada com a variação correspondente do gradiente de pressão com o número de Womersley $\Omega=1$.

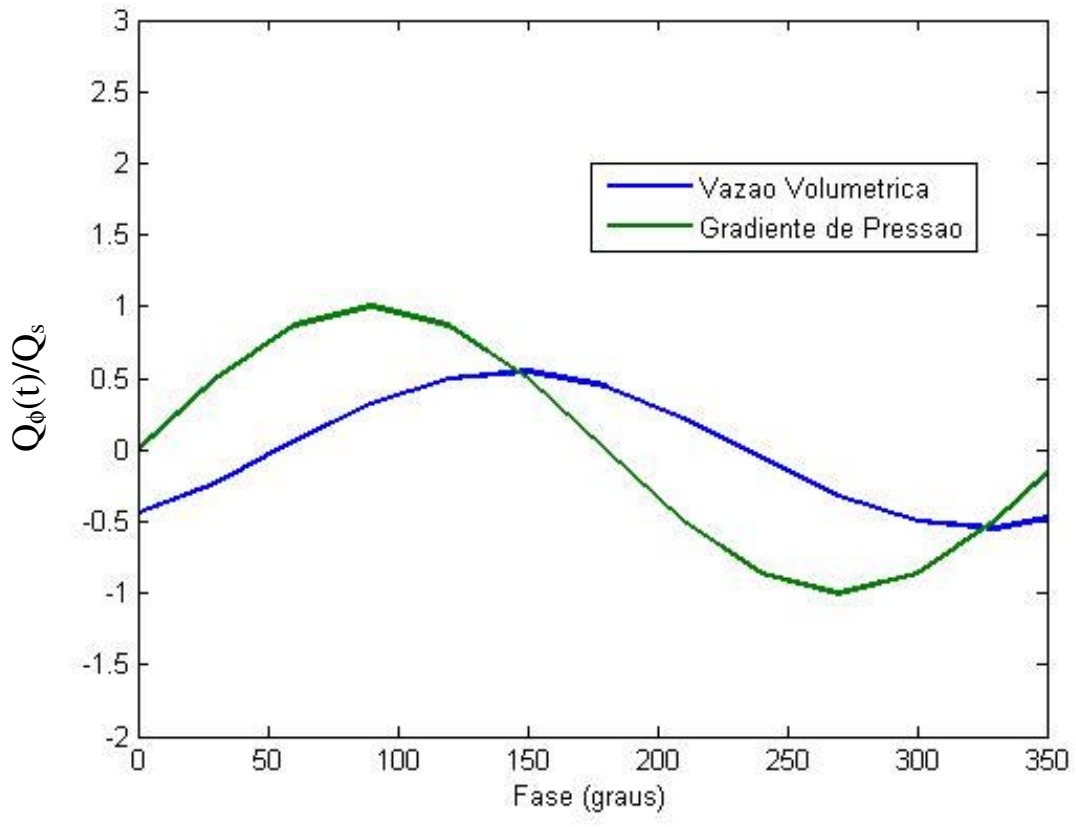

Figura 6.11. Variação da taxa de vazão volumétrica oscilatória $Q_{\phi}$ no ciclo oscilatório comparada com a variação correspondente do gradiente de pressão com o número de Womersley $\Omega=3$.

À medida que o número de Womersley diminui, a diferença de fase diminui correspondentemente, como pode ser visto na figura 6.10, e o inverso, também é 
verdadeiro, ou seja, à medida que o número de Womersley aumenta, a diferença de fase aumenta correspondentemente. Isso pode ser visto na figura $6.12(\Omega=10)$.

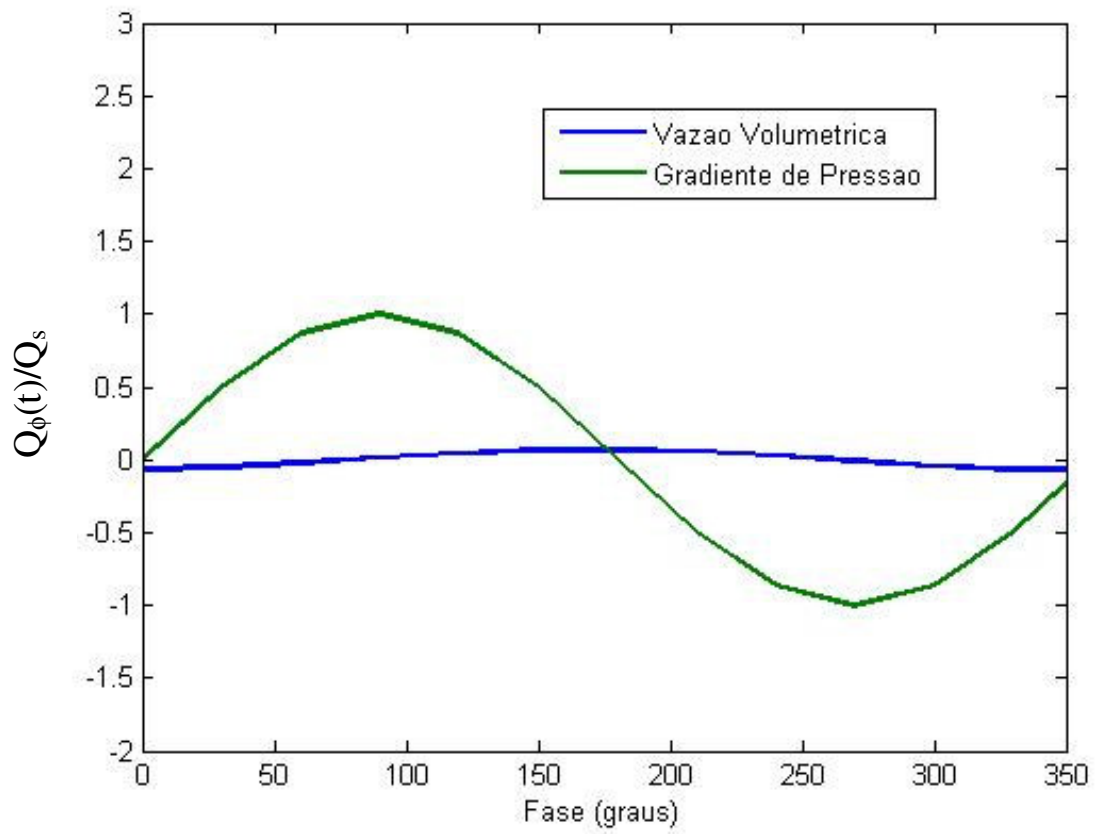

Figura 6.12. Variação da taxa de vazão volumétrica oscilatória $Q_{\phi}$ no ciclo oscilatório comparada com a variação correspondente do gradiente de pressão com o número de Womersley $\Omega=10$.

\subsection{Obtenção do perfil oscilatório da vazão a partir de um gradiente de pressão oscilatório}

Esse item abordará a análise numérica aplicada a um gradiente de pressão oscilatório com o objetivo de obter uma equação que forneça o perfil de vazão volumétrico oscilatório.

Womersley modificou alguns parâmetros da equação (6.59) e obteve uma equação mais simples para a obtenção dos perfis de velocidade a partir de valores tabelados. A equação obtida por Womersley é:

$$
u_{\phi}=\frac{M a^{2}}{\mu} \frac{M_{0}^{\prime}}{\Omega^{2}} \sin \left(\varpi t-\varphi+\varepsilon_{0}\right)
$$


onde

$$
\begin{aligned}
& \mathrm{a}=\text { raio do tubo; } \\
& \mu=\text { viscosidade dinâmica; } \\
& \mathrm{M}=\text { módulo da harmônica; } \\
& \mathrm{t}=\text { tempo; } \\
& \varphi=\text { fase da harmônica; } \\
& \varpi=\text { freqüência de oscilação; } \\
& \frac{M_{0}^{\prime}}{\Omega^{2}} \text { e } \varepsilon_{0}=\text { são parâmetros tabelados de Womersley. }
\end{aligned}
$$

Integrando a equação (6.65) sobre o diâmetro do vaso, obtém-se a equação que representa o perfil de vazão oscilatório:

$$
Q_{\phi}=\frac{\pi a^{4} M}{\mu} \frac{M_{0}^{\prime}}{\Omega^{2}} \sin \left(\varpi t-\varphi+\varepsilon_{0}\right)
$$

Os termos da equação (6.66) já foram definidos na equação (6.65). A equação (6.66) representa o perfil da vazão volumétrica oscilatória obtida a partir de um gradiente de pressão oscilatório. Aplicando a série de Fourier sobre esse gradiente de pressão, podese obter os parâmetros da equação (6.66) e, em seguida inserir os valores numéricos de cada variável.

Os dados abaixo, como raio, freqüência, viscosidade dinâmica, densidade e o gráfico da pressão e do gradiente de pressão (figura 6.13) são referentes à região da artéria femoral de um cão retirado do livro de McDonald (1974). Nesse caso, a pressão e o gradiente de pressão estão definidos de acordo com a literatura médica (coluna de mercúrio), embora, sob o ponto de vista da literatura da mecânica dos fluidos ou da hidráulica esses termos correspondem à carga de pressão e ao gradiente de carga de pressão, respectivamente. 


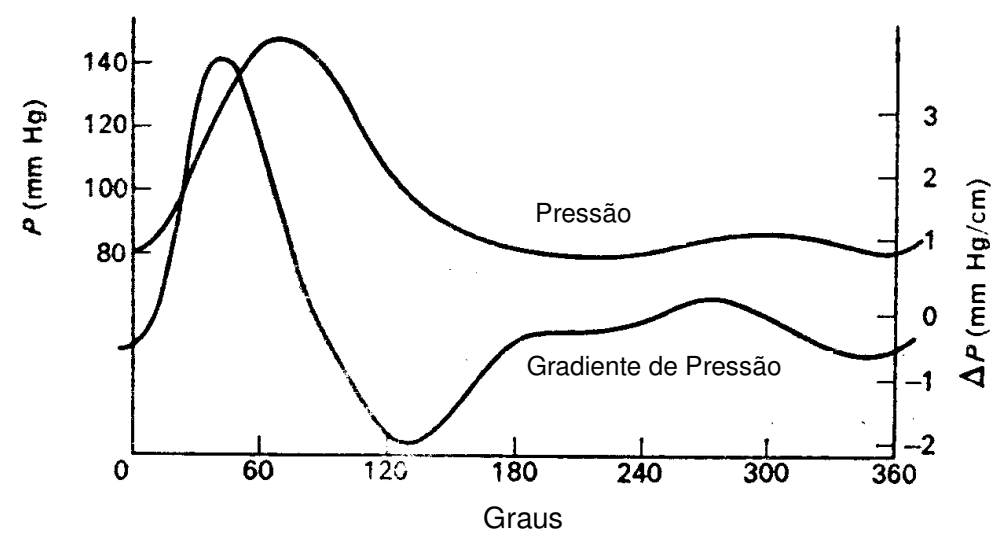

Figura 6.13. Curva do pulso de pressão e gradiente de pressão arterial medidos entre dois pontos distantes $5 \mathrm{~cm}$ na artéria femoral de cão. Extraído de McDonald (1974).

Dados:

- $\quad$ raio $(\mathrm{a})=0,13 \mathrm{~cm}$;

- freqüência (f) = 2,4 Hz;

- viscosidade dinâmica $(\mu)=0,04$ Poise;

- densidade $(\rho)=1,055 \mathrm{~g} / \mathrm{ml}$;

- gradiente de carga de pressão $(\Delta \mathrm{p} / \mathrm{L})=0,335 \mathrm{mmHg} / \mathrm{cm}$.

Com a curva do gradiente de carga de pressão em mãos, o passo seguinte é discretizar esse gráfico em intervalos iguais. Os números de intervalos considerados nesse trabalho foram de 50 intervalos (figura 6.14).

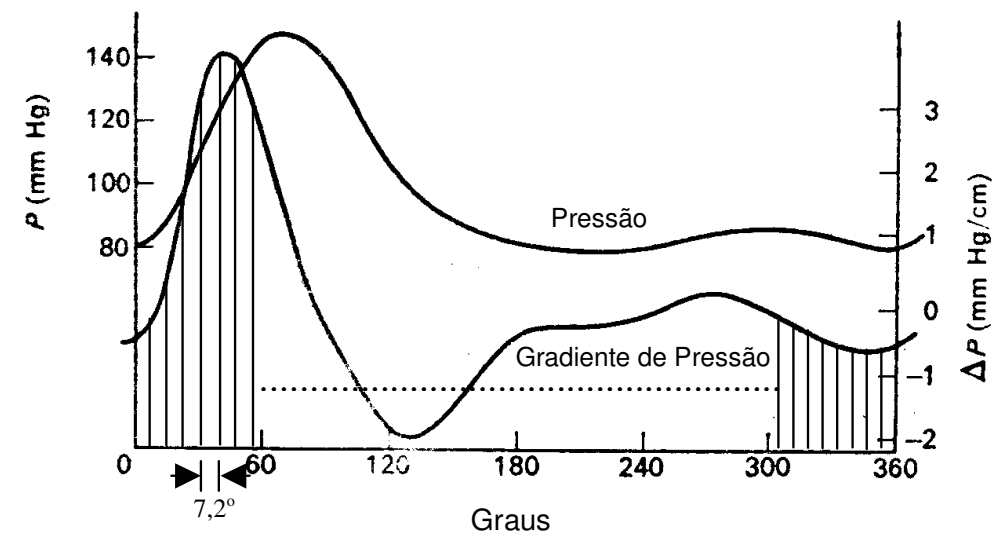

Figura 6.14. Gráfico discretizado do gradiente de pressão oscilatório em 50 partes iguais: $7,2^{\circ}$. 
Através do processo de discretização, obtêm-se dois vetores com 50 elementos cada, os quais, estão representados no anexo I (nesse anexo foi desenvolvido um programa em matlab para fornecer a vazão oscilatória a partir de dados do gradiente de pressão aquisitados) como x e y. Em seguida, escolhe-se o número de harmônicas a ser trabalhada para obter os coeficientes de Fourier (foram escolhidas 5 harmônicas). Aplicando a série de Fourier sobre os dois vetores, x e y, obtêm-se os coeficientes A e B de Fourier cujos valores são:

$$
\begin{aligned}
A & =\left[\begin{array}{lllll}
0.9655 & -0.1608 & -0.7776 & -0.3121 & -0.2677
\end{array}\right] \\
B & =\left[\begin{array}{lllll}
0.2338 & 1.2970 & 0.4308 & 0.0187 & -0.1326
\end{array}\right]
\end{aligned}
$$

A partir dos coeficientes de Fourier pode-se calcular o módulo e a fase de cada harmônica escolhida, cujos valores estão apresentados na tabela 6.1:

Tabela 6.1. Aplicação da série de Fourier para obtenção dos coeficientes de Fourier.

\begin{tabular}{|c|c|c|c|c|}
\hline Harmônicas & A (cosseno) & B (seno) & \multicolumn{3}{|c|}{ Módulo (M) } & Fase $\left(\varphi^{\mathbf{}}\right)$ \\
\hline $\mathbf{1}$ & 0,9655 & 0,2338 & 0,9934 & 13,60 \\
\hline $\mathbf{2}$ & $-0,1608$ & 1,2970 & 1,3069 & 97,07 \\
\hline $\mathbf{3}$ & $-0,7776$ & 0,4308 & 0,8889 & 151,02 \\
\hline $\mathbf{4}$ & $-0,3121$ & 0,0187 & 0,3127 & 176,57 \\
\hline $\mathbf{5}$ & $-0,2677$ & $-0,1326$ & 0,2987 & 206,35 \\
\hline
\end{tabular}

O próximo passo é o cálculo do número de Womersley para cada harmônica. O número de Womersley foi definido na equação (6.47) e os valores calculados são apresentados abaixo:

$$
\Omega=\left[\begin{array}{lllll}
2.5926 & 3.6665 & 4.4905 & 5.1852 & 5.7972
\end{array}\right]
$$

Através dos valores dos números de Womersley calculados, utiliza-se a tabela definida por Womersley que está no anexo I para calcular os parâmetros: $\frac{M_{0}^{\prime}}{\Omega^{2}}$ e $\varepsilon_{0}$. Dessa forma, com os parâmetros de Womersley, os módulos e fases de cada harmônica 
calculados, pode-se calcular o produto $M \times \frac{M_{0}^{\prime}}{\Omega^{2}}$ e a subtração $(\varepsilon-\varphi)^{\circ}$ cujos resultados estão apresentados na tabela 6.2.

Tabela 6.2. Cálculo dos parâmetros de Womersley.

\begin{tabular}{|c|c|c|c|c|c|}
\hline Harmônica & $\boldsymbol{\Omega}$ & $\mathbf{M}_{0}^{\prime} / \Omega^{2}$ & $\boldsymbol{\varepsilon}_{\mathbf{0}}$ & $\mathbf{M x M}_{\mathbf{0}} / \boldsymbol{\Omega}^{2}$ & $(\boldsymbol{\varepsilon}-\boldsymbol{\varphi})^{\mathbf{0}}$ \\
\hline 1 & 2,5926 & 0,0822 & 43,0110 & 0,0816 & 29,3976 \\
\hline 2 & 3,6665 & 0,0508 & 27,3484 & 0,0664 & $-69,7184$ \\
\hline 3 & 4,4905 & 0,0363 & 21,1650 & 0,0323 & $-129,8488$ \\
\hline 4 & 5,1852 & 0,0283 & 17,8863 & 0,0089 & $-158,6871$ \\
\hline 5 & 5,7972 & 0,0233 & 15,7683 & 0,0070 & 169,4228 \\
\hline
\end{tabular}

Nesse momento é necessário o cálculo do valor médio da vazão obtido através da equação de Poiseuille:

$$
Q_{s}=\frac{\pi a^{4} \Delta p}{8 \mu L}
$$

cujo valor encontrado é: $1,25 \mathrm{~mL} / \mathrm{s}$. Para completar os parâmetros da equação (6.66) deve-se calcular o seguinte produto para todas as harmônicas:

$$
Q_{\phi}=\frac{\pi a^{4}}{\mu} M \frac{M_{0}^{\prime}}{\Omega^{2}}
$$

cujos valores são:

$$
Q_{\phi}=\left[\begin{array}{lllll}
2,4404 & 1,9863 & 0,9656 & 0,2650 & 0,2083
\end{array}\right]
$$

Todos os parâmetros da equação (6.66) foram calculados, logo pode-se montar a equação que representa a oscilação da vazão volumétrica:

$Q_{\phi}(t)=1,25+2,44 \sin \left(x+29,4^{\circ}\right)+1,99 \sin \left(2 x-69,7^{\circ}\right)+0,97 \sin \left(3 x-129,85^{\circ}\right)+$ $0,27 \sin \left(4 x-158,69^{\circ}\right)+0,21 \sin \left(5 x+169,42^{\circ}\right)$

A representação gráfica da equação (6.69) está representada a seguir juntamente com o gradiente de pressão oscilatório: 


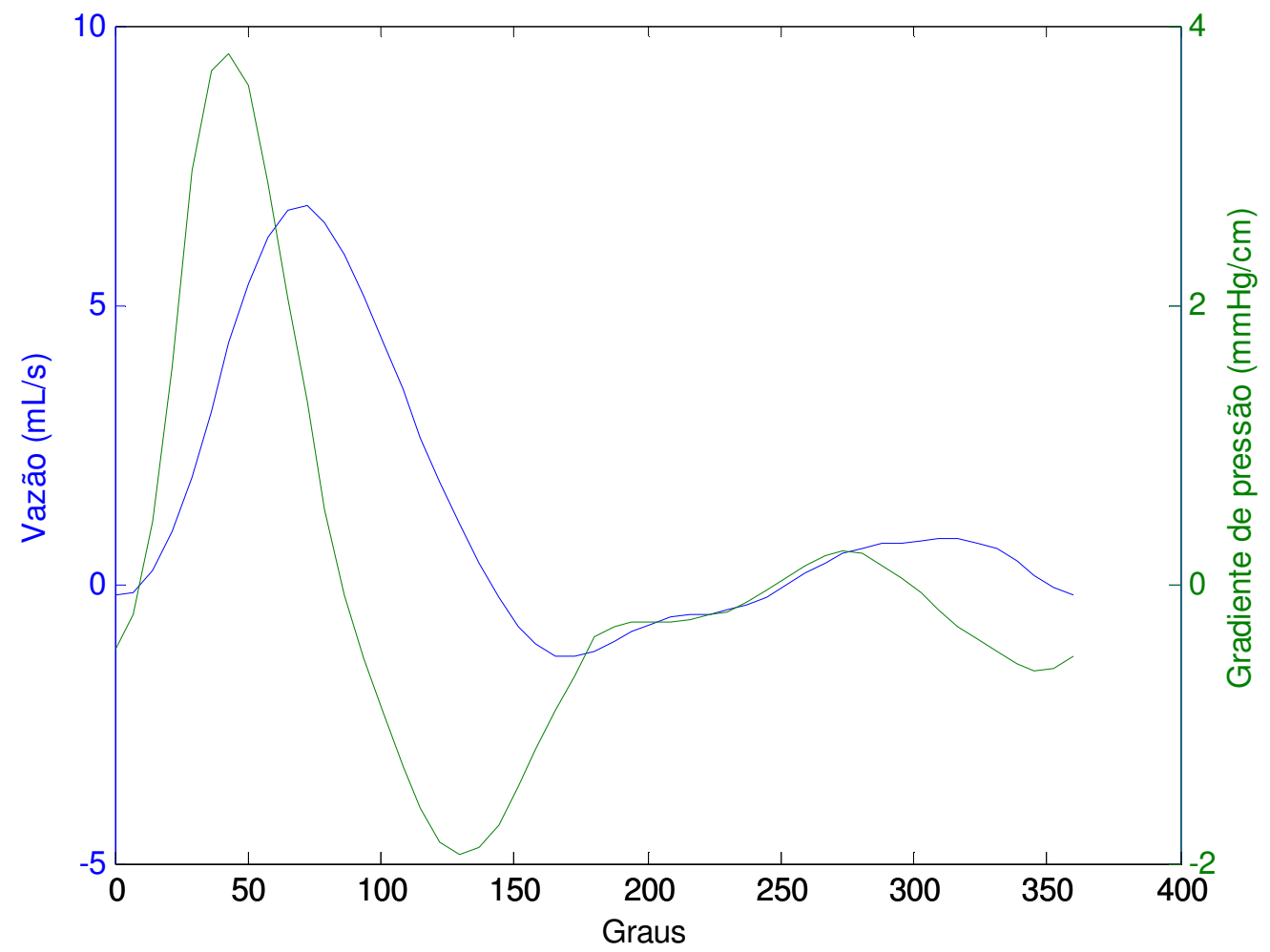

Figura 6.15. Representação do pulso oscilatório de vazão e do gradiente de carga de pressão na artéria femoral de um cão. 


\section{Metodologia}

\subsection{Análise da viscosidade}

A análise da viscosidade foi realizada para os seguintes polímeros: polietileno glicol (PEG4000), poliacrilamida 1822S e poliacrilamida 1340S cujos pesos moleculares são $4000 \mathrm{Da}(4 \mathrm{kDa}), 1,3 \times 10^{6} \mathrm{Da}(1300 \mathrm{kDa})$ e $2,0 \times 10^{6} \mathrm{Da}(2000 \mathrm{kDa})$, respectivamente. Esses polímeros foram escolhidos devido ao seu uso na literatura. A poliacrilamida foi usada anteriormente em nosso laboratório para análise de redução de arrasto em canais (Vilalta \& Ortiz, 2000), enquanto que o PEG4000 tem sido utilizado bastante na literatura médica (Bertuglia et al., 2006).

\subsection{Viscosímetros}

As medições de viscosidade foram realizadas com o intuito de analisar o comportamento das soluções poliméricas e verificar em quais concentrações poliméricas essas soluções poderiam ser classificadas como Newtonianas.

Para análise do comportamento da viscosidade da solução de PEG, foram utilizados o viscosímetro de Coutte rotacional da Brookfield, LVDV-II+ e o viscosímetro capilar tipo Ubbelohde junto ao Instituto de Pesquisa Tecnológica (IPT) para calcular o valor absoluto da viscosidade na temperatura do ensaio realizado junto ao Instituto de Ciências Biomédicas (ICB-I). Para a análise do comportamento da viscosidade da poliacrilamida foi utilizado o viscosímetro de Couette rotacional da Brookfield, DV-III+, junto ao Departamento de Engenharia Química da Universidade de São Paulo.

\subsubsection{Viscosímetro de Couette}

Considere um fluido dentro de um pequeno intervalo entre cilindros concêntricos, conforme apresentado na figura 7.1. Um torque se faz necessário para girar o cilindro interno numa velocidade de rotação constante $\omega$, com o cilindro externo permanecendo estacionário. A resistência à rotação do cilindro é devida à viscosidade do fluido. A tensão existente para resistir ao torque aplicado é a tensão de cisalhamento que depende diretamente do gradiente de velocidade, onde o y, para esse caso, pode ser considerado como sendo o raio r. Para um pequeno intervalo (h $<$ R), uma 
aproximação do gradiente de velocidade pode ser feita, assumindo um perfil de velocidade linear dentro deste intervalo.

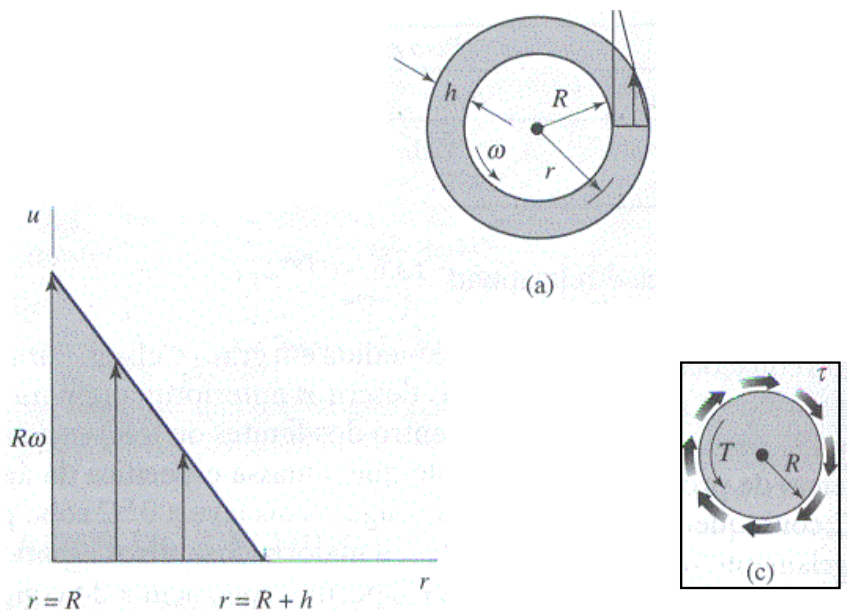

(b)

Figura 7.1. Representação dos cilindros e perfil de velocidade entre cilindros concêntricos: (a) cilindro interno girando; (b) distribuição de velocidades; (c) cilindro interno.

Assim,

$\frac{d u}{d r}=\frac{\varpi R}{h}$

em que h é a distância entre os cilindros. Lembrando-se da definição de torque, uma força aplicada em um braço de momento, tem-se

$T=$ Força $\mathrm{x}$ braço do momento

$T=$ tensão $\mathrm{x}$ área $\mathrm{x}$ braço do momento

e substituindo a equação 7.1 na definição de torque acima e isolando a viscosidade temse:

$\mu=\frac{T h}{2 \pi R^{3} \omega L}$

A área utilizada é aquela que está em contato com o fluido, ou seja, a área superficial do cilindro. 


\subsubsection{Viscosímetro Capilar de Força Gravitacional}

Esse tipo de viscosímetro é projetado apenas para medir a viscosidade do fluido em análise e, não o comportamento do fluido indicando se o mesmo é newtoniano ou não-newtoniano.

Os viscosímetros capilares permitem que o líquido flua em camadas e a figura 7.2 representa esse tipo de viscosímetro.

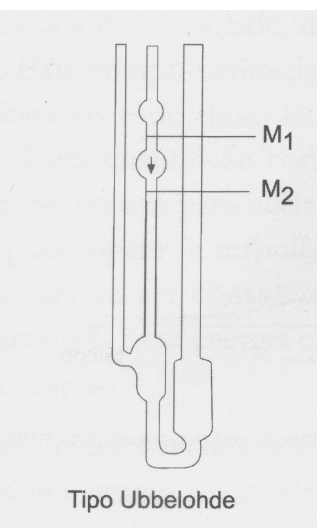

Figura 7.2. Viscosímetro capilar de força gravitacional: Ubbelohde. Extraído de Schramm (2006).

Nesse tipo de viscosímetro a amostra escoa através do capilar movida apenas devido ao seu próprio peso. A amostra é alimentada do reservatório superior que conduz a entrada do capilar. O peso da coluna de líquido sobre o orifício de saída é igual à energia potencial da amostra, o que força o líquido a escoar através do capilar.

A medida da viscosidade utilizando o viscosímetro do tipo Ubbelohde (Figura 7.2) requer a determinação do tempo necessário para que o nível do líquido desça através das marcas M1 e M2. As medidas resultantes do teste são dadas em unidades de viscosidade cinemática:

$$
v=C * \Delta t
$$

onde

$$
\begin{aligned}
& \Delta t=\text { período de tempo proporcional à viscosidade (s); } \\
& \mathrm{C}=\text { constante do instrumento relacionada às dimensões do capilar. }
\end{aligned}
$$


$\mathrm{O}$ viscosímetro cinemático utilizado apresentava um calibre $\mathrm{N}^{\mathrm{O}} 0 \mathrm{C}$ e a constante de calibração do instrumento de $0,0026716 \mathrm{~mm}^{2} / \mathrm{s}^{2}$.

\subsection{Preparo das soluções}

A - Preparo da solução para utilizar o viscosímetro de Couette tipo LVDV-II+:

- $5 \mathrm{~g}$ de polímero (PEG4000) foram inseridas em água destilada na presença e ausência da solução de krebs (1L). Essa solução foi agitada até que o polímero estivesse diluído nessa solução. A solução de krebs é a solução nutridora da artéria caudal;

- $16 \mathrm{ml}$ da solução polimérica foram introduzidas no reservatório do viscosímetro;

- O aparelho foi configurado para realizar as medições em diferentes rotações;

- A temperatura do ensaio foi mantida a $5^{\circ} \mathrm{C}$;

- O experimento foi iniciado.

Devido às limitações no viscosímetro, as medições de viscosidade foram realizadas, como exposta acima, à temperatura de $5^{\circ} \mathrm{C}$. Essas limitações estão associadas com o "range" de medição do equipamento. Próximo de $1 \mathrm{mPa}$.s os resultados da viscosidade oscilam bastante necessitando acoplar o "UL Adapter Acessory" para melhorar os resultados. Não se dispunha desse acessório.

B - Preparo da solução para utilizar o viscosímetro capilar tipo Ubbelohde:

- $5 \mathrm{~g}$ de polímero (PEG4000) foram inseridas em água destilada na presença e ausência da solução de krebs (1L). Essa solução foi agitada até que o polímero estivesse diluído nessa solução. A solução de krebs é a solução nutridora da artéria caudal;

- Um volume de $8 \mathrm{~mL}$ foi pipetado com auxílio de uma pêra de borracha;

- Esse volume foi introduzido no ramo não capilar do viscosímetro;

- A pêra foi acoplada no ramo capilar do viscosímetro e aspirando lentamente, assegurando-se que não haja formação de microbolhas no interior do tubo, até que a superfície livre do líquido ultrapasse o menisco superior de referência; 
- A pêra foi liberada, deixando o líquido escorrer livremente;

- A cronometragem foi iniciada no momento em que a superfície livre atingiu o menisco acima da dilatação (M1);

- A cronometragem foi encerrada no instante em que a superfície livre atingiu o menisco abaixo da dilatação (M2);

- As etapas 4 a 7 foram repetidas para cada tomada de tempo. No total foram realizadas 6 medições;

- Os tempos obtidos foram multiplicados pela constante de calibaração do equipamento.

C - Preparo da solução para utilizar o viscosímetro de Couette tipo DV-III+:

- Uma solução mãe de poliacrilamida foi preparada com concentração de 100ppm (partes por milhão);

- A partir dessa solução, as outras concentrações foram obtidas (5, 10, 30, 60 e 75 ppm) utilizando a seguinte equação: $C_{i} \cdot V_{i}=C_{f}$. $V_{f}$. Onde $C_{i}$ e $C_{f}$ designam a concentração inicial e final e $V_{i}$ e $V_{f}$ designam os volumes final e inicial;

- A solução mãe foi agitada por um período de aproximadamente 6 horas (60-100 rpm);

- $16 \mathrm{~mL}$ de solução polimérica foram retiradas de cada concentração especificada acima e inserida no reservatório do viscosímetro;

- O aparelho foi configurado para realizar as medições em diferentes rotações;

- A temperatura do ensaio foi mantida a $25^{\circ} \mathrm{C}$;

- O experimento foi iniciado.

\subsection{Bancada experimental da EPUSP}

Os ensaios para análise da redução de arrasto foram realizados utilizando os polímeros: PEG4000, as poliacrilamidas 1822S e 1340S e o Polyox WSR-301 a diferentes concentrações. De acordo com os resultados da análise da viscosidade, a poliacrilamida em concentrações baixas, 5 e 10 ppm, e o PEG4000 em concentração de até 5000 ppm apresentaram comportamento de fluido Newtoniano e, o Polyox WSR- 
301, também apresenta comportamento de fluido Newtoniano para as concentrações utilizadas nesse trabalho de acordo com os resultados de Antonova \& Lazarov (2004), logo essas concentrações foram escolhidas para a análise de redução de arrasto na bancada experimental da EPUSP. O uso do Polyox WSR-301 surgiu devido ao PEG4000 não apresentar o fenômeno da redução de arrasto na bancada experimental da EPUSP, conforme pode ser visto no item 8.2.2 dos resultados. A literatura comenta que os polímeros de pesos moleculares menor que $1 \times 10^{6} \mathrm{Da}(1000 \mathrm{kDa})$ não apresentam o fenômeno da redução de arrasto, logo esse polímero (Polyox WSR-301) passou a ser utilizado já que apresenta a mesma estrutura química do PEG4000, porém com um peso molecular mil vezes maior (da ordem de $1000 \mathrm{kDa}$ ). A concentração de $5000 \mathrm{ppm}$ do PEG4000 foi escolhida porque, sob essas condições, apresentou redução de arrasto em leitos arteriais caudais cujos resultados estão apresentados no item 8.3. Os procedimentos de obtenção das soluções poliméricas foram apresentados no item 7.1.

A análise da redução de arrasto foi verificada em tubos de silicone sem e com estenoses e capilar e, em tubos de borracha natural.

\subsubsection{Descrição da bancada experimental da EPUSP}

A concepção inicial da bancada experimental está apresentada em Guerino Silva (1998) e adaptações foram realizadas por Leal (2001) cujo objetivo foi analisar a ruptura de vasos sangüíneos (fig. 7.3) e novas adaptações foram realizadas durante o desenvolvimento desse trabalho conforme apresentado no item 8.2.1.

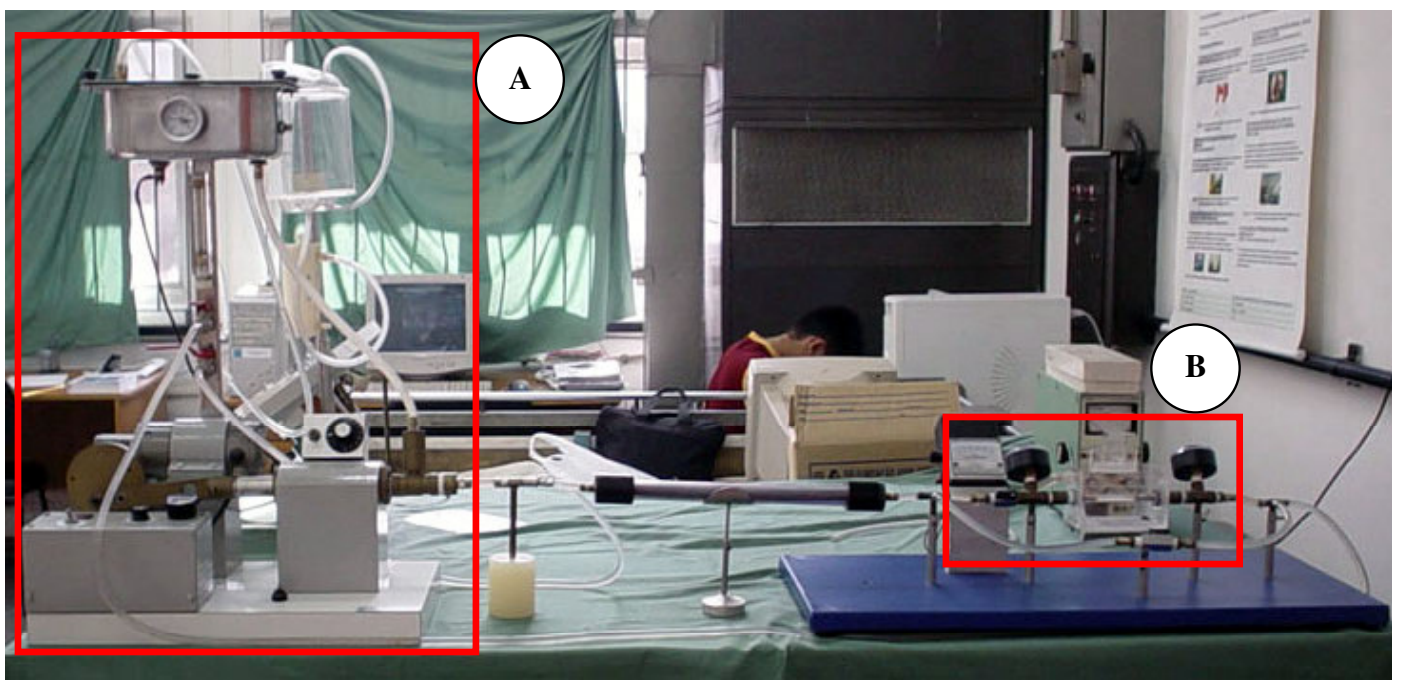

Figura 7.3. Simulador hidrodinâmico para estudos in vitro do sistema cardiovascular. A - unidade central de bombeamento; B - seção de teste. 
Basicamente, o simulador hidrodinâmico é composto por uma unidade central de bombeamento (A) e uma seção de teste (B) (Figura 7.3). A unidade central de bombeamento é composta por: motor de corrente contínua ( 1 ); reservatório ( $\mathrm{R}$ ), que faz a função do átrio; câmara do pistão ( 2 ), que faz a função do ventrículo; válvulas unidirecionais ( 3 e 4 ), enquanto que a seção de teste é composta por: tubo de silicone sem e com estenose, tubo capilar; manômetros ( 5 ) (Figura 7.4).

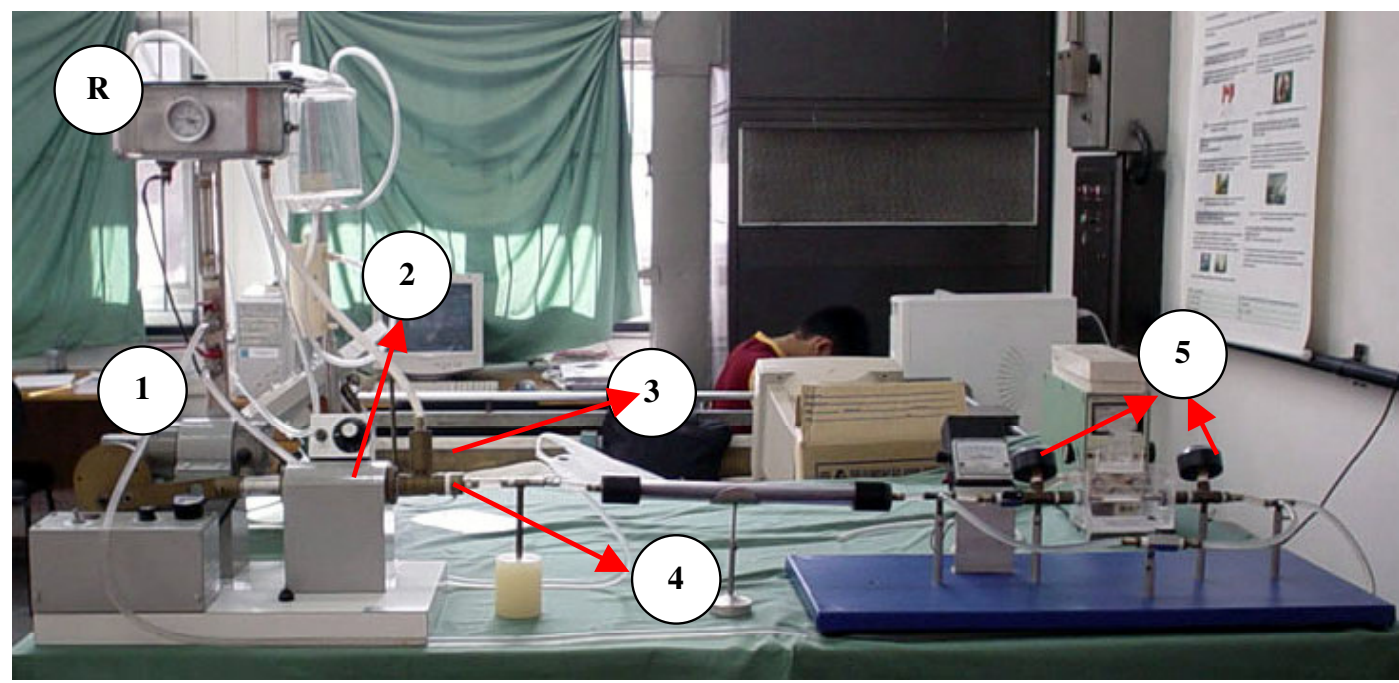

Figura 7.4. Descrição da unidade central de bombeamento e da seção de teste do simulador hidrodinâmico para estudos in vitro do sistema cardiovascular. $R$ reservatório; 1 - motor de corrente contínua; 2 - câmara do pistão; 3 e 4 - válvulas unidirecionais; 5 - manômetros.

A descrição do princípio de funcionamento do simulador hidrodinâmico está apresentada no item 8.2.

\subsubsection{Confecção dos tubos de silicone sem e com estenose}

Inicialmente foram criados os tubos de silicone sem e com estenose. O material usado para o desenvolvimento destes tubos foi o Sylgard 184 (Dow Corning) e, foram desenvolvidos no laboratório de Mecânica dos Fluidos. O material do molde utilizado para confeccionar o tubo de silicone sem estenose foi de latão e, aquele usado para confeccionar os tubos de silicones estenosados de $30 \%$ e $50 \%$ de redução de área, foi de alumínio (Figura 7.5 A e B) com as seguintes características adotadas preliminarmente:

- comprimento: $120 \pm 0,05 \mathrm{~mm}$; 
- diâmetro: $10 \pm 0,05 \mathrm{~mm}$.

Os moldes eram imersos numa solução de silicone (relação de 1:10 entre o silicone e o catalisador) e pré-aquecidos com o uso de um soprador e medindo-se a espessura de parede até obter o valor de $1 \mathrm{~mm}$. Esta etapa foi desenvolvida com a ajuda do aluno de doutorado Daniel Formariz Legendre e do Instituto Dante Pazanesse de Cardiologia.

(A)

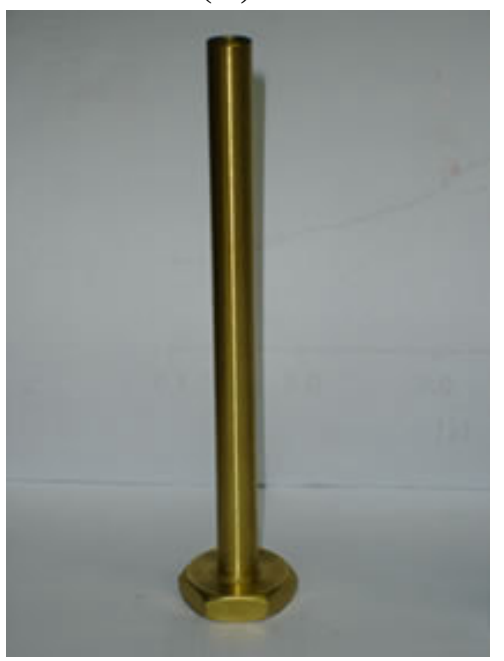

(B)
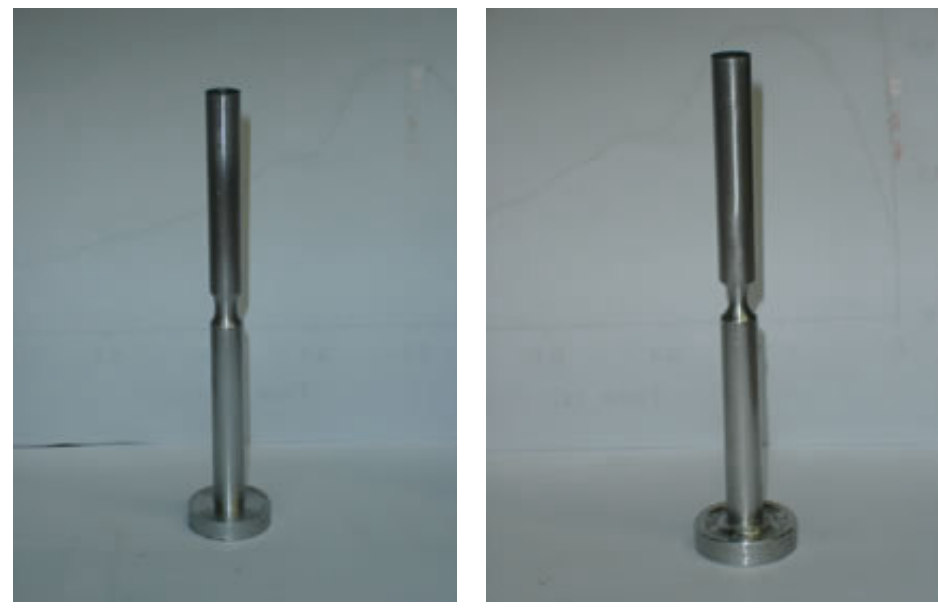

Figura 7.5. Moldes utilizados para o desenvolvimento dos tubos de silicone: (A) molde sem estenose; (B) moldes com $30 \%$ e $50 \%$ de redução de área.

A figura 7.6 apresenta os protótipos de silicone. As dimensões finais dos protótipos foram:

- comprimento: $86,9 \pm 0,05 \mathrm{~mm}$; 
- diâmetro: $10,6 \pm 0,05 \mathrm{~mm}$.

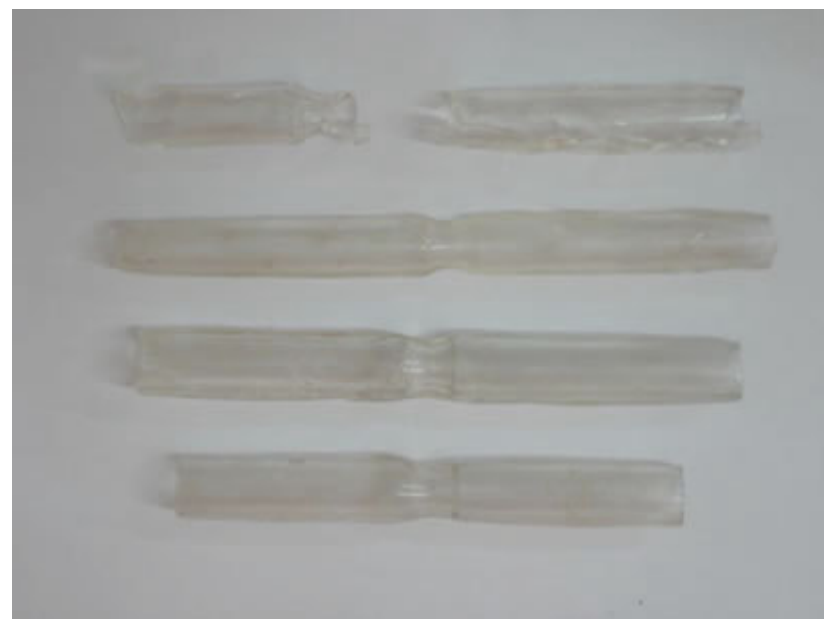

Figura 7.6. Representação dos tubos estenosados de silicone (Sylgard 184, Dow Corning).

\subsubsection{Tubo capilar}

Tubos capilares de silicone e de borracha natural foram usados para verificar a redução de arrasto. Os valores dimensionais dos tubos foram:

- comprimento: $410 \pm 0,05 \mathrm{~mm}$;

- diâmetro: $3 \pm 0,05 \mathrm{~mm}$.

\subsubsection{Medições das vazões e pressões}

As medições de pressão foram realizadas através do uso de dois manovacuômetros cujo certificado de calibração foi obtido da $\mathrm{ABSi}$ - Indústria e Comércio Ltda. O primeiro e segundo manovacuômetros apresentam uma faixa de medida de pressão de $-1 /+3$ e $-1 /+2 \mathrm{kgf} / \mathrm{cm}^{2}$ com valor de uma divisão de 0,05 $\mathrm{kgf} / \mathrm{cm}^{2}$.

A calibração da vazão foi realizada usando um cronômetro e uma proveta calibrada (Biomatic). As medidas foram realizadas através do enchimento da proveta até um volume conhecido e cronometrado o tempo necessário para atingir esse volume para as seguintes rotações: 40, 50, 60, 70, 80 e $90 \mathrm{rpm}$. 


\subsubsection{Medições da redução de arrasto}

Os diferenciais de pressões foram medidos para escoamento de água nas seguintes rotações: 40, 50, 60, 70, 80 e $90 \mathrm{rpm}$. Em seguida, os diferenciais de pressões eram novamente medidos na presença das soluções poliméricas (PEG4000, Polyox WSR-301, Poliacrilamidas 1822S e 1340S) em diferentes concentrações: 5, 10, 30, 50 e 100 ppm. Para o PEG4000, a concentração polimérica foi elevada até atingir valor de 5000 ppm para comparar com os resultados da redução de arrasto na bancada experimental do Instituto de Ciências Biomédicas. Com os diferenciais de pressões obtidos, esses eram inseridos na fórmula abaixo e calculados os valores das reduções de arrastos:

$$
\% \text { R.A. }=100 *\left(\frac{\Delta p_{s}-\Delta p_{p}}{\Delta p_{s}}\right)
$$

onde $\Delta p_{s}$ - diferencial de pressão na ausência do polímero;

$\Delta p_{p}$ - diferencial de pressão na presença do polímero.

\subsection{Bancada experimental do ICB-USP - Leitos arteriais caudais}

A realização dos ensaios na bancada experimental do ICB seguiu a Carta da Comissão de Ética em Experimentação Animal, sendo que toda e qualquer manipulação dos animais foi feita por professor ou alunos do ICB (anexo 2). Portanto, essa etapa do trabalho foi desenvolvida em parceria com o Instituto de Ciências Biomédicas I através do Departamento de Fisiologia e Biofísica no Laboratório de Fisiologia Vascular, sob a coordenação da Professora Doutora Luciana Venturini Rossoni e, também, com a participação de Juliana Fernandes Belettati, aluna de iniciação científica.

Nessa etapa, o polietileno glicol (PEG $4000 \mathrm{Da}$ - 5000 ppm) foi diluído na solução de Krebs e perfundido nos leitos arteriais caudais de ratos normotensos e hipertensos com o intuito de avaliar a redução de arrasto. 


\subsubsection{Descrição da bancada experimental do ICB}

A bancada experimental do ICB (Figura 7.7), basicamente, consiste de: dois banhos térmicos ( I e V ), onde um é usado para manter a solução de krebs a $37^{\circ} \mathrm{C}$ e o outro para manter o leito arterial caudal a temperatura de $37^{\circ} \mathrm{C}$; uma bomba peristáltica ( II ); captador de bolhas ( III ); transdutores de pressão ( IV ); e um microcomputador ( VI ).

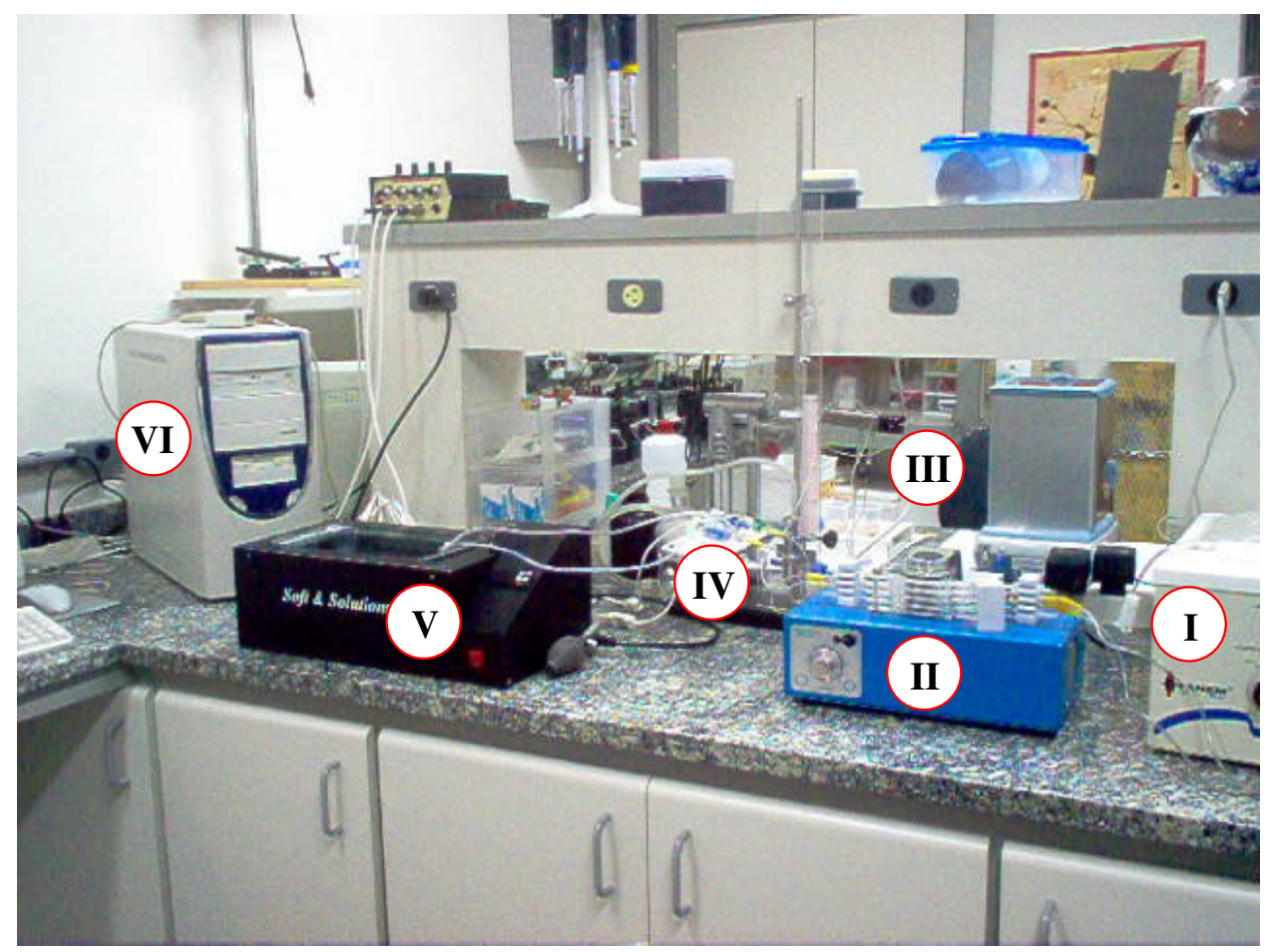

Figura 7.7. Descrição da bancada experimental utilizada no ensaio de redução de arrasto em leitos arteriais caudais.

\subsubsection{Obtenção do leito arterial caudal}

Os ratos (machos) normotensos e espontaneamente hipertensos (SHR) possuíam aproximadamente uma massa de 250-300g e 4-5 meses. Esses ratos eram mantidos no biotério de Criação do Instituto de Ciências Biomédica I (ICB - I) e, quando eles apresentavam idade e massa suficientes para iniciar o trabalho experimental, esses eram levados até o laboratório e anestesiados com ketamina/xilazina/acepromazina $(0,7 / 0,2 /$ 0,1 vol/vol, 0,8 mL/kg, i.p.) e heparinizados (500 UI, i.p.). No momento em que a 
anestesia tinha efeito sobre o rato, esse era colocado sobre uma placa de madeira e imobilizado na região das patas superiores e inferiores. Em seguida, um corte era feito na cauda do rato com o intuito de se chegar na artéria caudal. Através da identificação da artéria caudal, essa era canulada através do uso de um cateter (cateter intravenoso $24 \mathrm{G} 3 / 4$, Nipro) no sentido contrário ao fluxo sanguiíneo e, em seguida, a cauda era cortada do animal e levada para a bancada experimental (figura 7.8). A extremidade oposta ao cateter era cortada para que a solução de perfusão não retornasse pelo sistema venoso, mas sim, fosse descarregado para a atmosfera.

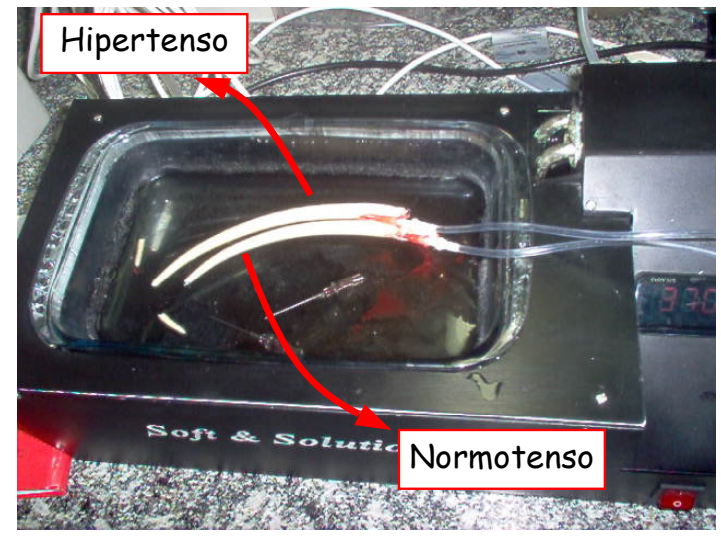

Figura 7.8. Artérias caudais de ratos normotensos (Wistar) e espontaneamente hipertensos (SHR).

A técnica de perfusão do leito arterial caudal está descrita em França et al. (1997). As artérias caudais eram perfundidas com solução de Krebs-Henseleit, composto por (em mM): NaHCO3 27,2; $\mathrm{NaCl}$ 119; NaH2PO4 1,0; MgSO4 1,2; KCl 5,0; $\mathrm{CaCl} 2$ 1,25; glicose 11,0; EDTA 0,03. Essa solução era mantida à temperatura constante de $37 \pm 0,5^{\circ} \mathrm{C}$, gaseificada pelo borbulhamento de mistura carbogênica contendo $95 \%$ de $\mathrm{O}_{2}$ e $5 \%$ de $\mathrm{CO}_{2}$ mantendo o pH estável em 7,4. O fluxo era mantido por meio de uma bomba peristáltica (Milan, Colombo, Paraná, Brasil). A pressão de perfusão média (PPM) no leito arterial caudal era medida através de um transdutor de pressão (UTAH, USA) conectado a um pré-amplificador (AECAD 0804, SP, Brasil) situado entre a bomba peristáltica e a cânula arterial. Esse pré-amplificador era conectado a um sistema de aquisição de dados (DATAQ DI194-RS - WinDaq); o qual era ligado a um computador (PC Pentium), possibilitando a realização dos registros, continuamente. Na verdade, a PPM é o diferencial de carga de pressão entre a região 
proximal e distal da artéria caudal, mas como na nomenclatura biomédica essa é chamada de pressão então essa nomenclatura vai ser utilizada nesse trabalho.

As preparações eram mantidas por um período de estabilização de 30-45 min e, em fluxo constante de $2,5 \mathrm{~mL} / \mathrm{min}$ e, em seguida, eram iniciados os protocolos experimentais. Considerando a relação Pressão = Fluxo x Resistência, sendo o fluxo constante, as variações de pressão registradas indicavam variações da resistência vascular.

\subsubsection{Protocolo experimental}

I. Avaliação da reatividade vascular do leito arterial caudal em resposta a mudanças de fluxo.

Com a finalidade de avaliar a influência da variação de fluxo na reatividade arterial caudal, após o período de estabilização, os leitos arteriais de ratos Wistar e SHR eram submetidos a fluxos de 1,$5 ; 2,5 ; 5,0 ; 7,5$ e $10 \mathrm{~mL} / \mathrm{min}$. Em cada fluxo a preparação era mantida por 10min.

II. Avaliação do polietileno glicol (PEG4000 - 5000 ppm) no leito arterial caudal em resposta as mudanças de fluxo.

Para verificar a participação do polietileno glicol nos leitos arteriais caudais em resposta as mudanças de fluxo, curvas de variação de fluxo eram realizadas na ausência e presença do polímero. Após realização da primeira curva de fluxo, eram esperadas duas horas para estabilização da preparação em fluxo constante de 2,5mL/min. Após esse intervalo a solução nutridora inicial era substituída por uma solução de Krebs- Henseleit contendo polietileno glicol (4000 kDa, 5000ppm, Synth), a qual era perfundida por uma hora em fluxo constante de 2,5mL/min. Em seguida os leitos arteriais de ratos Wistar e SHR eram, novamente, submetidos a curvas de fluxos $(1,5$; $2,5 ; 5,0 ; 7,5$ e $10 \mathrm{~mL} / \mathrm{min})$.

III. Avaliação da influência do endotélio, do óxido nítrico, do fator hiperpolarizante derivado do endotélio e das prostaglandinas sobre a ação da perfusão do polietileno glicol nos leitos arteriais caudais.

Com o objetivo de estudar os mecanismos de ação do polietileno glicol e a influência do endotélio sobre essa ação, as seguintes substâncias eram avaliadas: óxido nítrico, fator hiperpolarizante derivado do endotélio, 
prostaglandinas sobre a ação da perfusão do polietilenoglicol no leito arterial caudal de ratos normotensos e hipertensos.

Para isso, as curvas de fluxo eram realizadas antes e após a lesão endotelial com \{3-[(3-cloroamidopropil) dimetilamônio]-I-propanossulfato\} (CHAPS $9 \mu \mathrm{g}, 90 \mu \mathrm{l}$, in bolus) e antes e após a infusão com o inibidor da óxido nítrico sintase, NG-nitro-L-arginine (L-NAME 10-4 M), com o inibidor não seletivo dos canais de potássio ativados por cálcio, com tetraetilamônio (TEA $20 \mathrm{mM})$ e com o inibidor da enzima ciclooxigenase, indometacina $(10 \mu \mathrm{M})$ na presença e ausência de polietilenoglicol (PEG 4000, 5000ppm).

IV. Avaliação da resposta de relaxamento a acetilcolina Ao fim de cada experimento eram realizadas pré-contrações com fenilefrina diluída na solução nutridora $(1,4 \mu \mathrm{L} / \mathrm{mL})$, seguida por aplicação de acetilcolina ( $5 \mu \mathrm{g}, 100 \mu \mathrm{L}$, in bolus) com a finalidade de testar a integridade endotelial. Eram considerados endotélios viáveis aqueles cuja porcentagem de relaxamento é maior ou igual a 50\% de relaxamento relativo.

\subsubsection{Medição do diâmetro arterial caudal}

Para a medição do diâmetro arterial caudal durante a perfusão, na vazão de 2,5 $\mathrm{mL} / \mathrm{min}$, foi necessário fixar o diâmetro da artéria caudal. Isso foi conseguido através do uso da solução fixadora de Bouin. O uso dessa solução ocorreu devido à utilização da microscopia óptica para medição do diâmetro arterial caudal. Para realizar essa medição, é necessária a confecção de lâminas histológicas. Basicamente as etapas para a confecção de lâminas histológicas são: coleta, fixação, inclusão e microtomia.

Para coleta e fixação das artérias caudais os seguintes procedimentos foram seguidos:

- Preparar a solução fixadora de bouin (Junqueira e Junqueira, 1983):

- Solução aquosa saturada de ácido pícrico $75 \mathrm{ml}$

○ Formol $25 \mathrm{ml}$;

○ Ácido acético $5 \mathrm{ml}$.

- Perfundir o leito arterial caudal na vazão fisiológica de $2,5 \mathrm{~mL} / \mathrm{min}$ com solução de krebs;

- Testar o endotélio com fenilefrina e acetilcolina;

- Trocar a solução de perfusão (krebs) pela solução de Bouin; 
- Perfundir o leito arterial caudal com a solução fixadora de Bouin entre 06 - 24 horas. Nesse trabalho, a solução fixadora de Bouin perfundiu o leito arterial caudal durante 8 horas;

- Retirar o excesso do ácido pícrico através da lavagem do leito arterial caudal em água corrente por 18 horas;

- Transferir o leito arterial caudal para álcool 50\%, durante 30 minutos;

- Armazenar o leito arterial caudal em álcool $70 \%$.

A etapa de inclusão consiste em impregnar o tecido com uma substância de consistência firme que permita, posteriormente, seccioná-lo em camadas delgadas. Pelo fácil manuseio e bons resultados, a parafina foi utilizada. Em seguida, após a aplicação da parafina fundida em blocos, esses blocos eram levados para o micrótomo e cortes eram realizados no leito arterial caudal. Após os cortes terem sido realizados, esses eram levados para as lâminas de vidros, corados e, em seguida prontos para serem realizados as medições dos diâmetros. Para a medição dos diâmetros arteriais caudais foi utilizado o microscópio óptico (Axiovert 200, Carl Zeiss). A área interna do vaso era delimitada e, em seguida calculada. Para a construção do modelo computacional, essa área foi utilizada considerando-a circular, e calculando-se o seu diâmetro.

O comprimento do leito arterial caudal era medido no momento de dissecação da artéria caudal.

\subsubsection{Cálculo da redução de arrasto a partir do fator de atrito}

Nesse item, foi desenvolvida a metodologia de cálculo da redução de arrasto a partir da utilização do cálculo do fator de atrito. Os casos de presença e ausência do endotélio para os ratos normotensos (Wistar) e espontaneamente hipertensos (SHR) foram abordados.

A partir da equação da energia pode-se chegar na equação de balanço de energia, conforme apresentada pela equação 7.5,

$$
\left(\frac{p_{1}}{\rho}+\frac{-u_{1}}{2}+g z_{1}\right)-\left(\frac{p_{2}}{\rho}+\frac{-2}{2}+g z_{2}\right)=h_{l t}
$$


onde p é a pressão $\left(\mathrm{N} / \mathrm{m}^{2}\right)$, $\rho$ é a densidade do fluido $\left(\mathrm{kg} / \mathrm{m}^{3}\right), \bar{u}$ é a velocidade média do escoamento $(\mathrm{m} / \mathrm{s})$, z é a posição do escoamento em relação a um plano de referência (m) e $h_{\mathrm{lt}}$ é a perda de carga total $\left(\mathrm{m}^{2} / \mathrm{s}^{2}\right)$. A interpretação física do termo $\mathrm{h}_{\mathrm{lt}}$ (perda de carga total) é uma perda de energia por unidade de massa de fluido em escoamento. $\mathrm{O}$ termo entre parênteses da equação 7.5 representa a energia mecânica por unidade de massa numa seção.

A perda de carga total, $\mathrm{h}_{\mathrm{lt}}$, representa a soma das perdas distribuídas, $\mathrm{h}_{\mathrm{l}}$, devidas aos efeitos de atrito no escoamento, com as perdas localizadas, $\mathrm{h}_{\mathrm{lm}}$, devidas a entradas, acessórios, etc. Para nossa aplicação foram consideradas apenas as perdas distribuídas. Logo, a equação (7.5) pode ser reescrita como,

$$
\left(\frac{p_{1}}{\rho}+\frac{\bar{u}_{1}^{2}}{2}+g z_{1}\right)-\left(\frac{p_{2}}{\rho}+\frac{\bar{u}_{2}^{2}}{2}+g z_{2}\right)=h_{l}
$$

Deve-se lembrar que a cauda está sendo considerada como um tubo cônico e que os pontos de medição das pressões estão na mesma cota, logo a equação (7.6) pode ser simplificada,

$$
\begin{aligned}
& h_{l}=\left(\frac{p_{1}}{\rho}+\frac{\bar{u}_{1}^{2}}{2}\right)-\left(\frac{p_{2}}{\rho}+\frac{\bar{u}_{2}^{2}}{2}\right) \\
& h_{l}=\left(\frac{p_{1}-p_{2}}{\rho}\right)-\left(\frac{\bar{u}_{2}-\bar{u}_{1}^{2}}{2}\right)
\end{aligned}
$$

Lembrando-se que vazão volumétrica é igual à velocidade multiplicada pela área e que a vazão na seção 1 , por exemplo, de um tubo é igual a vazão na seção 2 , logo pode-se calcular o termo da velocidade na equação (7.7),

$$
Q=u * A \therefore \quad Q_{1}=\bar{u}_{1} * A_{1} Q_{2}=\bar{u}_{2} * A_{2} \quad Q_{1}=Q_{2}=Q
$$

elevando ao quadrado as vazões teremos, 


$$
Q_{1}^{2}=\bar{u}_{1}^{2} * \frac{\pi^{2} d_{1}^{4}}{16} \text { e } \quad Q_{2}^{2}=\bar{u}_{2}^{2} * \frac{\pi^{2} d_{2}^{4}}{16}, \text { logo isolando os termos de velocidades }
$$

nas duas fórmula de vazões, tem-se,

$$
\frac{\bar{u}_{1}^{2}}{2}=\frac{8 Q_{1}^{2}}{\pi^{2}} \frac{1}{d_{1}^{4}} \quad \text { e } \quad \frac{\bar{u}_{2}^{2}}{2}=\frac{8 Q_{2}^{2}}{\pi^{2}} \frac{1}{d_{2}^{4}} \text {, assim subtraindo velocidade na seção } 2 \text { da }
$$

velocidade na seção 1 e lembrando-se que $\mathrm{Q}_{1}{ }^{2}$ é igual a $\mathrm{Q}_{2}{ }^{2}$, tem-se,

$$
\frac{\bar{u}_{2}^{2}}{2}-\frac{\bar{u}_{1}^{2}}{2}=\frac{8 Q^{2}}{\pi^{2}}\left[\left(\frac{1}{d_{2}}\right)^{4}-\left(\frac{1}{d_{1}}\right)^{4}\right]
$$

e substituindo a equação (7.8) na equação (7.7), tem-se

$$
h_{l}=\frac{\Delta p}{\rho}-\frac{8 Q^{2}}{\pi^{2}}\left[\left(\frac{1}{d_{2}}\right)^{4}-\left(\frac{1}{d_{1}}\right)^{4}\right]
$$

Agora, pode-se calcular o fator de atrito no tubo através da seguinte fórmula,

$$
f=\frac{2 h_{l} d}{L u^{-2}}
$$

onde d é um diâmetro médio $(\mathrm{m})$ e $\bar{u}$ é uma velocidade média $(\mathrm{m} / \mathrm{s})$. O fator de atrito universal no escoamento laminar é função apenas do número de Reynolds,

$$
f=\frac{64}{\operatorname{Re}}
$$

Assim, a redução de arrasto pode ser calculada,

$$
R A(\%)=100 *\left(\frac{f_{S}-f_{P}}{f_{S}}\right)
$$

onde $f_{S}$ e $f_{P}$ são o fator de atrito sem polímero e com polímero, respectivamente. 


\subsection{Distribuição espacial e temporal da tensão de cisalhamento ao longo do leito arterial caudal de ratos normotensos (Wistar) e espontaneamente hipertensos (SHR)}

O software Fluent baseado no método dos volumes finitos foi usado para avaliar a distribuição da tensão de cisalhamento espacial e temporalmente ao longo da artéria caudal dos ratos normotensos (Wistar) e espontaneamente hipertensos (SHR).

A geração da geometria e da malha do leito arterial caudal foi realizada no software Gambit 2.3.16. Para sua construção foram utilizadas as dimensões do diâmetro e do comprimento dos vasos conforme descritos no item 7.5.4. Durante a geração da malha, essa foi divida em duas regiões para facilitar a sua geração. A interface dessas duas regiões foi feita através da ferramenta denominada interior. Essa interface, interior, é interpretada pelo software Fluent como uma face invisível sendo utilizada para ligar as duas malhas das regiões diferentes, dessa forma, não impedindo a passagem do escoamento. A malha foi refinada na parede do vaso, com uma profundidade total de $0,03 \mathrm{~mm}$ (em direção ao centro do vaso) para melhor resolver os gradientes de velocidades. O número de nós foi de 78.166 com um total de 331.087 volumes tetrahédricos (Figura 7.9).

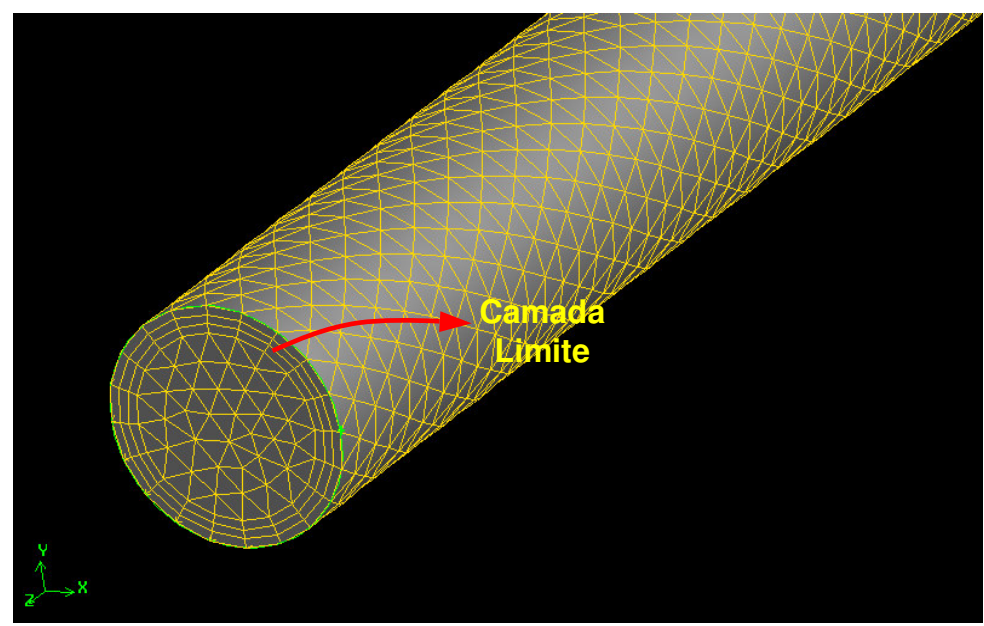

Figura 7.9. Malha computacional que representa a artéria caudal mostrando a camada limite.

Após a geração da geometria e da malha computacional, ainda no software Gambit 2.3.16, foram atribuídas a essa geometria as seguintes denominações: face de 
entrada, face de saída e parede, onde as condições de contornos foram inseridas no Fluent. Em seguida, essa malha foi exportada para o software Fluent 6.2.16.

No software Fluent, os seguintes modelos e condições de contornos foram inseridos:

- Modelo de viscosidade: newtoniano;

- Tipo de escoamento: laminar;

- Face de entrada: pulso de pressão aquisitados dos leitos arteriais;

- Face da saída: pressão efetiva igual a zero;

- Paredes rígidas.

A escolha do modelo de viscosidade e do tipo de escoamento foi baseada nos resultados da análise de viscosidade e no cálculo do número de Reynolds.

A inserção do pulso de pressão na face de entrada do modelo numérico foi feita através de uma udf (user defined function). Para a construção da udf, os seguintes passos foram necessários:

- Um pulso resultante de pressão foi obtido a partir da média dos pulsos dos animais;

- Um programa no matlab foi desenvolvido a partir da série de Fourier para obter uma equação que representasse o pulso resultante de pressão;

- Essa equação do pulso resultante de pressão foi inserida na udf escrita em C que alimentou o modelo numérico.

Cada uma das etapas mencionadas acima deveria ter sido feita para as diferentes vazões. Porém, durante o desenvolvimento do trabalho foi percebido que a inserção do pulso de entrada poderia ser realizada através de uma tabela de pontos. Logo, essa nova forma de inserção foi escolhida, pois a partir da média dos pulsos de pressões, esses poderiam alimentar o modelo numérico diretamente na presença e ausência do endotélio e do PEG4000.

O capítulo de modelagem matemática de escoamento em tubos rígidos foi desenvolvido com o intuito de ser aplicado na modelagem numérica, porém não foi necessário, já que a inserção do pulso de pressão adquirido da bancada experimental do ICB foi inserida como condição de contorno no modelo numérico. A modelagem matemática forneceu subsídios para o entendimento do comportamento dos perfis de velocidade num escoamento oscilatório. 


\section{Resultados}

\subsection{Análise da viscosidade}

\subsubsection{Polietileno glicol}

Os resultados apresentados nas figuras 8.1 e 8.2 foram obtidos a partir da utilização do viscosímetro LVDV-II+. Estes resultados são referentes à solução polimérica do PEG4000 com concentração de 5000 ppm na presença e ausência da solução de Krebs. Essas figuras apresentam o diagrama reológico.

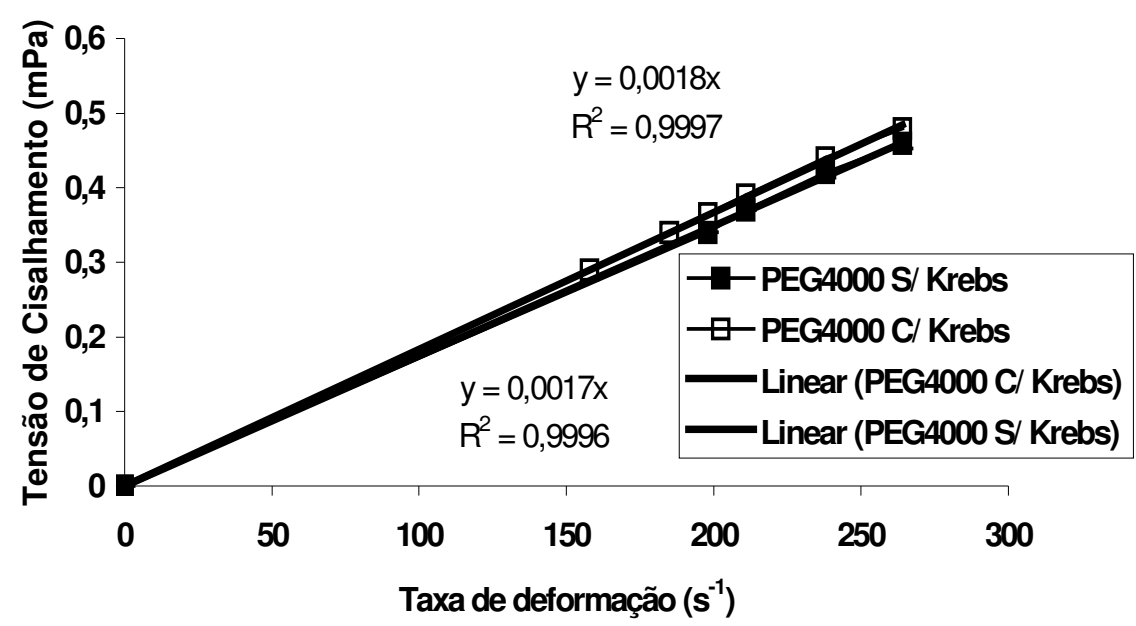

Figura 8.1. Tensão de cisalhamento versus taxa de deformação para a solução polimérica (PEG4000 - 5000ppm) sem e com Krebs.

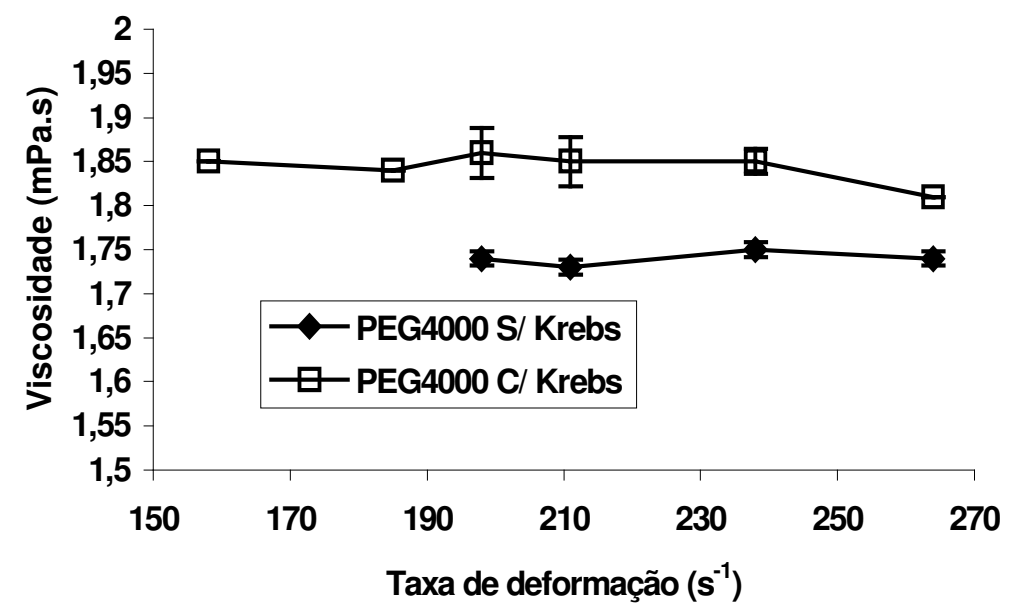

Figura 8.2. Viscosidade versus taxa de deformação para a solução polimérica (PEG4000 - 5000 ppm) sem e com Krebs. 
Nas figuras 8.1 e 8.2, é possível verificar a linearidade apresentada pelos gráficos da tensão de cisalhamento versus taxa de deformação e da viscosidade versus taxa de deformação, mostrando que a hipótese de fluido Newtoniano para a solução polimérica de PEG4000 com concentração de 5000ppm na presença e ausência de Krebs pode ser aceita, lembrando-se que por definição um fluido newtoniano é aquele em a viscosidade não varia com a taxa de deformação. Sendo assim, a hipótese de fluido Newtoniano para a solução de Krebs com polímero (PEG4000 - 5000 ppm) será considerada no modelo numérico.

Conforme comentado, na metodologia, a temperatura do ensaio realizado com o viscosímetro LVDV-II+ foi de $5^{\circ} \mathrm{C}$, pois havia problemas na faixa de medição do equipamento. Diminuindo-se a temperatura do líquido a viscosidade aumenta e, mesmo assim o comportamento do fluido permanece Newtoniano. Porém, para a simulação numérica precisa-se do valor da viscosidade dinâmica na temperatura do ensaio no leito arterial caudal $\left(37^{\circ} \mathrm{C}\right)$. Sendo assim, utilizou-se o viscosímetro Ubbelohde para a determinação da viscosidade à temperatura do ensaio. Esse viscosímetro é usado para o cálculo da viscosidade de fluidos Newtonianos e, se aplica, portanto ao PEG4000 (5000 ppm), conforme demonstrado acima.

A tabela 8.1 apresenta os dados gerais de calibração do viscosímetro Ubbelohde e da amostra. A tabela 8.2 apresenta os resultados da viscosidade cinemática da solução de PEG4000 juntamente com a solução de Krebs.

Tabela 8.1. Dados gerais sobre o viscosímetro e a solução analisada.

\begin{tabular}{|c|c|}
\hline Instrumento utilizado & Viscosímetro Capilar Cinemático (Ubbelohde) \\
\hline Calibre & 0C \\
\hline $\begin{array}{c}\text { Cte de calibração do instrumento } \\
\left(\mathrm{mm}^{2} / \mathrm{s}^{2}\right)\end{array}$ & $\mathbf{0 , 0 0 2 6 7 1 6}$ \\
\hline Amostra & Solução de Krebs+ PEG4000 (5000 ppm) \\
\hline
\end{tabular}


Tabela 8.2. Análise do valor absoluto da viscosidade cinemática da solução polimérica (PEG4000 - 5000 ppm) com a adição da solução de Krebs.

\begin{tabular}{|c|c|c|c|c|}
\hline & \multicolumn{2}{|c|}{ Tempo escoamento } & Tempo total & Visc. Cinemática \\
\hline Leitura & $(\mathbf{m i n})$ & $(\mathbf{s})$ & $(\mathbf{s})$ & $\left(\mathbf{1 0}^{-\mathbf{6}} \mathbf{m}^{\mathbf{2}} \mathbf{s}\right)$ \\
\hline 1 & 4 & 40,61 & 280,61 & 0,750 \\
\hline 2 & 4 & 40,09 & 280,09 & 0,748 \\
\hline 3 & 4 & 40,42 & 280,42 & 0,749 \\
\hline 4 & 4 & 40,44 & 280,44 & 0,749 \\
\hline 5 & 4 & 40,09 & 280,09 & 0,748 \\
\hline 6 & 4 & 40,32 & 280,32 & 0,749 \\
\hline
\end{tabular}

Considerando que o valor da densidade da solução polimérica (PEG4000 - 5000 ppm) juntamente com a solução de Krebs é de $1000 \mathrm{~kg} / \mathrm{m}^{3}$, a viscosidade dinâmica pode ser calculada através da relação entre a viscosidade cinemática e da densidade conforme a equação (8.1):

$$
\mu=v * \rho
$$

onde $\mu$ é a viscosidade dinâmica (Pa.s), $v$ é a viscosidade cinemática $\left(\mathrm{m}^{2} / \mathrm{s}\right)$ e $\rho$ é a densidade do fluido, logo o valor da viscosidade dinâmica é 0,75 mPa.s. Esse valor será considerado no modelo numérico.

\subsubsection{Poliacrilamida}

Conforme comentado no item 7.1, a análise da viscosidade para a Poliacrilamida 1340S e 1822S foi realizada para diferentes concentrações poliméricas: 5, 10, 30, 60, 75 e $100 \mathrm{ppm}$ a temperatura de $25^{\circ} \mathrm{C}$. As figuras $8.3 \mathrm{~A}$ e B apresentam as relações entre as tensões de cisalhamento e as taxas de deformação para as soluções poliméricas de poliacrilamida $1340 \mathrm{~S}$ e $1822 \mathrm{~S}$ com concentração de 5 e $10 \mathrm{ppm}$, respectivamente, e comparando-se os seus comportamentos com o da água destilada. 

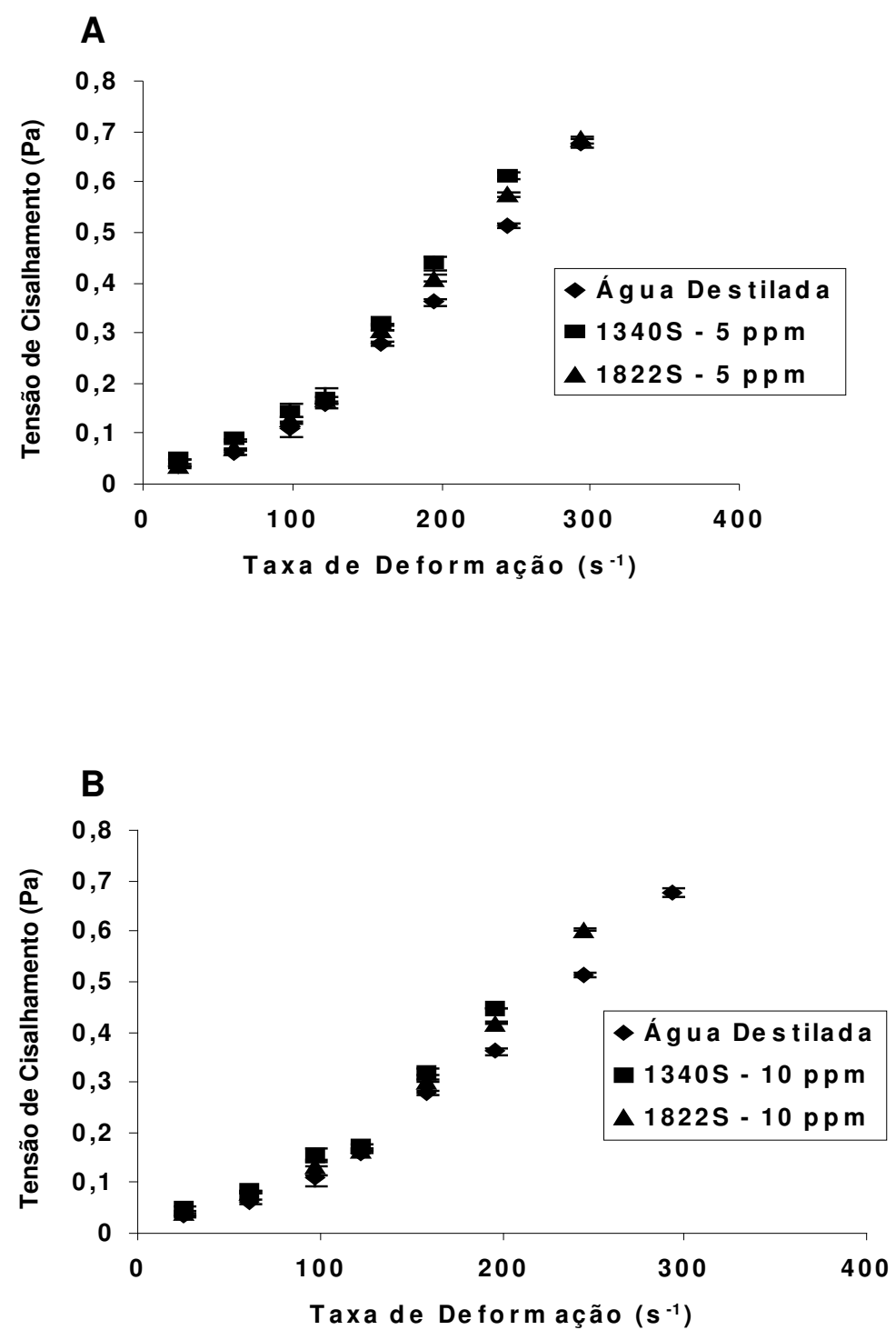

Figura 8.3. Tensão de cisalhamento versus taxa de deformação para as soluções da poliacrilamida $1340 \mathrm{~S}$ e 1822S: A - 5 ppm e B - 10 ppm, comparando-se com o comportamento da água destilada.

A figura 8.4 apresenta as relações entre as tensões de cisalhamento e as taxas de deformações para as soluções poliméricas de poliacrilamida $1340 \mathrm{~S}$ e $1822 \mathrm{~S}$ com as concentrações de 30, 60, 75 e 100 ppm. 

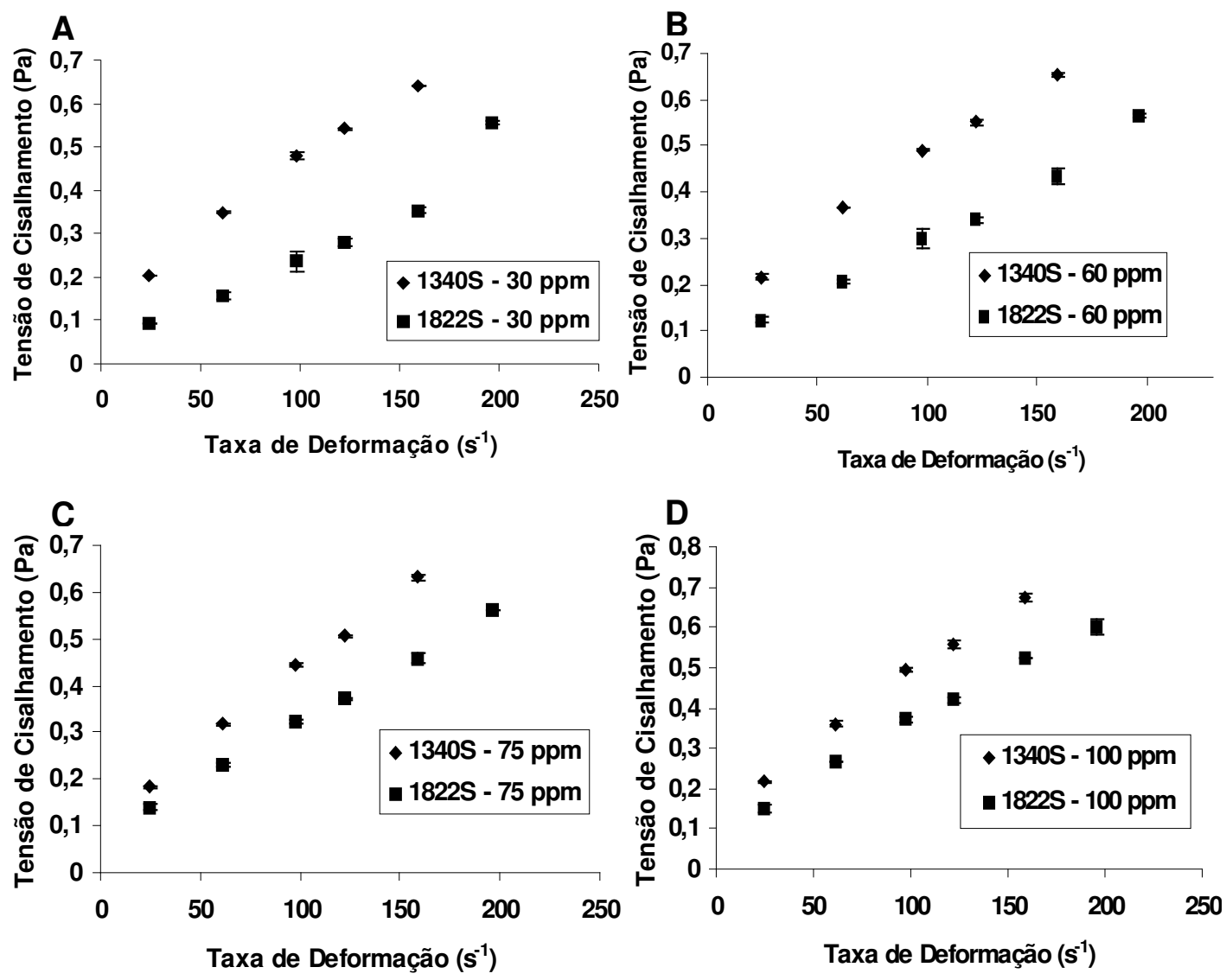

Figura 8.4. Tensão de cisalhamento versus taxa de deformação para as soluções da poliacrilamida 1340S e 1822S: A - 30 ppm, B - 60 ppm, C - 75 ppm e D - 100 ppm.

As figuras 8.3 A e B mostram que as soluções de poliacrilamidas $1340 \mathrm{~S}$ e $1822 \mathrm{~S}$ cujas concentrações são 5 e 10 ppm, respectivamente, comportam-se como a água destilada, ou seja, o comportamento de fluido Newtoniano pode ser atribuído a essas soluções poliméricas nessas concentrações. As figuras 8.4 A, B, C e D mostram o comportamento das soluções poliméricas em diferentes concentrações, 30, 60, 75 e 100 ppm, respectivamente. No diagrama reológico, curva da poliacrilamida 1340S sempre aparece acima da curva da poliacrilamida $1822 \mathrm{~S}$ devido ao maior peso molecular. Extrapolando os dados dessas curvas para atingir o eixo das ordenadas, percebe-se que esta não cruzará o eixo das ordenadas no zero, caracterizando um comportamento de fluido não-Newtoniano.

As figuras 8.5 e 8.6 mostram o comportamento do fluxo para água destilada e para a solução polimérica das poliacrilamidas $1822 \mathrm{~S}$ e $1340 \mathrm{~S}$ para diferentes concentrações: 5, 10, 30, 60, 75 e 100 ppm. 


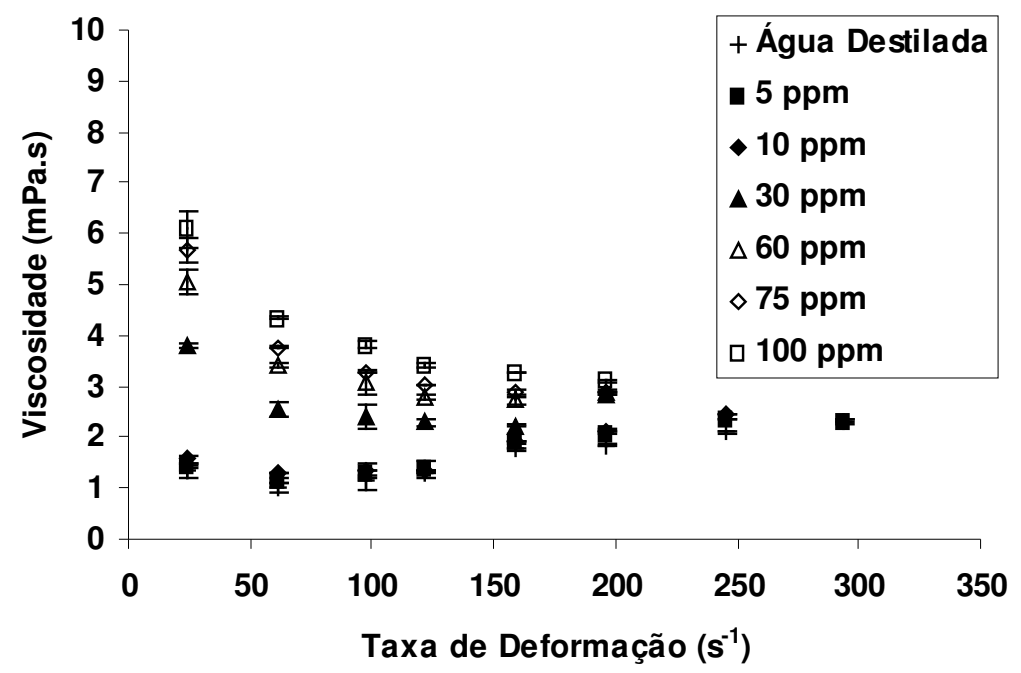

Figura 8.5. Viscosidade versus taxa de deformação para a solução da poliacrilamida $1822 S$ e para água destilada.

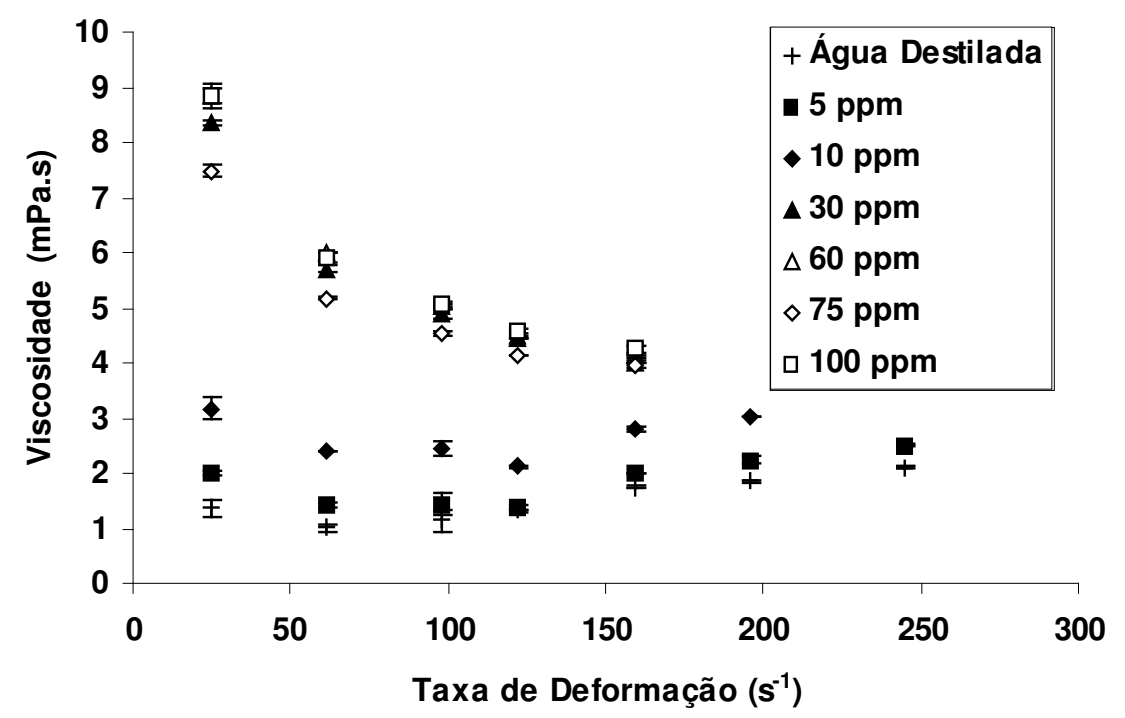

Figura 8.6. Viscosidade versus taxa de deformação para a solução da poliacrilamida 1340 s e para água destilada.

O comportamento da água destilada e das soluções poliméricas das poliacrilamidas $1822 \mathrm{~S}$ e $1340 \mathrm{~S}$ para concentrações de 5 e 10 ppm é semelhante, podendo-se caracterizar o comportamento dessas soluções poliméricas como de um fluido Newtoniano. Já para as maiores concentrações essa conclusão não pode ser feita. Percebe-se para as maiores concentrações, acima de 30 ppm, o comportamento de um 
fluido não-newtoniano. Tal comportamento pode ser atribuído a um comportamento de um fluido pseudoplástico. Pois, o que caracteriza esse tipo de fluido é a diminuição do valor da viscosidade com o aumento da taxa de deformação e, esse comportamento está apresentado de forma bastante clara nos resultados das figuras 8.5 e 8.6. Os valores de viscosidade obtidos para as soluções poliméricas da poliacrilamida 1340S são maiores do que aqueles obtidos para as soluções poliméricas da poliacrilamida 1822S. Essa diferença pode ser atribuída ao maior peso molecular da poliacrilamida 1340S. A partir dos resultados apresentados acima, pode-se concluir que as soluções poliméricas das poliacrilamidas $1822 \mathrm{~S}$ e $1340 \mathrm{~S}$ para as concentrações de 5 e 10 ppm tem comportamento de fluidos Newtonianos.

\subsection{Bancada experimental da EPUSP}

\subsubsection{Comparação entre a função ventricular e o simulador hidrodinâmico}

Conforme comentado no item 7.4.1, novas adaptações foram realizadas na bancada experimental da EPUSP durante o desenvolvimento desse trabalho (figura 8.7). Os seguintes dispositivos foram inseridos na bancada: um conversor $\mathrm{CA} / \mathrm{CC}$ para controlar o motor de corrente contínua ( 1 ); um dispositivo guia para alinhar a carga do pistão axialmente, diminuindo o esforço vertical sobre a câmara do pistão ( 2 ); a distância entre a unidade de bombeamento e a seção de teste foi aumentada para permitir o desenvolvimento do escoamento ( 3 ). 


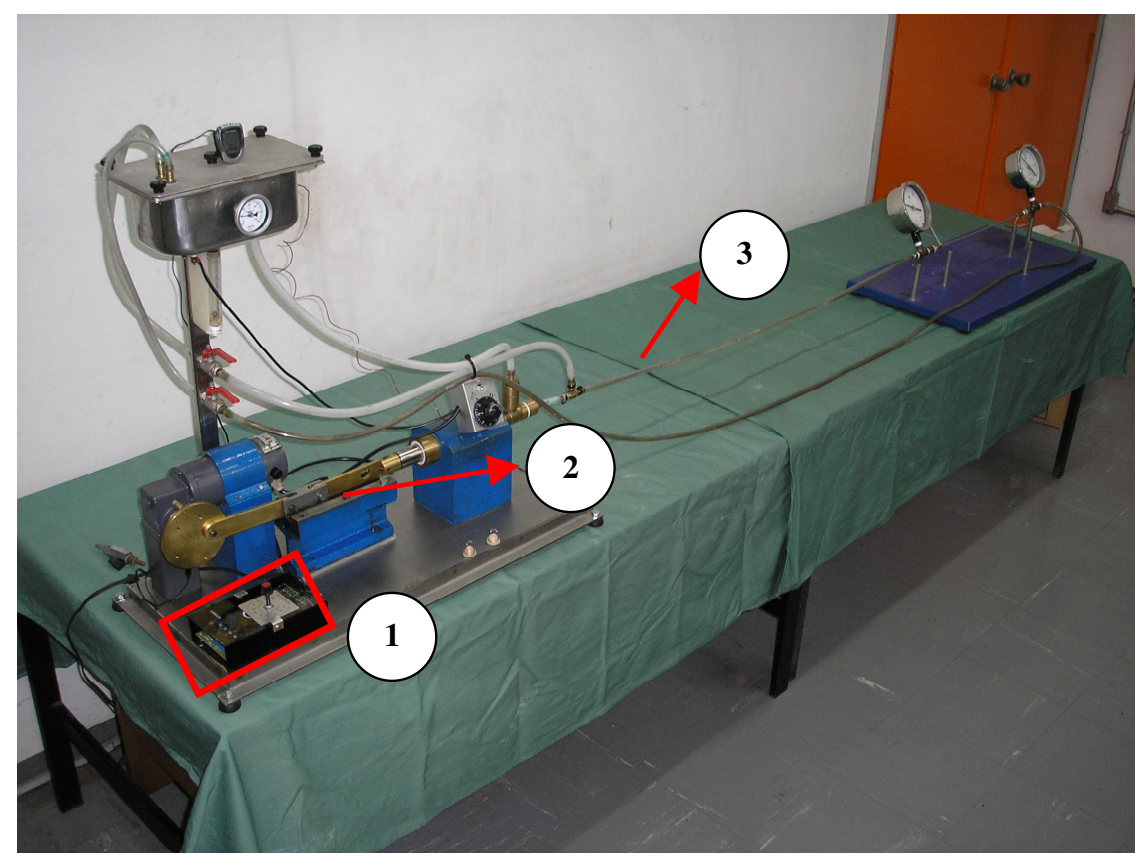

Figura 8.7. Simulador hidrodinâmico para estudos in vitro do sistema cardiovascular. 1 - conversor CA/CC; 2 - dispositivo guia; 3 - tubo de silicone.

O princípio de funcionamento do simulador hidrodinâmico é baseado na função ventricular (Figura 8.8). Inicialmente o átrio esquerdo recebe o sangue oxigenado que retorna do pulmão, através da veia pulmonar, direcionando-o para o ventrículo esquerdo. Nesse momento a válvula mitral está aberta permitindo o enchimento desse ventrículo. Por outro lado, a válvula aórtica está fechada, pois a pressão dentro do ventrículo ainda não é suficiente para ultrapassar a pressão na artéria aorta. Quando a pressão ventricular torna-se maior que a pressão na artéria aorta, a válvula aórtica abrese, permitindo o fluxo sangüíneo para a artéria aorta e a válvula mitral fecha-se não permitindo o retorno do fluxo para o átrio (Schauf et al., 1993). Tem-se assim o ciclo sistólico-diastólico do sistema circulatório. 


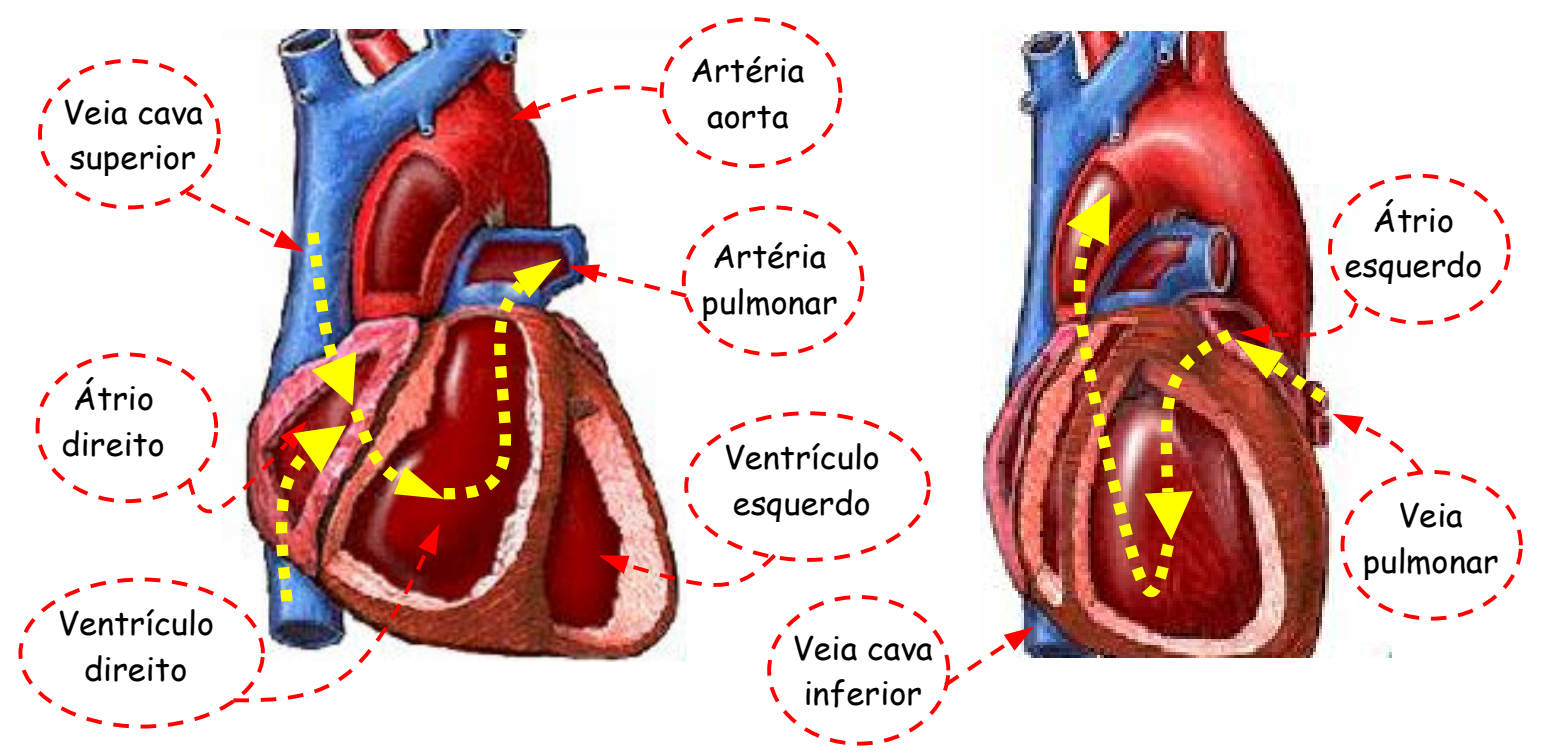

Figura 8.8 Representação das cavidades do coração, das artérias e veias (em vermelho) juntamente com o caminho percorrido pelo sangue durante o ciclo sistólicodiastólico (em amarelo).

O simulador hidrodinâmico tenta representar em semelhança esse ciclo. Inicialmente o fluido de trabalho enche o compartimento do pistão (ventrículo esquerdo), que nesse momento está admitindo o fluido de trabalho vindo do reservatório (átrio esquerdo) que corresponde à fase de enchimento do ventrículo, fase diastólica. Essa etapa ocorre porque a pressão no reservatório é maior do que a pressão na câmara do pistão e, dessa forma a válvula 1 (válvula mitral) está aberta permitindo a passagem do fluido de trabalho para o compartimento do pistão (ventrículo). Concomitantemente, a pressão no sistema é maior do que a pressão dentro do pistão e, por esse motivo a válvula 2 (valvular aórtica) está fechada não permitindo a passagem do fluido de trabalho para o sistema. Quando a pressão dentro da câmara do pistão torna-se maior do que a pressão do sistema, a válvula 2 (válvula aórtica) abre-se permitindo o fluido de trabalho escoar para o sistema (fase sistólica). Assim, o ciclo sistólico-diastólico no simulador hidrodinâmico está completo (Figura 8.9). Todavia, o objetivo do simulador hidrodinâmico não é a reprodução em semelhança do fluxo através das câmaras cardíacas, mas sim, a simulação do escoamento pulsátil através do sistema vascular periférico. 


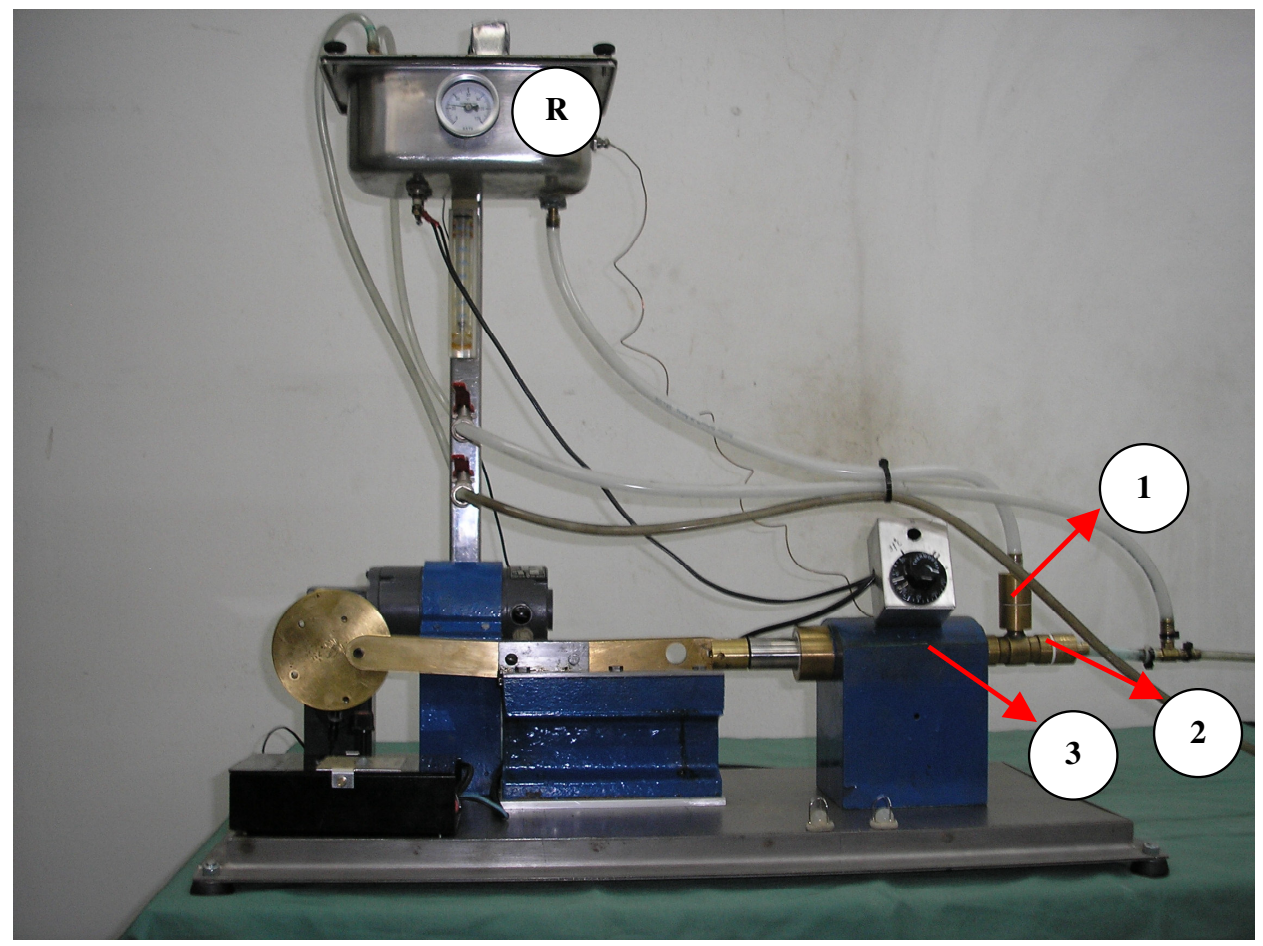

Figura 8.9. Unidade central de bombeamento do simulador hidrodinâmico para estudos in vitro do sistema cardiovascular. $R$ - reservatório; 1 e 2 - válvulas unidirecionais; 3 - câmara do pistão.

\subsubsection{Redução de arrasto nos tubos de silicone com e sem estenose e em tubos capilar de látex e de silicone}

Conforme comentado, no item 7.4.5, a redução de arrasto é calculada através das medições dos diferenciais de pressões obtidos na presença e ausência dos polímeros estudados nesse trabalho. Tanto a poliacrilamida quanto o PEG4000 não apresentaram redução de arrasto nos tubos de silicone com e sem estenoses (diâmetro-10 mm). Esse fato foi atribuído ao baixo valor do número de Reynolds atingido para essas condições: $8 \times 10^{3}$.

Em seguida, foram trocados os tubos com ou sem estenoses por um tubo capilar de látex. Através dessa troca diminuímos a rigidez dos tubos, aumentamos o seu comprimento em torno de 4,5 vezes e diminuímos o seu diâmetro em torno de 3 vezes (diâmetro - $3 \mathrm{~mm}$ ). Com a diminuição do diâmetro, mantendo a mesma vazão, além da diminuição da rigidez dos tubos, o número de Reynolds médio (definido a partir da vazão média), para a rotação de $90 \mathrm{rpm}$, atingiu valores da ordem de $2 \times 10^{4}$. Tanto para os tubos de silicone com e sem estenose como para o tubo capilar de látex as 
concentrações dos polímeros utilizadas chegaram a valores de $100 \mathrm{ppm}$. Para o PEG4000, o valor de concentração atingiu valores da ordem de 5000 ppm. Mais uma vez, o fenômeno da redução de arrasto não ocorreu, mesmo para essa faixa de número de Reynolds.

Uma nova mudança foi feita, dessa vez foi trocado o tubo capilar de látex por outro tubo capilar de silicone com as mesmas dimensões do tubo de látex, porém com uma maior rigidez. $\mathrm{O}$ aumento da rigidez elevou bastante a resistência ao escoamento. Esse fato pode ser visto através do número de Reynolds máximo alcançado nessa fase: $1,3 \times 10^{4}$. Para essa condição, o fenômeno da redução de arrasto ocorreu para as poliacrilamidas, porém para o PEG4000 isto não ocorreu, conforme pode ser visto pelos gráficos apresentados a seguir. Assim, o Polyox WSR-301, cuja estrutura química é semelhante a do PEG4000, porém o peso molecular é da ordem de mil vezes maior, foi inserido no escoamento, analisado-se o seu efeito redutor de arrasto.

A figura 8.10 apresenta as curvas do diferencial de pressão x número de Reynolds para diferentes concentrações poliméricas da poliacrilamida $1822 \mathrm{~S}$.

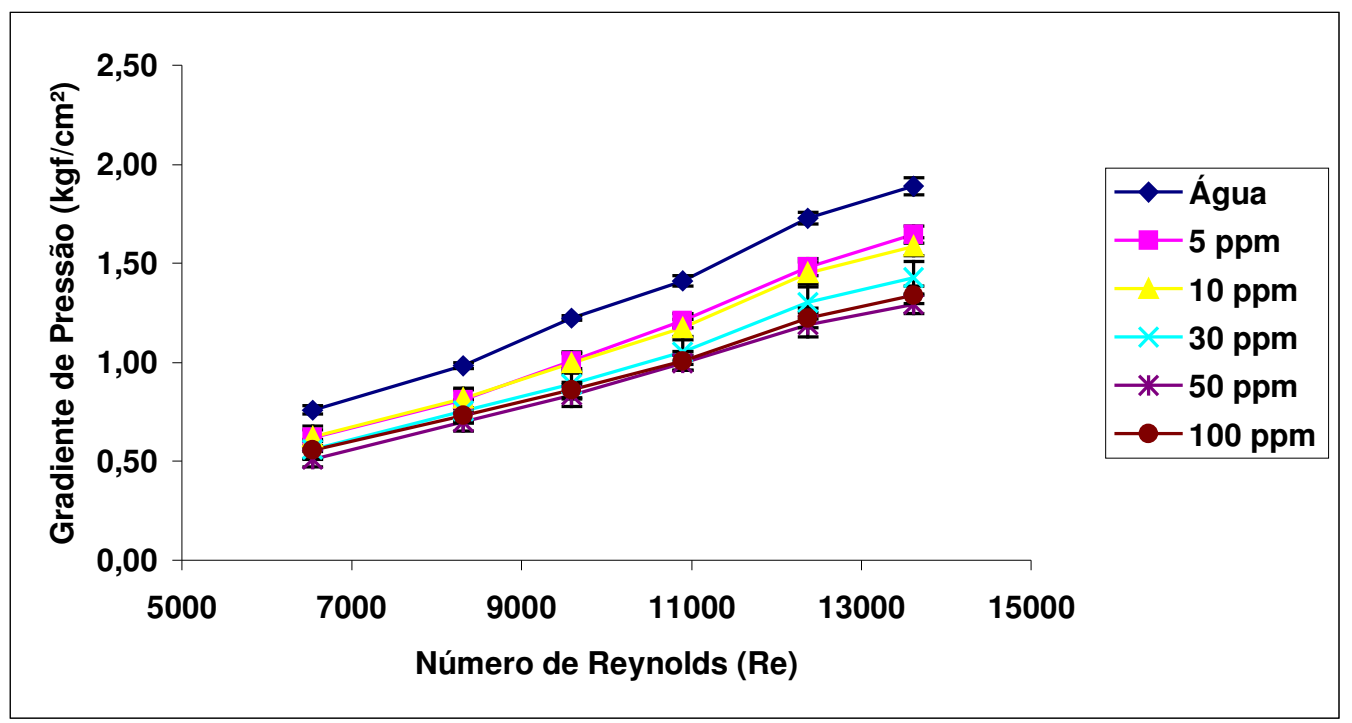

Figura 8.10. Curva do gradiente de pressão x número de Reynolds no tubo capilar de silicone para diferentes concentrações poliméricas da poliacrilamida $1822 \mathrm{~S}$.

Nessa figura, percebe-se um aumento crescente do gradiente de pressão com o aumento do número de Reynolds de forma linear. Um maior gradiente de pressão ocorre para água, enquanto que na presença do polímero, há um menor gradiente de pressão, mostrando uma diminuição na resistência ao escoamento. Com o incremento do polímero na água, ou seja, com o aumento da concentração polimérica tem-se uma 
menor resistência ao escoamento. Essa diminuição da resistência atinge um limite entre a faixa de 50 a $100 \mathrm{ppm}$.

A figura 8.11 apresenta a curva do gradiente de pressão versus número de Reynolds para diferentes concentrações poliméricas da poliacrilamida 1340S. Com o aumento do número de Reynolds há um aumento no gradiente de pressão cujo valor diminui com o aumento da concentração polimérica. Essa diminuição do gradiente de pressão mostra a diminuição na resistência ao escoamento. Valores de concentração polimérica acima de $30 \mathrm{ppm}$, praticamente, não diminuem o gasto de energia, atingindose assim um valor limite de diminuição da resistência ao escoamento.

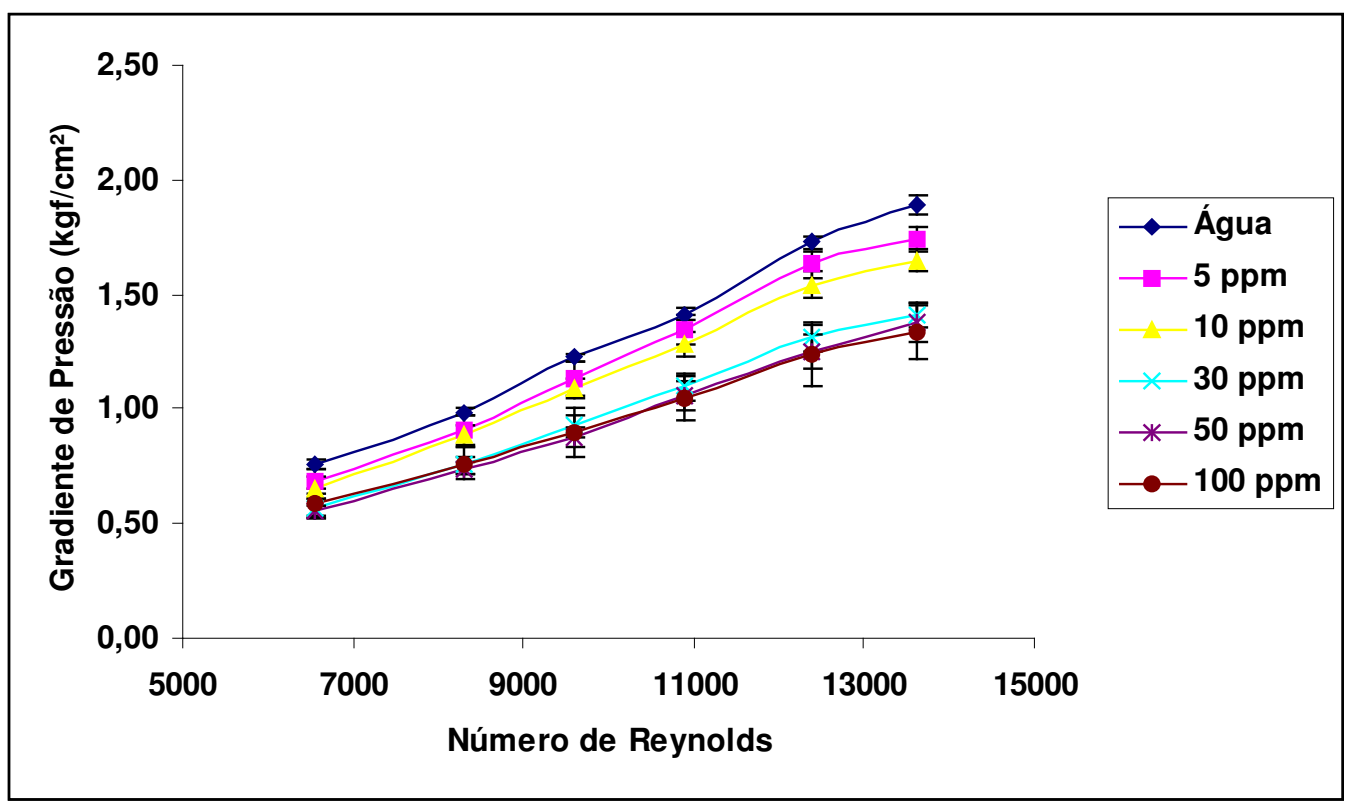

Figura 8.11. Curva do gradiente de pressão x número de Reynolds no tubo capilar de silicone para diferentes concentrações poliméricas da poliacrilamida $1340 \mathrm{~S}$.

A figura 8.12 apresenta as curvas do gradiente de pressão versus número de Reynolds para diferentes concentrações poliméricas do Polyox WSR-301. Com o aumento do número de Reynolds há um aumento no gradiente de pressão, cujo valor diminui com o aumento da concentração polimérica. Essa diminuição no gradiente de pressão ocorre de maneira mais brusca para as concentrações de 5 e $10 \mathrm{ppm}$, enquanto para as maiores concentrações de 30 a 100 ppm, ocorre de forma menos acentuada. Para valores de concentração polimérica acima de 30 ppm, não há diminuição no gradiente de pressão atingindo-se assim um valor limite nessa concentração. 


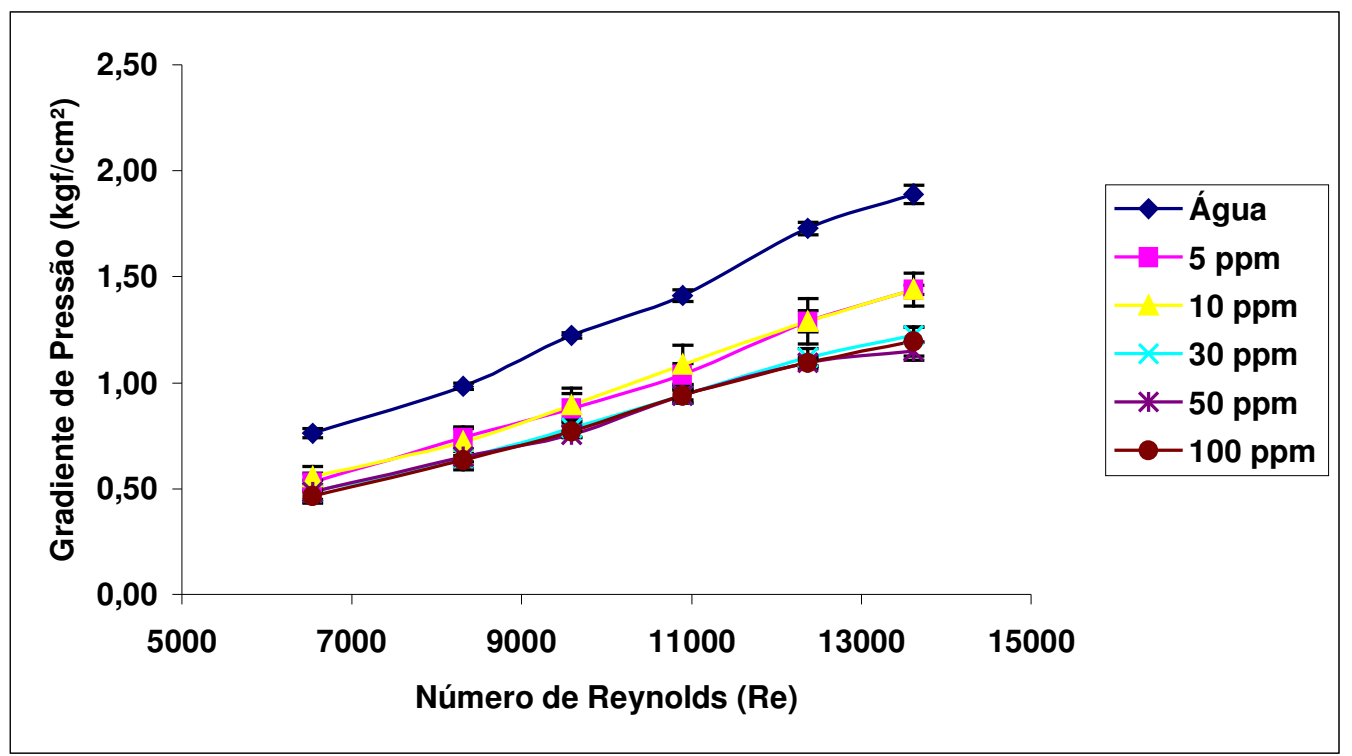

Figura 8.12. Curva do gradiente de pressão x número de Reynolds no tubo capilar de silicone para diferentes concentrações poliméricas do Polyox WSR-301.

A figura 8.13 apresenta as curvas do gradiente de pressão versus número de Reynolds para as concentrações poliméricas dos polímeros: poliacrilamida 1822S, poliacrilamida 1340S e para o Polyox WSR-301 na concentração de 5 ppm. Essa concentração polimérica apresentou comportamento de fluido newtoniano.

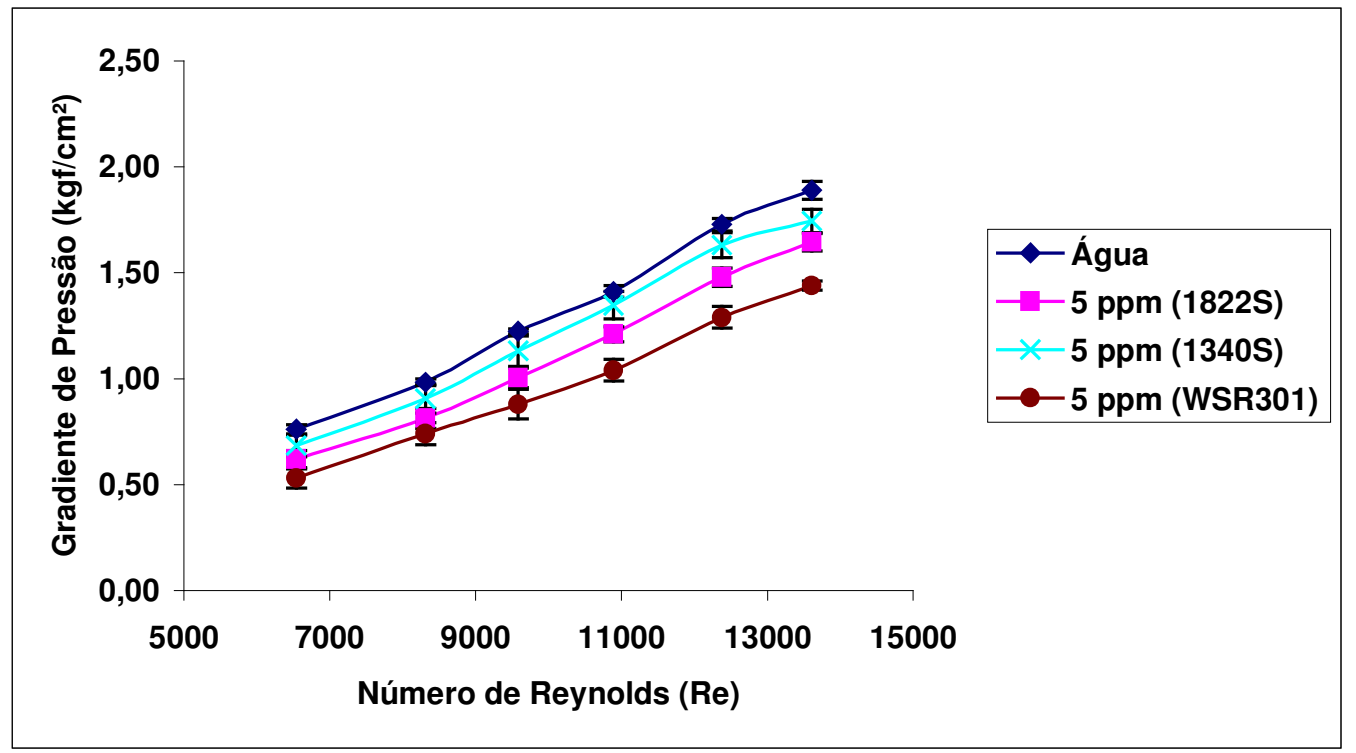

Figura 8.13. Curva do gradiente de pressão x número de Reynolds no tubo capilar de silicone para concentração polimérica de $5 \mathrm{ppm}$ para os polímeros: poliacrilamidas $1822 S$ e 1340 S e Polyox WSR-301. 
Pode ser visto na figura 8.13 que para baixas concentrações poliméricas ( $5 \mathrm{ppm}$ ), há uma diminuição no gradiente de pressão. Essa diminuição é maior na presença do polímero Polyox WSR-301 do que na presença das poliacrilamidas 1822S e 1340S.

Para a maior concentração polimérica utilizada nesse trabalho (100 ppm), o Polyox WSR-301 apresenta menor valor para o gradiente de pressão, enquanto que as poliacrilamidas apresentam maiores valores dos gradientes de pressão (figura 8.14).

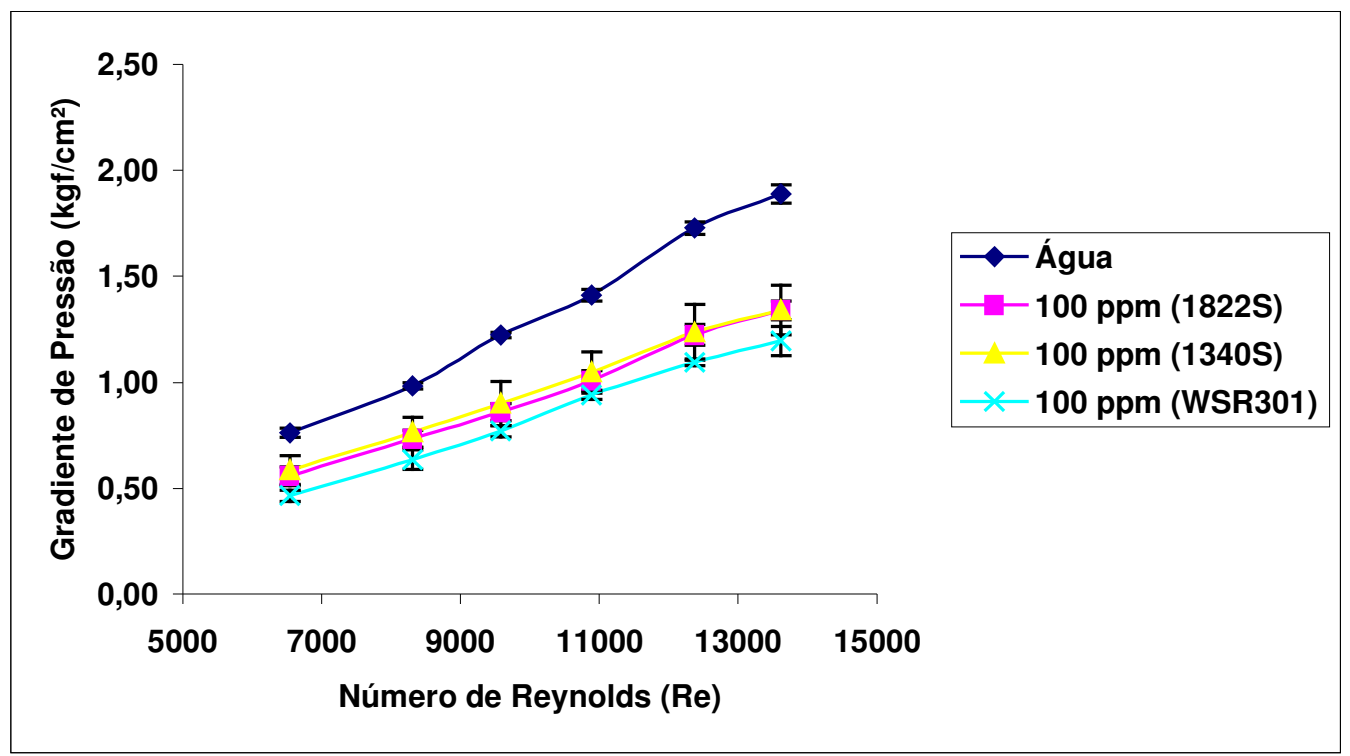

Figura 8.14. Curva do gradiente de pressão x número de Reynolds no tubo capilar de silicone para concentração polimérica de 100 ppm para os polímeros: poliacrilamidas $1822 S$ e 1340 s e Polyox WSR-301.

Os resultados apresentados a seguir mostram a redução de arrasto versus número de Reynolds cujos valores variam de 2350 até 13600. Essa faixa do número de Reynolds engloba desde a transição até o escoamento turbulento.

Na figura 8.15, tem-se os resultados da redução de arrasto para concentração polimérica de 5 ppm para os polímeros: poliacrilamidas 1822S e 1340S e para o polyox WSR-301. Para a faixa de transição do escoamento laminar para o turbulento, número de Reynolds entre 2300 e 4000, não há redução de arrasto e esse fato se estende até o número de Reynolds em torno de 6500. A partir desse valor do número de Reynolds, inicia-se o fenômeno da redução de arrasto. Os maiores valores de redução de arrasto ocorrem para o Polyox WSR-301, cujos valores médios estão em torno de 25\%, seguido da poliacrilamida $1822 \mathrm{~S}(14,8 \%)$ e da poliacrilamida $1340 \mathrm{~S}(6,3 \%)$. 


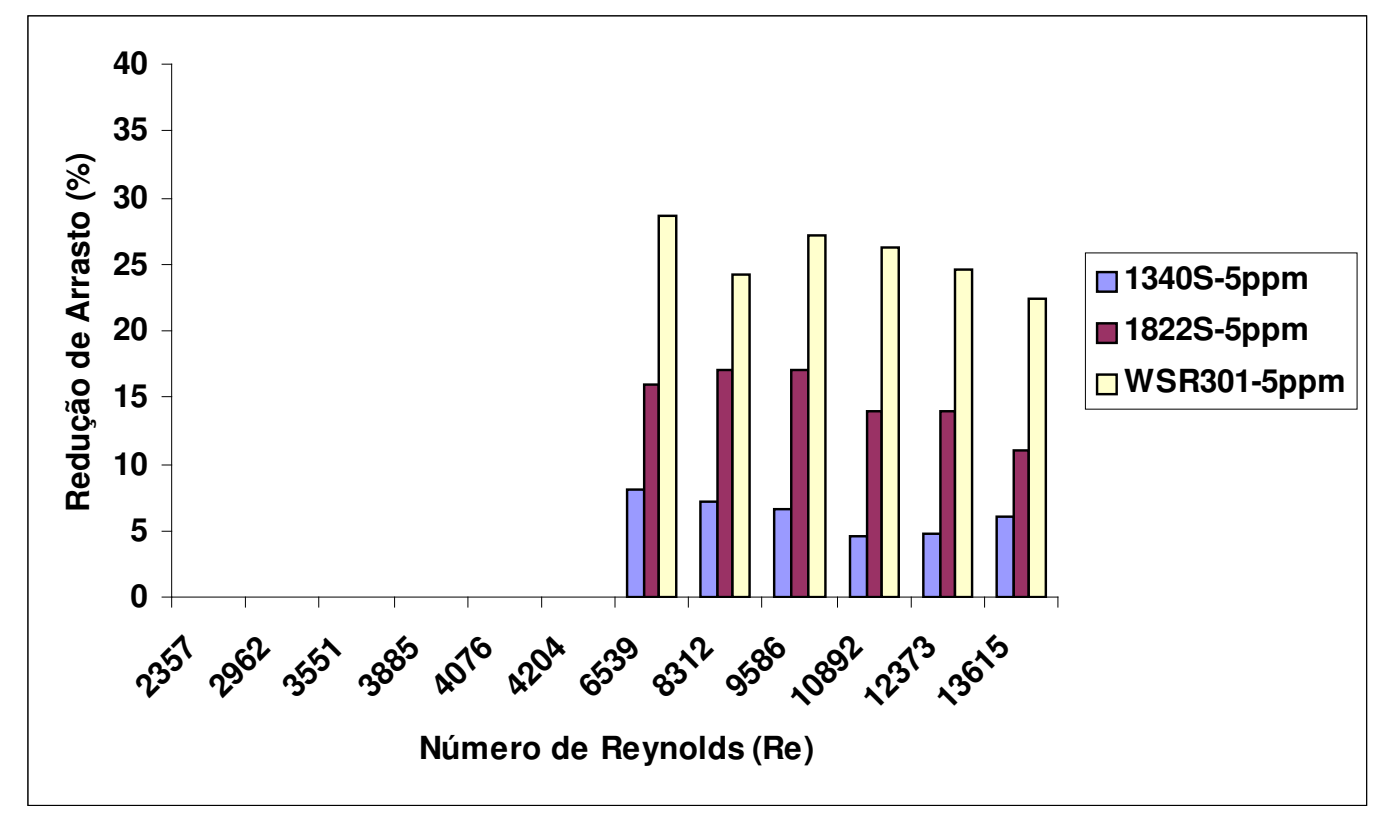

Figura 8.15. Redução de arrasto versus número de Reynolds para concentração polimérica de $5 \mathrm{ppm}$ para os polímeros: poliacrilamidas $1340 \mathrm{~S}$ e $1822 \mathrm{~S}$ e Polyox WSR-301.

A figura 8.16 apresenta a porcentagem de redução de arrasto versus número de Reynolds para as soluções poliméricas das poliacrilamidas 1822S, $1340 \mathrm{~S}$ e polyox WSR-301 para concentração de 30 ppm. Os valores da redução de arrasto praticamente se igualam para as poliacrilamidas $1822 \mathrm{~S}$ e $1340 \mathrm{~S}$ e o início da redução de arrasto ocorre para a faixa de transição do escoamento laminar para o turbulento $(\operatorname{Re} \approx 3000)$. Já para o polyox WSR-301, o início da redução de arrasto é retardado para valores de número de Reynolds da ordem de 4000. Outro fato que chama atenção na figura 8.15 é o valor médio da redução de arrasto para as poliacrilamidas $1822 \mathrm{~S}$ e $1340 \mathrm{~S}$, na faixa de transição do escoamento laminar para o turbulento, cujo valor está em torno de $10 \%$ e, esse valor é aumentado em média para $25 \%$ quando se tem escoamento turbulento. Enquanto para o polyox WSR-301, a faixa de redução de arrasto se restringe praticamente ao escoamento turbulento ( $34 \%$ de redução de arrasto). 


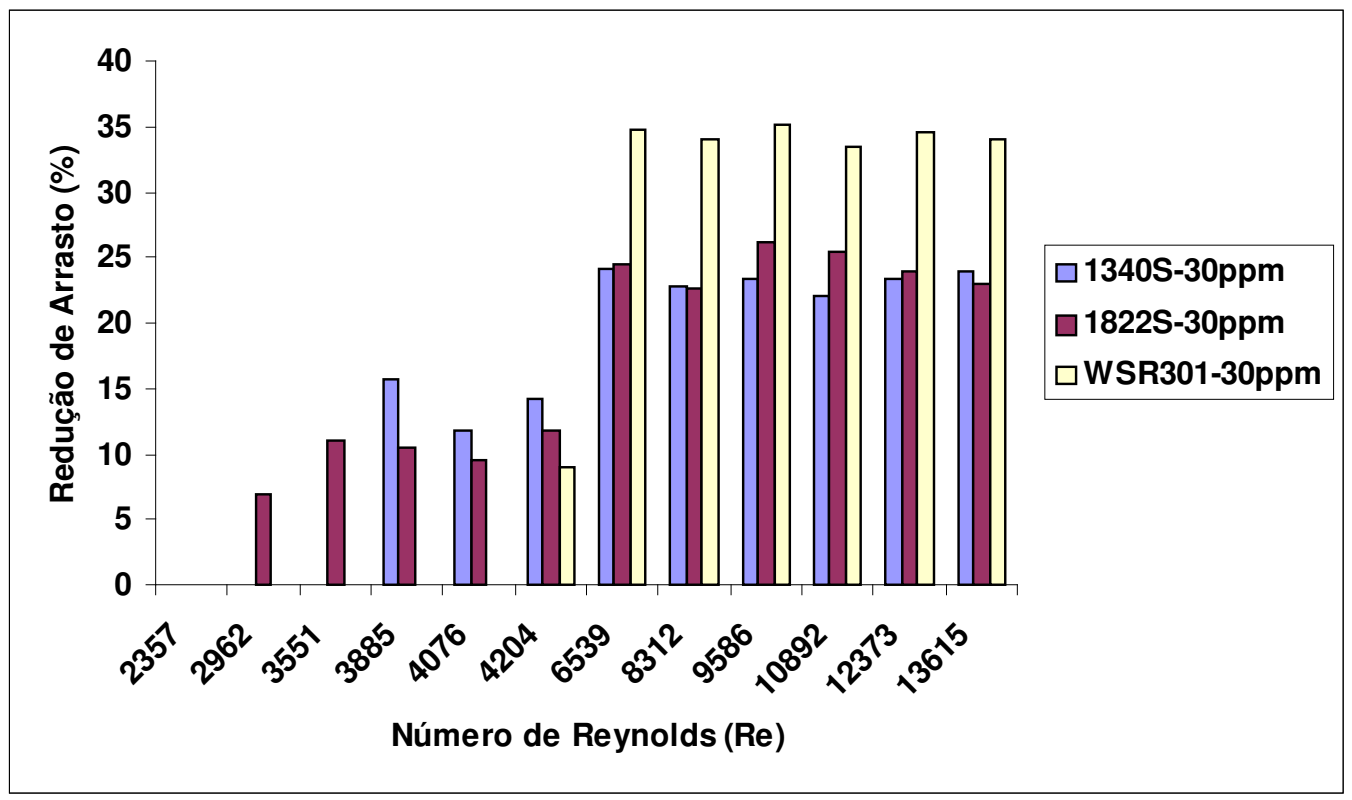

Figura 8.16. Redução de arrasto versus número de Reynolds para concentração polimérica de 30 ppm para os polímeros: poliacrilamidas $1340 \mathrm{~S}$ e $1822 \mathrm{~S}$ e Polyox WSR-301.

A figura 8.17 apresenta a redução de arrasto versus número de Reynolds para concentração polimérica de $100 \mathrm{ppm}$ para os polímeros: poliacrilamidas 1822S e 1340S e polyox WSR-301. Mais uma vez, tem-se os valores da redução de arrasto para as policarilamidas $1822 \mathrm{~S}$ e $1340 \mathrm{~S}$ praticamente igualados e iniciando o fenômeno da redução de arrasto para a faixa de transição do escoamento laminar para o turbulento $(\operatorname{Re} \approx 3000)$. Novamente, o polyox WSR-301 apresenta o início da redução no final da faixa de transição do escoamento laminar para o turbulento $(\operatorname{Re} \approx 4000)$. Os valores da redução de arrasto apresentados pelas poliacrilamidas $1822 \mathrm{~S}$ e $1340 \mathrm{~S}$ para a faixa de transição é da ordem de $17 \%$ e para a faixa turbulenta está em torno de $27,5 \%$, enquanto que para o polyox WSR-301, tem-se aproximadamente $35 \%$ de redução de arrasto dentro da faixa turbulenta. 


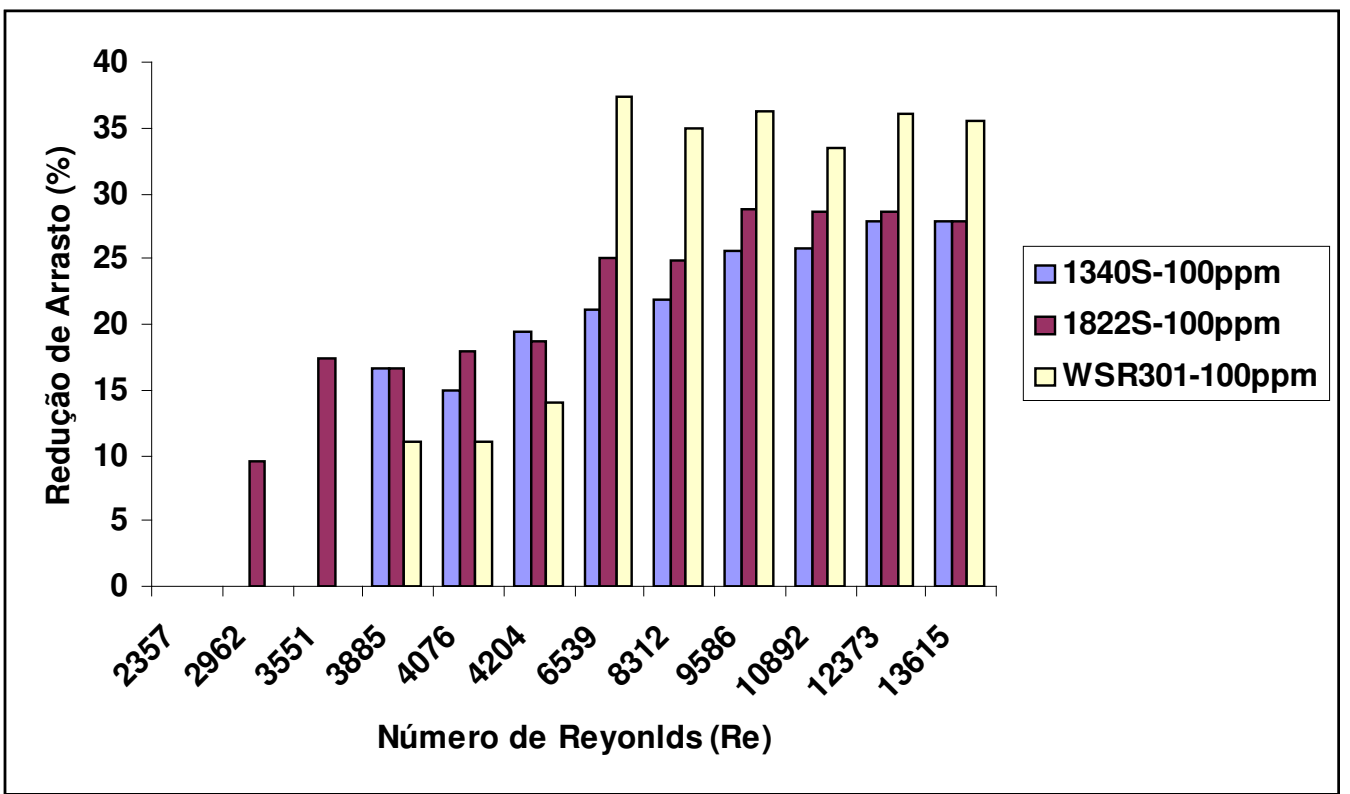

Figura 8.17. Redução de arrasto versus número de Reynolds para concentração polimérica de 100 ppm para os polímeros: poliacrilamidas $1340 S$ e $1822 S$ e Polyox WSR-301.

Conforme comentado anteriormente nesse item, o PEG4000 não apresentou o fenômeno da redução de arrasto em nenhuma das concentrações utilizadas nesse trabalho quando inseridos no escoamento em tubos rígidos. Paralelamente aos ensaios realizados, na bancada experimental da EPUSP, esse polímero estava sendo usado na bancada experimental do ICB em leitos arteriais caudais de ratos normotensos e hipertensos. Nessa bancada, o PEG4000 com concentração de 5000 ppm apresentou o fenômeno da redução de arrasto. Em seguida, são apresentados os resultados na bancada experimental do ICB.

\subsection{Bancada experimental do ICB-USP - Leitos arteriais caudais}

Inicialmente foi verificada a reatividade do leito arterial caudal dos ratos normotensos e hipertensos na presença de fluxo e, em seguida, foi verificada a ação das células endoteliais, do PEG4000 e da inibição dos vasodilatadores sobre a pressão de perfusão média (PPM). 


\subsubsection{Comprimento e diâmetro arterial caudal}

A figura 8.18 ilustra a medição do comprimento do leito arterial caudal. Para essa medição foram utilizadas quatro artérias de ratos normotensos (Wistar) e quatro artérias de ratos espontaneamente hipertensos (SHR). Os comprimentos das artérias não variaram muito apresentando valores da ordem de $110,53 \pm 30,78 \mathrm{~mm}$.

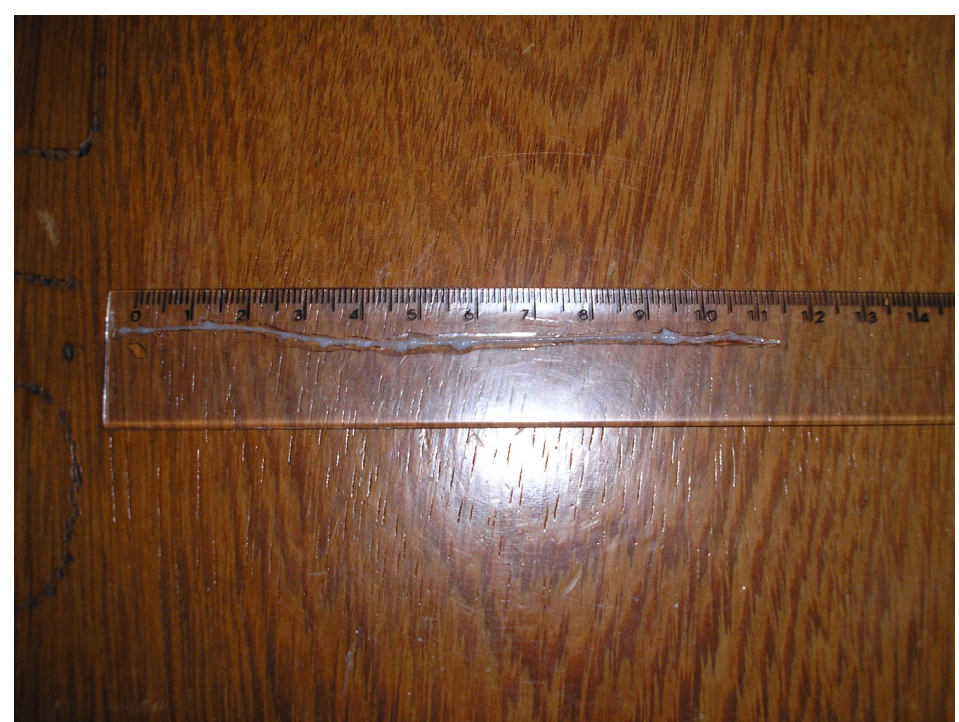

Figura 8.18. llustração da medição do comprimento da artéria caudal.

Inicialmente, tinha-se medido o diâmetro externo do leito arterial caudal sem a sua pressurização e foram obtidos os seguintes valores: 553,31 $\pm 70,56 \mu \mathrm{m}$ (proximal) e $263,87 \pm 20,63 \mu \mathrm{m}$ (distal). Após a pressurização e a medição do diâmetro interno, esses valores não variaram muito em relação ao diâmetro externo. Os valores estão apresentados na figura 8.19. Para a simulação numérica foram utilizados os valores dos diâmetros externos. Novas simulações foram realizadas para o diâmetro interno, mas não houve variação acentuada dos valores da tensão de cisalhamento. 


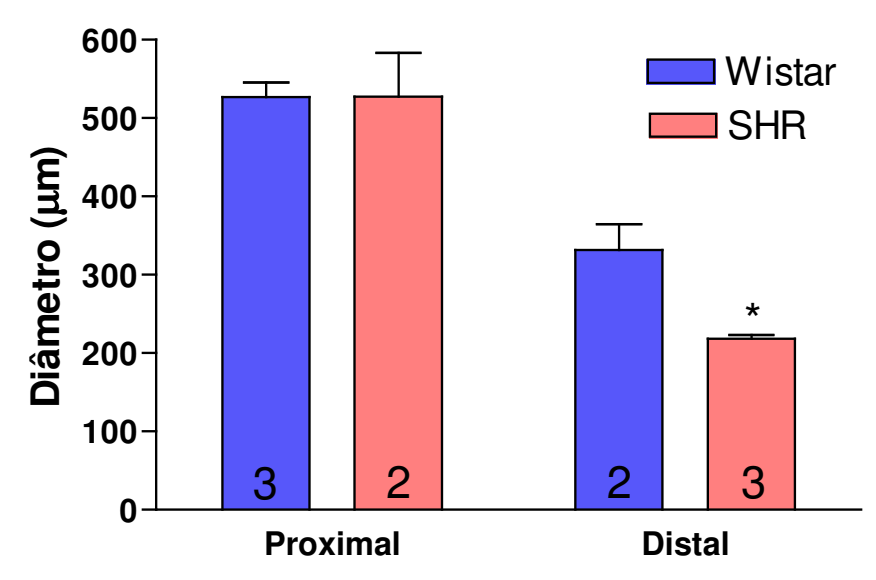

Figura 8.19. Diâmetros arteriais caudais proximais e distais de ratos normotensos (Wistar) e espontaneamente hipertensos (SHR). Teste t; $\mathrm{P}<0,05$ * vs Wistar.

A figura 8.20 ilustra as porções mediais do leito arterial caudal de um rato normotenso (Wistar). Pode ser visto nessa figura que ocorre uma diminuição do diâmetro interno da porção proximal para a porção distal e, ocorre um aumento na espessura de parede do vaso na porção distal quando comparada com a porção proximal. Isso ocorre devido à artéria caudal ser um vaso de transição entre condutância e resistência. Os vasos de condutância apresentam uma parede mais fina e calibre mais desenvolvido, enquanto que no vaso de resistência ocorre o inverso, ou seja, há maior espessura da parede e menor diâmetro interno.
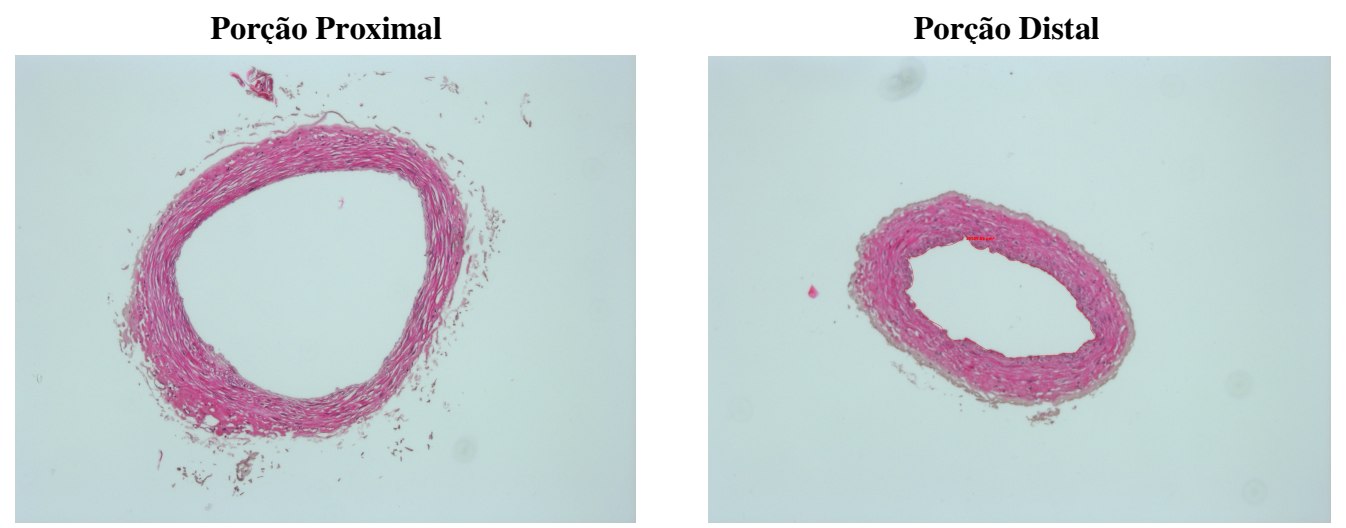

Figura 8.20. Variação do diâmetro interno e da espessura da parede do vaso nas porções proximais e distais de uma artéria de rato normotenso (aumento de 10x). 
Para uma visualização mais clara de alguns componentes da parede do vaso, um aumento foi utilizado na região próxima da parede conforme pode ser visto na figura 8.21 (aumento de 40x).

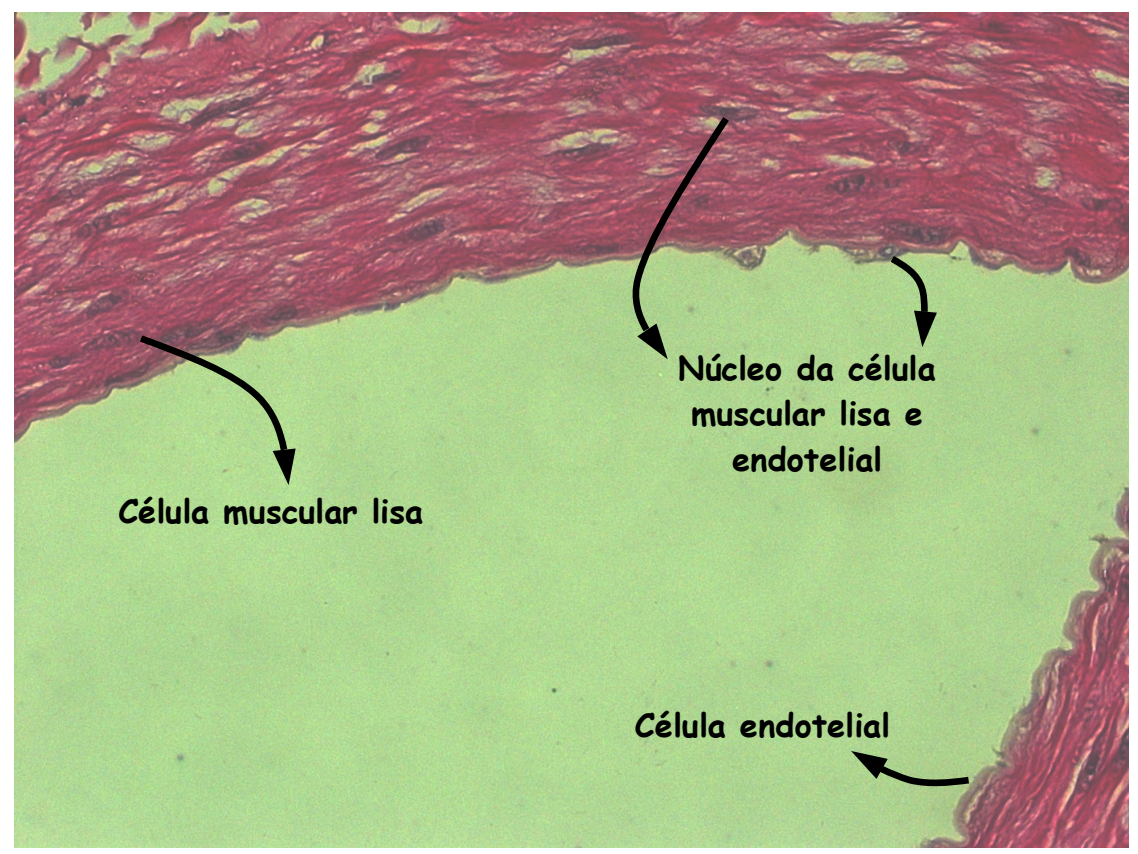

Figura 8.21. Alguns componentes da parede do vaso arterial caudal de um rato normotenso: célula endotelial e muscular (aumento de 40x).

\subsubsection{Avaliação da reatividade vascular do leito arterial caudal em resposta a mudança de fluxo}

A figura 8.22 apresenta a PPM versus fluxo para os leitos arteriais caudais dos ratos normotensos (Wistar) e espontaneamente hipertensos (SHR). Pode ser visto nessa figura que ocorre um aumento da PPM com o aumento do fluxo. Porém os valores da PPM são maiores para o SHR do que para o Wistar, mostrando a sua maior reatividade vascular. 


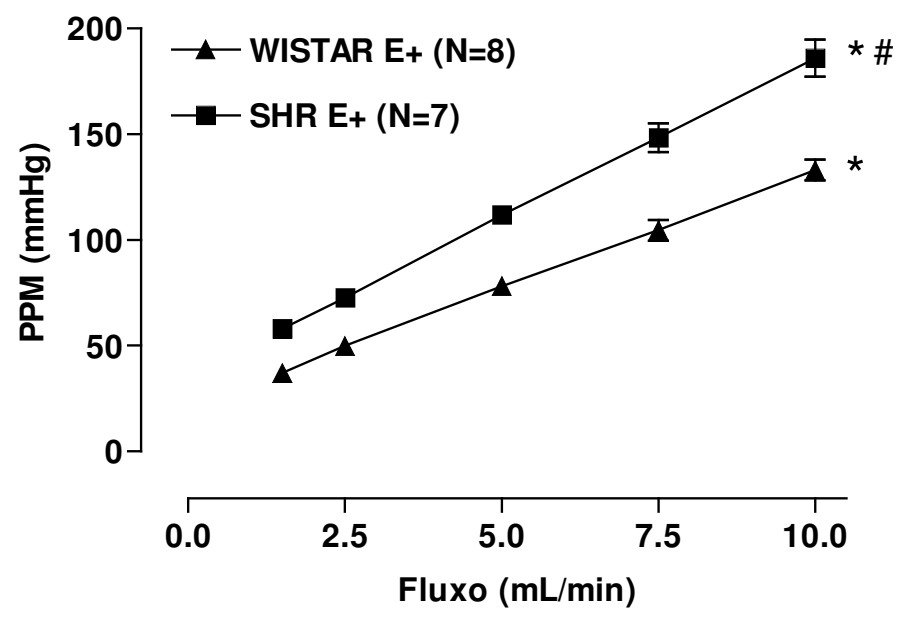

Figura 8.22. Curva de PPM $x$ fluxo em leitos arteriais caudais de ratos normotensos (Wistar) e espontaneamente hipertensos (SHR). ANOVA; $\mathrm{P}<0,05$ * vs fluxo; \# vs Wistar ( $\mathrm{N}$ representa o número de animais).

8.3.3 Avaliação do polietileno glicol (PEG4000) no leito arterial caudal em resposta as mudanças de fluxo.

A figura 8.23 apresenta a curva da PPM x fluxo para os ratos normotensos (Wistar) e espontaneamente hipertensos (SHR) na presença e ausência do PEG 4000 (5000 ppm).

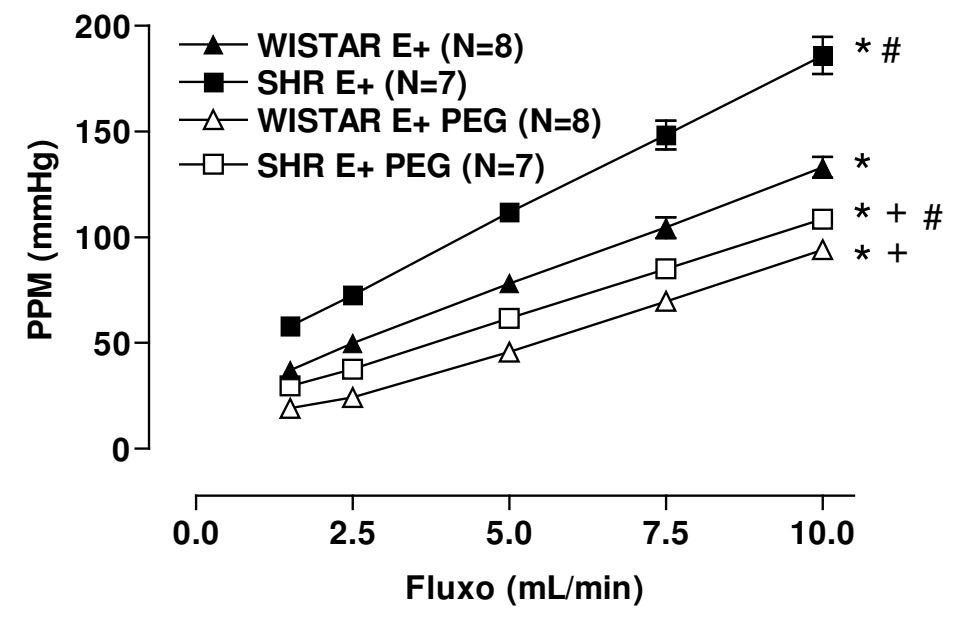

Figura 8.23. Curva de PPM x fluxo em leitos arteriais caudais de ratos normotensos (Wistar) e espontaneamente hipertensos (SHR) na presença e ausência de PEG. E+ indica presença das células endoteliais. ANOVA; $P<0,05^{*}$ vs fluxo; \# vs Wistar; + vs ausência de PEG.

Tanto na presença quanto na ausência do PEG4000, os valores da PPM em ambas as cepas aumentaram com o aumento do fluxo. Porém na presença do PEG4000, os valores 
da PPM são diminuídos mostrando a ação do PEG4000 em reduzir a resistência ao escoamento.

8.3.4 Avaliação da influência do endotélio, do óxido nítrico, do fator hiperpolarizante derivado do endotélio e das prostaglandinas sobre a ação da perfusão do polietileno glicol nos leitos arteriais caudais.

A figura 8.24 apresenta a PPM versus fluxo para o Wistar na presença (E+) e ausência (E-) do endotélio, bem como, sobre a ação da inibição dos vasodilatadores. Pode-se perceber nessa figura a participação do endotélio no controle da PPM em resposta a mudanças dos fluxos, pois na ausência das células endoteliais (E-), ocorre um aumento nos valores da PPM. Através da inibição do óxido nítrico pelo LNAME (LN), também, tem-se um discreto aumento nos valores da PPM em comparação a presença das células endoteliais (E+) sem a ação dos inibidores. Na presença da indometacina (INDO), o inibidor das prostaglandinas, também há um aumento nos valores da PPM, enquanto que na presença do tetraetilamônio (TEA) não há diferença nos valores da PPM em relação ao controle (E+). Dessa forma, tem-se principalmente a participação da prostaciclina na diminuição dos valores da PPM em resposta ao fluxo e de forma menos acentuada a participação do óxido nítrico, enquanto o EDHF parece não exercer influênica.

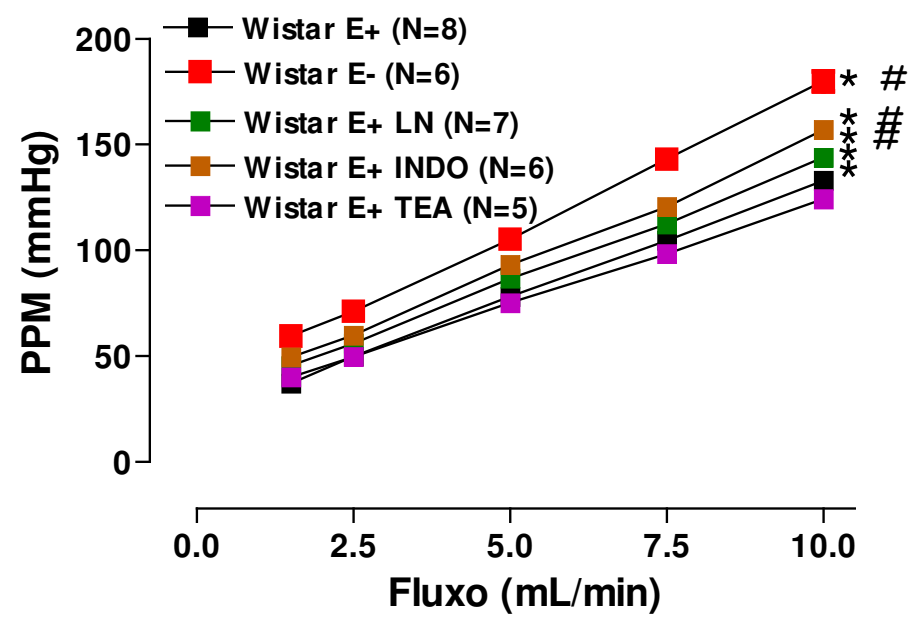

Figura 8.24. Curva de PPM x fluxo em leitos arteriais caudais de ratos normotensos (Wistar): com ( $E+)$ e sem (E-) endotélio, e após a infusão durante trinta minutos com LNAME (LN), indometacina (INDO) ou tetraetilamônio (TEA). ANOVA; $P<0,05$ * vs fluxo; \# vs $\mathrm{E}+$. 
Na figura 8.25, pode-se perceber que o endotélio não participa das respostas da PPM em relação ao fluxo, pois os valores da PPM, tanto para a curva SHR E+ quanto para SHR E-, são praticamente iguais. Outro efeito que pode ser analisado na figura 8.24 é a falta de participação do óxido nítrico no controle da PPM juntamente com o EDHF em termos estatísticos. Enquanto que, a ação da indometacina, inibidor das prostaglandinas, diminui os valores da pressão de perfusão média. Assim, tem-se a diminuição nos valores da PPM em resposta ao fluxo devido à ação da indometacina, inibindo a ação de prostanóides vasoconstritores.

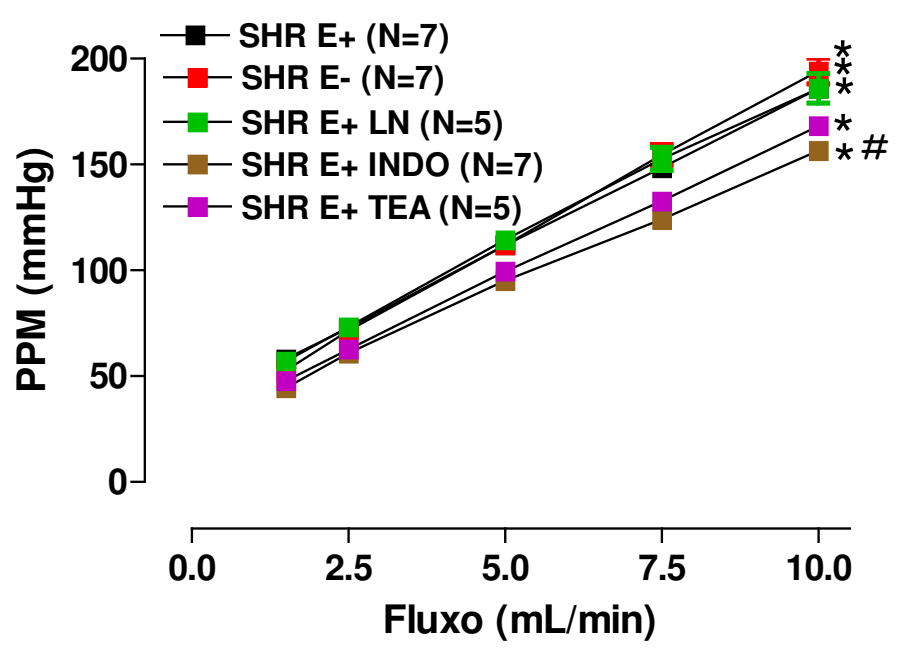

Figura 8.25. Curva de PPM $x$ fluxo em leitos arteriais caudais de ratos hipertensos (SHR): com ( $E+)$ e sem (E-) endotélio, e após a infusão durante trinta minutos com $L-$ NAME (LN), indometacina (INDO) ou tetraetilamônio (TEA). ANOVA; $P<0,05$ * vs fluxo; \# vs $E_{+}$.

As figuras 8.26 A, B, C e D apresentam a PPM versus fluxo para os animais Wistar na presença e ausência do endotélio, bem como, a ação dos inibidores dos vasodilatadores e do PEG4000. Na figura 8.26 A, conforme comentado anteriormente, percebe-se a participação das células endoteliais modulando negativamente o aumento da PPM. A presença do PEG4000 causa diminuição nos valores da PPM na presença e ausência do endotélio. Nas figuras $8.26 \mathrm{~B}, \mathrm{C}$ e D, as quais apresentam a ação dos inibidores do óxido nítrico, das prostaglandinas e dos canais de potássio ativados por cálcio, o PEG4000 normaliza as curvas de PPM versus fluxo. A partir dos comentários feitos acima, percebe-se que o PEG4000 está diminuindo a resistência ao escoamento independentemente da presença do endotélio e dos inibidores dos vasodilatadores. 

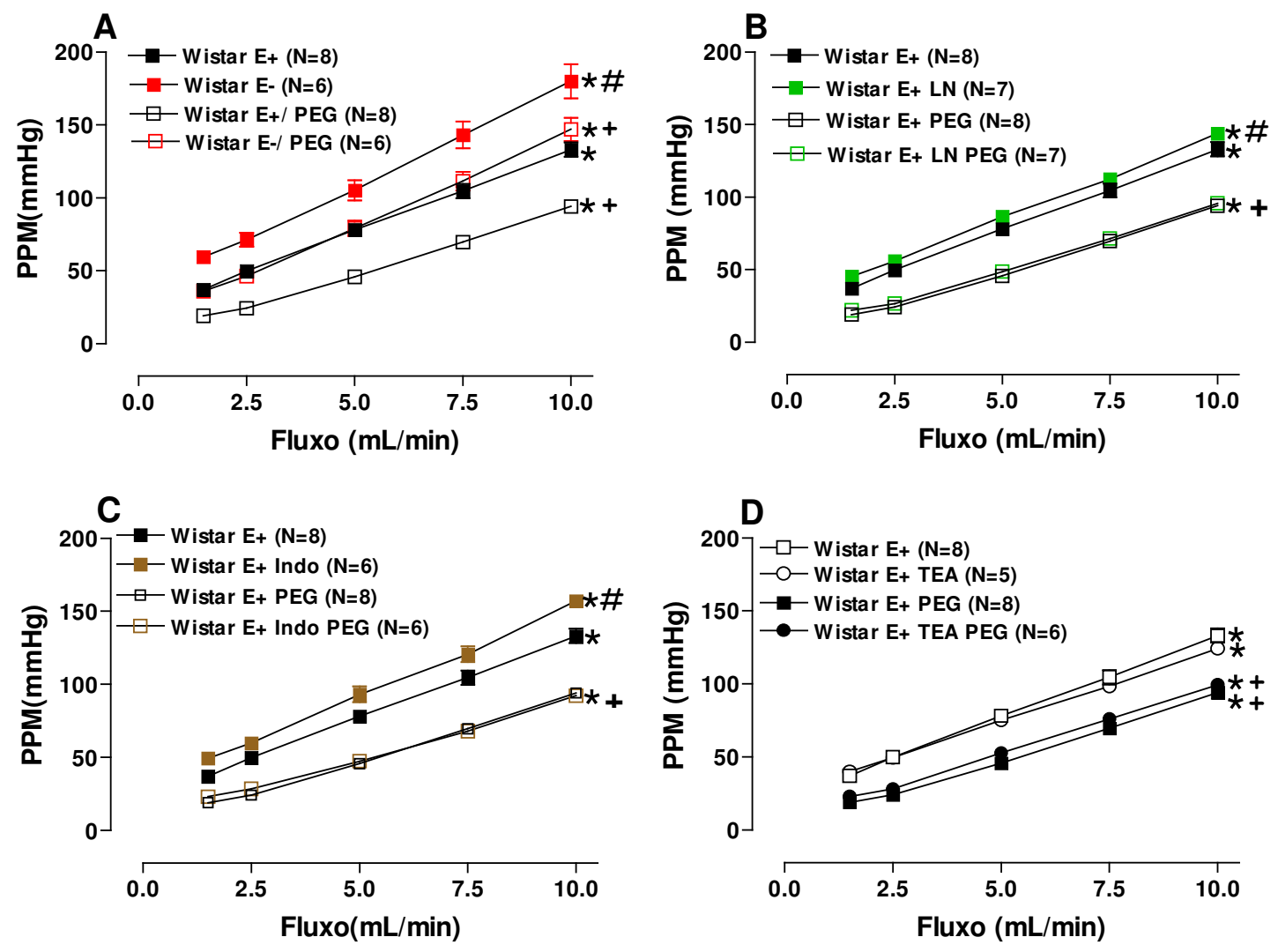

Figura 8.26. Curva de PPM x fluxo em leitos arteriais caudais de ratos normotensos (Wistar): com ( $E+$ ) e sem (E-) endotélio, e após a infusão durante trinta minutos com LNAME (LN), indometacina (INDO) ou tetraetilamônio (TEA) na presença e ausência do PEG4000. ANOVA; P<0,05 * vs fluxo; \# vs E+; + vs ausência do PEG4000.

As figuras 8.27 A, B, C e D apresentam a PPM versus fluxo para os animais espontaneamente hipertensos (SHR) na presença e ausência do endotélio, bem como, a ação dos inibidores dos vasodilatadores e do polietileno glicol. Na figura 8.27 A, conforme comentado anteriormente, percebe-se que as células endoteliais não participam das respostas da PPM em relação ao aumento do fluxo. A presença do PEG4000 causa diminuição nos valores da PPM na presença e ausência do endotélio. Nas figuras 8.27 B, C e D, as quais apresentam a ação dos inibidores do óxido nítrico, das prostaglandinas e dos canais de potássio ativados por cálcio, o PEG4000 praticamente normaliza as curvas de PPM versus fluxo, a menos da curva SHR E+ TEA/ PEG, onde para os maiores fluxos há um aumento nos valores da PPM em relação à curva SHR E+/ PEG. Assim, o PEG4000 está atuando na presença e ausência das células endoteliais, bem como, na presença dos inibidores, contribuindo para a diminuição da resistência ao escoamento. 

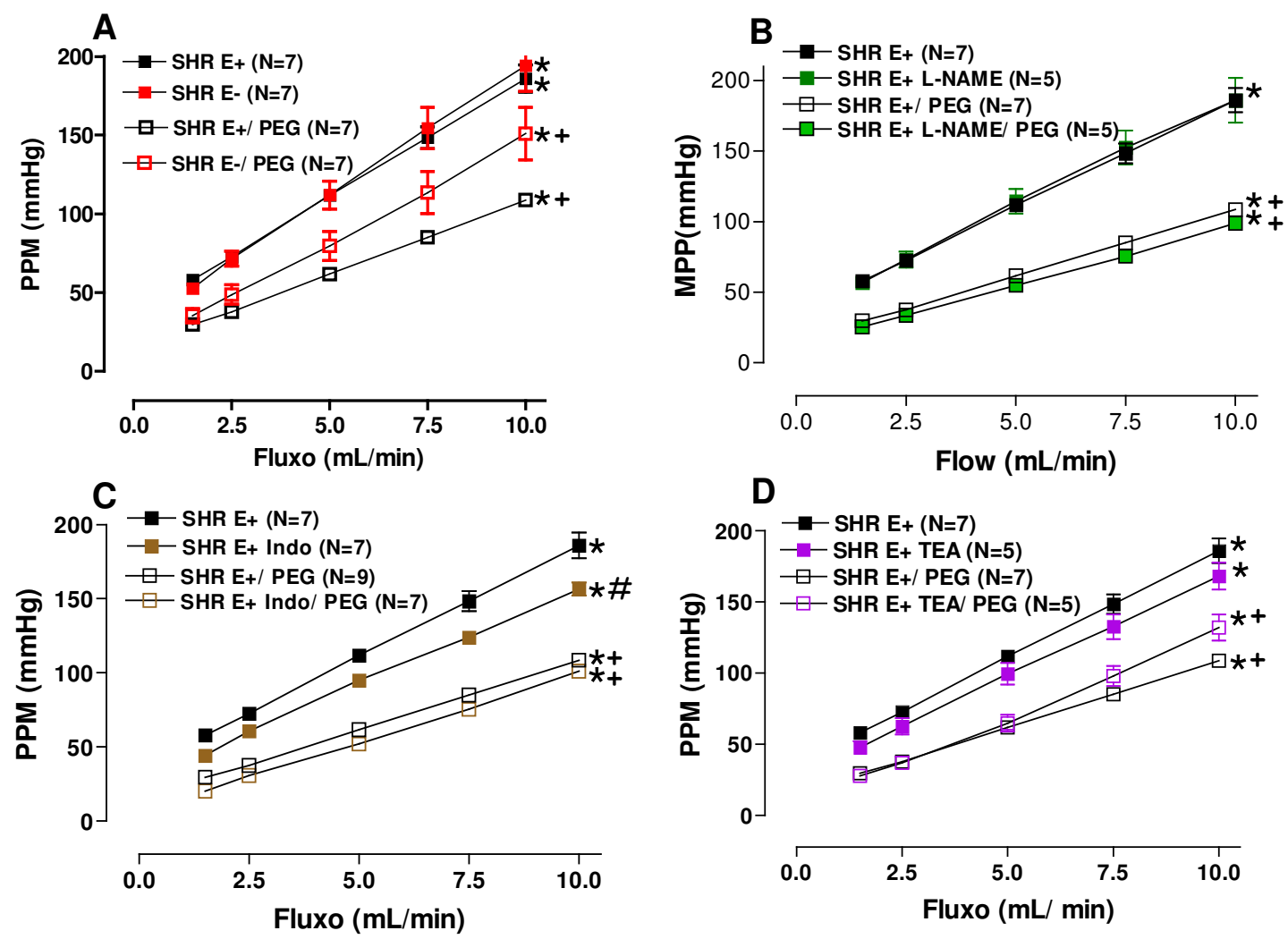

Figura 8.27. Curva de PPM $x$ fluxo em leitos arteriais caudais de ratos hipertensos (SHR): com ( $E+$ ) e sem (E-) endotélio, e após a infusão durante trinta minutos com LNAME (LN), indometacina (INDO) ou tetraetilamônio (TEA) na presença e ausência do PEG4000. ANOVA; P<0,05 * vs fluxo; \# vs E+; + vs ausência do PEG4000. 
8.3.5 Avaliação da redução de arrasto a partir do cálculo do fator de atrito nos leitos arteriais caudais de ratos normotensos (Wistar) e espontaneamente hipertensos (SHR).

A análise da redução do fator de atrito, na ausência do PEG, está apresentada na figura abaixo. A figura 8.28 mostra a ação das células endoteliais na redução do fator de atrito e compara-se com o fator de atrito universal.

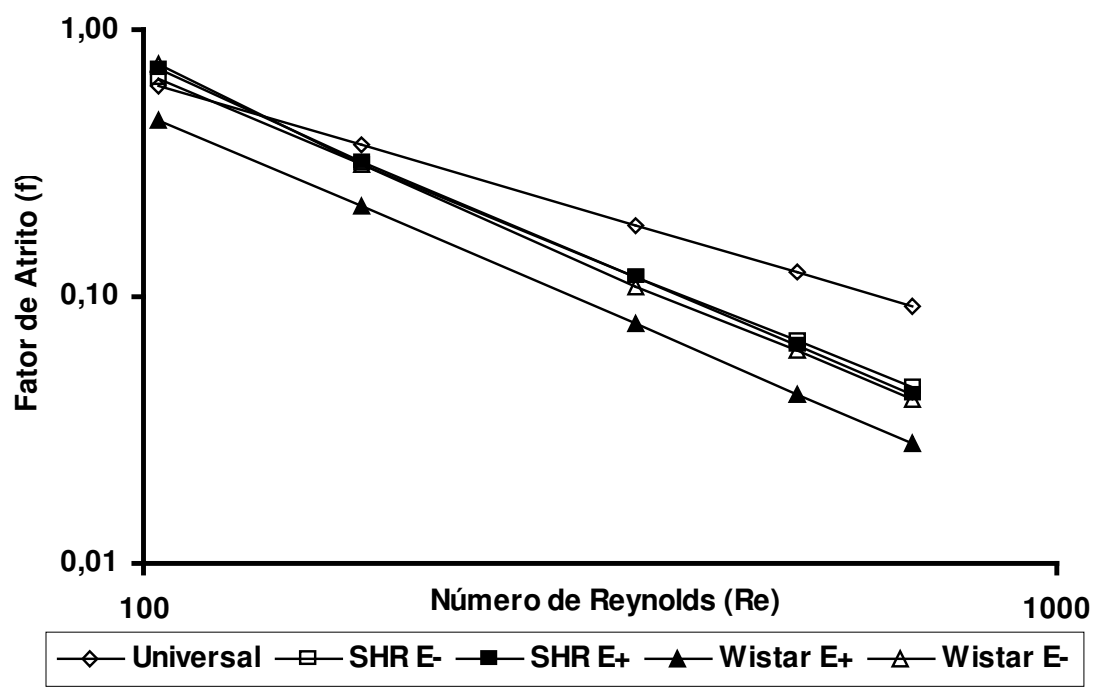

Figura 8.28. Variação do fator de atrito versus número de Reynolds na presença $(E+)$ e ausência (E-) das células endoteliais e comparando-se com o fator de atrito laminar.

Na figura 8.28, pode-se perceber que os valores iniciais da curva do fator de atrito universal versus número de Reynolds calculado para escoamento laminar em tubos rígidos é bastante próximo dos valores das curvas do fator de atrito versus número de Reynolds encontradas para os animais Wistar E-, SHR E- e SHR E+ cujo vaso é flexível. Porém, à medida que o número de Reynolds aumenta, o valor do fator de atrito universal torna-se maior do que para os animais Wistar E-, SHR E- e SHR E+. Os menores valores do fator de atrito ocorrem para o animal normotenso Wistar E+.

A figura 8.29 apresenta a ação do PEG4000 na redução do fator de atrito na presença das células endoteliais e comparando com o fator de atrito universal. 


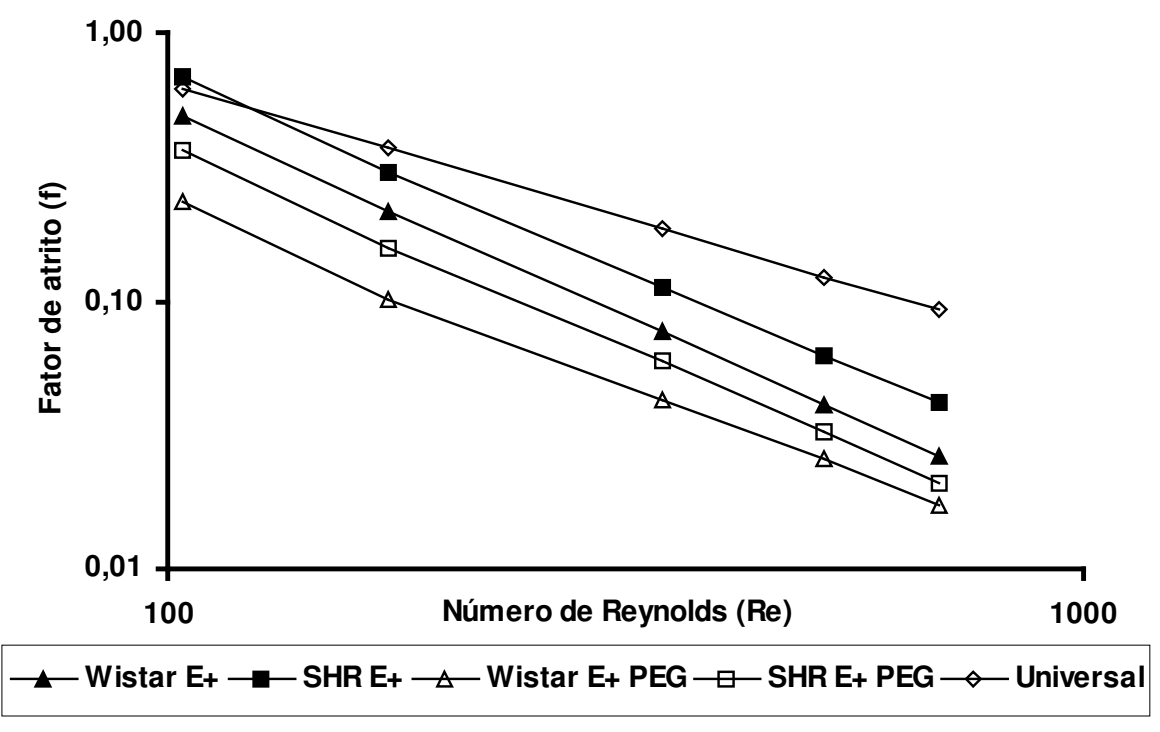

Figura 8.29. Variação do fator de atrito versus número de Reynolds em leitos arteriais caudais de ratos normotensos (Wistar) e espontaneamente hipertensos (SHR) na presença do PEG4000 e na presença $(E+)$ das células endoteliais.

Os valores do fator de atrito são maiores para o animal espontaneamente hipertenso (SHR). Conforme o número de Reynolds aumenta o fator de atrito diminui caracterizando um escoamento laminar. Na presença do PEG4000, há redução no fator de atrito para as duas cepas analisadas. Mais uma vez, os menores valores do fator de atrito estão apresentados na curva do animal normotenso (Wistar). A redução no fator de atrito devido ao PEG leva a redução na tensão de cisalhamento sobre as células endoteliais.

A figura 8.30 mostra a ação do PEG4000 na redução do fator de atrito em leitos arteriais caudais de ratos normotensos (Wistar) e espontaneamente hipertensos (SHR) na ausência das células endoteliais (E-). 


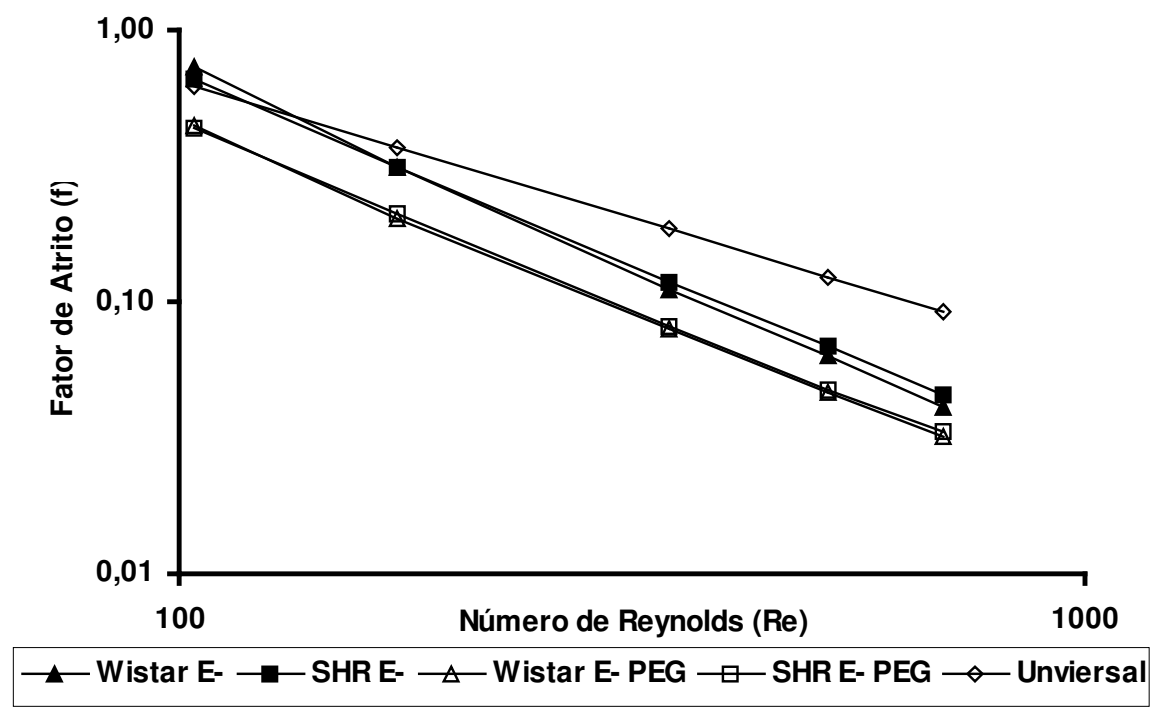

Figura 8.30. Variação do fator de atrito versus número de Reynolds em leitos arteriais caudais de ratos normotensos (Wistar) e espontaneamente hipertensos (SHR) na presença do PEG4000 e na ausência (E-) das células endoteliais.

Na figura 8.30, o efeito do PEG4000 nos leitos arteriais caudais de ambas as cepas é bastante claro, porém comparando-se com os resultados apresentados na figura anterior (8.29), percebe-se que ocorre uma diminuição na redução do fator de atrito. Isso quer dizer que a ação do PEG4000 como redutor de arrasto é intensificado pela presença das células endoteliais $(\mathrm{E}+)$. Esse efeito fica mais claro mostrando a redução de arrasto versus fluxo, como apresentado na figura 8.31. 


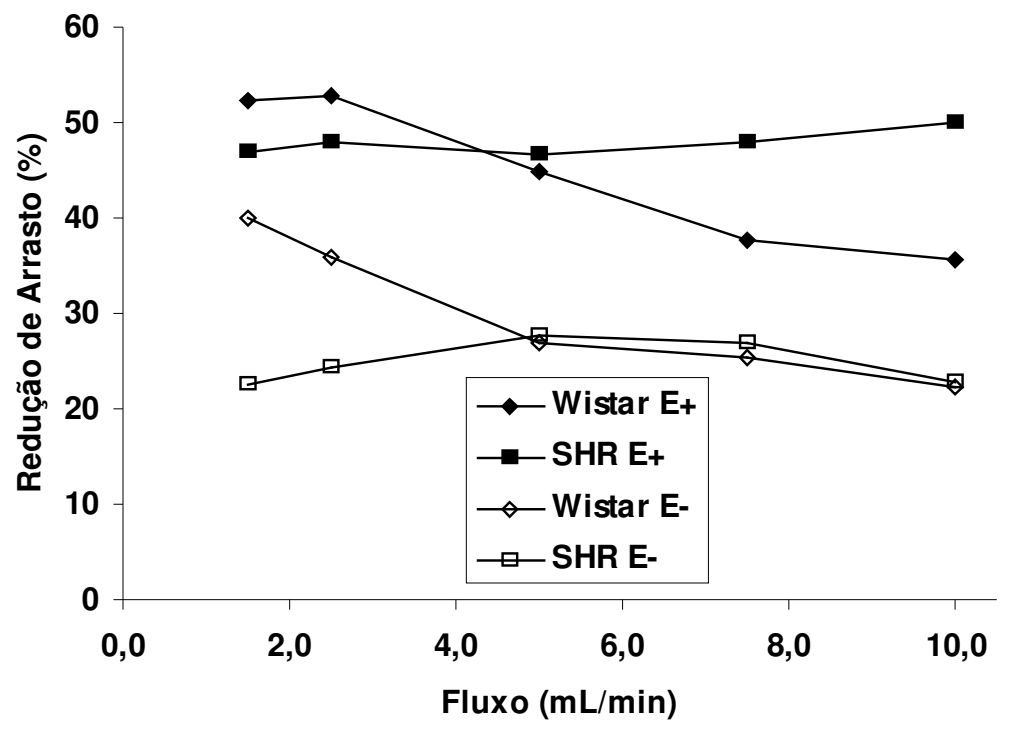

Figura 8.31. Porcentagem de redução de arrasto versus fluxo em leitos arteriais caudais de ratos normotensos (Wistar) e espontaneamente hipertensos (SHR) na presença das células endoteliais $\left(E_{+}\right)$e na ausência das células endoteliais (E-).

Na figura 8.31, pode-se perceber o efeito do PEG4000 como redutor de arrasto em ambas as cepas. No Wistar E+ e Wistar E-, a redução de arrasto diminui com o aumento do fluxo. Para o Wistar E+, a redução de arrasto diminui de 52\% para $35 \%$ nos respectivos fluxos de $1,5 \mathrm{~mL} / \mathrm{min}-10 \mathrm{~mL} / \mathrm{min}$. No Wistar E-, a redução de arrasto diminui de $40 \%$ para $22 \%$ nos respectivos fluxos de $1,5 \mathrm{~mL} / \mathrm{min}$ e $10 \mathrm{~mL} / \mathrm{min}$. Enquanto que para o SHR E+ e SHR E-, a redução de arrasto é praticamente constante. Para o SHR E+, tem-se uma faixa de redução de arrasto de 47\%-49\% para os fluxo entre $1,5-10 \mathrm{~mL} / \mathrm{min}$, respectivamente. E, para o SHR E-, a faixa de redução de arrasto 22, 27 e $22 \%$ para os fluxos 1,5; 5,0 e $10 \mathrm{~mL} / \mathrm{min}$. Dessa forma, percebe-se que a presença do endotélio intensifica o efeito do PEG4000.

8.3.6 Distribuição espacial e temporal da tensão de cisalhamento nos leitos arteriais caudais de ratos normotensos (Wistar) e espontaneamente hipertensos (SHR).

Conforme comentado, anteriormente, a entrada do pulso de pressão no modelo numérico foi desenvolvida a partir da média dos pulsos dos animais analisados, gerando o pulso de pressão de entrada. Essa etapa foi desenvolvida para os animais normotensos (Wistar) e espontaneamente hipertensos (SHR) na presença e ausência do endotélio. 
A figura 8.32 apresenta os gráficos da PPM versus tempo para os animais normotensos (Wistar) na presença e ausência do endotélio e do PEG4000. Pode-se perceber um aumento gradual nos valores da PPM com o aumento da vazão, sendo maiores na ausência do endotélio ou do PEG4000 (figuras 8.32 A e C). Enquanto que na presença do endotélio ou do PEG4000, os valores da PPM são menores (figuras 8.32 B e D). Dessa forma, fica claro que o endotélio e o PEG4000 auxiliam no controle da PPM.
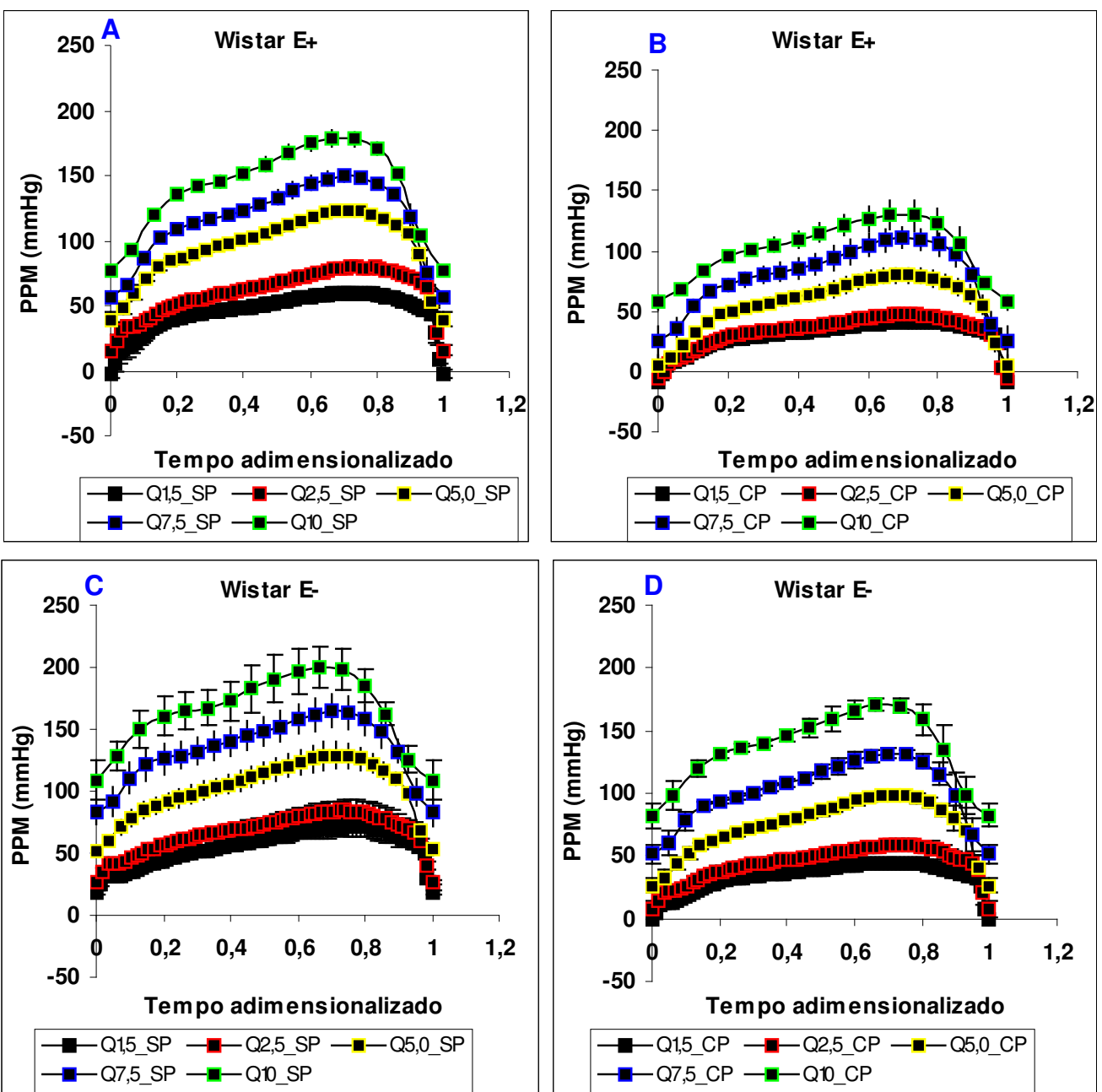

Figura 8.32. Pulsos de pressão de perfusão média versus tempo em leitos arteriais caudais de ratos normotensos (Wistar): $(A)$ na presença do endotélio $(E+)$ e ausência do PEG4000; (B) na presença do endotélio $(E+)$ e do PEG4000; $(C)$ na ausência (E-) do endotélio (E-) e do PEG4000; (D) na ausência do endotélio (E-) e na presença do PEG4000.

A figura 8.33 apresenta os gráficos da PPM versus tempo para os animais espontaneamente hipertensos (SHR) na presença (E+) e ausência (E-) do endotélio e do 
PEG4000. Pode-se perceber um aumento gradual nos valores da PPM com o aumento da vazão, porém diferentemente do animal normotenso (Wistar), o endotélio não participa do controle da PPM, pois os valores dessa na presença e ausência do endotélio, praticamente são iguais (figuras 8.33 A e C). Na presença do PEG4000, há redução nos valores da PPM na presença e ausência do endotélio, porém essa redução é maior na presença do endotélio (figura $8.33 \mathrm{~B}$ e D).
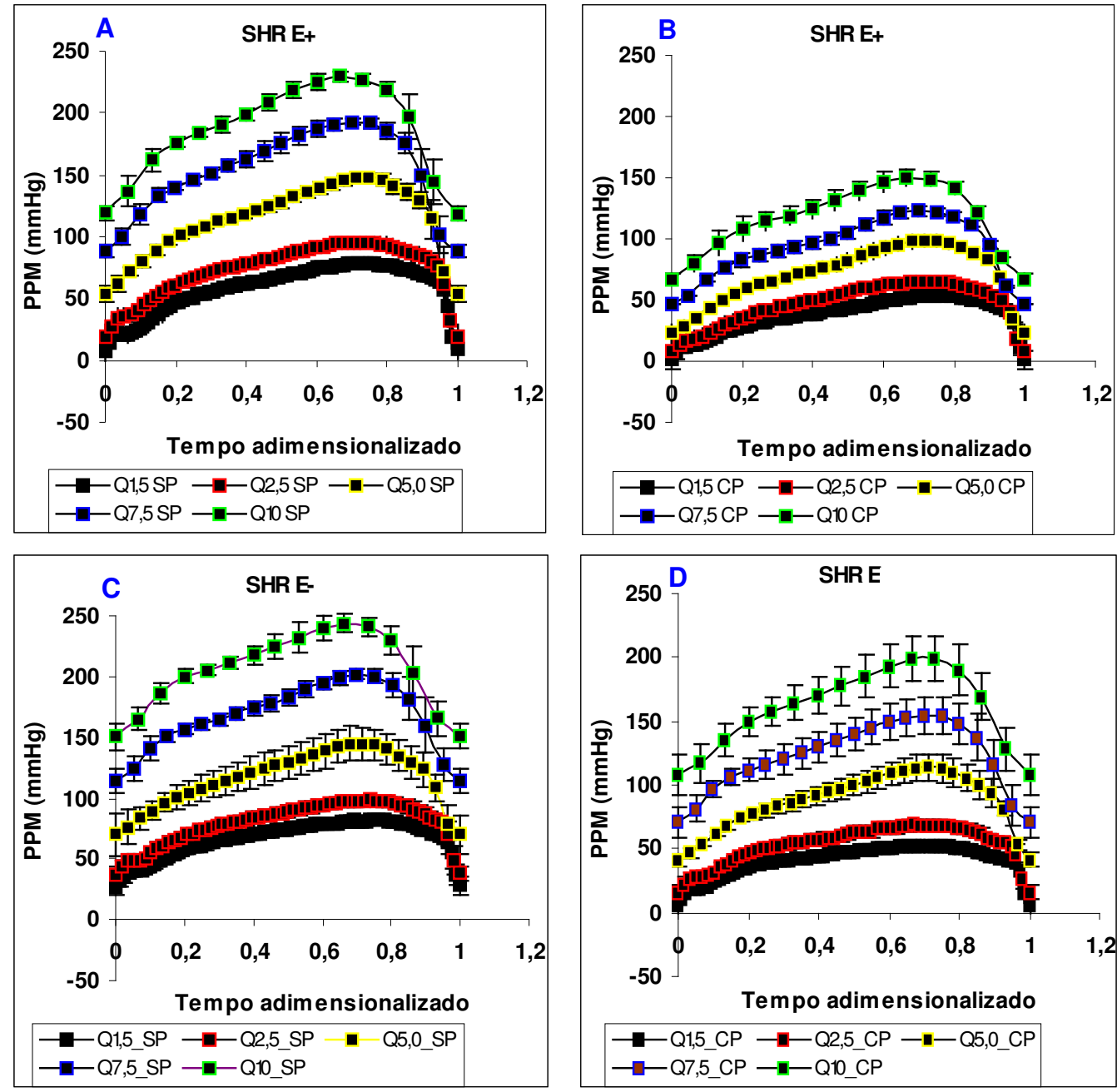

Figura 8.33. Pulsos de pressão de perfusão média versus tempo em leitos arteriais caudais de ratos espontaneamente hipertensos (SHR): (A) na presença do endotélio $(E+)$ e ausência do PEG4000; (B) na presença $(E+)$ do endotélio e do PEG4000; (C) na ausência (E-) do endotélio e do PEG4000; (D) na ausência (E-) do endotélio e na presença do PEG4000.

A figura 8.34 apresenta pulsos de pressão de perfusão média versus tempo para vazão de $2,5 \mathrm{~mL} / \mathrm{min}$. Essa vazão representa a vazão fisiológica da cauda, logo os gráficos da distribuição da tensão de cisalhamento vão ser apresentados para essa vazão 
específica. Os pontos em destaque representam os instantes onde as distribuições das tensões de cisalhamentos são plotadas. Mais uma vez, fica claro a participação do endotélio e do PEG4000 no controle da PPM nos animais Wistar e SHR, sendo a ação do endotélio intensificado pela presença do PEG4000 (Figuras 8.34 B e D).
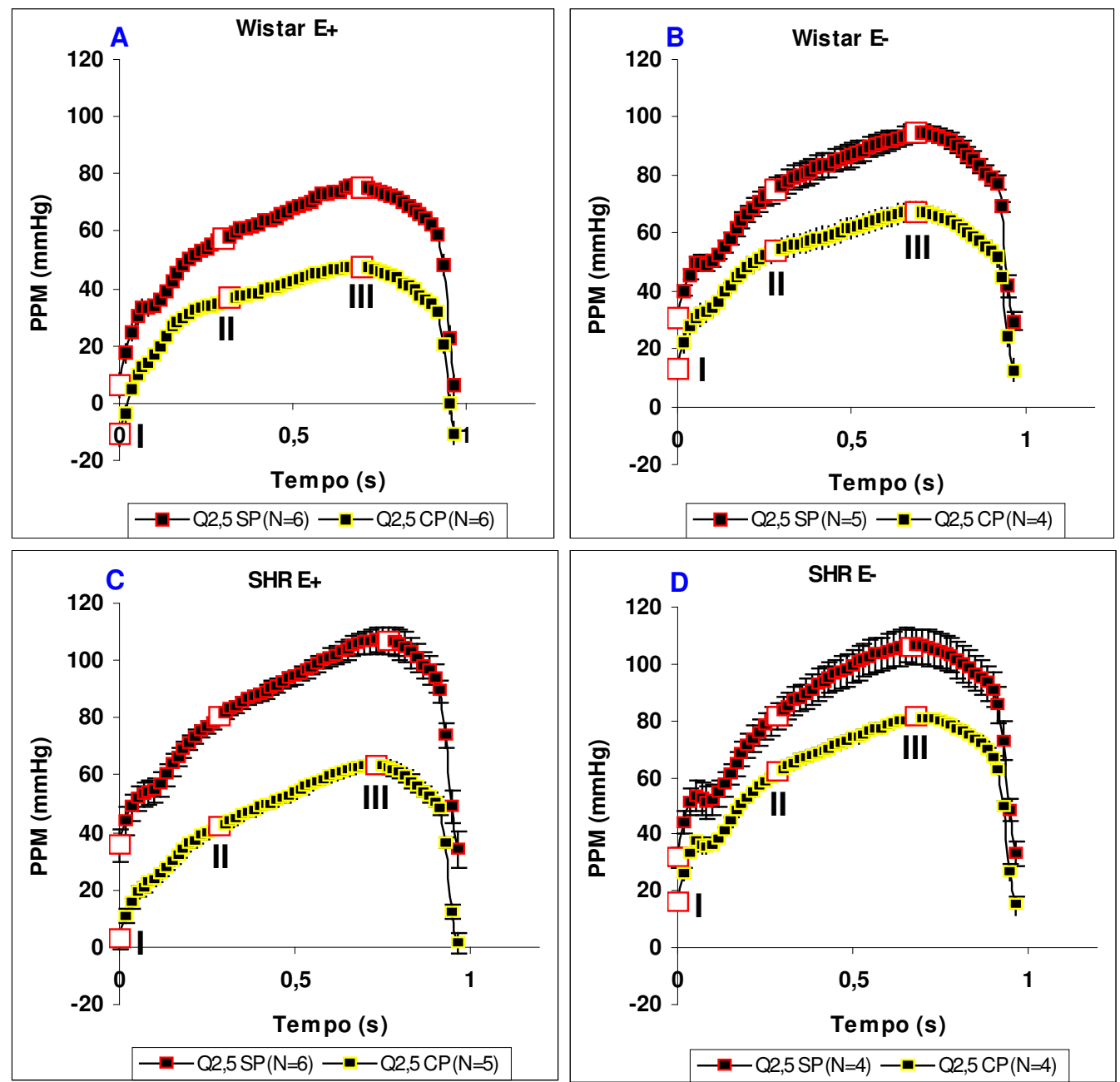

Figura 8.34. Pulsos de pressão de perfusão média versus tempo em leitos arteriais caudais de ratos normotensos (Wistar) e espontaneamente hipertensos (SHR) na presença e ausência do PEG4000: (A) na presença do endotélio ( $E+)$ (Wistar); (B) na ausência do endotélio (E-) (Wistar); (C) na presença do endotélio ( $E+$ ) (SHR); (D) na ausência do endotélio (E-) (SHR).

A figura 8.35 apresenta a distribuição espacial e temporal da tensão de cisalhamento ao longo da parede arterial dos leitos arteriais caudais de ratos normotensos (Wistar) e espontaneamente hipertensos (SHR) na presença (E+) e ausência (E-) das células endoteliais. Pode-se perceber que ocorre aumento da tensão de cisalhamento ao longo da parede do vaso devido à redução do diâmetro ao longo da 
mesma e, também, um aumento dessa tensão temporalmente, atingindo valor máximo no instante III do ciclo para todas as situações analisadas. A redução nos valores da tensão de cisalhamento devido à presença do endotélio está clara para todos os instantes analisados no animal Wistar. Além disso, percebe-se que a presença do endotélio no animal SHR não modula a tensão de cisalhamento, pois há uma sobreposição dos resultados desse com SHR E-, enquanto que no Wistar, o endotélio está modulando os valores da tensão de cisalhamento, pois no Wistar E-, os valores da tensão de cisalhamento são elevados igualando-se aos valores obtidos para o SHR.

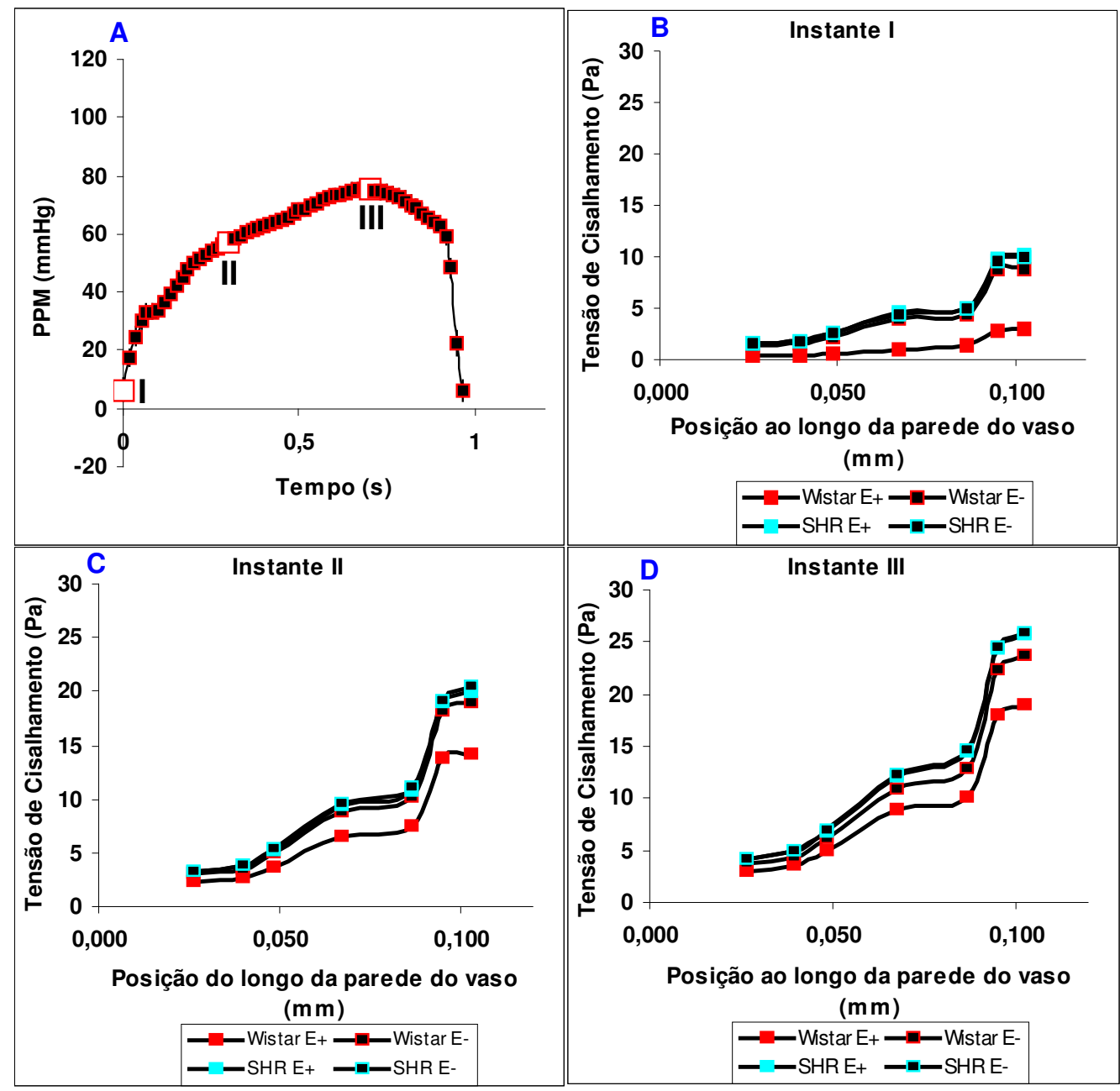

Figura 8.35. (A) Os instantes em que as tensões de cisalhamento são plotadas; (B), (C) e (D) Distribuição espacial e temporal da tensão de cisalhamento em leitos arteriais caudais de ratos normotensos (Wistar) e espontaneamente hipertensos (SHR) na presença $\left(E_{+}\right)$e ausência ( $\left.E_{-}^{-}\right)$do endotélio nos instantes especificados acima.

A figura 8.36 apresenta a distribuição espacial e temporal da tensão de cisalhamento ao longo da parede arterial dos leitos arteriais caudais de ratos 
normotensos (Wistar) e espontaneamente hipertensos (SHR) na presença (E+) das células endoteliais e na presença do PEG4000. A presença do PEG4000 reduz os valores das tensões de cisalhamentos para todas as situações analisadas. No instante I, os valores da tensão de cisalhamento para o Wistar E+ são negativos.
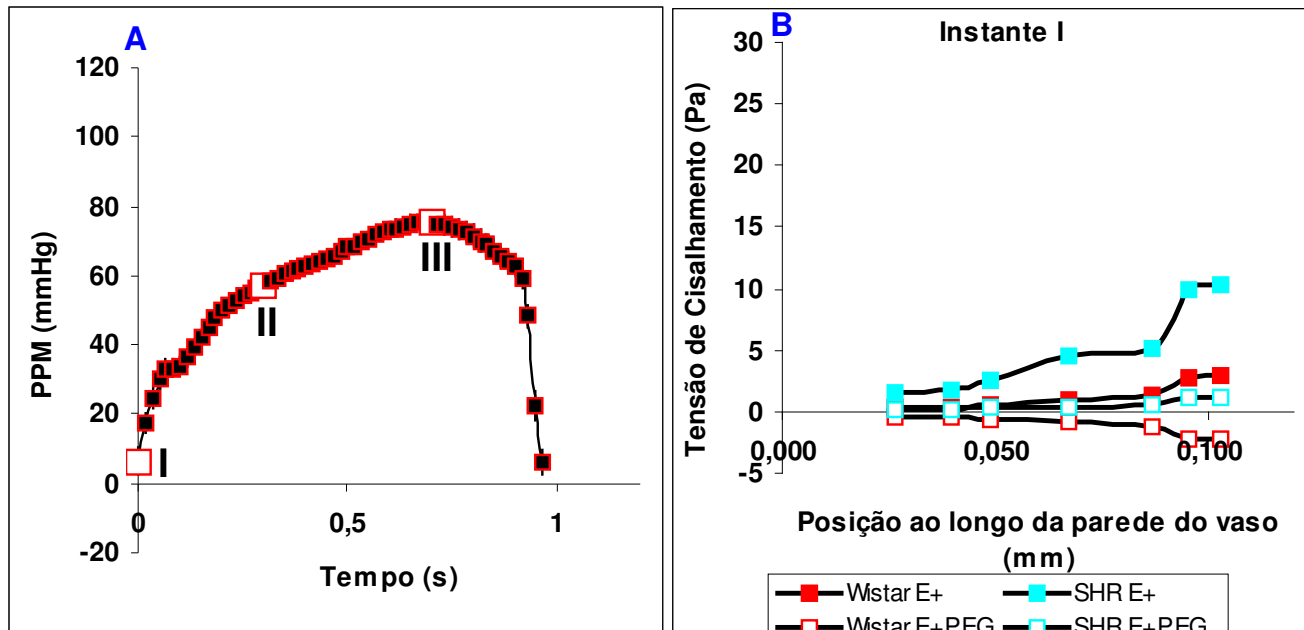

Posição ao longo da parede do vaso $(\mathrm{m} \mathrm{m})$
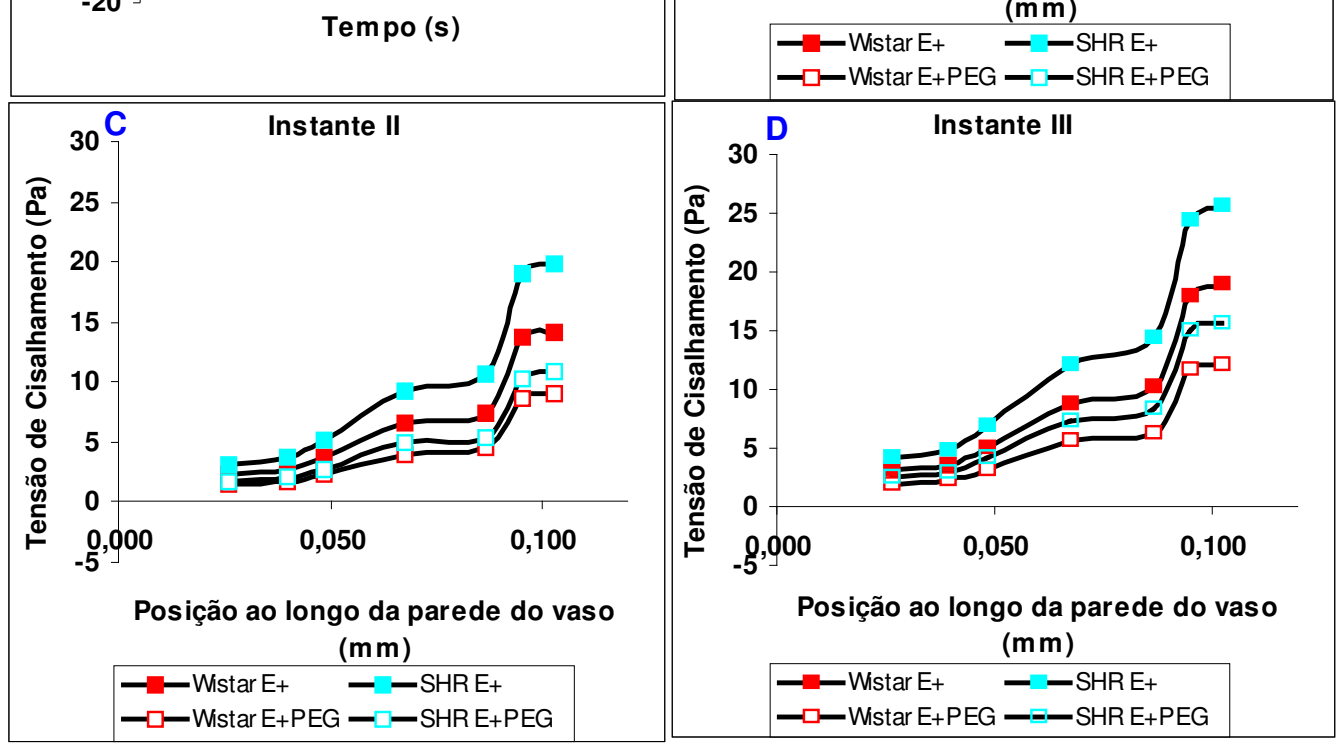

Figura 8.36. (A) Os instantes em que as tensões de cisalhamento são plotadas; (B), (C) e (D) Distribuição espacial e temporal da tensão de cisalhamento em leitos arteriais caudais de ratos normotensos (Wistar) e espontaneamente hipertensos (SHR) na presença $\left(E_{+}\right)$do endotélio e na presença do PEG4000.

A figura 8.37 apresenta a distribuição espacial e temporal da tensão de cisalhamento ao longo da parede arterial dos leitos arteriais caudais de ratos normotensos (Wistar) e espontaneamente hipertensos (SHR) na ausência (E-) das células endoteliais e na presença do PEG4000. A redução nos valores da tensão de cisalhamento ocorre para todas as situações analisadas, porém o efeito do PEG4000 é 
menor na ausência do endotélio do que na presença desse.
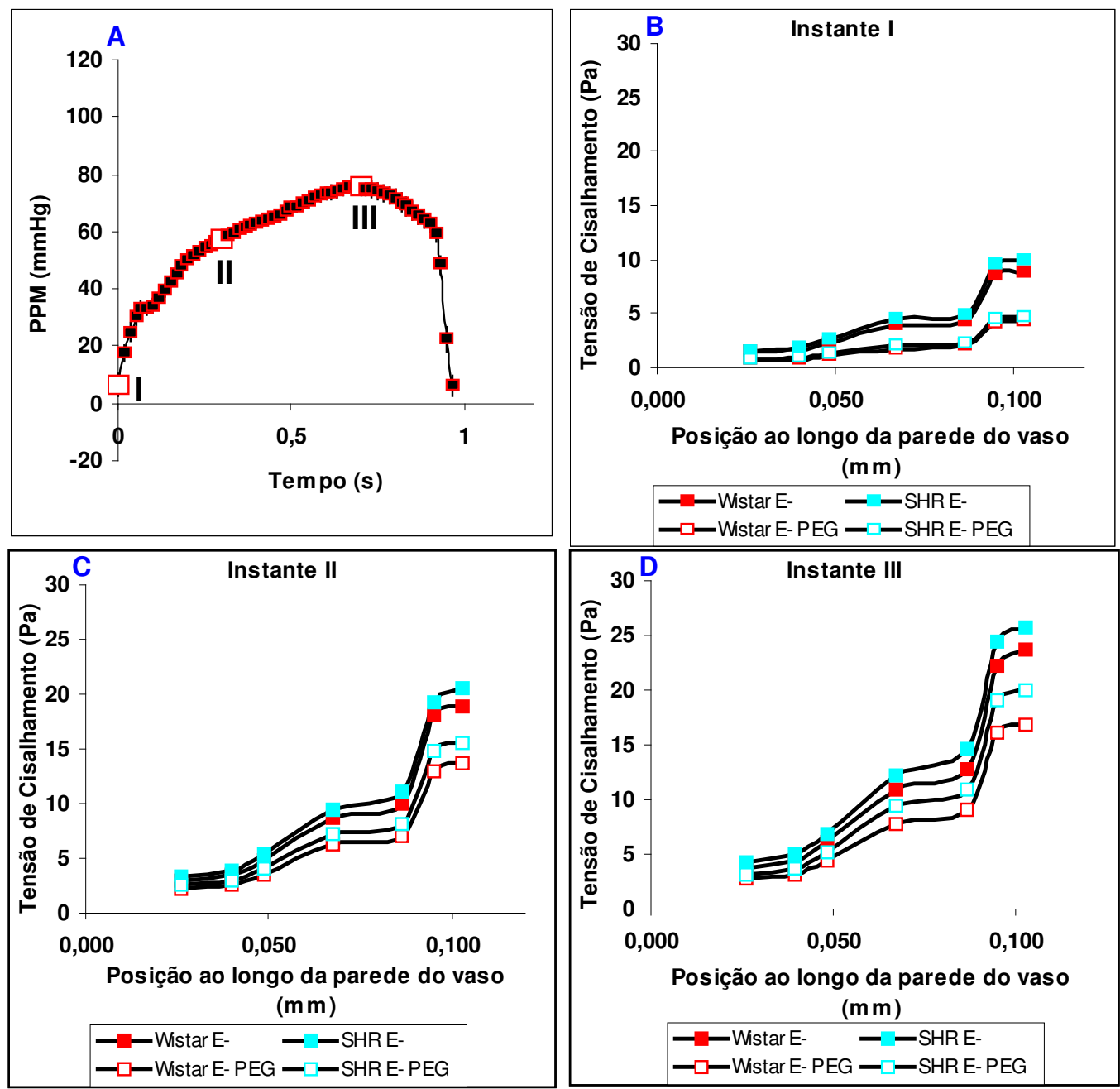

Figura 8.37. Distribuição espacial e temporal da tensão de cisalhamento em leitos arteriais caudais de ratos normotensos (Wistar) e espontaneamente hipertensos (SHR) na ausência (E-) do endotélio e na presença do PEG4000. 


\section{Discussão dos Resultados}

\subsection{Análise da Viscosidade}

\subsubsection{Polietileno glicol}

A reologia descreve a deformação de um corpo sob a influência de tensões. Corpos podem ser sólidos, líquidos ou gases. Os corpos reais não são nem sólidos ideais e nem fluidos ideais. Os sólidos reais também podem se deformar irreversivelmente quando sob a influência de forças que ultrapassam seu limite de escoamento. De modo geral, os fluidos podem ser classificados de acordo com a relação entre a tensão de cisalhamento e a taxa de deformação:

$$
\tau=\mu \frac{d u}{d y}
$$

onde $\tau$ é a tensão de cisalhamento $(\mathrm{Pa}), \mu$ é a viscosidade dinâmica (Pa.s), $d u / d y$ é a taxa de cisalhamento $\left(\mathrm{s}^{-1}\right)$. A equação (9.1) é a lei de Newton da viscosidade para escoamento unidimensional. Os fluidos que obedecem esta lei são chamados de fluidos newtonianos e os fluidos não-newtonianos são todos aqueles que não obedecem à lei de Newton da viscosidade (Figura 9.1).

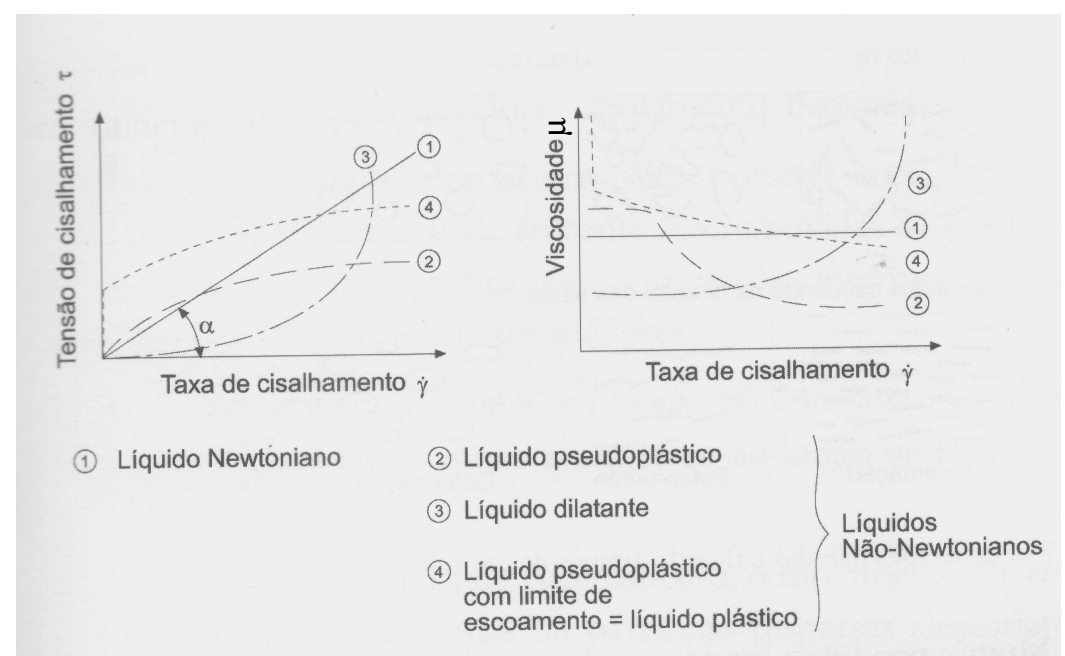

Figura 9.1. Diagrama reológico: tensão de cisalhamento e viscosidade versus taxa de cisalhamento de fluido Newtoniano e não-Newtoniano. Extraído de Schramm (2006).

A partir da figura 9.1, pode-se perceber que os fluidos newtonianos são aqueles em que a relação entre a tensão de cisalhamento e a taxa de cisalhamento ou entre a viscosidade e a taxa de cisalhamento apresenta um comportamento linear. Dessa forma, 
analisando os resultados das figuras 8.1 e 8.2, percebe-se que o comportamento apresentado pela solução polimérica (sem e com Krebs) de PEG4000 (5000ppm) é linear, ou seja, a relação entre a tensão de cisalhamento ou a viscosidade com a taxa de cisalhamento é linear caracterizando o comportamento de fluido newtoniano. Além disso, de acordo com Bird et al. (2004), a resistência ao escoamento de todos os gases e líquidos, com peso molecular menor que cerca de $5000 \mathrm{Da}(5 \mathrm{kDa})$, é descrita pela equação 9.1, e tais fluidos são classificados como fluidos newtonianos. Sendo assim, a solução do PEG4000 (5000 ppm) juntamente com a solução de Krebs, tem um comportamento de fluido Newtoniano.

Koller e Huang (1999) obtiveram valor da viscosidade dinâmica da solução de Krebs de 0,7mPa.s. Neste trabalho, para a solução de Krebs com polímero (PEG4000) cuja concentração foi de 5000 ppm, obteve-se como resultado do valor da viscosidade 0,75 mPa.s (pág. 72). Dessa forma, fica claro que essa concentração de polímero praticamente não altera o valor da viscosidade da solução.

\subsubsection{Poliacrilamida}

As figuras 8.3 A e B mostram que as soluções de poliacrilamidas $1340 \mathrm{~S}$ e $1822 \mathrm{~S}$ cujas concentrações são 5 e 10 ppm, respectivamente, comportam-se como a água destilada, ou seja, o comportamento de fluido Newtoniano pode ser atribuído a essas soluções poliméricas nessas concentrações. As figuras 8.4 A, B, C e D mostram o comportamento das soluções poliméricas em diferentes concentrações, 30, 60, 75 e 100 ppm, respectivamente. Nessas figuras, as curvas da poliacrilamida 1340S sempre aparecem acima da curva da poliacrilamida $1822 \mathrm{~S}$ devido ao maior peso molecular. Extrapolando os dados dessas curvas para atingir o eixo das ordenadas, percebe-se que esta não cruzará o eixo das ordenadas no zero, caracterizando um comportamento de fluido não-Newtoniano.

As figuras 8.5 e 8.6 mostram que o comportamento da água destilada e das soluções poliméricas das poliacrilamidas $1822 \mathrm{~S}$ e $1340 \mathrm{~S}$ para concentrações de 5 e 10 ppm são semelhantes, podendo-se caracterizar o comportamento dessas soluções poliméricas como de um fluido Newtoniano. Os valores de viscosidade obtidos para as soluções poliméricas da poliacrilamida 1340 S são maiores do que aqueles obtidos para as soluções poliméricas da poliacrilamida 1822S. Essa diferença pode ser atribuída ao 
maior peso molecular da poliacrilamida 1340S. A partir dos resultados apresentados acima, mais uma vez, pode-se concluir que as soluções poliméricas das poliacrilamidas $1822 \mathrm{~S}$ e $1340 \mathrm{~S}$ a concentrações de 5 e $10 \mathrm{ppm}$ podem ser consideradas fluidos Newtonianos. Enquanto para as concentrações acima de 30 ppm, as soluções poliméricas apresentam comportamento de fluido não-newtoniano. Como pode ser visto nessas figuras (8.5 e 8.6), os valores da viscosidade diminuem com o aumento da taxa de deformação. Esse tipo de comportamento é característico de fluido pseudoplástico. A figura 9.2 apresenta a forma de algumas substâncias dispersas no líquido em repouso e fluindo através de um tubo.

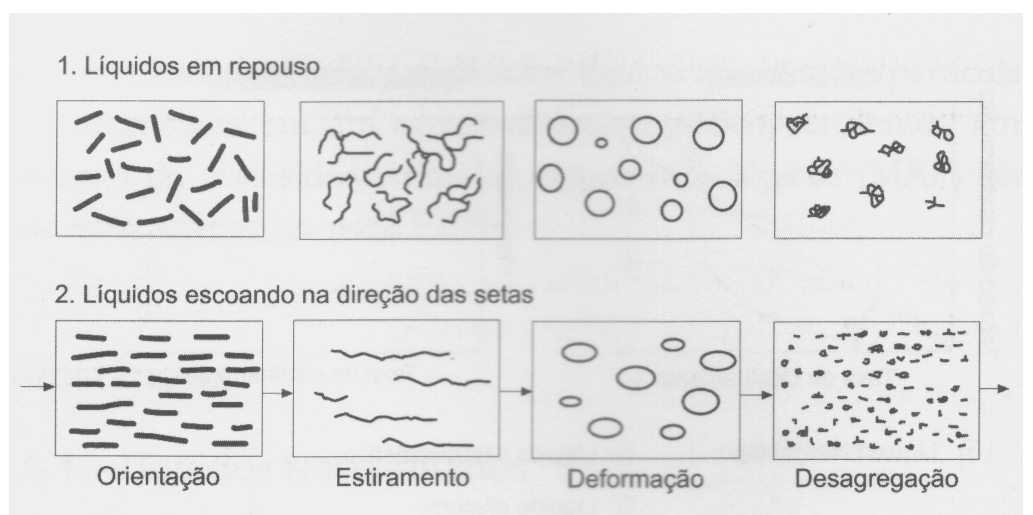

Figura 9.2. Formas de algumas substâncias dispersas no líquido em repouso e fluindo através de um tubo. Extraído de Schramm (2006).

Essas substâncias em repouso podem se apresentar como partículas de forma irregular ou em forma de gotas de líquido dispersa em outro líquido ou ainda existem as soluções poliméricas que se apresentam como longas cadeias entrelaçadas e enoveladas. Quando em repouso, todos esses materiais irão manter uma ordem interna irregular e serão caracterizados por uma considerável resistência interna ao fluxo, ou seja, uma alta viscosidade (Figura 9.2).

Com o aumento das taxas de deformações, partículas rígidas se orientam na direção do fluxo. Nas moléculas poliméricas em solução ou no estado fundido, os entrelaçamentos entre elas podem ser desfeitos fazendo com que as moléculas se alinhem e se orientem na direção do fluxo. O alinhamento de moléculas ou partículas permite que elas escorreguem entre si mais facilmente. Partículas com forma esférica podem ser deformadas para a forma de uma "bola de futebol americano", ou seja, menores no diâmetro e mais alongadas longitudinalmente. Células vermelhas do sangue suspensa no plasma podem ter sua forma alterada, reduzindo o diâmetro e alongando-se, 
o que significa uma passagem mais fácil através dos pequenos vasos sangüíneos e uma maior taxa de escoamento.

\subsection{Bancada Experimental da EPUSP}

9.2.1 Comentários gerais sobre a redução de arrasto em tubos de silicone com e sem estenose e em tubos capilares de látex e de silicone

Conforme comentado, no item 8.2.2, não houve redução de arrasto para nenhuma concentração e tipo de polímeros (PEG4000 e poliacrilamidas) usados nesse trabalho, nos tubos com e sem estenoses cujo diâmetro foi de $10 \mathrm{~mm}$. O valor do número de Reynolds obtidos nesse escoamento foi de $8 \times 10^{3}$. Em seguida, esses tubos foram trocados por um tubo capilar de látex (diâmetro de $3 \mathrm{~mm}$ ), sem estenose, cuja rigidez do material foi diminuída, e conseguiu-se atingir valores da ordem de $2 \times 10^{4}$ do número de Reynolds, e mesmo assim, não foi obtida a diminuição dos valores do gradiente de pressão. Novamente, outra troca ocorreu entre o tubo capilar de látex e o tubo capilar de silicone com uma rigidez maior cujo diâmetro foi de $3 \mathrm{~mm}$. Essa rigidez diminui o número de Reynolds máximo atingido no experimento para $1,3 \times 10^{4}$. Para essa condição, as diminuições dos valores dos gradientes de pressões surgiram quando as soluções poliméricas de poliacrilamidas eram usadas, porém para as soluções poliméricas com o PEG4000 não houve essa redução, mesmo para concentrações de 5000 ppm. Essa concentração de 5000 ppm de PEG4000 foi escolhida para efeito de comparação com os resultados obtidos na bancada experimental do ICB.

A utilização do PEG nesta pesquisa foi estimulada pelas publicações de Marina Kameneva, Professora Pesquisadora da Universidade de Pittsburgh, que utilizou este polímero redutor de arrasto. Em suas publicações, o PEG apresenta redução de arrasto da ordem de 60\% (Kameneva et al., 2004). Mais especificamente, ela comenta em seus artigos que polímeros redutores de arrasto devem possuir pesos moleculares superiores a 1000 kDa e, essa condição, é aceita e confirmada por vários pesquisadores. Em um de seus trabalhos, ela usou PEG 200, PEG 3500 e um polímero natural extraído de Aloe Vera (babosa) com peso molecular de $4000 \mathrm{kDa}$. O PEG 200 foi utilizado em concentrações de 5 e 75 ppm, enquanto o PEG 3500 e o polímero natural foram utilizados com concentrações de apenas 5 ppm. A variação do número de Reynolds no escoamento foi de 4.330 - 17.330. Esse experimento foi realizado num tubo de vidro com comprimento de $92 \mathrm{~cm}$ e diâmetro interno de 0,49 $\mathrm{cm}$. Como resultado, ela 
comenta que o PEG 200 não apresentou redução de arrasto enquanto o PEG 3500 e o polímero natural apresentaram redução de arrasto e atribuiu este fato ao peso molecular dos polímeros. O peso molecular apresentado por ela nesse experimento e em outro artigo (Kameneva \& Fink, 2005) é da ordem de valores superiores a $10^{5} \mathrm{Da}$ (100 kDa). O PEG 200, especificado por ela, possui peso molecular de $200 \mathrm{kDa}$ e o PEG 3500 possui peso molecular de $3500 \mathrm{kDa}$ e o polímero natural possui peso molecular de 4000 $\mathrm{kDa}$. Dessa forma, os polímeros que apresentam pesos moleculares inferiores a 1000 kDa, não apresentam o fenômeno da redução de arrasto.

Mediante o exposto acima, utilizamos o PEG 4000 como possuindo peso molecular da ordem de $4000 \mathrm{kDa}$, pois de acordo com Kameneva, PEG 4000 corresponde a um peso molecular de $4000 \mathrm{kDa}$. Porém, em nenhum dos nossos experimentos obtivemos redução de arrasto para esse polímero com esse peso molecular e nem para o PEG 8000 com concentração de 10000 ppm em escoamentos laminares e turbulentos. Dessa forma, pedimos um laudo para Labsynth Produtos para Laboratórios Ltda. Neste laudo, o valor do peso molecular do PEG 4000 foi de 3874,3 Da. Além desse resultado, utilizamos o catálogo (2006-2007) da Sigma-Aldrich e o valor do peso molecular para o PEG 4000 é por volta de $4000 \mathrm{Da}$ (4 kDa), ou seja, os números que sucedem as letras PEG representam o peso molecular em Da do especificado polímero e, não em kDa. Assim, houve um engano por parte de Kameneva nos valores dos pesos moleculares do PEG que nos conduziu, inicialmente, ao uso do polímero PEG 4000 como apresentando um peso molecular de $4000 \mathrm{kDa}$, mas como exposto acima, esse apresenta um peso molecular da ordem de $4000 \mathrm{Da}(4 \mathrm{kDa})$.

Assim, uma explicação para a ausência da redução de arrasto na presença do PEG, na bancada experimental da EPUSP, é devido ao seu peso molecular ser inferior a $1 \times 10^{6} \mathrm{Da}(1000 \mathrm{kDa})$. A literatura apresenta que polímeros de elevado peso molecular atuam na camada de transição (buffer-layer), através do incremento da viscosidade localmente e, dessa forma alterando o comportamento turbulento nesta região, minimizando a flutuação turbulenta na direção perpendicular a parede. Este efeito está envolvido no comprimento da cadeia polimérica. Como a estrutura química do polímero é linear, esta sofre estiramento nessa região diminuindo a geração de turbulência ou mudando o comportamento turbulento, minimizando a perda de carga no escoamento.

A partir dessa informação, passou-se a usar o Polyox WSR-301, cuja estrutura química é semelhante ao PEG4000, porém o seu peso molecular é da ordem de 1000 vezes maior (4000 kDa). Assim, foi obtida a redução de arrasto. 


\subsubsection{Redução de arrasto no tubo capilar de silicone}

Analisando as figuras $8.10,8.11$ e 8.12, percebe-se que há diminuição nos valores do gradiente de pressão na presença do polímero quando comparado com os valores do gradiente de pressão somente na presença da água. Para essas curvas tem-se diminuição nos valores dos gradientes de pressão desde a concentração de 5 ppm. Praticamente, não há diminuição nos valores do gradiente de pressão ao passar de 5 ppm para 10 ppm. Já de 10 ppm para 30 ppm, há diminuição nos valores dos gradientes de pressão atingindo seus valores máximos de redução.A partir de 30 ppm não se têm maiores valores de reduções nos gradientes de pressão. Dentre os polímeros utilizados, as maiores reduções nos valores dos gradientes de pressão ocorrem na presença do Polyox WSR-301(figura 8.12). Numa concentração de apenas 5 ppm, tem-se uma elevada redução dos gradientes de pressão (figura 8.13), sendo o Polyox WSR-301, o polímero que apresenta maior eficiência na redução dos gradientes de pressão, seguido da poliacrilamida 1822 S e por último a poliacrilamida 1340S. Já para os maiores valores de concentrações poliméricas (100 ppm) utilizados nesse trabalho, tem-se o Polyox WSR-301 apresentando maior eficiência na redução dos valores do gradiente de pressão, enquanto que para as poliacrilamidas 1822S e 1340S, os valores dos gradientes de pressões se sobrepõem.

As figuras $8.15,8.16$ e 8.17 apresentam o fenômeno da redução de arrasto em função dos valores de número de Reynolds desde a transição de escoamento laminar $(\operatorname{Re}=2300)$ até o escoamento turbulento $(\operatorname{Re}=13600)$. O fenômeno da redução de arrasto não ocorre para escoamento laminar, como era esperado, já que é bastante conhecido da literatura que os polímeros redutores de arrasto não causam redução nesse regime de escoamento. É sabido da literatura que esses polímeros apresentam o fenômeno de redução de arrasto em escoamentos laminares com perturbações, tais como escoamento laminar pulsátil ou escoamento de Coutte com vórtices de Taylor a baixos números de Reynolds (Driels \& Ayyash (1976), Keller et al. (1975)). Mesmo assim, no simulador hidrodinâmico apresentando escoamento laminar pulsátil, o fenômeno da redução de arrasto não foi verificado.

Pode ser observado na figura 8.15 que para baixa concentração de polímero ( 5 ppm), o início da redução de arrasto ocorre para valores de número de Reynolds de 
6500 que está na faixa de escoamento turbulento, sendo que o Polyox WSR-301 apresenta maiores valores de redução de arrasto quando comparado com as poliacrilamidas. Aumentando a concentração polimérica para 30 ppm (figura 8.16), ocorre um aumento nos valores da redução de arrasto e o início da redução de arrasto ocorre mais cedo. Pode ser observado que para as poliacrilamidas 1822S e 1340S, o início da redução de arrasto ocorre para valores de número de Reynolds de 3000 e 3800 , respectivamente, enquanto que para o polyox WSR-301, esse efeito fica concentrado dentro da faixa turbulenta $(\operatorname{Re}>4000)$. Analisando a figura 8.17, cuja concentração polimérica é de 100 ppm, percebe-se que praticamente não há aumento nos valores da redução de arrasto e nem mudança no número de Reynolds para o início da redução de arrasto quando comparado com a figura 8.16. Assim, valores superiores a $30 \mathrm{ppm}$ desses polímeros não trazem benefícios para serem utilizados para as condições experimentais usadas nesse trabalho. Possivelmente, maiores valores de reduções de arrasto poderiam ser obtidos para escoamentos com valores de Reynolds mais elevados.

Conforme comentado acima, para diferentes faixas de número de Reynolds ocorrem diferentes valores da redução de arrasto. De acordo com a literatura, isto pode ser visto em outros trabalhos, como por exemplo, em Vilalta \& Ortiz (2000), que existem cinco regimes:

- Regime laminar;

- Regime de transição do escoamento laminar para turbulento;

- Regime turbulento sem redução de atrito;

- Regime turbulento com redução de atrito;

- Regime turbulento com redução de atrito, independentemente dos parâmetros poliméricos.

Esses regimes podem ser comparados, como por exemplo, nas figuras 8.15, 8.16 e 8.17. Para o regime laminar não há redução de arrasto independente da concentração polimérica. Depois, tem-se a o regime de transição do escoamento laminar para turbulento, cuja faixa de Reynolds varia de 2300 - 4000, e ainda não apresenta a redução de arrasto. Em seguida, tem-se o regime turbulento sem redução de atrito cujo valor do número de Reynolds se encontra entre 4000 e 6500. Esses dois últimos regimes podem ser vistos na figura 8.15, enquanto que nas figuras 8.16 e 8.17, o fenômeno da redução de arrasto é apresentado nesses regimes. Após, essa faixa, tem-se o regime turbulento com redução de atrito, para valores de Reynolds maiores que 6500. E, para 
finalizar, tem-se o regime turbulento com redução de atrito, independentemente dos parâmetros poliméricos, apresentando que o fenômeno em estudo é limitado por um valor que é independente dos parâmetros poliméricos, ou seja, incrementos dos valores da concentração polimérica não conseguem mais melhorar a eficiência dos polímeros nas condições experimentais desse trabalho.

Ambos os polímeros, o polyox WSR-301 e as poliacrilamidas são os tipos de polímeros mais usados para aplicações comerciais. Eles apresentam moléculas flexíveis e lineares e, podem ser obtidos numa ampla faixa de pesos moleculares. Estudos demonstram que as poliacrilamidas podem suportar maiores valores de cisalhamento do que o polyox WSR-301 (Hoyt, 1986). Dessa forma, os valores de redução de arrasto para o polyox WSR-301 ficariam diminuídos com o decorrer do tempo de utilização devido à degradação polimérica por parte do cisalhamento e os valores da redução de arrasto das poliacrilamidas, como resiste mais ao cisalhamento, promoveriam uma maior eficiência. Porém como nosso intuito de aplicação desses polímeros é no âmbito vascular, onde se têm pequenos valores de cisalhamento, a eficiência do polyox WSR301 é preservada.

Outro fato interessante é que para baixas concentrações poliméricas (5 ppm), o polyox WSR-301 e a poliacrilamida 1822 S são os polímeros que apresentam uma maior eficiência de redução de arrasto. E esses são os dois polímeros que apresentam menores valores de viscosidade nessa faixa de concentração e ambos os polímeros apresentam comportamento de fluido newtoniano. Como pode ser visto na figura 9.3, o polyox WSR-301, também denominado como óxido de polietileno (PEO), apresenta comportamento de fluido newtoniano para as concentrações usadas nesse trabalho (para taxa de deformação superior a $0,1 \mathrm{~s}^{-1}$ ) e, na figura 8.5 , a poliacrilamida $1822 \mathrm{~S}$ apresenta comportamento de fluido newtoniano para concentração de 5 e 10 ppm. Assim, a maior eficiência na redução de arrasto apresentado nesse trabalho, cujo polímero é o polyox WSR-301, ocorre para solução apresentando comportamento de fluido newtoniano, ou seja, esse polímero não está mudando o comportamento da solução na qual ele está sendo diluído. 

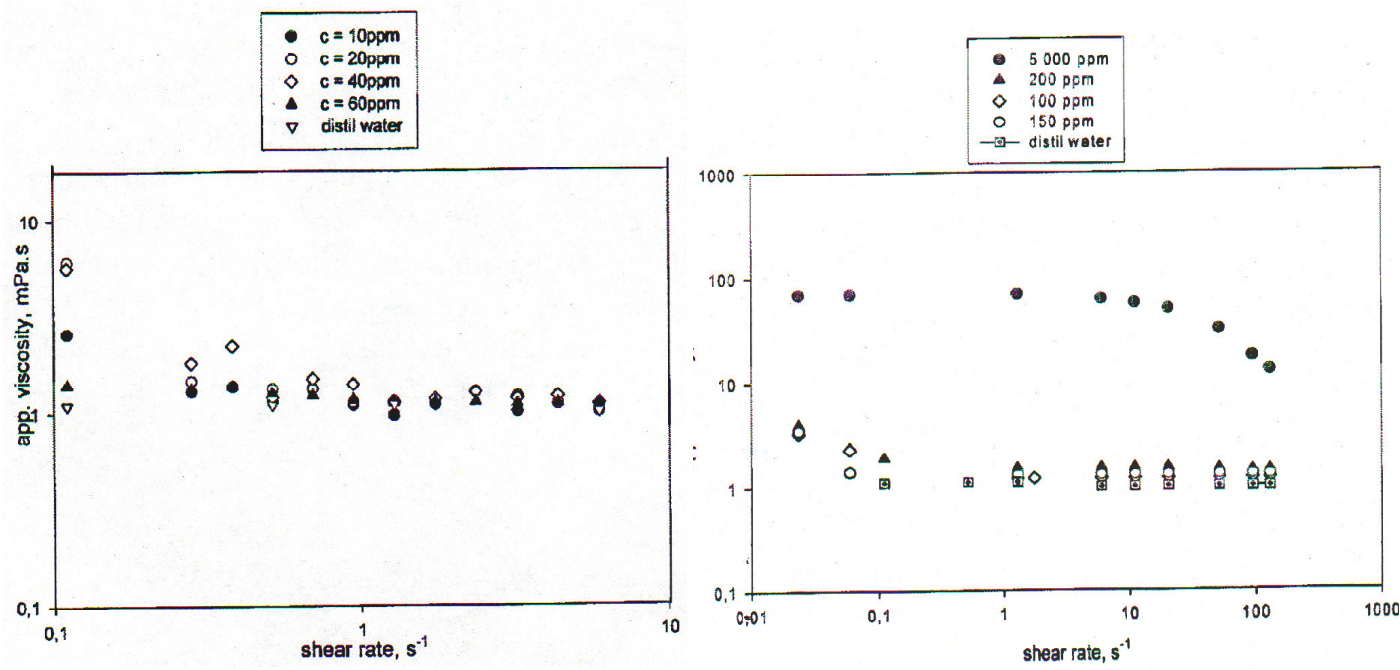

Figura 9.3. Viscosidade versus taxa de cisalhamento para a solução de PEO para concentrações de 10, 20, 40, 60, 100, 150, 200 e 500 ppm e água destilada. (Antonova \& Lazarov, 2004).

De uma forma geral, até os dias atuais, o fenômeno da redução de arrasto vem sendo estudado com o intuito de entender cada vez mais a interação dos aspectos químicos, mecânicos e hidrodinâmicos com o escoamento turbulento. Há diversos trabalhos mostrando que as partículas das substâncias redutoras de arrasto (moléculas compridas e flexíveis) interagem estreitamente com as partículas do solvente, mudando substancialmente o comportamento do escoamento turbulento na região da parede. Nessa região, ocorrem diminuições das pulsações transversais de velocidade e pressão, e dessa forma exerce uma decisiva influência no nível geral da turbulência e no comportamento de todo o escoamento.

\subsection{Bancada Experimental do ICB}

\subsubsection{Reatividade do leito arterial caudal em resposta ao fluxo}

Como pode ser visto na figura 8.22, os valores da pressão de perfusão média são maiores para o animal SHR do que para o animal Wistar, mostrando que há maior reatividade no leito arterial caudal do SHR. Esse resultado foi demonstrado pela primeira vez em animais SHR por Konishi \& Su (1983) que atribuiram esse fato à falta de relaxamento mediada pelo endotélio e, sabe-se que este fenômeno ocorre progressivamente com o aumento da idade (Hongo et al., 1988). Ultimamente, tem-se 
atribuído o aumento da pressão arterial, em patologias como hipertensão, devido ao aumento da resistência periférica. A resistência periférica é determinada principalmente pelos vasos de resistência, que consistem de pequenas artérias, cujos diâmetros são menores que $300 \mu \mathrm{m}$ (Chirstensen \& Mulvany, 2001). Trabalhos recentes têm demonstrado que o aumento da resistência periférica é devido à diminuição do diâmetro interno do vaso, pelo menos em parte (Mulvany, 2002). Essa diminuição do diâmetro interno do vaso é devido à mudança estrutural, conhecido como remodelamento (Haegerty et al., 1993) que pode ser eutrófico (rearranjo das células musculares) ou hipertrófico (aumento no número de células). Esse remodelamento pode ser visto na figura 8.19, onde o animal SHR apresenta um diâmetro interno menor do que no animal Wistar. Assim, de acordo com a equação de Poiseuille (equação 9.2), o principal fator de resistência do escoamento é o raio que está elevado à quarta potência. Dessa forma, com a diminuição do raio há aumento da potência de bombeamento e, conseqüentemente, aumento da pressão.

$$
Q=\frac{\pi \Delta p D^{4}}{128 \mu L}
$$

\subsubsection{Influência do endotélio, do óxido nítrico, do fator hiperpolarizante derivado do endotélio e das prostaglandinas sobre a ação da perfusão do polietileno glicol nos leitos arteriais caudais}

A participação do endotélio na liberação de substância que é capaz de relaxar a musculatura lisa vascular foi demonstrada por Furchgott \& Zawadzki (1980). Hoje, sabe-se que o endotélio controla o tônus da musculatura lisa vascular pela produção de mediadores que podem produzir vasodilatação ou vasoconstrição. Os principais fatores relaxantes derivados do endotélio são o óxido nítrico (NO), as prostaglandinas e o fator hiperpolarizante derivado do endotélio (EDHF). Sabendo-se disso, primeiramente fomos verificar qual a participação das células endoteliais no controle da pressão de perfusão média nos leitos arteriais caudais de ratos Wistar e SHR. A figura 8.24 apresenta os resultados da PPM versus fluxo na presença e ausência do endotélio, bem como, dos inibidores do óxido nítrico (LNAME), da prostaglandina (indometacina) e do fator hiperpolarizante derivado do endotélio (tetraetilamônio). A ausência do endotélio eleva bastante a PPM mostrando a participação do endotélio no controle da PPM, ou 
seja, o endotélio é capaz de liberar substâncias vasodilatadoras para o controle da PPM. Ainda na figura 8.24, percebe-se que os principais vasodilatadores derivados do endotélio que estão participando do controle da PPM são a prostaciclina e o óxido nítrico, já que na inibição dessas substâncias ocorre aumento da PPM, enquanto que o EDHF não participa desse controle, pois através da sua inibição, os valores da PPM não foram alterados quando comparados com a presença do endotélio.

No animal SHR, conforme apresentado na figura 8.25, a participação do endotélio, do NO e do EDHF, não interferem no controle da PPM. Como o SHR é um modelo experimental de hipertensão arterial e sabe-se que nesses modelos a vasodilatação dependente do endotélio está bastante reduzida (Vanhoutte \& Boulanger, 1995), isto explica a falta de participação do endotélio no controle da PPM. Uma possível explicação para a não participação do NO é devido ao aumento do estresse oxidativo nos animais SHR. Vários são os trabalhos apresentando o aumento na produção de ânions superóxidos em vasos de resistência (mesentérica) e em vasos de condutância (aorta) (Rodriguez-Iturbe et al., 2003; Tanito et al., 2004; Shokoji et al., 2003; Park et al., 2002). Esses aniôns superóxidos reagem com o NO para formar o peroxinitrito $\left(\mathrm{ONOO}^{-}\right)$, diminuindo a biodisponibilidade do $\mathrm{NO}$ e, conseqüentemente seu efeito como vasodilatador. Da mesma forma que o endotélio produz as substâncias vasodilatadoras, esse também produz substâncias vasoconstritoras. Uma dessas substâncias vasoconstritoras é a prostagladina $\mathrm{H}_{2}\left(\mathrm{PGH}_{2}\right)$ que em condições fisiológicas a sua produção é baixa, porém em condições patológicas, como por exemplo, na hipertensão, o seu efeito torna-se bastante pronunciado. E uma vez que ocorra sua inibição, na presença da indometacina, haverá uma menor ação vasoconstritora permitindo a ação das outras substâncias vasodilatadoras contribuindo para diminuição da PPM. Assim, na presença da indometacina, inibidor das prostaglandinas, ocorre diminuição nos valores da PPM como pode ser visto na figura 8.25.

O polietileno glicol é um polímero solúvel em água, sem carga elétrica, sem afinidade com qualquer órgão específico, não-imunogênico e apresenta vários pesos moleculares (Harris \& Chess, 2003; Yamaoka et al., 1994). Ele é amplamente utilizado na indústria como componente de muitos materiais e processos, principalmente na biotecnologia. Devido a sua baixa toxicidade, ele tem sido aprovado pela FDA (Food \& Drug Administration) para consumo interno (Milton, 1992). Johnson et al. (1971) fez um amplo estudo acerca da toxicidade do PEG 4000 e mostrou que este pode ser administrado intravenosamente em animais (ratos, coelhos, macacos) em doses de 
$16 \mathrm{~g} / \mathrm{kg}$ (peso corporal do animal), o qual corresponde a $16-25 \%$ no plasma. E quando administrado em humanos, o PEG entre os pesos moleculares de $1000 \mathrm{Da}(1 \mathrm{kDa})$ e $6000 \mathrm{Da}$ (6 kDa) são excretados pelos rins (Milton, 1992). De acordo com os resultados apresentados no item 8.3.3 e 8.3.4, o PEG 4000 reduziu os valores da pressão de perfusão média nos ratos normotensos (Wistar) e espontaneamente hipertensos (SHR) na presença e ausência do endotélio, do LNAME, da indometacina e do tetraetilamônio (figuras 8.26 e 8.27). Bertuglia et al. (2006) utilizaram o PEG5000 e PEG10000 juntamente com um novo nitrato orgânico de PEG (PEG-NO) para reparar a disfunção endotelial na isquemia-reperfusão, onde a isquemia é a falta de suprimento sangüíneo a um determinado tecido orgânico e a reperfusão é a restauração desse suprimento. Eles mostraram que o PEG não teve efeito sob a condição controle, porém após a isquemia reperfusão, esse reduziu o estresse oxidativo, aumentou o diâmetro das artérias e a perfusão capilar. Possivelmente, o aumento do fluxo após a isquemia-reperfusão é devido o PEG se inserir na camada superficial do endotélio e, desse modo, tornar a membrana endotelial mais sensível à tensão de cisalhamento que é responsável pela vasodilatação e mais resistente ao estresse oxidativo. Portanto, a redução nos valores da PPM (Figuras 8.23, 8.26 e 8.27) é, possivelmente, devido o PEG tornar a membrana endotelial mais sensível à tensão de cisalhamento e, conseqüentemente, saindo do quadro da disfunção endotelial, liberando substâncias vasodilatadoras e tornando-a mais resistente ao estresse oxidativo.

\subsubsection{Redução de arrasto a partir do cálculo do fator de atrito nos leitos arteriais caudais de ratos normotensos (Wistar) e espontaneamente hipertensos (SHR).}

A partir dos gráficos do fator de atrito versus número de Reynolds, torna-se mais clara a participação das células endoteliais na redução do fator de atrito. Na figura 8.28, percebe-se que a presença do endotélio é crucial para diminuição do fator de atrito, desde que o animal não apresente a disfunção endotelial (Wistar). Para os animais SHR E+ e SHR E- os valores do fator de atrito são iguais. Os valores do fator de atrito são praticamente iguais para Wistar E- e SHR E + mostrando que o animal Wistar Ecomporta-se como um animal patológico (SHR), confirmando a hipótese da disfunção endotelial neste animal (SHR).

O efeito do PEG4000 juntamente com as células endoteliais são apresentados na figura 8.29. Na presença das células endoteliais, os valores do fator de atrito são 
menores do que quando comparados com os valores do fator de atrito universal (fator de atrito de Darcy-Weisbach) e, na presença do PEG4000, os valores do fator de atrito diminuem ainda mais, confirmando-se assim, a hipótese de que o PEG4000 reduz a resistência ao escoamento.

$\mathrm{Na}$ ausência do endotélio, o PEG4000 diminui a resistência do escoamento, conforme apresentado na figura 8.30. Porém, essa diminuição é menor do que na presença do endotélio, conforme pode ser visto na figura 8.31. Nessa figura, tem-se a redução de arrasto versus fluxo e pode ser visto que na presença do endotélio a redução de arrasto é maior. No Wistar E+ e Wistar E-, o efeito do PEG4000 como redutor de arrasto diminui com o aumento do fluxo, enquanto, para o SHR, a redução de arrasto se dá praticamente constante, independentemente do fluxo. Outro efeito claro que pode ser visto na figura 8.31 é o efeito das células endoteliais na participação da redução de arrasto. No Wistar E-, a redução de arrasto diminuiu em média em torno de 33\%, enquanto no SHR E-, esta redução em média ficou em torno de 48\%. Para o animal SHR, a redução de arrasto pode ser atribuída 50\% para o efeito do PEG e 50\% para o efeito das células endoteliais, pois na ausência das células endoteliais a redução de arrasto caiu em torno de $50 \%$. A partir desses resultados pode-se concluir que a ação da redução de arrasto em leitos arteriais caudais de ratos normotensos (Wistar) e espontaneamente hipertensos (SHR) é intensificada pela presença $(\mathrm{E}+)$ das células endoteliais. Assim, a redução de arrasto nesses leitos pode ser entendida como apresentando efeito mecânico e fisiológico, pois na ausência do endotélio o fenômeno da redução de arrasto permanece.

\subsubsection{Distribuição espacial e temporal da tensão de cisalhamento nos leitos arteriais caudais de ratos normotensos (Wistar) e espontaneamente hipertensos (SHR).}

Conforme comentado no item 8.3.6, as simulações computacionais foram realizadas para a vazão fisiológica caudal de $2,5 \mathrm{~mL} / \mathrm{min}$. A principal limitação da simulação numérica é devido as paredes do vaso serem consideradas rígidas. Porém, há trabalhos na literatura apresentando que quando o modelo de distensibilidade de parede era incluído na simulação computacional, a estrutura global do escoamento permanecia sem mudança quando comparada com o modelo de referência rígida, com pequena 
diminuição nos valores da tensão de cisalhamento no modelo de distensibilidade de parede (Hofer et al., 1996).

A análise da tensão de cisalhamento sobre as células endoteliais é importante, pois essas células, que revestem a parede interna do vaso, são sensíveis às mudanças do fluxo sangüíneo, de pressão, de sinais inflamatórios e de hormônios circulantes, portanto, essas células são capazes de integrar sinais hemodinâmicos e humorais e modular o tônus vasomotor de acordo com as necessidades metabólicas teciduais locais (Amodeo \& Heimann, 2003). Além disso, o principal estímulo fisiológico para produção do NO é a tensão de cisalhamento (Davies, 1995). O aumento do fluxo sangüíneo e, conseqüentemente, da tensão de cisalhamento, logo após a sua elevação, conduz a ativação aguda da eNOS (enzima) levando a uma rápida liberação de NO que tem como conseqüência fisiológica a regulação rápida do diâmetro vascular. Caso esse novo valor de tensão de cisalhamento permaneça por algumas horas, esse estimula um aumento na expressão do mRNA e na expressão protéica da eNOS (Figura 9.1). Essas etapas são possíveis de ocorrer devido ao endotélio possuir mecanorreceptores que detectam alterações mecânicas, como nesse caso a variação da tensão de cisalhamento, e transforma em sinais bioquímicos, cujo resultado nesse caso é a liberação do NO.

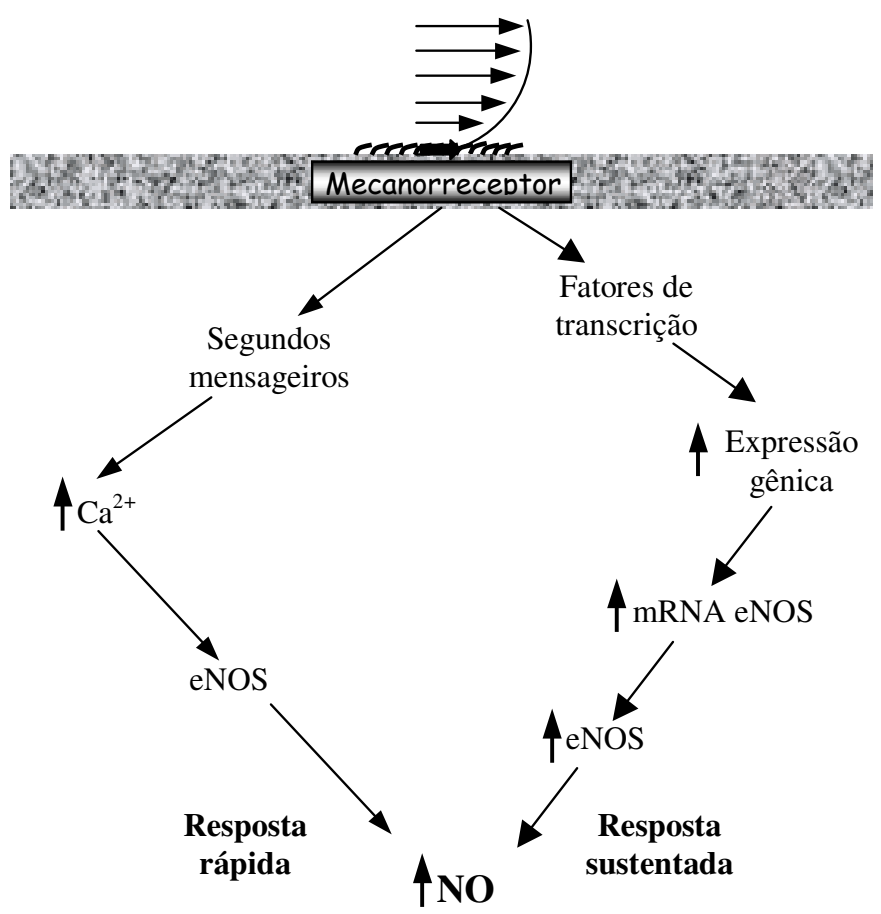

Figura 9.4. Mecanismo da liberação de óxido nítrico em resposta ao fluxo sangüíneo. Extraído de Cingolani et al. (2004). 
Vários trabalhos na literatura mostram que a dilatação induzida pela tensão de cisalhamento devido ao aumento do fluxo está reduzida em arteríolas de músculo esquelético de ratos espontaneamente hipertensos (SHR) de idade acima de 12 semanas quando comparadas com os ratos normotensos (Koller \& Huang, 1994; Koller \& Huang, 1995; Matrogui et al., 1997). Essa alteração contribui para o aumento da resistência vascular periférica. Estudos demonstram que essa resposta reduzida ocorre devido à falha da porção mediada pelo óxido nítrico (NO), considerando que a porção mediada pela prostaglandina (prostaciclina) está presente (Koller \& Huang, 1995).

Nos resultados apresentados nesse trabalho, os valores das tensões de cisalhamento foram maiores nos animais hipertensos quando comparados com os valores obtidos com os animais normotensos. Isto pode ser atribuído a um aumento da presença ou produção de ânions superóxidos que leva a uma menor biodisponibilidade do óxido nítrico, conforme comentado no parágrafo anterior. A participação do endotélio na redução da tensão de cisalhamento, atuando como um redutor de arrasto torna-se claro nas figuras 8.35 e 9.5 .

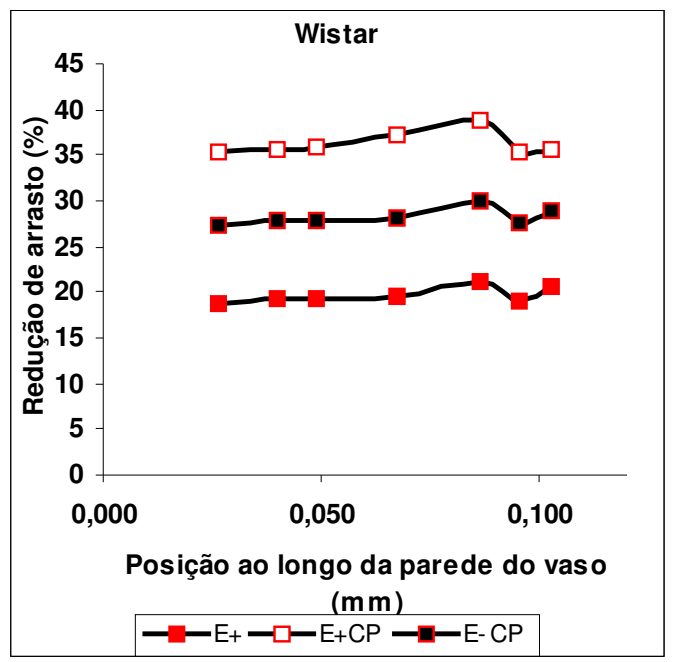

Figura 9.5. Porcentagem de redução de arrasto na presença das células endoteliais e do PEG4000 ao longo da parede do vaso para fluxo de $2,5 \mathrm{~mL} / \mathrm{min}$ (Wistar).

Valores da ordem de $20 \%$ de redução de arrasto ocorrem na presença das células endoteliais de animais Wistar (Figura 9.5). Esse valor é aumentado na presença do PEG4000, ou seja, a redução de arrasto proveniente das células endoteliais é intensificada pela presença do PEG4000. Alguns trabalhos na literatura apresentam o uso de polímeros redutores de arrasto em aplicações vasculares, porém nenhum dos trabalhos apresenta a relação entre os polímeros usados e as células endoteliais. $\mathrm{Na}$ 
maior parte desses trabalhos (Pacella et al., 2006; Marhefka et al., 2006; Macias et al., 2004; Kameneva et al., 2004), o efeito dos polímeros redutores de arrasto é apresentado como sendo devido à capacidade desses polímeros de atuar na camada de parede diminuindo a perda de carga em bifurcações e, com isso diminuindo a resistência ao escoamento. Além disso, outra hipótese adotada pelos grupos é que esses polímeros agem sobre os eritrócitos, fazendo com que essas células passem a ocupar a região de parede, ocupada inicialmente pelo plasma, assim ocorre um aumento da tensão de cisalhamento e, conseqüentemente promove a vasodilatação. Sawchuck et al. (1999) mostrou que o efeito desses polímeros ocorre através do aumento da taxa de deformação e, conseqüentemente, aumenta os valores da tensão de cisalhamento sobre a parede do vaso que, como consequiência, leva ao processo de vasodilatação. Para que essas hipóteses sejam válidas, é necessário que as células endoteliais estejam respondendo de maneira satisfatória ao fluxo, ou seja, o vaso não pode estar num quadro de disfunção endotelial. Isso quer dizer que a ação desses polímeros seria apenas nos quadros ausentes de disfunção endotelial, porém os nossos resultados apresentam que o PEG4000 age na ausência dos eritrócitos e no quadro de disfunção endotelial apresentado pelos animais espontaneamente hipertensos (SHR) (Figuras 8.36 e 9.6).

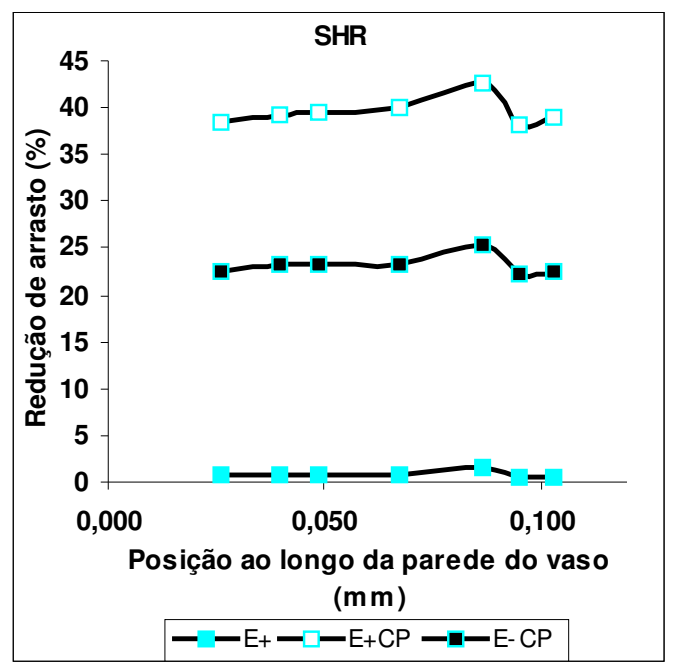

Figura 9.6. Porcentagem de redução de arrasto na presença das células endoteliais e do PEG4000 ao longo da parede do vaso para fluxo de $2,5 \mathrm{~mL} / \mathrm{min}$ (SHR).

Na figura 9.6, está claro o quadro da disfunção endotelial apresentado pelos animais SHR. A participação das células endoteliais na redução dos valores da tensão de cisalhamento é praticamente zero. Porém, na presença do PEG4000 os valores da redução de arrasto aumentam para 40\% e, na ausência do endotélio (E-), o PEG4000, 
também, apresenta sua capacidade de redutor de arrasto, porém essa capacidade é diminuída. Comparativamente, a diferença do efeito do PEG4000 nos animais SHR E+ e E- está em torno de $20 \%$, enquanto que nos animais Wistar E+ e E-, essa diferença diminui em torno de 9\%. Dessa forma, fica claro que o efeito do PEG4000 é maior na presença das células endoteliais.

Alguns trabalhos na literatura (Bertuglia et al., 2004; Bertuglia, 2005; Mochizuki et al., 2003) mostram que após um processo de isquemia-reperfusão, a tensão de cisalhamento nas arteríolas está diminuída, sugerindo que esse processo altera a mecanotransdução do endotélio via danos na formação de NO. Bertuglia et al. (2006) mostraram que, os processos de vasoconstrição e permeabilidade vascular, foram diminuídos na presença do PEG (PEG 5000 ou 10000). Eles atribuíram à capacidade do PEG de reparar danos na membrana endotelial e, dessa forma diminuir a produção de ânions superóxidos permitindo uma maior biodisponibilidade de NO. Assim, os menores valores da tensão de cisalhamento obtidos nesse trabalho na presença do PEG4000, possivelmente, são devido à diminuição da produção de ânions superóxidos e, dessa formar, permitindo a ação de vasodilatadores.

Diante do exposto acima, o efeito do PEG4000 como redutor de arrasto no sistema vascular vai além do mecanismo puramente mecânico (estiramento das moléculas, incremento da viscosidade local, reestruturação da turbulência), ou seja, há interação do polímero com a fisiologia vascular, melhorando o processo de vasodilatação, possivelmente, inibindo ou diminuindo os ânions superóxidos e, dessa forma, tornando o NO biodisponível.

\section{Conclusões}

No presente trabalho desenvolveu-se um estudo experimental sobre a viscosidade das soluções poliméricas de polietileno glicol (PEG4000) e poliacrilamidas $1822 \mathrm{~S}$ e $1340 \mathrm{~S}$ e sobre a redução de arrasto em duas bancadas experimentais, onde uma bancada está localizada na EPUSP e a outra no ICB-I. O intuito do estudo foi analisar o fenômeno da redução de arrasto a partir de simulação experimental complementada por simulação computacional, de modo a se obter a distribuição da tensão de cisalhamento ao longo do leito arterial caudal de ratos normotensos e hipertensos. 


\subsection{Análise Viscosa}

As seguintes conclusões são possíveis de serem estabelecidas para o estudo da viscosidade das soluções poliméricas:

- O polietileno glicol (PEG4000) apresenta comportamento de fluido newtoniano para a concentração utilizada nesse trabalho - 5000 ppm;

- As poliacrilamidas $1822 \mathrm{~S}$ e $1340 \mathrm{~S}$ apresentam comportamento de fluido newtoniano para as concentrações de 5 e 10 ppm. Para concentrações maiores que $30 \mathrm{ppm}$, as soluções poliméricas apresentam comportamento de fluido não-newtoniano (pseudoplástico);

\subsection{Bancada experimental da EPUSP}

As seguintes conclusões são possíveis de serem estabelecidas:

- A redução de arrasto mostrou-se dependente do tipo de polímero, da sua concentração e do tipo de escoamento;

- Polímeros com peso molecular da ordem 1000 Da não apresentam redução de arrasto em tubos rígidos, por exemplo, o PEG4000. Porém, o Polyox WSR-301, cuja estrutura química é semelhante ao do PEG4000, mas com um peso molecular da ordem de $10^{6} \mathrm{Da}$, apresenta redução de arrasto;

- Não existe redução de arrasto dentro do regime laminar, pelo menos em tubos rígidos, para nenhuma concentração e nenhum tipo de polímero utilizado nesse trabalho;

- As poliacrilamidas apresentam o fenômeno da redução de arrasto desde a transição do escoamento laminar para turbulento até o escoamento turbulento, enquanto que o Polyox WSR-301 restringe-se ao regime turbulento (Re>4000) e o PEG4000 não apresenta o fenômeno da redução de arrasto em nenhum dos regimes estudados nesse trabalho;

- O polyox WSR-301 mostrou-se mais eficiente na redução de arrasto do que as poliacrilamidas $1822 \mathrm{~S}$ e $1340 \mathrm{~S}$. 


\subsection{Bancada experimental do ICB-USP}

As seguintes conclusões são possíveis de serem estabelecidas:

- Os animais SHR apresentam uma reatividade maior do que os animais normotensos;

- As células endoteliais modulam a pressão de perfusão média;

- No animal normotenso (Wistar), os principais vasodilatadores estimulados pela tensão de cisalhamento são a prostaciclina e o óxido nítrico, sendo o último menos intenso;

- No animal espontaneamente hipertenso (SHR), ocorre uma severa diminuição da ação dos vasodilatadores, prevalecendo à ação dos vasoconstritores, como por exemplo, as prostagladinas;

- As células endoteliais são redutoras de arrasto;

- A redução de arrasto promovida pelo PEG4000 ocorre para os animais normotensos (Wistar) e espontaneamente hipertensos (SHR) em regime laminar, sendo mais intensa no SHR;

- A ação do polietileno glicol (PEG4000) como redutor de arrasto é intensificada pelas células endoteliais.

Finalizando, esse trabalho mostrou, pela primeira vez, a ação de polímeros redutores de arrasto associados com as células endoteliais em leitos arteriais caudais de ratos normotensos e hipertensos, tornando mais clara a ação desses polímeros no sistema vascular e contribuindo para ampliar a definição de redução de arrasto levando em consideração aspectos não só fluidodinâmicos, mas também, fisiológicos e bioquímicos. Além disso, esse trabalho mostra a possibilidade do uso da solução do PEG4000 para melhorar a função endotelial em situações crônicas de disfunção endotelial, possibilitando, dessa forma, o desenvolvimento de um fármaco derivado desse polímero ou que contenha as propriedades do mesmo. 


\section{Referências Bibliográficas}

Akhavan, R., Kamm, R.D., Shapiro, A.H., 1991a. An investigation of transition to turbulence in bounded oscillatory Stokes flows. Part 1. Experiments. Journal of Fluid Mechanics 225, 395-422.

Akhavan, R., Kamm, R.D., Shapiro, A.H., 1991b. An investigation of transition to turbulence in bounded oscillatory Stokes flows. Part 2. Numerical simulations. Journal of Fluid Mechanics 225, 423-444.

Amodeo, C., Heimann, J.C., 2003. Endotélio e hipertensão arterial sistêmica: mecanismos de lesão/novo alvo terapêutico? Rev. Soc. Cardiol Estado de São Paulo $13,121-129$.

Antonova, N., Lazarov, Z., 2004. Hemorheological and hemodynamic effects of high molecular weight polyethylene oxide solutions. Clinical Hemorheology and Microcirculation 30, 381-390.

Armechol - The Elegance Engineers - http://www.dow.com/ucc/amerchol/index.htm

Berger, S.A., Goldsmith, W. and Lewis, E.R., 1996, Introduction to bioengineering. England: Oxford University Press.

Bertuglia, S., Giusti, A., Picano, E., 2004. Effects of diagnostic cardiac ultrasound on oxygen free radical production and microvascular perfusion during ischemia reperfusion. Ultrasound Med Biol 30, 549-557.

Bertuglia, S., 2005. Mediated-shear stress increase in capillary perfusion induced by low intensity ultrasound in presence of microbubbles in postischemic reperfusion Crit Care Medic 33, 2061-2067.

Bertuglia, S., Veronese, F.M., Pasut, G., 2006. Polyethylene glycol and a novel developed polyethylene glycol-nitric oxide normalize arteriolar response and oxidative stress in ischemia reperfusion. Am J Physiol Heart Circ Physiol 4, H1536H1544.

Bird, R.B., Stewart, W.E., Lightfoot, E.N., 2004. Fenômenos de transporte, LTC Livro Técnicos e Científicos Editora S.A., pp 838.

Bottenberg, P., Cleymaet, r., de Muynck, C., Remon, J.P., Coomans, D., Michotte, Y. and Slop, D., 1991. Development and testing of bioadhesive, fluoride-containing slow-release tablets for oral use. The Journal of Pharmacy and Pharmacology 43(7), 457-464. 
Christensen, K.L., Mulvany M.J., 2001. Location of resistance arteries. J. Vas. Res 38, $1-12$.

Cingolani, H.E., Houssay, A.B. \& Cols, 2004. Fisiologia humana de Houssay. 7 ed. Atualizada e ampliada. Porto Alegre, Artmed, 1124p.

Davies, P.F., 1995. Flow-mediated endothelial mechanotransduction. Physiol. Rev. 75, 519-560.

Driels, M.R., Ayyash, S., 1976. Drag reduction in laminar flow. Nature 259, pp. 389390.

Faruqui, I.F., Otten, M.D., Polimeni, P.I., 1987. Protection against atherogenesis with the polymer drag-reducing agent Separan AP-30. Circulation 75, 627-635.

Fox, R.W., McDonald, A.T., 1998. Introdução à mecânica dos fluidos. Livros Técnicos e Científicos Editora S.A., Rio de Janeiro, 4ed, pp.253-255.

França, A.S.; Rossoni, L.V.; Amaral, S.M.C.; Vassalo, D.V., 1997. Reactivity of the isolated perfused rat tail vascular bed. Brazilian Journal of Medical and Biological Research. 30, 891-895.

Fung, Y.C., 1997. Biomechanics: circulation. Springer, New York, 2ed.

Furchgott, R. F. \& Zawadzki, J. V., 1980. The obligatory role of endothelial cells in the relaxation of arterial smooth muscle by acetylcholine. Nature 299, 373-376.

Guerino Silva, D., 1998. Um Simulador de Escoamento para Estudo in vitro dos Vasos Sangüíneos. Dissertação apresentada à Escola Paulista de Medicina.

Gyr, A., Bewersdorff, H.W., 1995. Drag Reduction of Turbulent Flows by Additives. Kluwer Academic Publishers, Dordrecht.

Harris, J.M., 1992. Poly(ethylene glycol) chemistry: biotechnical and biomedical applications. New York: Plenum Press, 385 p.

Harris, J.M., Chess, R.B., 2003. Effect of PEGylation on pharmaceuticals. Nat Rev Drug Discov 2, 214-221.

Haegerty, A. M., Aalkjaer, C., Bund, S. J., Korsgaard, N., Mulvany, M. J., 1993. Small artery structure in hypertension: dual processes of remodeling and growth. Hypertension 21, 391-397.

Hofer, M., G. Rappistsch, K. Perktold, W. Trubel, H. Schima, 1996. Numerical study of wall mechanics and fluid dynamics in end-to-side anastomoses and correlation to intimal hyperplasia. Journal of Biomechanics, 29, 1297-1308. 
Hongo, K., Nakagomi, T., Kassel, N.F., Sasaki, T., Lehman, M., Vollmer, D. G., Tsukahara, T., Ogawa, H., Torner, J., 1988. Effects of aging and hypertension on endothelium-dependent vascular relaxation in rat carotid artery. Stroke 19, 892-897.

Hoyt, J.W., 1986. Drag reduction. Enciclopedia of Polymer Science and Engineering 5, Wiley, New York, 129.

Hutchison, K.J., Campbell, J.D., Karpinski, E., 1989. Decreased poststenotic flow disturbance during drag reduction by polyacrylamide infusion without increased aortic blood flow. Microvascular Research 38, 102-109.

IARC. Monographs on the evaluation of carcinogenic risks to humans. Some industrial chemicals 60. Lyon: IARC - http://monographs.iarc.fr/

Johnson, K.A., Gorzinski, S.J., Bodner, K.M., Campbell, R.A., Wolf, C.H., Friedman, M.A., Mast, R.W., 1986. Chronic toxicity and oncogenicity study on acrylamide incorporated in the drinking water of Fischer 344 rats. Toxicol Appl Pharmacol 85,1 $54-68$.

Johnson, A.J., Karpatkin, M.H., Newman, J., 1971. Clinical investigation of intermediat and high-purity antihaemophilic factor (factor VIII) concentrates. Br J Haemtol 21, 21-41.

Junqueira, L.C.U., Junqueira, L. M. M. S., 1983. Técnicas básicas de citologia e histologia. São Paulo: Santos.

Kameneva, M.V., Repko, B.M., Krasik, E.F., Perricelli, B.C., Borovetz, H.S., 2003. Polyethylene glycol additives reduce hemolysis in red blood cell suspensions exposed to mechanical stress. ASAIO Journal, 537-542.

Kameneva, M.V., Wu, Z.J., Uraysh, A., Repko, B., Litwak, K.N., Billiar, T.R., Fink, M.P., Simmons, R.L., Griffith, B.P., Borovetz, H.S., 2004. Blood soluble dragreducing polymers prevent lethality form hemorrhagic shock in acute animal experiments, Biorheology, 41: 53-64.

Kameneva, M.V., Fink, M.P., 2005. Hemorrhagic shock, drag-reducing polymers and 'spherical cows'. Critical Care, Vol. 9, n’ 3, 304-305.

Keller, A., Kiss, G., Mackley, M.R., 1975. Polymer drag reduction in Taylor vortices. Nature 257, 304-305.

Kemwater Brasil S.A. - www.kemwater.com.br

Koller, A. \& Huang, A., 1994. Impaired nitric oxide-mediated flow-induced dilation in arterioles of spontaneously hypertensive rats. Circulation Research 74, 416-421. 
Koller, A. \& Huang, A., 1995. Shear stress-induced dilation is attenuated in skeletal muscle arterioles of hypertensive rats. Hypertension 25, 758-763.

Koller, A., Huang, An, 1999. Development of nitric oxide and prostaglandin mediation of shear stress-induced arteriolar dilation with aging and hypertension. Hypertension 34, 1073-1079.

Konishi, M. \& Su, C., 1983. Role of endothelium in dilator responses of spontaneously hypertensive rat arteries. Hypertension 5, 881-886.

Kulik, V.M., 2001. Drag reduction change of polyethyleneoxide solutions in pipe flow. Experiments in Fluids 31, 558-566.

Leal, E.B., 2001. Simulador Hidrodinâmico para Estudos "In Vitro" do Sistema Cardiovascular. Dissertação apresentada à Escola Politécnica da Universidade de São Paulo.

Leon, D.F., Shaver, J.A., 1974. Physiologic principles of heart sounds and murmurs. American Heart Association Monograph No. 46.

Lumley, J.L., 1969. Drag reduction by additives. Ann. Rev. Fuid Mech. 1, 367-384.

Macias, C.A., Kameneva, M.V., Tenhunen, J.J., Puyana, J.C., Fink, M.P., 2004. Survival in a rat model of lethal hemorrhagic shock is prolonged following resuscitation with a small volume of a solution containing a drag-reducing polymer derived from aloe vera. SHOCK 22, 151-156.

Mano, E.B., Mendes, L.C., 2004. Introdução a polímeros. 2 ed. rev. e ampl. - São Paulo: Edgard Blücher.

Matrougui, K., Jacques, M., Lévy, B. I., Henrion D., 1997. Impaired nitric oxide and prostaglandin-mediated responses to flow in resistance arteries of hypertensive rats. Hypertension 30, 942-947.

Marhefka, J.N., Marascalco, P.J., Chapman, T.M., Russel, A.J., Kameneva, M.V., 2006. Poly(N-vinylformamide) - A drag-reducing polymer of biomedical applications. Biomacromolecules 7, 1597-1603.

McAndrew, T., Page, M., Susan, A., 1993. Reduction of aqueous fluid drag with poly(vinylamine). Polymeric Materials Science and Engineering 62, 195-196.

McDonald, D.A., 1974. Blood flow in arteries. The Williams \& Wilkins Company, Ed. 2 London: Edward Arnold, pp 146-156.

McLachlan, N.W., 1955. Bessel functions for engineers. Clarendon Press, Oxford.

Medline Plus: http://www.nlm.nih.gov/medlineplus/druginfo/medmaster/a603032.html.

Milnor, W.R., 1989.Hemodynamics. Williams and Wilkins, Baltimore. 
Milton, H. J., 1992. Poly(Ethylene Glycol) Chemistry, Biotechnical and Biomedical Applications (Topics in Applied Chemistry-Series). New York: Plenum Press.

Mochizuki, S., Vink, H., Hiramatsu, O., Kajita, T., Shigeto, F., Spaan, J.A., Kajiya, F., 2003. Role of hyaluronic acid glycosaminoglycans in shear-induce endotheliumderived nitric oxide release. Am J Physiol Heart Circ Physiol 2, H722-H726.

Mostardi, R.A., Greene, H.L., Nokes, R.F., Thomas, L.C., Lue, T., 1976. The effect of drag-reducing agents on stenotic flow disturbances in dogs. Biorheology 13, 137.

Mostardi, R.A., Thomas, L.C., Greene, H.L., Van Esson, F., Nokes, R.F., 1978. Supression of atherosclerosis in rabbits using drag reducing polymers. Biorheology $15,1$.

Mulvany, M.J., 2002. Small artery remodeling and significance in the development of hypertension. News Physiol Sci 17, 105-109.

Nerem, R.M., 1992. Vascular fluid mechanics, the arterial wall, and atherosclerosis. ASME Journal of Biomechanical Engineerig 114, 274-282.

Nerem, R.M., Seed, W.A., Wood, N.B., 1971. An experimental study of the velocity distribution and transition to turbulence in the aorta. Journal of fluid mechanics, 137-160.

Nerem, R.M., Seed, W.A., 1972. An in vivo study of the nature of aortic flow disturbances. Cardiovascular Research 6, 1-14.

Orszag, S.A., Patera, A.T., 1983. Secondary instability of wall-bounded shear flows. Journal of Fluid Mechanics 128, 347-385.

Pacella, J.J., Kameneva, M.V., Csikari, M., Lu, E., Villanueva, F. S., 2006. A novel hydrodynamic approach to the treatment of coronary artery disease. European Heart Journal 27, 2362-2369.

Park, J. B., Touyz, R. M., Chen, X., Schiffrin, E. L., 2002. Chronic treatment with a superoxide dismutase mimetic prevents vascular remodeling and progression of hypertension in salt-loaded stroke-prone spontaneously hypertensive rats. American Journal of Hypertension 15, 78-84.

Ptasinski, P.K., Nieuwstadt, F.T.M., Van Den Brule, B.H.A.A., Hulsen, M.A., 2001. Experiments in turbulent pipe flow with polymer additives at maximum drag reduction. Flow, Turbulence and Combustion 66, 159-182.

Radin, I., Zakin, J.L., Hoffmann, H., 1975. Drag reduction in solid-fluid systems. AIChE J. 21, 51. 
Rodriguez-Iturbe, B., Zhan, C. D., Quiroz, Y., Sindhu, R. K., Vaziri, N.D., 2003. Antioxidant-rich diet relieves hypertension and reduces renal immune infiltration in spontaneously hypertensive rats. Htpertension 41, 341-346.

Samsamshariat, S.A., Hashemzadeh, M., Samsamshariat, Z., Movahed, M.R., 2005. Cardiovascular and hemodynamic effect of polyethylene glycol in Rats. Cardiovascular Revascularization Medicine 6, 70-72.

Sawchuck, A.P., Unthank, J.L., and Dalsing, M.C., 1999. Drag reducing polymers may decrease atherosclerosis by increasing shear in areas normally exposed to low shear stress. Journal of Vascular Surgery 30, 761-764.

Schauf, C., Moffett, D., Moffett, S., 1993. Fisiologia Humana, Editora Guanabara Koogan S.A., p. 690.

Schramm, G., 2006. Reologia e reometria: fundamentos teóricos e práticos. 2 ed. São Paulo - Artiliber Editora

Scrivener, O., Koop, C., 1977. Influence of polymer solutions on the structure of turbulence in a pipe. The Phys. Fluid 20, 10.

Seed, W.A., Wood, N.B., 1971. Velocity patterns in the aorta. Cardiovascular Research 5, 319-330.

Sellin, R.H.J., Hoyt, J.W., Scrivener, O., 1982. The effect of drag reducing additives on fluid flows and their industrial applications. Part I, Basics aspects. J. Hydr. Res. 20, 29-64.

Shokoji, T., Nishiyama, A., Fujisawa, Y., Hitomi, H., Kiyomoto, H., Takahashi, N., Kimura, S., Kohno, M., Abe, Y., 2003. Renal sympathetic nerve responses to tempol in spontaneously hypertensive rats. Hypertension 41, 266-273.

Tanito, M., Nakamura, H., Kwon, Y. W., Teratani, A., Masutani, H., Shioji, K., Kishimoto, C., Ohira, A., Horie, R., Yodoi, J., 2004. Enhanced oxidative stress and impaired thioredoxin expression in spontaneously hypertensive rats. Antioxidants \& redox signaling 6, 89-97.

Toms, B.A., 1949. Some observations on the flow of linear polymer solutions through straight tubes at large Reynolds numbers. In: Proceedings 1 st International Congress on Rheology. North Holland, Amsterdan, pp.135-141.

Uchida, S., 1956. The pulsating viscous flow superimposed on the steady laminar motion of incompressible fluid in a circular pipe. Zeitshrift für angewandte Mathematik und Physik 7: 403-422. 
Usui, H., Komoda, Y., 1988. Laser Doppler measurements of turbulence structure in drag reducing pipe flow with polymer injection. Journal of Chemical Engineering of Japan 21, 134-140.

Vanhoutte, P. M. \& Boulanger, C. M., 1995. Endothelium-dependent responses in hypertension. Hypertension Research 18, 87-89.

Vilalta, A. G., Ortiz, J.P., 1995. Análise da redução de atrito em escoamentos por adição de polímeros: ensaios experimentais com soluções de poliacrilamida. 103p. Boletim Técnico da Escola Politécnica da Universidade de São Paulo - BT/PME, 19p.

Vilalta, A. G., Ortiz, J. P., 2000. Modificações na estrutura de escoamentos turbulentos em canais devido à adição de polímeros. Mecanismos da redução de atrito. Boletim Técnico da Escola Politécnica da Universidade de São Paulo - BT/PME/0005, 13p.

Watson, G.N., 1958. A treatise on the theory of Bessel functions. Cambridge University Press. Cambridge.

Womersley, J.R., 1955. Oscillatory motion of a viscous liquid in a thin-walled elastic tube - I: The linear approximation for long waves. Philosophical Magazine 46, 199221.

Wood, N.B., 1999. Aspects of fluid dynamics applied to the larger arteries. Journal of Theoretical Biology 199, 137-161.

Xueming, S., Jianzhong, L., 2001. Experimental research on drag reduction by polymer additives. http://fluid.power.net/techbriefs/hanghzau/5_2_5.pdf.

Yamaoka, T., Tabata, Y., Ikada, Y., 1994. Distribution and tissue uptake of polyethylene glycol with different molecular weights after intravenous administration to mice. Journal of Pharmaceutical Sciences 83, 601-606.

Zamir, M., 2000. The Physics of pulsatile flow. Biological Physics Series. Springer, New York, pp. 39-111. 
ANEXO I

PERFIL DE VAZÃO OSCILATÓRIA A PARTIR DO GRADIENTE DE PRESSÃO OSCILATÓRIO - MATLAB 


\section{O programa abaixo foi desenvolvido no MATLAB.}

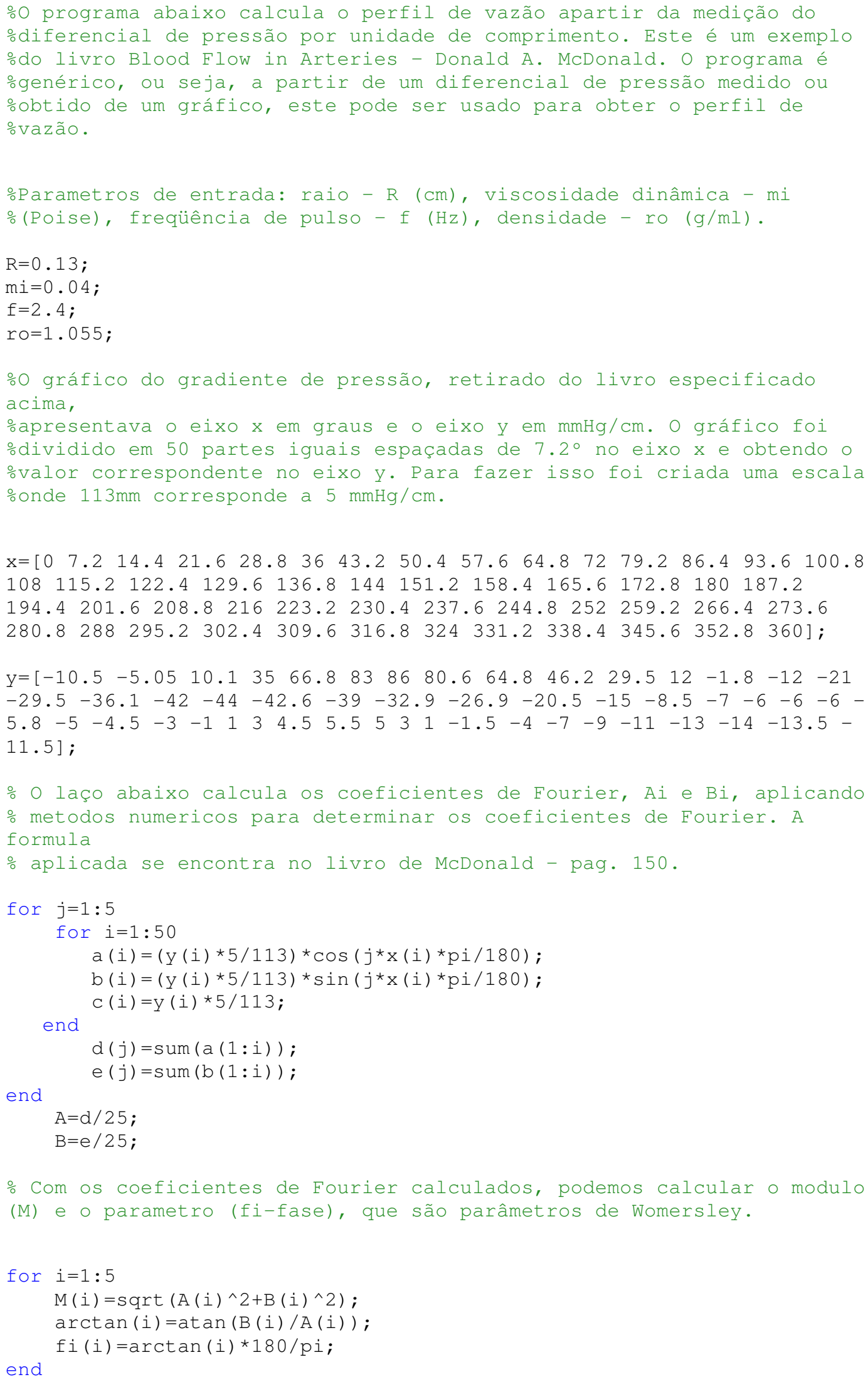




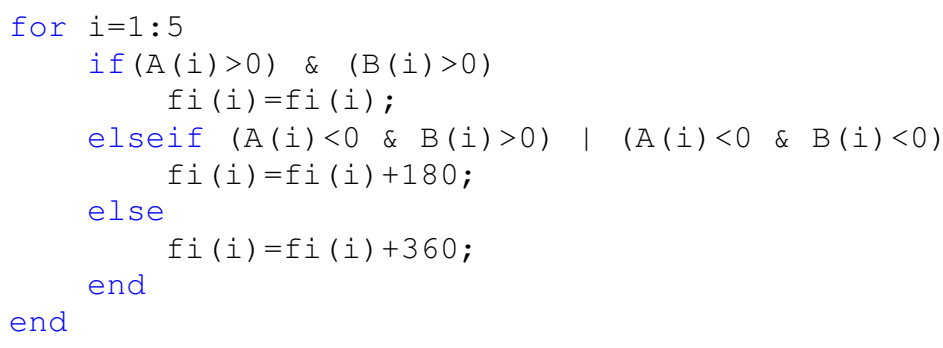

\% O vetor coluna abaixo refere-se ao termo epislon(ep_tab) (parâmetro de Womersley);

ep_tab $=[90.00 ; 89.98 ; 89.90 ; 89.79 ; 89.62 ; 89.40 ; 89.14 ; 88.83 ; 88.47 ; 88.07 ;$ $87.61 ; 87.11 ; 86.57 ; 85.97 ; 85.33 ; 84.65 ; 83.91 ; 83.14 ; 83.32 ; 81.45 ;$ $80.55 ; 79.60 ; 78.61 ; 77.59 ; 76.53 ; 75.44 ; 74.31 ; 73.16 ; 71.98 ; 70.77 ;$ $69.54 ; 68.30 ; 67.03 ; 65.76 ; 64.47 ; 63.18 ; 61.89 ; 60.59 ; 59.30 ; 58.02 ;$ $56.74 ; 55.47 ; 54.22 ; 52.98 ; 51.77 ; 50.57 ; 49.39 ; 48.24 ; 47.11 ; 46.01 ;$ $44.93 ; 43.88 ; 42.86 ; 41.86 ; 40.90 ; 39.96 ; 39.05 ; 38.17 ; 37.32 ; 36.50 ;$ $35.70 ; 34.93 ; 34.18 ; 33.46 ; 32.77 ; 32.09 ; 31.45 ; 30.82 ; 30.22 ; 29.64 ;$ $29.08 ; 28.53 ; 28.01 ; 27.51 ; 27.02 ; 26.55 ; 26.10 ; 25.66 ; 25.24 ; 24.83$; $24.43 ; 24.05 ; 23.68 ; 23.32 ; 22.98 ; 22.64 ; 22.32 ; 22.00 ; 21.70 ; 21.40 ;$ $21.11 ; 20.84 ; 20.56 ; 20.30 ; 20.05 ; 19.80 ; 19.55 ; 19.32 ; 19.09 ; 18.86 ;$ $18.65 ; 18.43 ; 18.23 ; 18.02 ; 17.83 ; 17.63 ; 17.44 ; 17.26 ; 17.08 ; 16.90 ;$ $16.73 ; 16.56 ; 16.39 ; 16.23 ; 16.07 ; 15.91 ; 15.76 ; 15.61 ; 15.46 ; 15.32 ;$ $15.18 ; 15.04 ; 14.90 ; 14.77 ; 14.63 ; 14.50 ; 14.38 ; 14.25 ; 14.13 ; 14.01 ;$ $13.89 ; 13.77 ; 13.66 ; 13.54 ; 13.43 ; 13.32 ; 13.21 ; 13.11 ; 13.00 ; 12.90 ;$ 


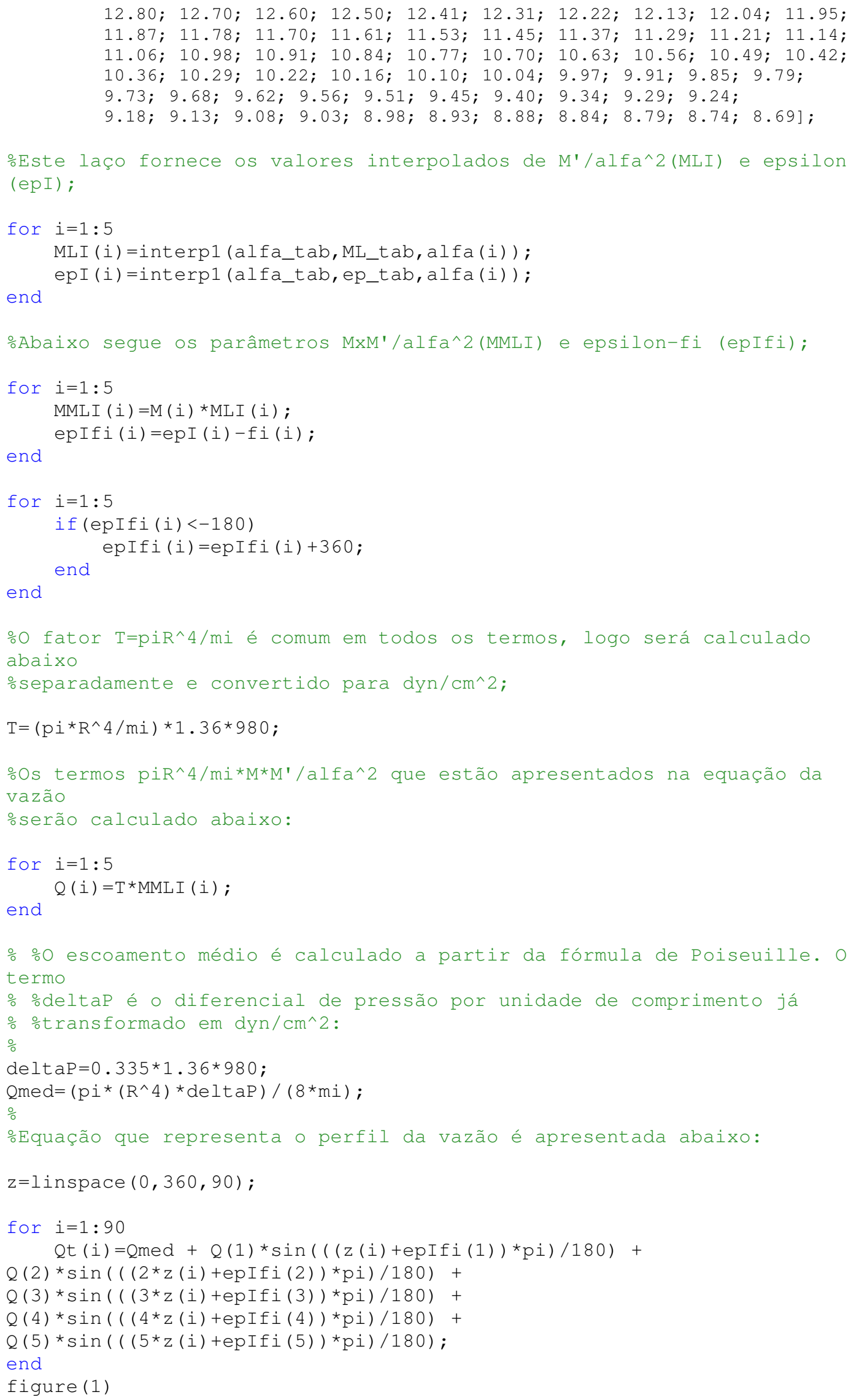


plot ( $z, Q t)$

xlabel ('Graus')

ylabel ('Vazão (mL/s)') 
ANEXO II

CARTA DA COMISSÃO DE ÉTICA EM EXPERIMENTAÇÃO ANIMAL 


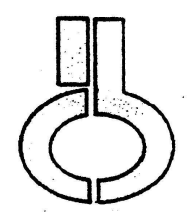

\section{Certipicado}

Certificamos que o protocolo registrado sob $n^{\circ} 87$ nas fls. 5 do livro 2 para uso de animais em experimentação, sob a responsabilidade da Profa. Dra. Luciana Venturini Rossoni, Coordenadora da Linha de Pesquisa "Modificaf̧oes na reatividade vascular à fentlefrina e na atividade e expressão da $\mathrm{Na}^{+} \mathrm{k}^{+}$-ATPase em artértas de ratos normotensos e espontaneamente hipertensos submettdos ao tratamento crôntco com ouabaina: mochulação endotelial" do qual participou(aram) o(s) aluno(s): Carolina Usuda Tanone e Janaina Memolo Potenza, está de acordo com os Principios Éticos de Experimentação Animal adotado pelo Colégio Brasileiro de Experimentação Animal (COBEA) e foi aprovado pela COMISSĀO DE ETICA EM EXPERIMENTAÇÃO ANIMAL (CEEA) em 19.10.2004.

São Paulo, 20 de outubro de 2004

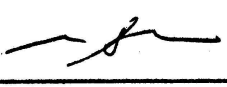

Profa. Dra. Marilia C. Leite Seelaender Coordenadora da CEEA

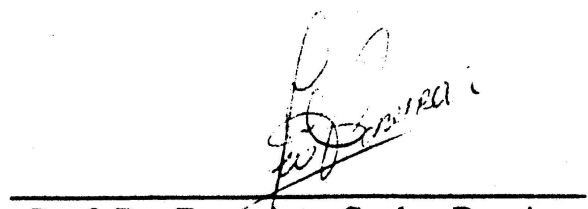

Prof. Dr. Francisco Carlos Pereira Secretärio da CEEA 